\title{
ADVANCED IMAGING TECHNIQUES FOR CARDIOVASCULAR RESEARCH
}

\author{
CARLOS VELASCO JIMENO
}

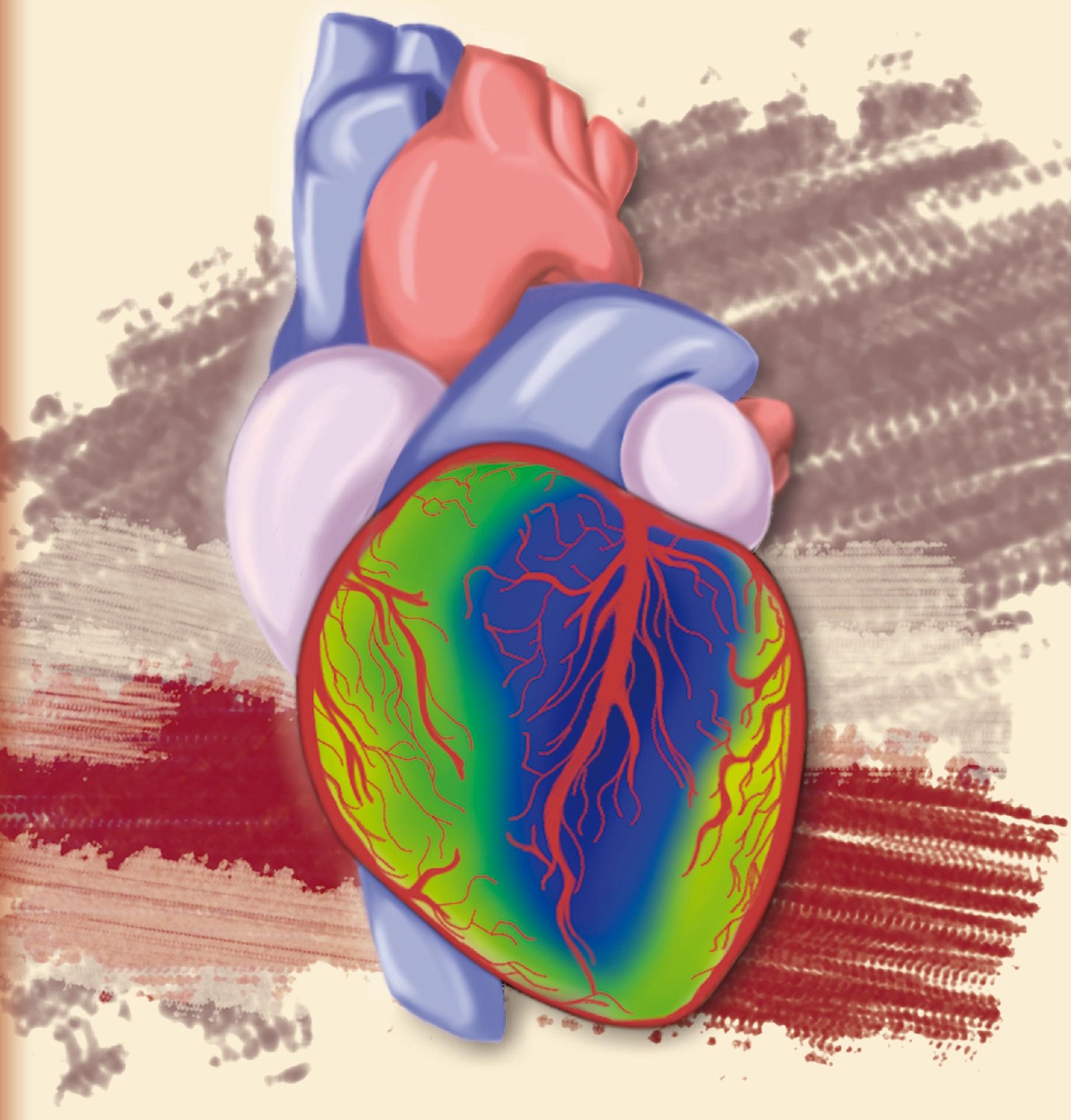





\section{ADVANCED IMAGING TECHNIQUES FOR}

\section{CARDIOVASCULAR RESEARCH}

\section{TÉCNICAS DE IMAGEN AVANZADA APLICADAS A LA INVESTIGACIÓN CARDIOVASCULAR}

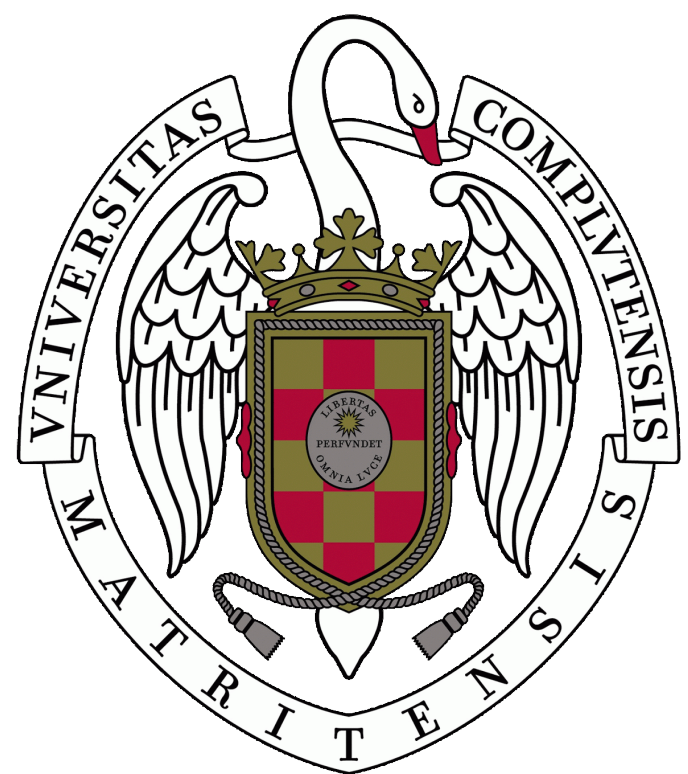

FACULTAD DE CIENCIAS FÍSICAS,

UNIVERSIDAD COMPLUTENSE DE MADRID

AUTHOR

\section{CARLOS VELASCO JIMENO}

SUPERVISORS

DR. SAMUEL ESPAÑA PALOMARES

DR. JESÚS MATEO DE CASTRO 
The author of this thesis, D. Carlos Velasco Jimeno was recipient of a fellowship Ayudas para contratos predoctorales de Formación del Profesorado Universitario FPU14-01794 from Ministerio de Educación del Gobierno de España.

The CNIC is supported by the Instituto de Salud Carlos III (ISCIII), the Ministerio de Ciencia, Innovación y Universidades (MCNU) and the Pro CNIC Foundation, and is a Severo Ochoa Center of Excellence (SEV-2015-0505). 


\section{DECLARACIÓN DE AUTORÍA Y ORIGINALIDAD DE LA TESIS PRESENTADA PARA OBTENER EL TÍTULO DE DOCTOR}

D./Dña. Carlos Velasco Jimeno

estudiante en el Programa de Doctorado en Física RD/99

de la Facultad de Ciencias Físicas

de la Universidad Complutense de

Madrid, como autor/a de la tesis presentada para la obtención del título de Doctor y titulada:

Técnicas de Imagen Avanzada Aplicadas a la Investigación Cardiovascular

Advanced Imaging Techniques for Cardiovascular Research

y dirigida por:

Samuel España Palomares

Jesús Mateo de Castro

\section{DECLARO QUE:}

La tesis es una obra original que no infringe los derechos de propiedad intelectual ni los derechos de propiedad industrial u otros, de acuerdo con el ordenamiento jurídico vigente, en particular, la Ley de Propiedad Intelectual (R.D. legislativo 1/1996, de 12 de abril, por el que se aprueba el texto refundido de la Ley de Propiedad Intelectual, modificado por la Ley $2 / 2019$, de 1 de marzo, regularizando, aclarando y armonizando las disposiciones legales vigentes sobre la materia), en particular, las disposiciones referidas al derecho de cita.

Del mismo modo, asumo frente a la Universidad cualquier responsabilidad que pudiera derivarse de la autoría o falta de originalidad del contenido de la tesis presentada de conformidad con el ordenamiento jurídico vigente.

En Madrid, a 28 de junio de 2019

Fdo.:

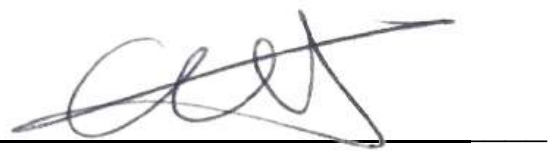




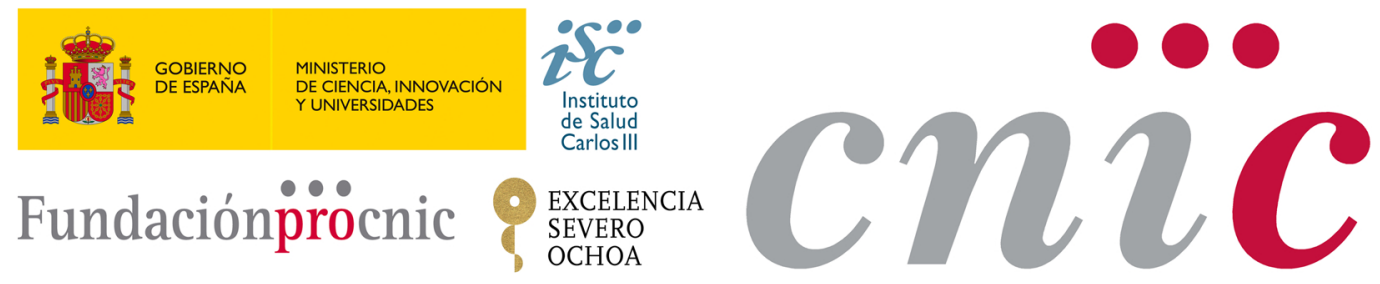

D. Samuel España Palomares, Doctor por la Universidad Complutense de Madrid, y D. Jesús Mateo de Castro, Doctor por la Universidad Complutense de Madrid, como directores,

\section{CERTIFICAN:}

Que D. Carlos Velasco Jimeno, licenciado en Ciencias Físicas por la Universidad Complutense de Madrid, ha realizado bajo su dirección la Tesis Doctoral titulada "Advanced Imaging Techniques for Cardiovascular Research" en el Centro Nacional de Investigaciones Cardiovasculares (CNIC) en Madrid.

Revisado el presente trabajo, expresan su conformidad para la presentación del mismo por considerar que reúne los requisitos necesarios para ser sometido a discusión ante el Tribunal correspondiente, para optar al grado de Doctor en Física por la Universidad Complutense de Madrid.

En Madrid, a 16 de Septiembre de 2019,

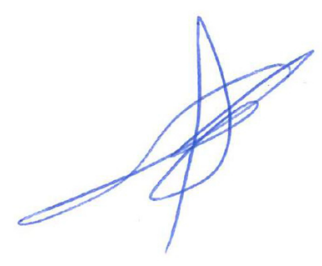

$\mathrm{V} .{ }^{\circ} \mathrm{B} .^{\circ}$ Director

Dr. Samuel España Palomares

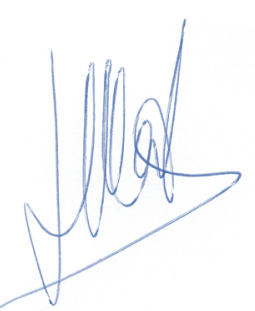

$\mathrm{V} .{ }^{\circ}{ }^{\circ}{ }^{\circ}$ Director

Dr. Jesús Mateo de Castro 

A los que me quieren. 

- Empieza por el principio — dijo el Rey con gravedad - y sigue hasta llegar al final; alli te paras.

- Lewis Carroll, Alicia en el país de las maravillas.

Querido lector, voy a contarte un secreto: mientras intento escribir estas líneas, estoy nervioso. Es probable que esta parte sea lo primero que leas de la tesis. Incluso puede que sea lo único que leas. Tal vez leas un poco por encima el resumen. Quizá hojees el libro buscando alguna imagen que merezca la pena (¡las hay!, ¡no todas son aburridas gráficas!). Pero, sobre todo, leerás los "agradecimientos". Al menos eso es lo que suelo hacer yo con las tesis que llegan a mis manos. Y estoy nervioso porque para mí es muy importante que entiendas que esta tesis no es solo mía, que es de todas las personas que me han ayudado con ella, y me preocupa no encontrar las palabras adecuadas para expresarlo. Si llego a ser doctor, lo seré gracias a la ayuda de muchos de los que nombro aquí abajo. Y espero agradecérselo como se merecen.

En primer lugar, gracias a la persona que me animó a hacer el doctorado en el CNIC. Gracias a ti, Vir, entré a hacer la tesis aquí en 2015. Y gracias a ti no abandoné en 2016. Ni en 2017. $\mathrm{Ni}$ en 2018. Cuando en 2016 no quería seguir con esto, me ayudaste a relativizar lo que estaba pasando y me diste la fuerza que necesitaba para seguir. Gracias por escuchar cada día, con paciencia, mis problemas y preocupaciones. Tú has sido mi mayor apoyo durante gran parte de esta tesis, y mi mayor fuente de inspiración. Has sido la mejor compañera de trabajo que he tenido jamás, y tu increíble capacidad de esfuerzo y sacrificio ha sido siempre un ejemplo para mí en los momentos más difíciles de estos años. Cada día que, durante el mes que estuve escribiendo la tesis, entraba al CNIC a las 8 y salía a las 22, me acordaba de que tú eso lo llevas haciendo varias veces a la semana desde hace años, y con un trabajo mucho más exigente. Para mí, siempre serás un ejemplo a seguir.

También quiero dar las gracias a la persona que más me ha ayudado dentro del CNIC todo este tiempo. Gracias, Jesús Mateo, por todo. El mayor descubrimiento que he hecho durante 
estos años no es nada de lo que hay escrito en los capítulos de la tesis; eres tú. Sin tu apoyo, no habría podido continuar con la tesis en 2017, y sin tu compañía no habría querido seguir haciéndola en 2018 ni en 2019. Sé que no voy a ser capaz de expresar en estas pocas líneas todo el agradecimiento y la admiración que siento por ti, pero lo voy a intentar... Espero haber aprendido todo lo que me has tratado de enseñar cada día. Todo este tiempo he intentado devolverte algo de todo lo que tú me dabas, pero creo que no ha sido suficiente, porque me has enseñado y ayudado demasiado. Me has enseñado lo que más te gusta con un entusiasmo y una paciencia inagotables. De verdad, no podrías haberte encontrado con un estudiante con menos conocimientos e interés por la biología que yo, y sin embargo ahora disfruto hablando de ello contigo, y digo más veces por día las palabras "SREBP2" o "PCSK9" que "fotón" o "centelleador". Fíjate si me has pegado la pasión por todo esto, que el paper que más veces he visitado durante mi tesis es éste: [66].

Pero, sobre todo, lo que más aprecio es lo que me has enseñado como persona. Me has demostrado que un director puede ser también tu mejor amigo, tu mejor profesor y tu mejor compañero de poyata. Me has demostrado que existen los científicos humildes, generosos y pacientes que no por ello dejan de ser enormes investigadores. Allá donde vaya después de la tesis, echaré de menos tus chistes malos, y te echaré de menos a ti, como "jefe" y como compañero. Espero que esto sea un "hasta pronto" y en un futuro pueda volver a trabajar contigo, para seguir aprendiendo contigo y de ti.

De no ser por Virginia y Jesús, estoy seguro de que este libro no existiría. Pero hay mucha más gente que me ha ayudado durante todo el proceso, y a ellos también les quiero dedicar unas líneas.

A Juan, Irene, Adriana y María: gracias por haberme aguantado todo este tiempo y por haberme ayudado siempre que os lo he pedido. Gracias por ayudarme con los experimentos, con los colores de las figuras, con las correcciones y revisiones. Gracias por hacer del laboratorio un lugar ameno de trabajo. Gracias por escuchar las dudas y los problemas que me surgían y tratar de resolverlas entre todos, y por enseñarme todo lo que os pedía. Y gracias especialmente por el apoyo en estos últimos meses. Sabéis de sobra que gracias a vosotros (iy a Jesús!) esta tesis está corregida y revisada. Que este trabajo esté bien escrito y redactado os lo debo únicamente a vosotros cinco.

A Fernando: gracias por estar siempre dispuesto a ayudarme y aconsejarme. Por aportar sensatez y poner siempre a mi disposición todos tus equipos. Siempre he podido contar contigo para cualquier problema, y para mí eso vale más que media tesis. Gracias por ser tan cercano y tan bueno; tus compañeros y alumnos tienen mucha suerte de tenerte cerca, ja pesar de que eres químico! Si no hubieras aparecido en estos párrafos, el apartado de agradecimientos habría quedado incompleto.

A Paula y a Jacob: gracias por ayudarme, y por confiar en mí y dejarme colaborar con vosotros. No sois conscientes de lo mucho que necesitaba poder ayudar y colaborar con otros grupos. Vosotros, y especialmente tú, Paula, me hicisteis recuperar la confianza en mí mismo. Gracias por hacer que me volviera a sentir útil. Gracias por pedir y escuchar mi opinión, confiar 
en mis análisis y dejarme enseñaros lo que he podido. Voy a echar de menos bajar a la 2N, Paula, con la esperanza de que te haya surgido algún problema que me sirva de excusa para dejar de hacer mis tareas y ponerme a ayudarte. De verdad, siempre os estaré agradecido por haberme dado la oportunidad de colaborar en vuestro proyecto, y haberme hecho sentir importante en vuestro equipo.

A Rubén: sin tu ayuda, esta tesis habría sido muy distinta. Siempre has estado disponible y dispuesto a ayudar con los animales, incluso fuera de tu horario laboral. Gracias por preocuparte por los cerdos y por solucionarnos tantos problemas y dudas que teníamos ahí abajo. Soy consciente de que sin tu destreza y paciencia no habríamos podido hacer los experimentos más complicados, y que te llevaste una buena dosis de radiación en la sala de fluoroscopia solo por ayudarnos. Los días que había experimento y había que poner el catéter a los cerdos, yo iba más feliz de lo habitual al CNIC, porque me dejabas entrar contigo y participar, y me enseñabas todo lo que podías. Siempre recordaré esos experimentos con el arco, y te estoy muy agradecido por dejarme ser parte de ellos, y estar ahí dentro ayudándote en lo que pudiera. También quiero agradecerte que confiaras en mí para hacer esas piezas en 3D. Tú también me has ayudado con eso a sentirme útil cuando más lo necesitaba.

A Rosa: ¡muchas gracias por hacer el corazón de la portada! Sé que no ha sido nada fácil, que has estado un montón de horas y que te has esforzado mucho (sobre todo en entender lo que yo te pedía que dibujaras, pero también en conseguir el resultado final). Que sepas que voy tan orgulloso diciéndole a todo el mundo que mi prima pequeña ha dibujado la ilustración de la portada. ¡Y todos dicen que ha quedado genial! Y si ha quedado genial la portada es gracias también a María, que le dio el toque final con esos brochazos artísticos e irrepetibles. ¡Muchísimas gracias a las dos! Gracias a vosotras tengo la portada de tesis más bonita del mundo $\backslash\left(\wedge^{\wedge}\right) /$.

Gracias a Cristina, porque la tesis no es sólo investigar y trabajar. También hay que hacer un montón de papeleos cada año. Pero contigo esos trámites no solo no daban miedo y pereza, sino que hacerlos era incluso divertido. Gracias por ayudarme con todo y resolverlo casi instantáneamente. Sé que te he dado más trabajo del habitual: memorias, justificaciones de cambios de director, solicitudes de estancia, cruce de emails con el ministerio, renuncias a estancia... y aun así siempre has conseguido zanjarlo todo en tiempo récord, y de buen humor. ¡Muchas gracias por ser como eres, y por ayudarme tanto!

Aún queda mucha gente a la que me siento agradecido. Gracias a los chicos y chicas del animalario (Tamara, Óscar, Inés, Nuria y al resto), por cuidar de los cerdos y prepararlos siempre que lo necesitaba. Gracias a Pedro por ayudarme siempre con los papeleos del doctorado en la secretaría de la facultad. A José Manuel, por firmar todo lo que hiciera falta casi al instante. A Miguel y Víctor, por poner a imprimir las piezas siempre que os lo pedía. Y a Bruno y Ángel, por ser tan buenos compañeros y "alumnos" durante el poco tiempo que estuve con vosotros.

Por supuesto, gracias a mi familia, y en especial a vosotros: mamá, papá y Víctor. Gracias por darme todo lo que he necesitado desde que nací para llegar hasta aquí. Gracias por vuestro 
esfuerzo diario y por haberme enseñado tanto. Gracias por entenderme y aguantarme, especialmente estos últimos 27 años, que seguro que no ha sido fácil. Nunca os he dicho lo que os quiero y lo agradecido que estoy por todo lo que hacéis por mí. De hecho, es probable que no os lo diga nunca así que aprovecho para dejarlo aquí escrito, para que lo podáis leer todas las veces que queráis.

Gracias a todos, de verdad por vuestro apoyo y vuestra ayuda cada día. Esta tesis también es vuestra. Y si habéis llegado hasta aquí leyendo, decídmelo y os daré un abrazo de sincero agradecimiento.

Y antes de acabar, hay dos personas más que deben aparecer en estas páginas. Gracias a Jesús Ruiz-Cabello (mi codirector de tesis durante un tiempo) y a Samuel. A ti, Jesús RuizCabello, te agradezco con sinceridad la oportunidad que me diste al acogerme en tu grupo de investigación a pesar de que en ese momento las fuentes de financiación eran escasas. Fuiste tú quien me avaló primero con la beca CIBERES y más tarde con la FPU.

Pero sobre todo os estoy muy agradecido a los dos porque gracias a vosotros me siento más orgulloso de lo que jamás pensé que llegaría a estar de esta tesis y de mí mismo. Me habéis enseñado la enorme importancia de tener un buen director de tesis, que sea profesional, leal, honrado, respetuoso y generoso. Me habéis enseñado que una tesis doctoral no solo se trata de trabajar en soledad acompañado únicamente de tu monitor de ordenador. Que la tesis también es aprender, colaborar, divulgar, confiar, compartir, enseñar, respetar... Que es afrontar los retos con humildad, siendo consciente de tus limitaciones y sabiendo asumirlas, y apoyarte en la experiencia de otros compañeros y aceptar su ayuda sin despreciar a nadie. Me habéis enseñado que la mejor manera de resolver diferencias con alguien es con calma, escuchando los argumentos de cada uno y sin gritar. Me habéis enseñado que no todo es blanco o negro, y que a veces lo que parecía negro puede ser gris oscuro, y lo que parecía blanco puede ser también gris oscuro, incluso más oscuro que el otro.

De no haberos conocido, no sé si mi tesis sería muy distinta a como lo es ahora. Pero sé que ninguna otra persona que menciono en estas páginas me podría haber enseñado todo lo que he aprendido de vosotros. Por ello, estoy muy agradecido de haberme cruzado con vosotros dos en mi tesis. Deseo que las próximas tesis que dirijáis sean tan entretenidas como lo ha sido esta para mí, y les deseo mucho ánimo a vuestros futuros doctorandos.

Ya está, ya se acaba. Sólo una cosa más: quiero dar las gracias a mi yo del pasado. Sólo nosotros dos sabemos lo que ha hecho para acabar esta tesis a tiempo. Y a mi yo del futuro: aquí tienes tu tesis. Cuídala bien, pero no la guardes al fondo de un cajón, tenla bien visible, que se vea bien la portada, y que vea todo el mundo lo orgulloso que estás de este trabajo. Cógela y reléela de vez en cuando, y aprovecha esos momentos para recordar todo lo que has vivido durante estos años. Que lo importante de la tesis no está aquí escrito; lo importante es el camino que has recorrido para llegar hasta aquí, y la gente que lo ha recorrido a tu lado. 


\section{Contents}

Declaración de Autoría y Originalidad iii

Visto Bueno de los Directores $\quad$ v

$\begin{array}{ll}\text { Agradecimientos } & \text { ix }\end{array}$

1 Motivation and thesis outline 1

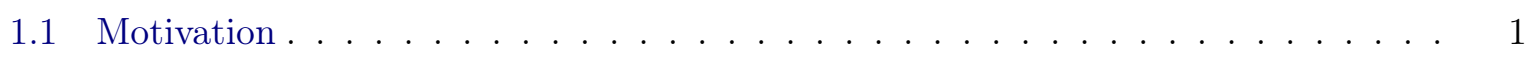

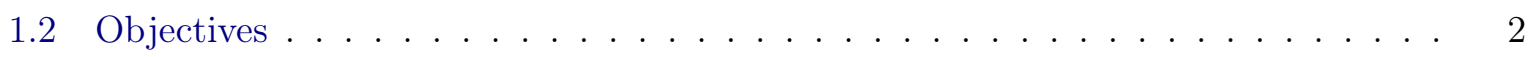

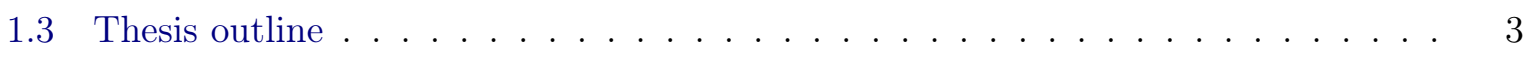

2 Introduction $\quad 5$

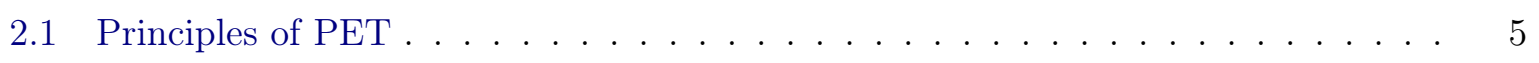

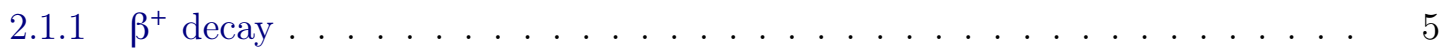

2.1 .2 Interaction of radiation with matter . . . . . . . . . . 6

2.1 .3 PET detection systems . . . . . . . . . . . . . . . . . 7

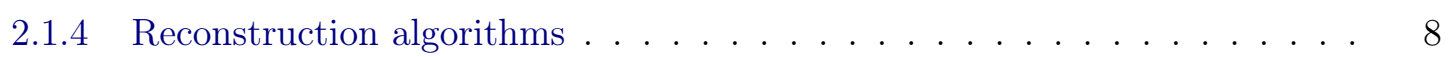

2.1.5 Data corrections . . . . . . . . . . . . . . . 8

2.1.6 PET radionuclides . . . . . . . . . . . . . . . . . . . . . 10

2.2 The cardiovascular system . . . . . . . . . . . . . . . . . . . . . . . . . . 12

2.2.1 The heart and the coronary circulation . . . . . . . . . . . . . 13

2.2.2 Cardiovascular disease . . . . . . . . . . . . . . . . . . 15

2.3 PET in cardiovascular disease . . . . . . . . . . . . . . . 15

2.3.1 Myocardial blood flow . . . . . . . . . . . . . . . . 16

2.3.2 Radiotracers used for MBF assessment . . . . . . . . . . . . . . . 16

2.3 .3 Myocardial viability . . . . . . . . . . . . . . . . . . . . . 17

2.4 Pharmacokinetic modeling in cardiac PET . . . . . . . . . . . . . 18

2.4 .1 Compartmental models . . . . . . . . . . . . . . . . . . . . . 18

2.4.2 One-tissue compartment model . . . . . . . . . . . . . . . . . . . 19

2.4.3 Two-tissue compartment model . . . . . . . . . . . . . . . . . . . . . 19

2.4.4 Blood flow, perfusion and extraction fraction . . . . . . . . 20 
2.4.5 Diffusible tracers and extracellular volume . . . . . . . . . . . . . . . . 21

2.5 Myocardial segmentation in cardiac PET . . . . . . . . . . . . . . . . . . 21

2.5.1 Heart orientation . . . . . . . . . . . . . . . . . . . . 22

2.5.2 Cardiac planes . . . . . . . . . . . . . . . . . . 22

2.5.3 Left ventricular segmentation . . . . . . . . . . . . . . . . 23

2.5.4 Assignment of segments to coronary artery territories . . . . . . . . . . . 23

3 Myocardial blood flow determination with ${ }^{68}$ Ga-DOTA-PET 25

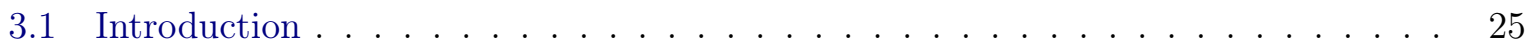

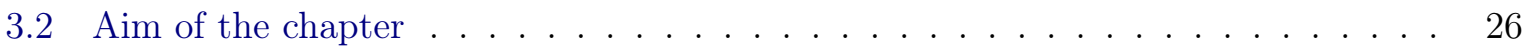

3.3 Methods . . . . . . . . . . . . . . . . . . . . . . . 27

3.3.1 Tracer production . . . . . . . . . . . . . . . . . 27

3.3.2 Study design and animal preparation . . . . . . . . . . . . . . 27

3.3.3 PET image acquisition . . . . . . . . . . . . . . . . . . . . . . . . . . 29

3.3.4 PET data analysis . . . . . . . . . . . . . . . . . . . . . . . . . 29

3.3.5 Microspheres analysis . . . . . . . . . . . . . . . . 33

3.3 .6 Statistical analysis . . . . . . . . . . . . . . . . . . 34

3.4 Results . . . . . . . . . . . . . . . . . . . . 34

3.4.1 Validation of $M B F_{\mathrm{PET}}$ versus gold standard $M B F_{\mathrm{MS}} \ldots \ldots \ldots$

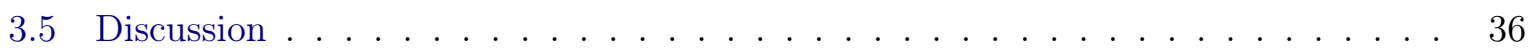

3.5 .1 Study Limitations _ . . . . . . . . . . . . . . . . . . . . 37

3.6 Conclusion . . . . . . . . . . . . . . . . . . . . . . . . . . 38

4 Viability assessment in a myocardial infarction model $\quad 39$

4.1 Introduction . . . . . . . . . . . . . . . . . . . . . . 39

4.2 Aim of the chapter . . . . . . . . . . . . . . . . . . 40

4.3 Methods . . . . . . . . . . . . . . . . . . . . . . . . . . 40

4.3.1 Study design and animal preparation . . . . . . . . . . . . . . . . . 40

4.3.2 CMR protocol and analysis . . . . . . . . . . . . . . . 41

$4.3 .3 \quad$ PET image acquisition . . . . . . . . . . . . . . . . . . . . . 41

$4.3 .4 \quad$ PET data analysis . . . . . . . . . . . . . . . . . . . . . . . 42

4.3 .5 Statistical analysis . . . . . . . . . . . . . . . . . 43

4.4 Results . . . . . . . . . . . . . . . . . . . . . . . . . . 43

4.4.1 Infarct assessment by CMR and PET . . . . . . . . . . . . . . . . 43

4.4 .2 Regional ECV and $M B F_{\mathrm{PET}}$ in $\mathrm{MI} \ldots \ldots \ldots \ldots 4 . \ldots \ldots$

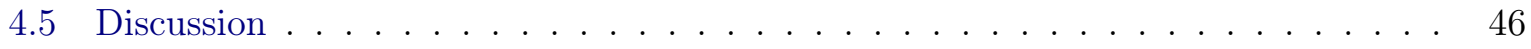

4.5 .1 Study Limitations . . . . . . . . . . . . . . . . . . . . . . 48 
4.6 Conclusions . . . . . . . . . . . . . . . . . . . . . . . . . . . 48

5 Pulmonary blood flow assessment using ${ }^{68}$ Ga-DOTA-PET $\quad 49$

5.1 Introduction . . . . . . . . . . . . . . . . . . . . . . . . . . 49

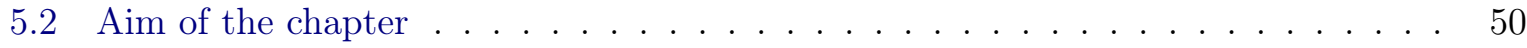

5.3 Methods . . . . . . . . . . . . . . . . . . . . . 50

5.3.1 Study design and animal preparation . . . . . . . . . . . . 50

$5.3 .2 \quad$ PET image acquisition . . . . . . . . . . . . . . . . . . 51

$5.3 .3 \quad$ PET data analysis . . . . . . . . . . . . . . . . . . 52

5.3 .4 Microspheres analysis . . . . . . . . . . . . . . . 54

5.3 .5 Statistical analysis . . . . . . . . . . . . . . . 56

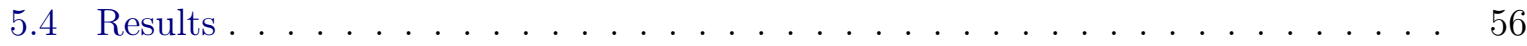

$5.4 .1 \quad$ Parametric PBF maps . . . . . . . . . . . . . . . . . . . 56

5.4 .2 Comparison $P B F_{\mathrm{PET}}$ versus $P B F_{\mathrm{MS}} \ldots \ldots \ldots \ldots 6$

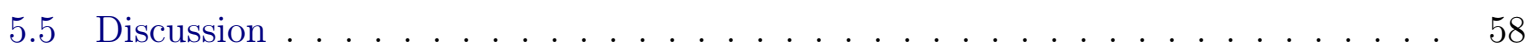

5.5 .1 Study limitations . . . . . . . . . . . . . . . . . . . . . . 60

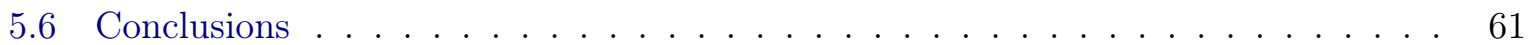

6 Multi-tracer PET using blood sampling spectroscopy $\quad 63$

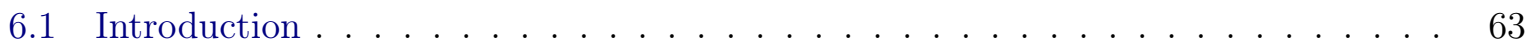

6.2 Aim of the chapter . . . . . . . . . . . . . . . . . . 64

6.3 Methods . . . . . . . . . . . . . . . . . . . . . . 65

6.3.1 Study design and experiment overview . . . . . . . . . . . . . 65

6.3.2 In vitro tracer separation by gamma spectroscopy . . . . . . . . . . . . . . 65

6.3 .3 Animal protocol . . . . . . . . . . . . . . . . . . . . 67

$6.3 .4 \mathrm{PET} / \mathrm{CT}$ image acquisition $\ldots \ldots \ldots \ldots \ldots$. . . . . . . . . 68

6.3.5 Separate AIF derivation from blood sample gamma spectroscopy . . . . . 69

6.3.6 Kinetic modelling and image analysis . . . . . . . . . . . . . . . 70

6.3.7 In vivo versus ex vivo myocardial tissue analysis . . . . . . . . . . . . . . 71

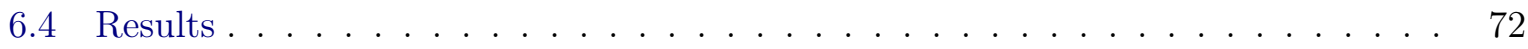

6.4.1 Tracer separation by gamma spectroscopy . . . . . . . . . . . . . . . 72

6.4.2 In vivo validation of multi-tracer PET against tissue analysis . . . . . . . 73

6.5 Discussion . . . . . . . . . . . . . . . . . . . . 76

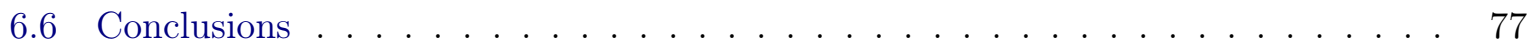

$\begin{array}{lll}7 & \text { A blood sampling detector for multi-tracer PET } & 79\end{array}$

7.1 Introduction . . . . . . . . . . . . . . . . . . . . . . 79 


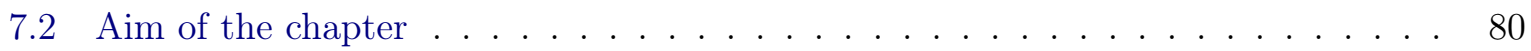

7.3 Methods . . . . . . . . . . . . . . . . . . . . . . 80

7.3.1 Blood sampling detector design . . . . . . . . . . . . . . 80

7.3.2 Data acquisition and signal processing . . . . . . . . . . . . . 81

7.3 .3 Device characterization . . . . . . . . . . . . . . . . 81

7.3 .4 In vivo evaluation . . . . . . . . . . . . . . . . . . . . . . . 82

7.3.5 Multi-tracer AIF detection by spectroscopic analysis . . . . . . . . . . . 83

7.4 Results . . . . . . . . . . . . . . . . . . . . . . 85

7.4.1 Detector performance and in vivo evaluation . . . . . . . . . . . . 85

7.4.2 Multi-tracer AIF separation by spectroscopic analysis . . . . . . . . . 87

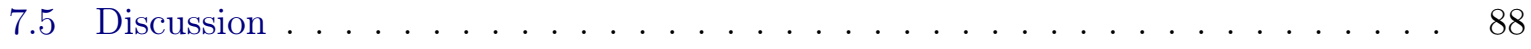

7.6 Conclusions . . . . . . . . . . . . . . . . . . . . . . . . . . 89

$\begin{array}{lll}8 & \text { Conclusions } & 91\end{array}$

$\begin{array}{ll}\text { Bibliography } & 93\end{array}$

$\begin{array}{ll}\text { A Publications derived from this thesis } & 111\end{array}$

B List of Abbreviations $\quad 113$

$\begin{array}{ll}\text { C Abstract } & 117\end{array}$

D Resumen $\quad 121$ 


\subsection{Motivation}

According to the World Health Organization, cardiovascular diseases (CVDs) are the first cause of death worldwide. About 17.9 million people died from this cause in 2017, representing approximately a third of the global deaths [181]. CVDs are a cluster of disorders triggered by multifactorial conditions in heart and blood vessels. CVDs encompasses stroke, rheumatic heart diseases, cardiomyopathies or coronary artery disease (CAD, such as angina and myocardial infarction) among others. Particularly, CAD is the most important disease in terms of mortality, causing more than $50 \%$ of the deaths $[93,103,125,181]$.

During the last decades, the cardiovascular community has put many efforts in the prevention, diagnosis and treatment of CVDs [19, 41, 65, 93], with many guidelines and reports frequently published and updated [165, 223]. One of the aims of these reports is to encourage change in patient care from a population-wide intervention, in order to attenuate risk in patients who have not yet established the disease. This is the so-called primary prevention, devoted to prevent CVDs by promoting a healthy lifestyle throughout life [7]. The secondary prevention of CVDs is about reducing the risk in patients with established disease. The guidelines at this point are at an individual-level intervention [199], such as lipid management through treatment with statin therapy, or blood pressure and weight control.

The cost-effectiveness of these primary and secondary interventions has been demonstrated $[8,65,68,69,124]$, and, although CVDs have been the leading cause of mortality in the world 
for more than two decades, with a vast majority of these cardiovascular deaths occurring in lowand middle- income countries [103, 126, 181], a declining trend in the mortality by CAD has been observed during the last years [149].

This trend cannot be solely attributed to the preventive guidelines [142], but also to the advances in evidence-based medical (i.e. development of antithrombotic agents) and surgical treatments (percutaneous coronary interventions) [63, 211]. The advances made in the last decades have resulted in a reduction in morbidity and mortality of CVDs. As a consequence, the higher survival rate after an acute event has raisedn the number of patients that suffer from a chronic cardiovascular disease as a result of the underlying CAD. Nevertheless, left regional or global ventricular dysfunction associated with CAD may not be irreversible; a substantial number of patient will find a functional recovery of myocardium after coronary artery revascularization $[54,104,146]$.

In this line, the American College of Cardiology/American Heart Association (ACC/AHA) task force has presented a set of guidelines for the initial clinical assessment of patients presenting heart failure [93]. There, they highly recommend the use of non-invasive imaging techniques to evaluate the eligibility of revascularization [93] by assessing two important physiological parameters, the myocardial blood flow (MBF) and the myocardial viability. Several non-invasive imaging techniques can perform these assessments, including: single photon emission computed tomography (SPECT) [140, 216], cardiac magnetic resonance (CMR) [62], echocardiography (EC) [121, 145], or positron emission tomography (PET) [43, 46, 136, 154, 190].

Among all these techniques, PET has been considered a "gold standard" for MBF and viability assessment $[15,20,50,112,218]$, thanks to its quantitative nature and superior detection sensitivity [28].

However, despite its recognized high diagnostic value, the situation of cardiac PET in clinical routine is far from optimal. Many factors impede its implementation worldwide, especially the complexity and cost of scanners, and, more importantly, the complexity of production, short physical half-life and low availability of PET radiotracers. Under these circumstances, we understand that the development of novel translational perfusion PET radiotracers must be focalized in their ease and low-cost production and high availability, without losing its diagnostic value.

\subsection{Objectives}

The goal of this thesis is to explore new applications of a ${ }^{68}$ Ga-labeled radiotracer $\left({ }^{68} \mathrm{Ga}\right.$-DOTA* $)$ in order to contribute to the expansion of cardiac PET in the clinical setting. We will focus in this radiotracer because of its potential high affordability thanks to its generator-based obtention. During this work we will study and validate the capability of this tracer to assess many cardiovascular-related parameters such as MBF and viability, among others. Furthermore, we will propose and study a new methodology that will permit the use of more than one radiotracer

*DOTA is the abbreviated name of the chelator $1,4,7,10$-tetraazacyclododecane- $\mathrm{N}, \mathrm{N}^{\prime}, \mathrm{N}^{\prime \prime}, \mathrm{N}^{\prime \prime \prime}$-tetraacetic acid 
in a single scan. With this methodology, multiple-tracer scans could be performed, and in so doing, the high cost usually attributed to PET scans could be dramatically reduced.

\subsection{Thesis outline}

In Chapter 2 we will introduce all the concepts that are necessary to understand the rest of the thesis. This introduction is not intended to be neither an original nor an exhaustive compendium of the topics related to cardiovascular PET and its clinical applications, but rather a mere summary of well-known concepts that are thoroughly described in many articles, reviews and books. On the other hand, the rest of the thesis is the result of the original multidisciplinary work that has been carried out for the last four years by the author with the invaluable help of his collaborators and supervisors. This work is structured as follows:

In Chapter 3 we will present ${ }^{68} \mathrm{Ga}$-DOTA as a PET radiotracer able to provide in vivo assessment of myocardial blood flow. The measurements obtained will be compared against those simultaneously obtained with fluorescent microspheres, which are considered to be the gold standard for perfusion measurements. The studies were carried out in pigs under rest and stress conditions.

In Chapter 4 we will evaluate the capability of this same radiotracer to assess another important physiopathological parameter, the extracellular volume fraction of the myocardial tissue, which provides an idea of myocardial viability. In this case, the proof of concept was tested in a swine model of myocardial infarction.

In Chapter 5, we will focus in pulmonary perfusion. In this part, we will validate ${ }^{68} \mathrm{Ga}$ DOTA as a pulmonary blood flow PET-tracer in healthy pigs. Once more, the results were be validated against those obtained by fluorescent microspheres as gold-standard measurements.

For the rest of the thesis we will move from single tracer scans to multiple-tracer scans.

In Chapter 6 we will propose a new methodology that will permit us to perform dynamic PET scans with more than one radiotracer simultaneously. For that purpose, we combined ${ }^{68} \mathrm{Ga}-$ DOTA with ${ }^{18}$ FDG. This new methodology, which is based on the spectroscopic analysis of blood samples manually obtained from the subject, will be proposed and validated both in vitro and in vivo.

In Chapter 7 we will present a blood sampling detector that will be able to perform the methodology introduced in the previous chapter in an automated fashion, so that human intervention will be minimized and, with that, radiation exposure of the technical personnel. The detector will be presented and characterized, and its performance evaluation in vitro and in vivo will be shown.

To conclude, in Chapter 8 we will present the final remarks of this work. 


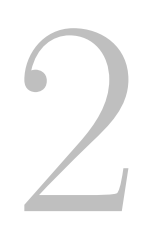

INTRODUCTION

\subsection{Principles of PET}

Positron Emission Tomography (PET) is a non-invasive imaging technique that allows in vivo monitoring of metabolic processes in an organism. It is based on the detection of the gamma rays resulting from the annihilation of the positrons emitted by a radiotracer that has been administered to the subject. These radiotracers are chemical compounds in which one or more atoms have been replaced by a radionuclide that emits a positron following a $\beta^{+}$decay. In this process, two annihilation photons are emitted (almost) collinearly in opposite directions. The PET camera is formed by several rings of detector blocks in which these annihilation photons may incide and produce an electric pulse. All these pulses are collected and processed and, finally, an image of the radioactivity distribution inside the subject is obtained.

\subsection{1 $\beta^{+}$decay}

As explained above, the radiotracers utilized in PET are labeled with $\beta^{+}$-emitter radionuclides. A $\beta^{+}$decay process can be described as:

$$
\mathrm{p} \rightarrow \mathrm{n}+\mathrm{e}^{+}+v_{\mathrm{e}}
$$

In this process, the proton $(p)$ is converted into a neutron $(n)$, a positron $\left(e^{+}\right)$and an electron neutrino $\left(v_{\mathrm{e}}\right)$. However, this $\beta^{+}$decay process cannot occur in isolated protons, due to energy constrains [166]. It can only occur in proton-rich atoms, that achieve stability by converting a 
proton into a neutron:

$$
{ }_{\mathrm{Z}}^{\mathrm{A}} \mathrm{X} \rightarrow{ }_{\mathrm{Z}-1}^{\mathrm{A}} \mathrm{Y}+\mathrm{e}^{+}+v_{\mathrm{e}}
$$

The emitted positron has an initial energy that can take a continuum of values up to a maximum [16]. This maximum energy differs among radioisotopes, being an intrinsic parameter of the radionuclide. There are many other properties (such as half-life of the parent nucleus, way of production or branching ratio) that differ between radioisotopes. This has contributed to propose many as labeling agents since the development of the first PET scanners more than forty years ago [163, 208]. Please refer to section 2.1.6 for more information on these properties.

\subsubsection{Interaction of radiation with matter}

Since its emission from the $\beta^{+}$decay, the positron travels a finite distance (usually a few millimeters) while losing kinetic energy by interactions with the surrounding matter (via ionization events with other atoms or by radiation after an inelastic scattering) [111]. Once it has lost all of its kinetic energy, the positron annihilates with an electron nearby (in fact, they momentarily form an onium, an exotic atom composed by the electron and the positron orbiting around their center of mass) and produces two annihilation gamma rays. These gamma rays have an energy of $511 \mathrm{keV}$ each, and they are emitted in (almost) opposite directions to conserve momentum.

Gamma rays interact with matter by three main types of interactions: photoelectric absorption, Compton scattering and pair production. However, pair production is only energetically possible when the gamma ray energy exceeds the sum of the electron and positron masses (1.022 $\mathrm{MeV}$ ) and hence, it is not possible from an annihilation photon. Consequently, the high-energy photons emitted by the $e^{+} e^{-}$annihilation interact with surrounding matter mostly by photoelectric absorption and Compton scattering, which are further briefly described:

- In the photoelectric absorption an atom absorbs totally the energy of the incident photon. As a result, this photon disappears and the absorbed energy is employed to eject an orbital electron (called photoelectron) from the absorber atom. This photoelectron has a kinetic energy given by:

$$
E_{e^{-}}=h v-E_{b},
$$

where $E_{b}$ is the binding energy of the photoelectron to the atom's shell where it comes from.

- Compton scattering is a collision between a photon and a loosely bound orbital electron (termed as recoil electron) [35]. In this kind of interactions, the incoming gamma ray deflects through a certain scattering angle $\theta$ and transfers part of its energy to the recoil electron. Compton scattering is the predominant interaction mechanism for annihilation photons. The energy of the scattered photon $\left(E_{\gamma^{\prime}}\right)$ is related to its scattering angle $(\theta)$ by the following expression:

$$
E_{\gamma^{\prime}}=\frac{E_{\gamma}}{1+\left(E_{\gamma} / m_{e} c^{2}\right)(1-\cos \theta)},
$$

where $m_{e}$ is the electron rest mass $(511 \mathrm{keV})$ and $E_{\gamma}$ is the energy of the incident photon. 
The probability that an annihilation gamma ray experiences an interaction when passing through a certain thickness of a material, essentially depends on its energy and the composition and the thickness itself, and it is denoted as the attenuation coefficient $\mu$. Since PET is based on the detection of annihilation photons that have not interacted within the subject, an extended description of PET detectors is given below.

\subsubsection{PET detection systems}

The objective of PET detectors is to convert the incident radiation emitted from the radioactive source into a measurable electric signal that can be quantified and digitized. Radiation detectors can be generally divided into three broad categories [9, 111]: proportional (gas) chambers, semiconductor detectors and scintillation detectors. Scintillation detectors are the most commonly used in PET detection systems and hence they are presented here with more detail.

Scintillation detectors are detection systems composed by a scintillator (a special material able to convert part of the energy released after the radiation absorption into visible light) coupled to a photodetector (a light detection system that converts the visible light into electrical current). There are many properties that determine the performance of a scintillator. Table 2.1 shows some of the most commonly used scintillators in PET devices along with their properties [117].

Table 2.1: Physical properties of common scintillators for PET. ${ }^{a}$

\begin{tabular}{lccccccccc}
\hline Scintillator & NaI & BGO & GSO & LSO & LYSO & LGSO & LuAP & YAP & LaBR $_{3}$ \\
\hline Peak emission wavelength $(\mathrm{nm})$ & 410 & 480 & 430 & 420 & 420 & 415 & 365 & 350 & 360 \\
Index of refraction & 1.85 & 2.15 & 1.85 & 1.82 & 1.81 & 1.80 & 1.94 & 1.95 & 1.90 \\
Light output $\left(10^{3} \mathrm{ph} / \mathrm{MeV}\right)$ & 41 & 9 & 8 & 30 & 30 & 16 & 12 & 17 & 60 \\
Decay time $(\mathrm{ns})$ & 230 & 300 & 60 & 40 & 40 & 65 & 18 & 30 & 16 \\
Density $\left(\mathrm{g} / \mathrm{cm}^{3}\right)$ & 3.67 & 7.13 & 6.71 & 7.35 & 7.19 & 6.5 & 8.34 & 5.5 & 5.3 \\
Effective Z & 50 & 73 & 58 & 65 & 64 & 59 & 65 & 33 & 46 \\
Hygroscopic & Yes & No & No & No & No & No & No & No & Yes \\
Magnetic susceptibility & No & No & Yes & No & No & Yes & No & No & No \\
\hline a Table modified from [117]. & & & & & & & & &
\end{tabular}

The light outputted by the scintillator material is converted into an electrical current by a photodetector. Most clinical PET scanners use photomultipliers (PMTs) as photodetectors, due to its unique combination of very high gain $\left(>10^{6}\right)$, low noise and fast response relative to other photo-sensing devices [117]. Avalanche photodiodes (APDs) are another kind of photodetectors. They are semiconductor devices insensitive to magnetic fields and with a larger photon detection ratio compared to PMTs. However, APDs are not frequently utilized in PET due the fast frontend electronics required for processing signals coming from individual APDs [219].

A viable alternative to PMTs are silicon photomultipliers (SiPMs) [175]. These are singlephoton-sensitive devices [174] based on single-photon APDs densely packed on a silicon substrate. SiPMs possess extremely high sensitivity, high gain and low operating voltage. SiPMs can also work under the presence of a high magnetic field, which makes them a perfect substitute of PMTs $[53,113,226]$ in bimodal positron emission tomography/magnetic resonance (PET/MR) scanners that have received increasing attention in recent years [153, 209]. 
All the electric pulses produced by the photodetectors are continuously digitized and associated to unique time-energy-position events. These recorded events are associated to pairs of coincidences and further analyzed to produce the final image. Data reconstruction and the subsequent corrections applied to the final image are detailed below.

\subsubsection{Reconstruction algorithms}

One of the advantages of PET against other tomographic imaging techniques is that PET is based on detection of the two gamma rays emitted from each $e^{+} e^{-}$annihilation. In order to obtain a final image of the radiotracer distribution inside the administered patient, all the events recorded during the acquisition need to be appropriately processed. However, it is out of the scope of this introduction to detail the different reconstruction algorithms available. There are two main categories of reconstruction algorithms: analytical and numerical (iterative).

The most common analytical reconstruction algorithm is the filtered backprojection (FBP). This algorithm essentially performs the Fourier transformation of angular projections, applies the ramp filter in the frequency domain, performs the inverse-transform of the resultant product, backprojects the filtered projection and sums over all filtered projections [206, 210].

The iterative reconstruction algorithms are based on the attempt to maximize or minimize a target function determined by the particular algorithm used [206]. They usually provide a more accurate estimate than analytical methods, at expense of more computational demand. One of the most widely used iterative algorithms is the ordered subsets expectation maximization algorithm (OSEM) [45], which is an accelerated version of the maximum-likelihood expectation maximization (ML-EM) method. The last iterative method worth to be mentioned is the 3Ddedicated row-action maximum-likelihood algorithm (3D-RAMLA) [32], which is a (theoretically faster) special case of OSEM and it is implemented on many clinical PET scanners.

\subsubsection{Data corrections}

The reputation of PET as a quantitative imaging tool is largely based on the fact that an exact correction for attenuation of the signal is theoretically achievable. However, this and many other factors (such as count-rate losses, variations in detector efficiency, detection of scattered events, etc) have an impact on the quantitative accuracy of resultant PET images. In this section, these sources of error are described along with the approaches used to correct them.

\section{Decay}

In some PET studies, data are acquired over time periods similar to the half-life of the administered radionuclide [35]. In such situations, a correction by the physical decay occurred during the measurement time interval must be carried out. The decay-corrected activity during the time frame in which PET acquisition has been conducted is given by:

$$
D=\frac{\left(t_{2}-t_{1}\right) \lambda \mathrm{e}^{-\lambda t_{1}}}{1-\mathrm{e}^{-\lambda\left(t_{2}-t_{1}\right)}},
$$


where $\lambda$ is the decay constant of the employed radionuclide, and $t_{1}$ and $t_{2}$ are the start and end times of the PET frame. Whenever $\lambda$ and the timeframe start and duration are known, decay correction will be possible.

\section{Scatter}

As previously stated, annihilation photons emitted from the $\beta^{+}$decay may interact with surrounding matter and scatter. As a consequence, the gamma ray will deflect and lose part of its energy. Many of these scattered photons never reach a detector, but there is a percentage that may still hit one of the detectors, provoking a so-called scatter coincidence. Such scatter events can be discriminated from true events on the basis of their energy. However, this approach is not optimal, because photons are more likely to scatter at small angles, thus losing less energy. Therefore, a very good energy resolution is needed to discriminate them from the true $511 \mathrm{keV}$ ones. To overcome this situation, apart from improving energy resolution, most clinical scanners have already implemented sophisticated algorithms [120, 227].

\section{Attenuation}

The probability of interaction of a photon with a certain energy with matter is given by the attenuation coefficient $\mu$, which depends on the energy itself, along with the electron density of the material. However, due to the fact that PET is based on the detection of coincident photons, the attenuation probability of a coincidence event does not depend on the location within the line that virtually joins the two opposite detectors (known as line of response, LOR) but on the thickness of material that both photons (in sum) have to cross [14] and the material itself. In the past, the most common attenuation correction method involved the performance of a transmission scan (a scan of the patient before radiotracer injection with radioactivity emitted by an external rotating radioactive source) and a blank scan (a scan without the patient). The difference in the counts detected between both scans was assumed to be only caused by attenuation through the patient. Another possibility is the CT-based correction method, in which attenuation coefficient for every voxel within the field of view (FOV) is derived from CT Hounsfield units, and then a correction is applied to the final image. Due to the popularity and success of combined Positron Emission Tomography/Computed Tomography (PET/CT) scanners, this is the most common attenuation correction approach.

\section{Random coincidences}

It is possible for two photons that did not come from the same annihilation to be erroneously identified as having occurred simultaneously (actually, they are not simultaneously detected but are measured within the resolving coincidence time window $\tau$ in which the scanner works). In this case, the scanner unavoidably treats this detection as an annihilation produced somewhere in the line between the two detectors where the (not truly related) gamma rays entered [49]. Such false coincidence is called a random coincidence. Random coincidences produce a background noise over the resultant image, and its magnitude depends on the radioisotope distribution. The 
number of random coincidences per second $\left(R_{i j}\right)$ proportionally depends on $\tau$ :

$$
R_{i j}=2 \tau r_{i} r_{j}
$$

where $\tau$ is the coincidence resolving time of the scanner, and $r_{i}$ and $r_{j}$ are the counts per second (singles rate (SR)) of two independent detectors. Two main approaches may correct for this undesired effect. In the first one, $R_{i j}$ can be determined for every pair of detectors by estimating each SR [49]. The second approach utilizes a delayed coincidence channel, in which timing signals from one detector are delayed by a time much greater than $\tau$ [111]. In this way, any coincidence measured by the delayed channel can only be random. Once the random coincidence rate is known, it can be subtracted from the measured true events.

\section{Partial volume effect (PVE)}

Partial volume refers to the apparent loss of activity concentration within a certain region of interest (ROI) of the PET image. Due to limitations in spatial resolution and tissue sampling, the true activity concentration does not correspond with the activity concentration that is actually measured. This apparent loss of activity is figuratively said to spilled in (or spilled out) of the ROI, so that the measured activity concentration is lower (or greater) than what it should be, ideally. PVE can severely affect PET images both qualitatively and quantitatively. Hence, a partial volume correction (PVC) is usually applied. There are many PVCs that can be applied [200]. Recovery coefficient [203] (in which a correction factor that accounts for the estimated count loss is applied to the ROI) is a simple method commonly used in PET tumor imaging [72, 89]. A more complex method is the geometric transfer matrix method [182], which can account for spillover among any number of structures.

\subsubsection{PET radionuclides}

Since the development of the first PET scanner [163, 208] many radioisotopes have been proposed as labeling agents according to different physical properties and production pathway (see Table 2.2). The most important properties that can determine the use and success of a PET radioisotope are [37]:

\section{Half-life}

The half-life is defined as the time required for half of the original population of the radionuclides to decay. Usually half-lives of the radioisotopes used in PET are short (in the order of seconds to minutes). This is advantageous in terms of radiation safety, as it translates into a reduced radiation dose delivered to patients and clinical personnel. However, with a short half-life time, production and managing of radiotracers are limited to specific and costly facilities, thus limiting its implementation on clinical use. 


\section{Positron range}

The maximum kinetic energy of the emitted positron is directly proportional to its range in the tissue. As a consequence, PET images obtained from short-range positron emitters (such as ${ }^{11} \mathrm{C}$,

${ }^{18} \mathrm{~F}$ or ${ }^{89} \mathrm{Zr}$ ) will have better spatial resolution than those obtained from long-range ones. The lower the positron range, the less blurred final PET image.

\section{Prompt gamma emission}

Some of the positron-emitter radioisotopes obey to a decay scheme in which they also emit additional prompt gamma rays $[37,132]$. This property could lead to PET image blurring due to the production of multiple coincidences. However, this additional gamma ray emission may become beneficial in some situations such as in multiple-tracer scans, as we will see in Chapters 6 and 7.

\section{Branching ratio}

Radionuclides may have more than one decay mode, and the branching ratio defines the probability that a certain decay mode takes place. $\beta^{+}$decay may compete with electron capture, another decay mode in which an orbital electron is captured by the nucleus and combines with a proton to form a neutron. As an example, $88.9 \%$ of the decays of ${ }^{68} \mathrm{Ga}$ into ${ }^{68} \mathrm{Zn}$ are by positron emission (almost $99 \%$ of these decays produce a positron with a maximum energy of $1.899 \mathrm{MeV}$ and $1 \%$ produce a positron with a maximum energy of $822 \mathrm{keV}$ ), and $11.1 \%$ are by electron capture. In this case, the $\beta^{+}$decay branching ratio for ${ }^{68} \mathrm{Ga}$ would be 0.889 as seen in Table 2.2.

Branching ratio not only applies to $\beta^{+}$decay mode but to all kind of decays. Table 2.2 also reflects prompt-gamma branching ratio, a parameter that will become of great importance in Chapters 6 and $7 .{ }^{68} \mathrm{Ga}$ results to be a non-pure positron emitter, i.e., sometimes ${ }^{68} \mathrm{Ga}$ decays into an excited state of ${ }^{68} \mathrm{Zn}$ which promptly decays into a stable state of ${ }^{68} \mathrm{Zn}$ through the emission of an additional gamma ray. The energy of this gamma emission may take different values, but the probability of those emissions (branching ratio) are all negligible except for the one with $E_{\gamma}=1.077 \mathrm{MeV}$. This prompt gamma emission occurs 3.2 times per 100 decays of ${ }^{68} \mathrm{Ga}$. Hence, $\mathrm{Br}_{\gamma}(\mathrm{Ga})$ is considered to be $3.2 \%$. Fig. 2.1 shows a simplified decay scheme of ${ }^{68} \mathrm{Ga}$.

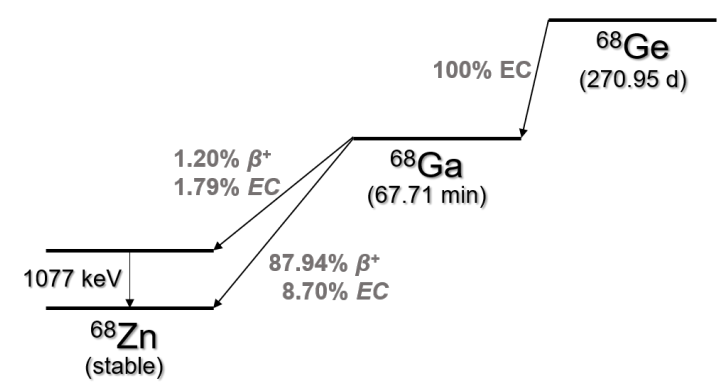

Figure 2.1: Decay scheme of ${ }^{68}$ Ga. 


\section{Production type}

The vast majority of radioisotopes used in PET are produced from cyclotrons. Besides, some of these radioisotopes (such as ${ }^{11} \mathrm{C},{ }^{13} \mathrm{~N},{ }^{15} \mathrm{O}$ or ${ }^{18} \mathrm{~F}$ ) are elements present in most of biologic substances, and therefore they can be used to label many biological molecules in order to monitor processes that occur inside an organism. However, isotope production from cyclotrons is very expensive due to the high cost derived from installation, maintenance and daily operation. This is an important factor that limits the widespread use of PET worldwide.

Radionuclide benchtop generators are an alternative to cyclotrons. These devices contain a mixture of the parent (the long-lived radionuclide that will undergo the $\beta^{+}$decay) and the daughter (the short-lived radionuclide that results from the $\beta^{+}$decay). The parent is continuously decaying into the daughter, so that the daughter can be continually obtained on site. Consequently, radioisotopes such as ${ }^{68} \mathrm{Ga}$ or ${ }^{82} \mathrm{Rb}$ can be readily available in hospitals from generators, which provides an almost unlimited daily production, avoiding costly cyclotrons.

Table 2.2: Most common radionuclides used in PET. ${ }^{a}$

\begin{tabular}{|c|c|c|c|c|c|c|c|c|}
\hline Radionuclide & Half-life & $\begin{array}{c}E_{\max }\left(\beta^{+}\right) \\
\quad(\mathrm{MeV})^{\mathrm{b}}\end{array}$ & $\begin{array}{l}R_{\max } \\
(\mathbf{m m})^{\mathrm{c}}\end{array}$ & $\begin{array}{l}B r_{\beta^{+}} \\
(\%)^{\mathrm{d}}\end{array}$ & $\begin{array}{c}\text { Prompt } \gamma \\
\text { emitter }\end{array}$ & $\begin{array}{c}E_{\max }(\gamma) \\
(\mathrm{MeV})\end{array}$ & $B r_{\gamma}(\%)$ & Production type \\
\hline${ }^{11} \mathrm{C}$ & $20.3 \mathrm{~min}$ & 0.96 & 4.2 & 99.8 & No & - & - & Cyclotron \\
\hline${ }^{13} \mathrm{~N}$ & $10.0 \mathrm{~min}$ & 1.198 & 5.5 & 99.8 & No & - & - & Cyclotron \\
\hline${ }^{15} \mathrm{O}$ & $2.0 \mathrm{~min}$ & 1.732 & 8.4 & 99.9 & No & - & - & Cyclotron \\
\hline${ }^{18} \mathrm{~F}$ & $109.8 \mathrm{~min}$ & 0.634 & 2.4 & 96.9 & No & - & - & Cyclotron \\
\hline${ }^{64} \mathrm{Cu}$ & $12.7 \mathrm{~h}$ & 0.653 & 2.5 & 17.5 & No & - & - & Cyclotron \\
\hline${ }^{68} \mathrm{Ga}$ & $67.8 \mathrm{~min}$ & 1.899 & 9.2 & 88.9 & Yes & 1.077 & 3.2 & ${ }^{68} \mathrm{Ge} /{ }^{68} \mathrm{Ga}$ Generator \\
\hline${ }^{76} \mathrm{Br}$ & $16.2 \mathrm{~h}$ & 3.382 & 17.1 & 32.1 & Yes & $0.559,0.657$ & $74.0,15.9$ & Cyclotron \\
\hline${ }^{82} \mathrm{Rb}$ & $1.3 \mathrm{~min}$ & 3.378 & 17.0 & 94.9 & Yes & 0.777 & 15.1 & ${ }^{82} \mathrm{Sr} /{ }^{82} \mathrm{Rb}$ Generator \\
\hline${ }^{86} \mathrm{Y}$ & $14.7 \mathrm{~h}$ & 1.221 & 5.6 & 17.5 & Yes & $1.077,0.627$ & $82.5,32.6$ & Cyclotron \\
\hline${ }^{89} \mathrm{Zr}$ & $78.4 \mathrm{~h}$ & 0.902 & 3.8 & 22.7 & No & - & - & Cyclotron \\
\hline${ }^{124} \mathrm{I}$ & $100.8 \mathrm{~h}$ & 1.535 & 10.0 & 22.4 & Yes & $0.602,1.691$ & $62.9,11.2$ & Cyclotron \\
\hline
\end{tabular}

a Adapted from [16, 37].

b Energy of the most frequent $\beta^{+}$decay mode.

c Maximum range in water.

d Sum of $B r_{\beta^{+}}$of the two most frequent $\beta^{+}$decay modes.

\subsection{The cardiovascular system}

Now that we have introduced the basics of PET, and since this dissertation is focused on the applications of PET for cardiovascular imaging, it is time to introduce some concepts related to the human cardiovascular system. 


\subsubsection{The heart and the coronary circulation}

The cardiovascular system of humans is a closed network consisting of the heart, the blood and the blood vessels, including arteries, veins and capillaries [133]. This system is intended to supply tissues in the body with oxygen and other nutrients, transport hormones and remove metabolic waste products (through the lymphatic system) [80]. The cardiovascular system actually has two components, the systemic circulation and the pulmonary circulation. The pulmonary circulation is in charge of blood oxygenation, whereas the systemic circulation is intended to deliver that oxygenated blood to the rest of the body.

The heart is the main organ in the cardiovascular system. It is a hollow, muscular pump, which main function is to propel blood throughout the body and plays a key role in both pulmonary and systemic circulations. The heart has four chambers: right atrium, left atrium, right ventricle, and left ventricle [204]. The atria are the two upper chambers, while the ventricles are the two lower ones (see Fig. 2.2).

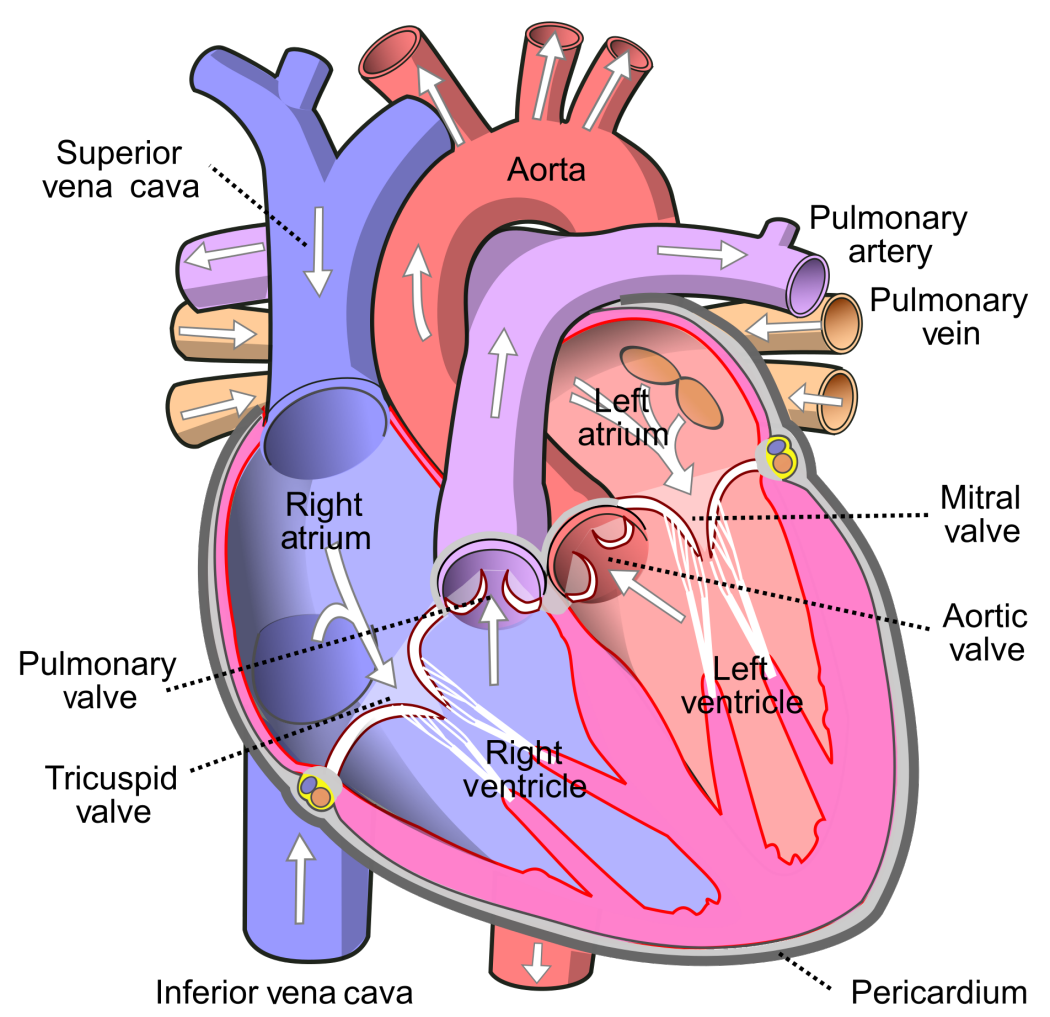

Figure 2.2: Diagram of the human heart. Blood flows following the direction of white arrows. (Illustration "Diagram of the human heart (cropped)", by wapcaplet, licensed under CC-BY 3.0).

Deoxygenated blood arrives to the right atrium from (mainly) the vena cava and the coronary sinus. This blood is sent down to the right ventricle to be pumped through the pulmonary artery to the lungs for re-oxygenation (see Fig. 2.3). After completing the pulmonary circulation loop, it enters into the heart again, this time through the left atrium, which pumps the oxygenated blood through the mitral valve into the left ventricle. The left ventricle is much thicker as compared with the right, due to the greater force needed to pump blood to the rest of the body 
through the aortic valve to the aorta.

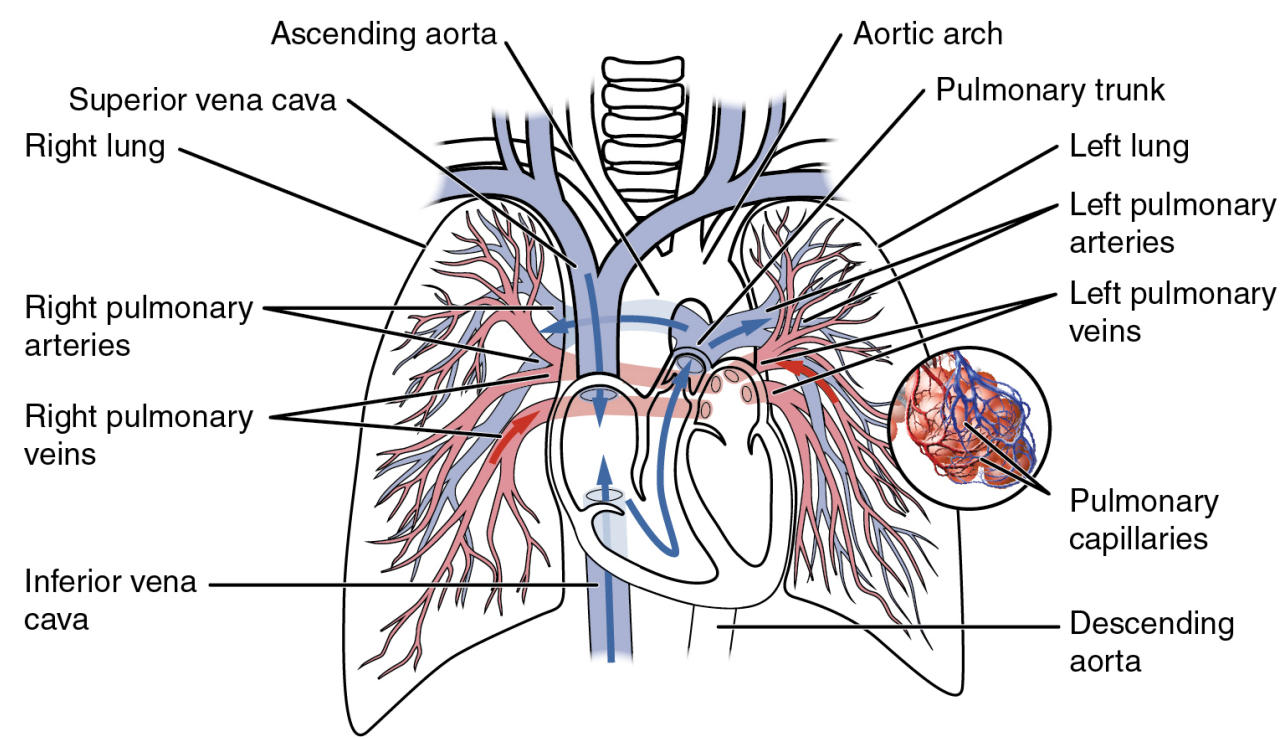

Figure 2.3: Pulmonary circulation in the heart. Deoxygenated blood flows following the blue arrows. After oxygen exchange in pulmonary capillaries, it returns to the heart through the pulmonary veins as oxygenated blood. Illustration ("2119 Pulmonary Circuit”, by OpenStax College, licensed under CC-BY 3.0).

Like the rest of the organs in the body, the heart muscle also needs a continuous supply of oxygenated blood, and this is provided by the coronary arteries. This blood supply to the myocardium is the so-called coronary circulation. Right above the aortic valve, there are two small openings that permits a portion of that blood deviating to the heart muscle (the myocardium) [25]. These two openings existing above the aortic valve, at the beginning of the aorta (the aortic root) originate the two coronary arteries; the left coronary artery and the right coronary artery. The left coronary artery bifurcates in two branches: the left anterior descending (LAD), and the left circumflex (LCX) (see Fig. 2.4). These branches, along with the right coronary artery (RCA) are the three main coronary arteries that supply blood to the heart muscle.

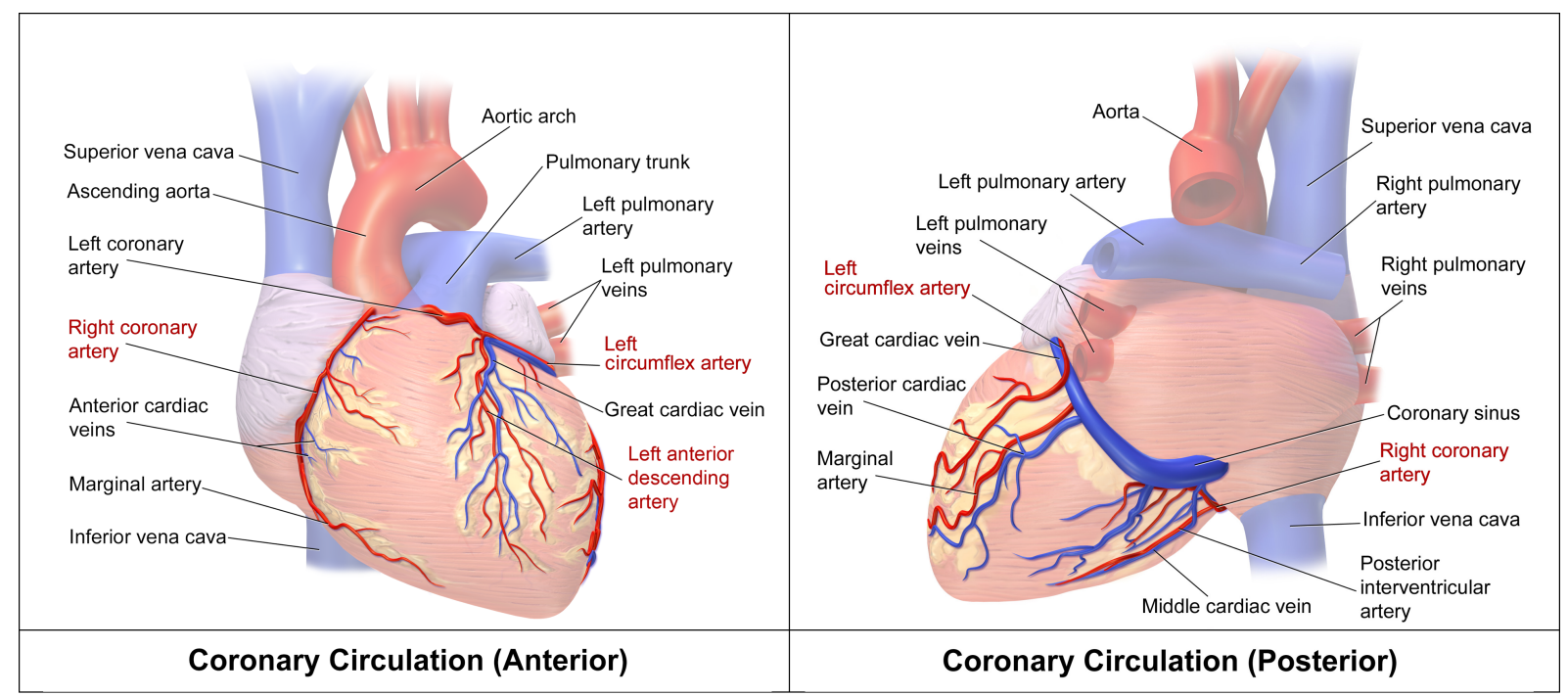

Figure 2.4: Anterior and posterior views of the coronary circulation in myocardium. The main coronary arteries are highlighted in red. Illustrations licensed under CC-BY 3.0 [221]. 
The coronary circulation is of major importance not only to the heart muscle, but also to the rest of the body, including the brain. The heart is continuously pumping blood to the rest of the body, and to do so it needs to be constantly supplied by oxygenated blood. The slightest interruption in this supply may quickly provoke a heart attack, a situation in which the myocardium results damaged by oxygen starvation. This and other diseases that affect the cardiovascular system, and the coronary circulation in particular, are detailed in the next subsection.

\subsubsection{Cardiovascular disease}

The cardiovascular disease (CVD) is the class of diseases that involve the heart and the blood vessels. Many diseases are englobed under this classification; angina, myocardial infarction, stroke, heart failure, pulmonary heart disease and pulmonary hypertension are only a few of them [222]. The major cause of CVD is atherosclerosis. Atherosclerosis is a chronic inflammatory condition in which the inside of an artery narrows due to the formation of an abnormal accumulation of fatty lipids, calcium, inflammatory cells and connective tissue, the so-called "plaque". This plaque may be formed in any artery in the body, including coronary arteries, and may stay asymptomatic for a long period of time. However, when a coronary artery suffers a marked narrowing due to the growth of the plaque, the blood flow supplied to the myocardium gets restricted and can produce symptoms such as chest pain or angina pectoris. Moreover, if the blood flow to any part of the myocardium is completely restricted for a few minutes, the consequent oxygen starvation causes the myocardial cells of the affected zone to die or become damaged. This is known as a heart attack, or myocardial infarction (MI). Angina or myocardial infarction are some of the many diseases englobed under the term Coronary Artery Disease (CAD), also known as Ischemic Heart Disease (IHD). CAD is the most common CVD [181], the leading cause of death, and is predicted to remain so for the next years [134]. Hence, early and accurate diagnostic testing has become a critical factor in the detection and optimal management of CAD. In the next section, the possibilities of PET as a noninvasive diagnostic tool for CAD diagnosis are explored.

\subsection{PET in cardiovascular disease}

PET, and more recently combined PET/CT have been used for decades as a diagnostic and prognostic tool for cardiovascular disease. Cardiac PET presents a wide variety of research applications; imaging myocardial innervation or fatty acid uptake, gene expression and gene therapy monitoring, lesion detection in atherosclerosis, or hypoxia measurement, are some representative examples [20, 131]. However, there are two main clinical applications of cardiac PET that stand out over the rest: quantitative assessment of myocardial blood flow and assessment of myocardial viability. 


\subsubsection{Myocardial blood flow}

The presence of high-grade coronary stenoses is a sign of obstructive CAD, and it can be detected non-invasively by PET, but also by anatomical imaging techniques such as computed tomography angiography. Nevertheless, the central goal nowadays has shifted from diagnosing obstructive $\mathrm{CAD}$ to detecting patients who are at risk for developing $\mathrm{CAD}$ or who already have preclinical (although not obstructive) CAD. This early diagnosis of patients at risk may translate into the ability to prevent, halt progression of promote regression of atherosclerosis before it becomes clinically overt [46].

PET is able to identify this subclinical CAD [190, 191] by assessing coronary microvascular function. It can be identified by quantifying the hyperemic MBF (which represents the maximum MBF achievable by the heart during maximum vasodilatation of the coronary vascular bed) and comparing it against resting values. For that, rest/stress studies are performed and the ratio of MBFs under stress and rest condition is calculated (stress may be induced by physical exercise during the test or, whenever this is not possible, by pharmacological induction, typically through adenosine). This ratio is called coronary flow reserve (CFR) and serves as an empirical cut-off to decide whether there is an elevated cardiac risk (CFR under 1.5) or a favorable prognosis (CFR over 2.3$)^{*}[228]$.

\subsubsection{Radiotracers used for MBF assessment}

Only a few radiotracers are clinically used for cardiac MBF assessment: ${ }^{15} \mathrm{O}$-labeled water $\left(\mathrm{H}_{2}{ }^{15} \mathrm{O}\right)$ [6, 22], ${ }^{13} \mathrm{~N}$-labeled ammonia $\left({ }^{13} \mathrm{NH}_{3}\right)$ [94, 189] and ${ }^{82} \mathrm{Rb}$ [88]. Additionally, a novel ${ }^{18} \mathrm{~F}$-labeled radiotracer $\left({ }^{18} \mathrm{~F}\right.$-BMS-747158-02, known as ${ }^{18} \mathrm{~F}$-Flurpiridaz) has been proposed and validated in pigs [156] and humans [24, 128, 130] and it is currently in a phase III trial for clinical use. Some characteristics of these radiotracers can be found in Table 2.3.

Table 2.3: Most common radiotracers used in cardiac PET for MBF assessment. ${ }^{a}$

\begin{tabular}{|c|c|c|c|c|}
\hline & Image resolution & $\begin{array}{c}\text { Myocardial } \\
\text { extraction fraction }\end{array}$ & $\begin{array}{l}\text { Pharmacological stress } \\
\text { imaging protocol }\end{array}$ & $\begin{array}{l}\text { Treadmill exercise } \\
\text { imaging protocol }\end{array}$ \\
\hline $\mathrm{H}_{2}{ }^{15} \mathrm{O}$ & Intermediate & $100 \%$ & Feasible & Not feasible \\
\hline${ }^{13} \mathrm{NH}_{3}$ & Intermediate-high & $80 \%$ & Feasible & Feasible but not practical \\
\hline${ }^{82} \mathrm{Rb}$ & Lowest & $65 \%$ & Feasible & Not feasible \\
\hline${ }^{18}$ F-Flurpiridaz & Highest & $94 \%$ & Feasible & Feasible \\
\hline
\end{tabular}

a Adapted from [129].

From the FDA-approved ${ }^{\dagger}$ radiotracers, $\mathrm{H}_{2}{ }^{15} \mathrm{O}$ seems to be the ideal one, since it is a freely diffusible tracer (i.e. its myocardial extraction fraction is the highest possible), and it does not depend on the metabolic state of the myocardium [198]. However, $\mathrm{H}_{2}{ }^{15} \mathrm{O}$ quickly reaches activity concentration equilibrium between blood pool and myocardium, which may interfere in the quantification, and therefore the blood pool contribution may be eliminated. Such elimination can be accomplished by acquiring a second set of images after a inhalation of ${ }^{15} \mathrm{O}$-labeled

*These values are approximate; to date, there is no consensus over the optimal cut off values, and many possibilities can be found in the literature.

${ }^{\dagger}$ FDA refers to Food and Drug Administration: the federal agency of the US Department of Health and Human Services that regulates the use of radiopharmaceuticals in humans. 
carbon monoxide $\left({ }^{15} \mathrm{CO}\right)$, that irreversibly binds to hemoglobin in blood [52] and provides an independent image of the blood pool, that will be subtracted from the main image. However, this needed but impractical procedure is a limiting factor for the widespread implementation of $\mathrm{H}_{2}{ }^{15} \mathrm{O}$ in the clinical setting.

Regarding the promising ${ }^{18} \mathrm{~F}$-Flurpiridaz, it also possesses some characteristics that may convert it into a widely used MBF radiotracer in the future, if approved by FDA. Apart from its high extraction fraction, it is a ${ }^{18} \mathrm{~F}$-labeled drug, which facilitates a broader access to this agent due to higher availability than on-site ${ }^{15} \mathrm{O}$ and ${ }^{13} \mathrm{~N}$ cyclotrons and more adequate half-life than ${ }^{82} \mathrm{Rb}$. Furthermore, its long half-life permits routine exercise stress testing, which is not a feasible option for $\mathrm{H}_{2}{ }^{15} \mathrm{O}$ or ${ }^{82} \mathrm{Rb}$. Apart from their physical and logistical characteristics, each radiotracer provides a quantitative assessment of MBF by the analysis of dynamic PET scans. However, this analysis may differ amongst radiotracers depending on their uptake mechanism, and hence, each radiotracer may obey a different pharmacokinetic model. A more detailed description of the two most relevant pharmacokinetic models used in this work can be found in section 2.4 .

\subsubsection{Myocardial viability}

After a prolonged reduction in blood flow provoked by a coronary artery obstruction, the myocytes existing in the affected myocardial region commence to die due to the decreased oxygen supply. Over the following weeks, the ischemic region follows a complex process [52] that ends with the formation of a collagenous scar that lacks the structure necessary for the normal contraction. As stated above, the consequent loss of contractility may not be irreversible, though. Predicting, to some extent, an eventual recovery after revascularization is the goal of myocardial viability assessment. In order to get a full insight of the utility of myocardial viability, some definitions must be presented:

- Scarred myocardium refers to the situation in which the loss of contractility is irreversible due to high amount of fibrotic tissue replacing the myocytes that existed before the ischemia.

- Hibernating myocardium can be described as the chronic LV dysfunction due to reduced MBF that can be partially or completely reversed after revascularization [169-171].

- Stunned myocardium refers to the acute post-ischemic dysfunction characterized by normal flow but reduced function in the absence of myocardial necrosis [99], with gradual return of contractile activity.

In the last two situations, myocardium is dysfunctional, albeit viable, i.e., it may return to its normal function after revascularization. The ability to assess whether a myocardium is still viable (either hibernating or stunned) or not (scarred) is of extreme importance in the management of a patient that suffers from CAD or left ventricular dysfunction, as it may determine whether the patient is suitable for revascularization [104]. 
PET is accepted as the gold standard for viability assessment. A distinction between viable and non-viable myocardium can be done by the combination of regional myocardial perfusion (MBF) and myocardial metabolic activity measurement, as shown in Table 2.4. The regional metabolic activity measurement is assessed by ${ }^{18} \mathrm{FDG}[164,172] .{ }^{18} \mathrm{FDG}$ refers to fluorodeoxyglucose, a glucose analogue labeled with ${ }^{18} \mathrm{~F}$. This molecule competes with glucose for uptake by high-glucose-demanding cells such as cardiomyocytes. However, this molecule gets trapped inside the cells after phosphorylation, as it lacks a 2-hydroxyl group present in normal glucose. Thanks to this mechanism, it has been demonstrated that ${ }^{18} \mathrm{FDG}$ uptake is directly proportional to the utilization of exogenous glucose [172], making ${ }^{18} \mathrm{FDG}$ a perfect radiotracer for metabolic activity assessment.

Table 2.4: Characteristics of the different myocardial states.

\begin{tabular}{|c|c|c|c|c|}
\hline Classification & Perfusion & Contractile function & FDG uptake & Metabolism \\
\hline Nonischemic & Normal & Normal & Normal & Normal \\
\hline Stunned & Normal & Reduced but reversible ${ }^{a}$ & High & Normal/increased \\
\hline Hibernated & Reduced & Reduced but reversible ${ }^{b}$ & High & Normal/increased ${ }^{c}$ \\
\hline Scarred & Reduced/absent & Reduced & Low & Reduced/absent \\
\hline
\end{tabular}

As a final remark, it must be pointed out that there is another interesting way to assess the myocardial viability without monitoring the glucose uptake with ${ }^{18} \mathrm{FDG}$. It can be done by analyzing the composition of the tissue remaining in the post-ischemic [161] regions. This is routinely done by CMR, which can identify scarred and fibrotic tissue [110] by assessing the extracellular volume fraction (ECV). ECV is described as the fraction of tissue that is not occupied by cells. In this line, PET has been recently used to assess myocardial viability by means of ECV quantification [109].

\subsection{Pharmacokinetic modeling in cardiac PET}

\subsubsection{Compartmental models}

PET imaging gives quantitative information about the biodistribution and kinetics of a radiopharmaceutical throughout a target structure and/or organ. A single static image may be collected at a specific time, but sometimes it may become more useful to record the time-course biodistribution of the radiotracer by performing a dynamic PET scan. In such case, the time dependence of the radiotracer biodistribution may give a deeper insight of the tracer kinetics, and physiological parameters, such as blood flow or tracer binding, may be obtained.

The radioactivity concentration in a given tissue depends primarily on two factors; the local physiology and the time-course of the tracer radioactivity concentration in blood or plasma [16]. The relationship between the concentration and those two factors can be mathematically modeled. Compartmental modeling is the most commonly applied method to determine the uptake and clearance of radiotracers in tissue $[4,102]$. In these models, each compartment refers 
to a possible state of the radiotracer, either physical (i.e., its location) or chemical (i.e., its binding state) and a set of equations describe mathematically the movements between compartments. The nature and number of these equations will depend on the number of compartments needed to describe the behavior of the radiotracer imaged. The two most used pharmacokinetic models employed in cardiac PET imaging are briefly described below.

\subsubsection{One-tissue compartment model}

The one-tissue compartment model (1TCM) describes the bidirectional flux of radiotracer between blood capillaries and myocardial tissue. The unidirectional radiotracer flux from blood to tissue is given by $K_{1} C_{a}(t)$, and the unidirectional radiotracer flux from tissue to blood is given by $k_{2} C_{t}(t)$. Therefore, the differential equation describing the rate of change of the radiotracer tissue concentration is:

$$
\frac{d C_{t}(t)}{d t}=K_{1} C_{a}(t)-k_{2} C_{t}(t)
$$

where $K_{1}$ describes the rate of entry of radiotracer from blood to tissue and has units of milliliter of blood per minute per milliliter of tissue. $k_{2}$ describes the rate of return of tracer from tissue to blood, in units of fraction of radiotracer leaving the tissue per minute. The radiotracer tissue concentration $C_{t}(t)$ can be directly measured from PET images. Finally, the radiotracer concentration in blood, $C_{a}(t)$ (usually known as the Arterial Input Function, AIF) has to be determined. It is usually measured either from the dynamic PET image, or from the analysis of blood samples withdrawn from the scanned patient. Eq. 2.7 can be analytically solved, yielding the following solution:

$$
C_{t}(t)=C_{a}(t) \otimes K_{1} \mathrm{e}^{-k_{2} t}
$$

where $\otimes$ stands for the one-dimensional convolution.

\subsubsection{Two-tissue compartment model}

In the two-tissue compartment model (2TCM), the first tissue compartment refers to the extravascular extracellular part of the tissue (the interstitial space), while the second compartment refers to the intracellular space. The two differential equations that describe the radiotracer concentration are:

$$
\begin{aligned}
& \frac{d C_{1}(t)}{d t}=K_{1} C_{a}(t)-\left(k_{2}+k_{3}\right) C_{1}(t)+k_{4} C_{2}(t) \\
& \frac{d C_{2}(t)}{d t}=k_{3} C_{1}(t)-k_{4} C_{2}(t) .
\end{aligned}
$$

It is of special interest the case in which the radiotracer can enter the second compartment, but does not leave. This is what happens for ${ }^{18} \mathrm{FDG}$ cellular uptake. Due to the impossibility of the molecule to follow the glycolytic pathway, ${ }^{18} \mathrm{FDG}$ gets trapped inside the cell, which mathematically implies $k_{4}=0$. In this case, the analytical solution of the total radiotracer concentration $C_{t}(t)$ in tissue is:

$$
C_{t}(t)=C_{a}(t) \otimes\left(\frac{K_{1} k_{2}}{k_{2}+k_{3}} \mathrm{e}^{-\left(k_{2}+k_{3}\right) t}+\frac{K_{1} k_{3}}{k_{2}+k_{3}}\right)
$$




\subsubsection{Blood flow, perfusion and extraction fraction}

The 1TCM described above allows us to obtain the physiologically meaningful parameters $K_{1}$ and $k_{2}$ and, although MBF is not any of these parameters, it is indeed related with $K_{1}$, as we will see below.

The rate $J_{t}$, at which the radiotracer activity perfuses the tissue can be described (see Fig. $2.5)$ as the difference between the arterial flux $\left(J_{a}\right)$ and the venous $\left(J_{V}\right)$. If the radiotracer does not accumulate in tissue, then, Fick principle establishes that:

$$
J_{t}=J_{a}-J_{V}
$$

where $J_{a}$ and $J_{V}$ are defined as the product between the blood flow $\left(F^{\ddagger}\right)$ and the arterial and venous radiotracer concentration respectively $\left(C_{a}\right.$ and $\left.C_{V}\right)$ :

$$
\begin{aligned}
J_{a} & =F C_{a} \\
J_{V} & =F C_{V} .
\end{aligned}
$$

Thus, Eq. 2.12 becomes:

$$
J_{t}=F\left(C_{a}-C_{V}\right)
$$

The unidirectional first-pass extraction, $E$, is defined as the fraction of tracer that travels from the capillaries into tissue on a single pass, and is equal to:

$$
E=\frac{C_{a}-C_{V}}{C_{a}}
$$

Eqs. 2.15 and 2.16 can be combined to express $J$ in terms of the blood flow, the extraction

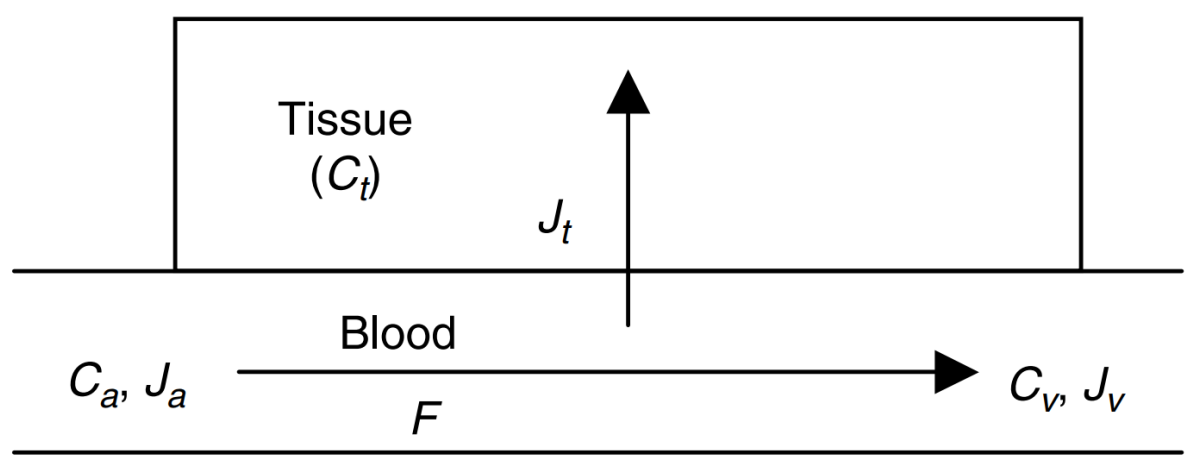

Figure 2.5: Tracer flow through a capillary. $C_{a}$ and $C_{V}$ denote the radiotracer concentration in arterial and venous blood, respectively. The radiotracer enters into the capillary with a flux $J_{a}$ and leaves it by tissue extraction $\left(J_{t}\right)$ and venous circulation $\left(J_{V}\right)$. This illustration was reproduced from [150].

$\ddagger$ This term, $F$, receives different names when referring to perfusion of a particular tissue, such as Pulmonary Blood Flow (PBF) or Myocardial Blood Flow (MBF). 
fraction and arterial blood radiotracer concentration:

$$
J=K_{1} C_{A}=(F \cdot E) C_{A},
$$

which means:

$$
K_{1}=F \cdot E .
$$

This extraction fraction can be modeled $[39,176]$ in terms of the capillary permeabilitysurface product $(P S)$ and the blood flow $(F)$ itself:

$$
E=1-\mathrm{e}^{-\frac{\mathrm{PS}}{F}} .
$$

In the particular case of $E=1$, tissue perfusion and blood flow are exactly the same physiological parameter, since, in this case, all blood flowing through the capillaries perfuses the tissue.

\subsubsection{Diffusible tracers and extracellular volume}

Extracellular volume fraction (ECV) is, as detailed in section 2.3, another physiological parameter that becomes of great importance when assessing myocardial viability. This parameter can also be obtained from compartmental model analysis of a diffusible tracer that cannot pass through the cellular membrane. In such situation, ECV equals the so-called volume of distribution $\left(V_{T}\right)$, defined as the ratio between the radiotracer concentration in a region of the target tissue and in blood $\left(C_{t} / C_{a}\right)$ at equilibrium [77]. Being at equilibrium means that there is a null net radiotracer flux between blood and tissue $\left(J_{t}=d C_{t} / d t=0\right)$. Then, using Eq. 2.7:

$$
0=K_{1} C_{a}-k_{2} C_{t} \rightarrow \frac{C_{t}}{C_{a}}=\mathrm{ECV}=\frac{K_{1}}{k_{2}} .
$$

\subsection{Myocardial segmentation in cardiac PET}

PET is an imaging technique and, as for every imaging technique, the resultant images are a composition of small picture elements (pixels). Every pixel is geometrically associated with a spatial (and time, in case of dynamic PET scans) coordinate. In the particular case of three-dimensional (tomographic) imaging techniques, such pixels are denoted as volume elements (voxels). The 3D positions associated with every voxel are spatially ordered following three predefined planes: axial, sagittal, and coronal (see Fig. 2.6A). These planes have an anatomical meaning; the axial plane divides the body into cranial and tail portions; the coronal plane divides it into dorsal and ventral, and the sagittal plane divides it into left and right. However, they lose their utility when the protagonist is the heart, since cardiac axes are not parallel to the body axes, and hence, the anatomical planes do not clearly transect the ventricles or atria.

Over the years, many attempts have been done to define standards for plane selection and orientation display for serial myocardial slices generated by $2 \mathrm{D}$ or 3D imaging. Eventually, 


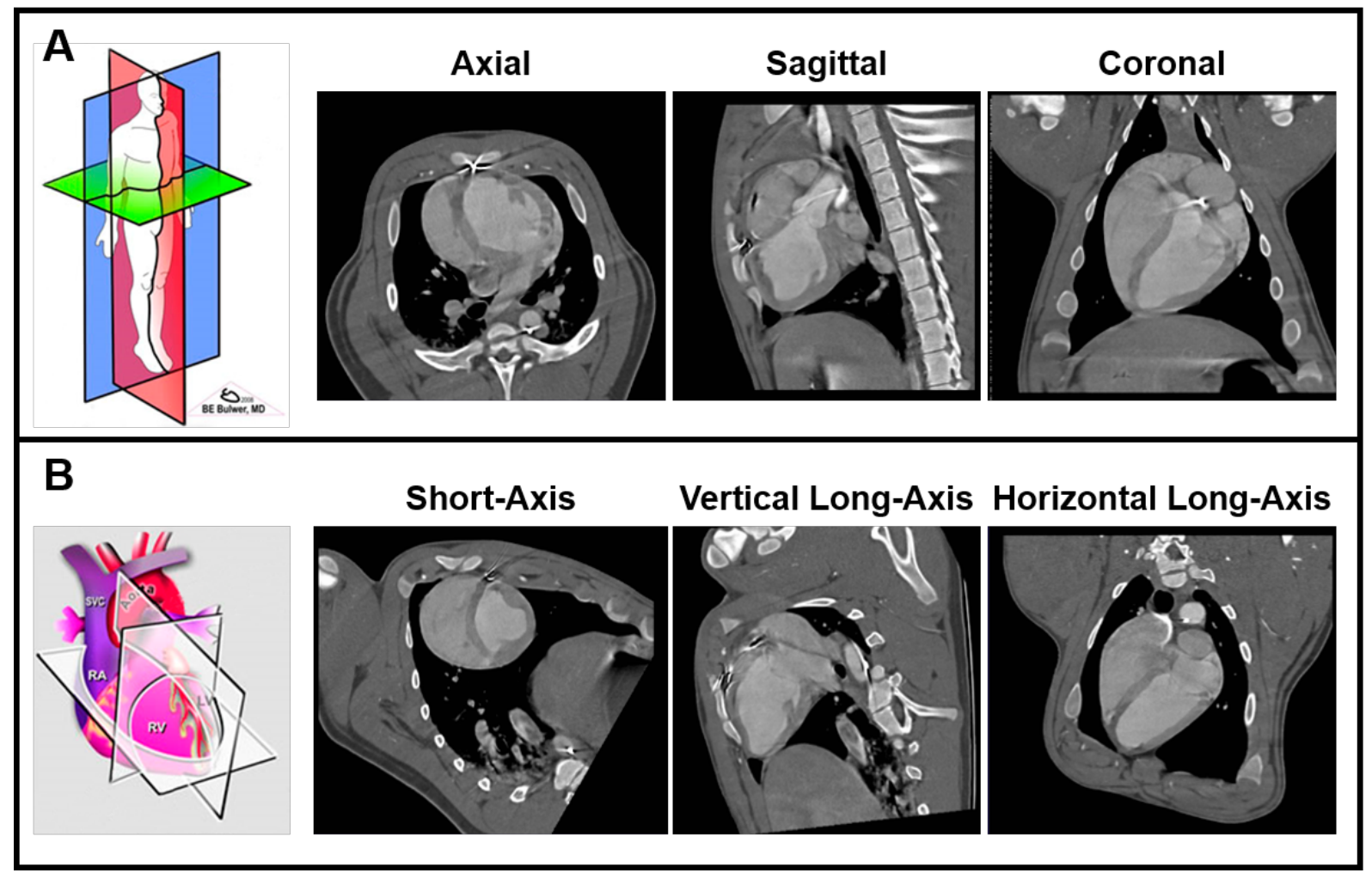

Figure 2.6: $A$ : Axial, sagittal and coronal slices of a contrast-CT of the thorax of a pig. These slices correspond to the anatomical planes. B: Short-axis, vertical long-axis and horizontal long-axis orientations referred as cardiac planes. (Illustrations of the anatomical and cardiac planes were obtained from [33]).

a consensus was made for the nomenclature, segmentation and assignment of coronary artery territories [34] and all the analyses presented in this thesis follow those recommendations. Thus, a brief description (extracted from [34]) is provided here:

\subsubsection{Heart orientation}

The consensus in research and clinical patient management displays parallel and normal planes relative to the long axis of the left ventricle. This axis transects the apex and the center of the mitral valve plane. Therefore, as a recommendation, all cardiac imaging modalities should orient the heart using the long axis of the left ventricles as a reference.

\subsubsection{Cardiac planes}

The nomenclature of these planes are: short, vertical long-axis, and horizontal long-axis. In that way, the vertical long-axis view approximates the apical 2-chamber echocardiographic view (in which left ventricle and left atrium are displayed simultaneously), and the horizontal long-axis view approximates the apical 4-chamber view (in which the four heart cavities are displayed at the same time) (see Fig. 2.6B). 


\subsubsection{Left ventricular segmentation}

This approach divides the muscle of the left ventricle into a variable number of segments. Although different models have been proposed depending on the desired application, the most common model employed in cardiac nuclear PET imaging is the 17-segment model. This model provides the best agreement with the available anatomic data and creates a distribution of $35 \%$, $35 \%$ and $30 \%$ for the basal, mid-cavity and apical thirds of the heart.

For a correct segmentation, the left ventricle should be equally divided in thirds which are perpendicular to the long axis of the heart. This will generate three circular slices of the left ventricle: basal (from the mitral annulus to the tips of the papillary muscles), mid-cavity (a region that includes the entire length of the papillary muscles) and apical (beyond the papillary muscles until cavity ends) short-axis. These slices will be further divided in 6,6 and 4 segments respectively, being segments 1-6 related to basal slice, 7-12 to mid-cavity and 13-16 to apical slice. The 17th segment will correspond to the apical cap (see Fig. 2.7).
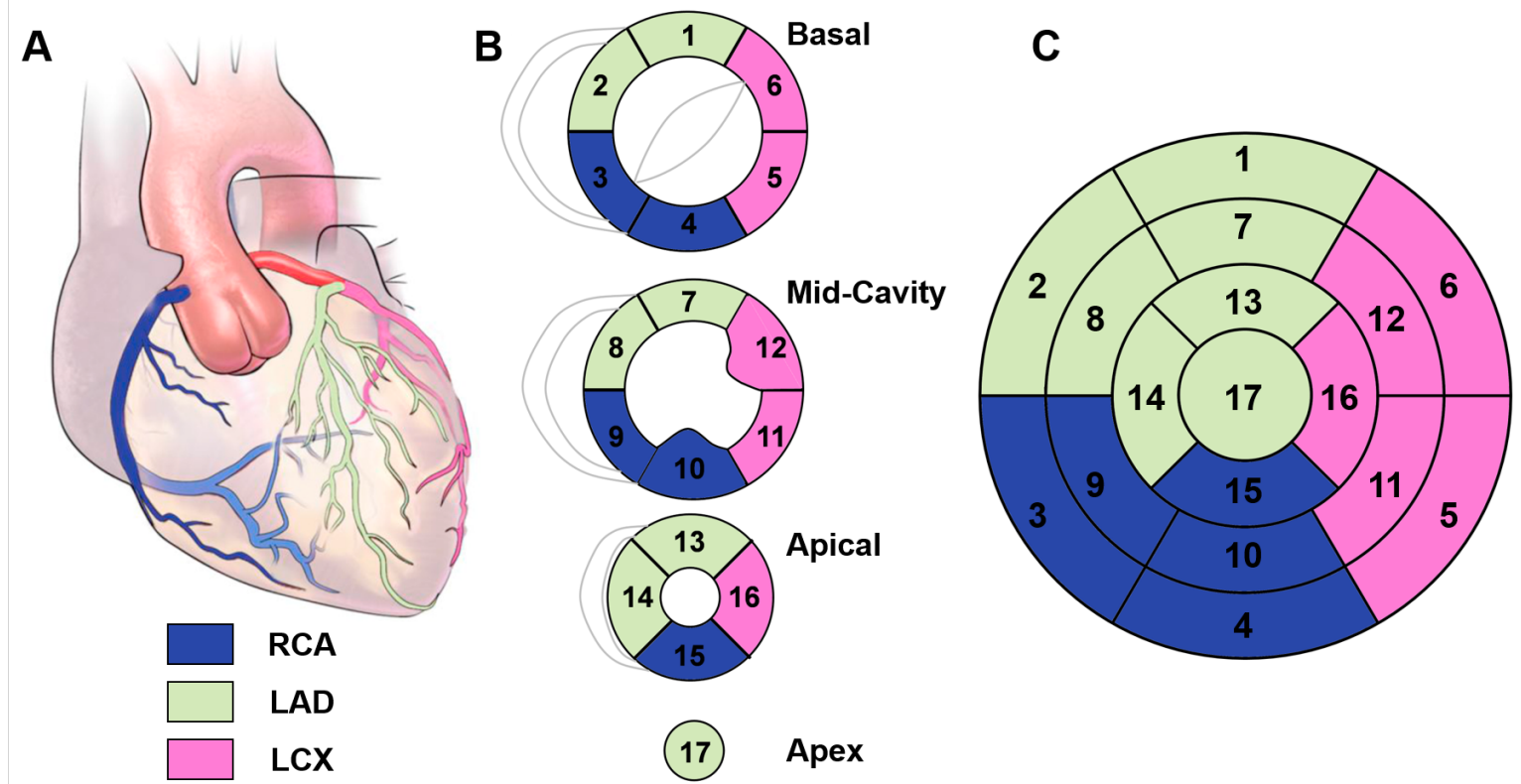

Figure 2.7: Myocardial segmentation into territories and segments. A: illustration of the heart with its three main coronary arteries (image modified from [115]). B: Left ventricular segmentation into basal, mid-cavity and apical slices plus apical cap segment. C: Bullseye representing the 17-segment model. Green, blue and pink regions correspond to myocardial territories irrigated by LAD, RCA and LCX coronary arteries respectively.

\subsubsection{Assignment of segments to coronary artery territories}

There is a significative variability in the coronary artery blood supply to myocardial segments. Thus, some of the segments are sometimes assigned to one or other arterial territory. In this work we have followed the most common convention. Fig. 2.7 shows the assignment of each segment to the territories corresponding to LAD, RCA and LCX blood supply employed in this work. 
MYOCARDIAL BLOOD FLOW DETERMINATION WITH ${ }^{68}$ GA-DOTA-PET

\subsection{Introduction}

Among the many applications of PET in nuclear medicine, myocardial perfusion imaging (MPI) arises as the gold standard tool for noninvasive assessment of coronary artery disease (CAD) [48]. CAD is the leading cause of morbidity and mortality and a major source of disability worldwide [21]. Hence, its accurate diagnosis becomes important in risk stratification and selection of an appropriate management strategy. A complete assessment of known or suspected CAD must include not only anatomical but functional evaluation, and this can be done by many noninvasive imaging modalities such as CMR, SPECT and PET among others. SPECT is currently the preferred clinical tool to perform MPI, with an utilization ratio of more than 10:1 with respect to PET. However, although reliable, the information provided by SPECT is qualitative or, at most, semi-quantitative, and the technique itself presents limitations such as long imaging protocols, poor image resolution or reduced specificity due to attenuation artifacts. Altogether, these limitations may translate into an underestimation of the degree of ischemia, especially in case of multivessel disease [23]. On the other hand, PET provides an absolute quantification with better spatial resolution, faster imaging protocols, and lower radiation doses received by patients. On the top of that, PET also has higher sensitivity and specificity for detection of CAD [86]. However, although PET superior diagnostic accuracy over SPECT is well known and widely recognized, and despite $\mathrm{PET}$ is considered the gold standard in CAD detection, the adoption of cardiac PET has not been widespread.

The main reason for the underutilization of PET in the MPI field is the higher cost of a 
PET/CT scanner (about 4-5 times more expensive than a SPECT gamma camera) and, more importantly, the reduced availability of the needed radiotracers. At present, the most utilized radiotracers for MPI in PET are ${ }^{13} \mathrm{NH}_{3},{ }^{82} \mathrm{Rb}$ and $\mathrm{H}_{2}{ }^{15} \mathrm{O}$ [190]. However, their short half-life $\left(\mathrm{t}_{1 / 2}\left({ }^{13} \mathrm{~N}\right)=9.97 \mathrm{~min}, \mathrm{t}_{1 / 2}\left({ }^{15} \mathrm{O}\right)=122 \mathrm{~s}, \mathrm{t}_{1 / 2}\left({ }^{82} \mathrm{Rb}\right)=75 \mathrm{~s}\right)$ limits widespread clinical use due to the need of a nearby cyclotron $\left({ }^{13} \mathrm{~N}\right.$ and $\left.{ }^{15} \mathrm{O}\right)$ or expensive and dedicated generators $\left({ }^{82} \mathrm{Rb}\right)$. More recently, as stated in Chapter 1, Flurpiridaz, which is based on labeled ${ }^{18} \mathrm{~F}[156,226]$, has appeared as a good candidate. This tracer is currently in late stages of FDA approval and shows potential to spread the use of PET for MBF image as its production does not depend on an onsite cyclotron or generator. Nonetheless, the relatively long half-life of ${ }^{18} \mathrm{~F}$ ( $\sim 110 \mathrm{~min}$ ) involves much prolonged studies for sequential rest-stress tests and it still would require the existence of a local cyclotron. The radiotracers named above are, essentially, the main agents used for PET MPI. Although they are all well-established radiotracers, the necessity of a widely available and low-cost probe, with an adequate half-life, has not been fulfilled yet.

However, in the past years, ${ }^{68} \mathrm{Ga}$ has emerged as an alternative radioisotope. ${ }^{68} \mathrm{Ga}$ is a positron emitting radioisotope that is continuously available at a reasonable cost from a ${ }^{68} \mathrm{Ge} /{ }^{68} \mathrm{Ga}\left({ }^{68} \mathrm{Germanium} /{ }^{68} \mathrm{Gallium}\right)$ generator [30]. This system is particularly attractive due to the long half-life of the parent ${ }^{68} \mathrm{Ge}(271 \mathrm{~d})$ combined with a suitable half-life of the daughter ${ }^{68} \mathrm{Ga}(68 \mathrm{~min})$ for its use in clinical studies. Lately, several ${ }^{68} \mathrm{Ga}$-labeled radiopharmaceuticals have been used in clinical PET studies [196], mainly in the field of neuroendocrine tumor and prostatic cancer imaging. But despite several attempts, the development of ${ }^{68}$ Ga-labeled radiopharmaceuticals suitable for MBF imaging has not yet succeeded [207].

More recently, Autio et al. proposed the novel radiotracer ${ }^{68} \mathrm{Ga}$-DOTA for assessment of blood flow in experimental inflammation using a rat model [11]. The radioisotope ${ }^{68} \mathrm{Ga}$, chelated with DOTA was hypothesized to behave as its analogue probes based on gadolinium (Gd-DOTA and Gd-DTPA*), which are widely used for contrast-enhanced CMR [122]. Following the hypothesis of Autio et al., if the Gd-based contrast agents succesfully work as probes in CMR, ${ }^{68} \mathrm{Ga}$-DOTA may function as a probe for assessment of myocardial blood flow by PET. If so, this novel compound may become a promising tracer in cardiac PET imaging, due to its low production cost and high availability.

\subsection{Aim of the chapter}

In this chapter, we propose the use of ${ }^{68} \mathrm{Ga}-\mathrm{DOTA}$ as a new MPI tracer for in vivo PET assessment of MBF. We evaluated the feasibility of this radiotracer as a new myocardial perfusion agent in healthy pigs. To do so, a set of eight pigs was scanned under rest and (pharmacologicallyinduced) stress, mimicking the conditions under which these tests are performed in clinical routine.

In addition, the absolute MBF values obtained with ${ }^{68} \mathrm{Ga}$-DOTA-PET were validated using fluorescent microspheres (MS) [75], which is the accepted (but highly invasive) gold standard for

\footnotetext{
*2-[Bis[2-[bis(carboxymethyl)amino]ethyl]amino]acetic acid.
} 
perfusion quantification due to the predictable behavior of the MS in the vascular bed.

\subsection{Methods}

\subsubsection{Tracer production}

${ }^{68} \mathrm{Ga}\left(\mathrm{t}_{1 / 2}=68 \mathrm{~min}\right)$ was available from a ${ }^{68} \mathrm{Ge} /{ }^{68} \mathrm{Ga}$ generator system (ITG Isotope Technologies, Garching GmbH, Germany). ${ }^{68} \mathrm{Ga}$ was eluted with $4 \mathrm{ml}$ of $0.05 \mathrm{M} \mathrm{HCl}$ and added to a solution containing $200 \mu \mathrm{g}$ of DOTA dissolved in 0.25 M HEPES buffer $\mathrm{pH}$ 4.5. The mixture was heated at $95{ }^{\circ} \mathrm{C}$ for 20 min. Finally, $90 \mu \mathrm{l}$ of $\mathrm{NaOH} 1 \mathrm{M}$ and $5 \mathrm{ml}$ of $\mathrm{NaCl} 0.9 \%$ were added yielding ${ }^{68} \mathrm{Ga}$-DOTA with a radionuclide purity at radio- $\mathrm{HPLC}^{\dagger}>95 \%$. About $200-600 \mathrm{MBq}$ of ${ }^{68} \mathrm{Ga}$-DOTA were obtained from each reaction, depending on the age of the generator.

\subsubsection{Study design and animal preparation}

The experiments were performed in a group of animals consisting of eight healthy Large White pigs ( 4 females and 4 males, mean weight $38.8 \pm 6.9 \mathrm{~kg}$ ). The study was conducted according to the guidelines of the current European Directive and Spanish legislation and approved by the regional ethical committee for animal experimentation. Briefly, anesthesia was induced by intramuscular injection of ketamine $(20 \mathrm{mg} / \mathrm{kg})$, xylazine $(2 \mathrm{mg} / \mathrm{kg})$, and midazolam $(0.5 \mathrm{mg} / \mathrm{kg})$, and maintained by continuous intravenous infusion of ketamine $\left(2 \mathrm{mg} \cdot \mathrm{kg}^{-1} \cdot \mathrm{h}^{-1}\right)$, xylazine $(0.2$ $\left.\mathrm{mg} \cdot \mathrm{kg}^{-1} \cdot \mathrm{h}^{-1}\right)$, and midazolam $\left(0.2 \mathrm{mg} \cdot \mathrm{kg}^{-1} \cdot \mathrm{h}^{-1}\right)$. During the entire procedure the animals were ventilated with 50\%/50\% oxygen/air mixture. Prior to the imaging session, the animals underwent a catheterization procedure in the fluoroscopy room. A 5-French Judkins-Left catheter was inserted into the left ventricle (LV) from the right femoral artery. A 1.8-2.6-French coronary micro-guide catheter (Finecross MG, Terumo Medical Corporation, Somerset, NJ, USA) was passed through the aforementioned catheter and guided to the left atrial appendage (LAA) of the heart. This micro-guide catheter served to deliver the fluorescent microspheres used for the MBF validation right into animal's left atrium. This procedure revealed as a critical step in the experimental protocol; only in case of a successful placement of the micro-guide catheter inside the LAA, the experiment could be continued. The positioning of the catheter was done under fluoroscopic guidance, using a Veradius mobile C-arm (Philips Healthcare, Best, The Netherlands). An illustrative image of the micro catheter placement in the LAA can be observed in the Fig. 3.1.

Once the micro-guide catheter was placed in the LAA, the animals were moved to the PET/CT imaging room. From that moment, oxygen saturation levels via pulse oximetry, heart rate (HR), non-invasive systolic and diastolic arterial pressure, and electrocardiogram signal (ECG) were monitored until the end of the study. The animals were scanned under three different physiological conditions covering a broad range of MBF values. For that purpose, three dynamic ${ }^{68} \mathrm{Ga}$-DOTA-PET/CT scans were performed sequentially on each animal with 30 minutes delay between the beginning of consecutive PET scans (Fig. 3.2). The first scan was

\footnotetext{
${ }^{\dagger}$ High performance liquid chromatography.
} 

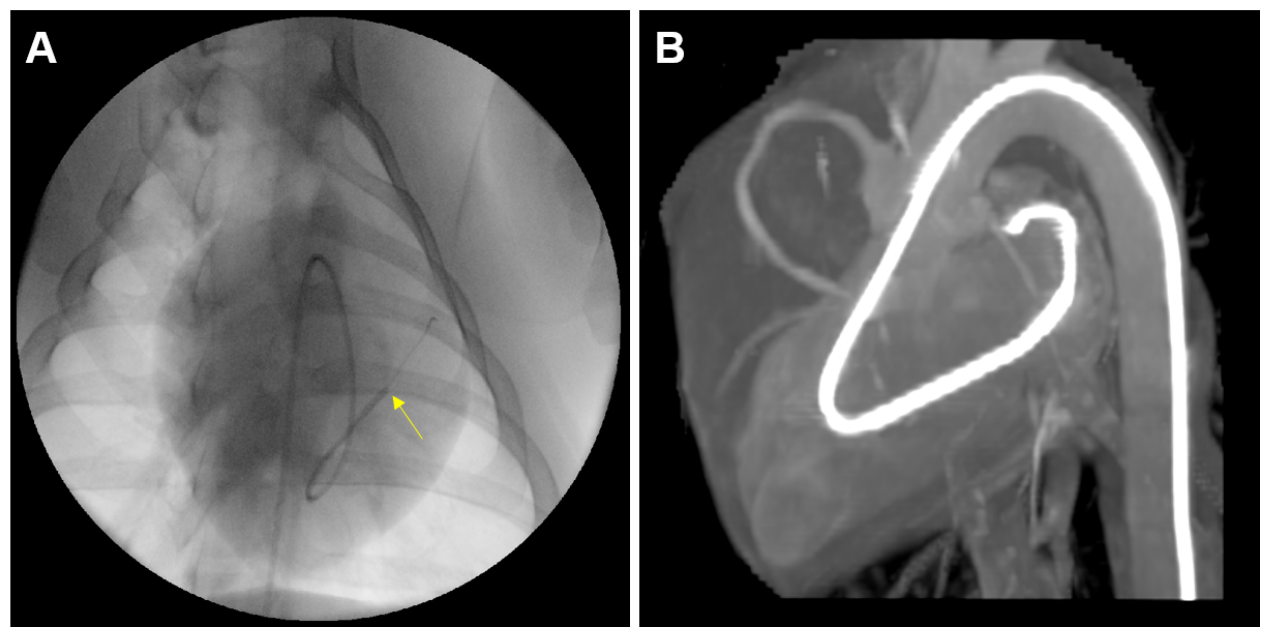

Figure 3.1: A: Fluoroscopy image of the cardiac catheterization performed on one of the animals. The JudkinsLeft catheter enters the $L V$ from the aorta and the tip of the micro-guide catheter leaves the bigger one and enters the LAA (yellow arrow). B: Maximum intensity projection (MIP) of a contrast CT performed on the same animal at the end of the imaging session. One of the objectives of the contrast-CT scan was to assess the position of the micro-guide catheter at the end. If the tip remained inside the LAA, it was assumed that the microspheres were delivered in the correct place.
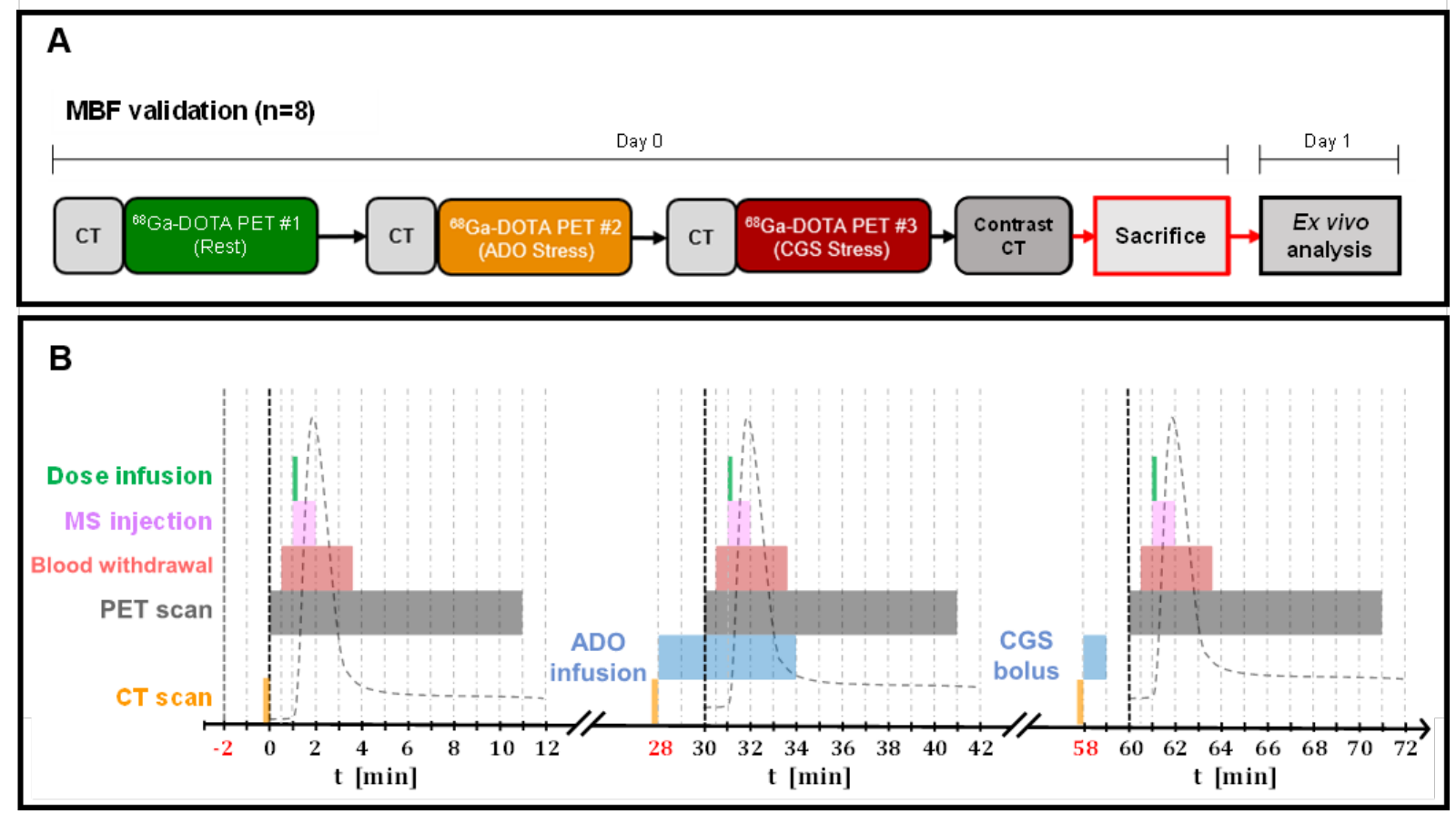

Figure 3.2: A: Schematic drawing of the study approach. B: Scheme of experimental protocol followed during $M B F$ validation studies represented as a timeline. Colored boxes show time periods where every action was being performed. The timeline is superimposed on a schematic AIF (dashed line). ADO stands for adenosine and CGS stands for CGS-21680.

performed at resting condition. A second scan was performed under pharmacological stress induced with adenosine (400-600 $\mu \mathrm{g} \cdot \mathrm{kg}^{-1} \cdot \mathrm{min}^{-1}$, Sigma-Aldrich, Tres Cantos, Madrid, Spain). Adenosine was infused intravenously for 6 minutes, starting 3 minutes before radiotracer injection. Since adenosine mediates coronary microvascular dilation mainly through adenosine A2A receptor activation [85], we also used the selective A2A receptor agonist CGS-21680 (Santa Cruz 
Biotech. Inc., Dallas, TX, USA) in order to reach higher and longer lasting MBF values. Therefore, a third scan was performed under pharmacological stress induced with CGS-21680 (10-15 $\mu \mathrm{g} / \mathrm{kg}$ ), administered as an intravenous bolus injection 3 minutes before radiotracer injection. Radiotracer was injected simultaneously to the injection of $15 \mu \mathrm{m}$ fluorescent microspheres (MS) (FluoroSpheres®, Molecular Probes, Eugene, OR, USA) consisting of $10^{6}$ beads diluted into 10 $\mathrm{ml}$ of saline containing $0.01 \%$ Tween $80^{\ddagger}$ to avoid aggregation. A different MS color was used on each of the injections performed on the same animal including green $(\lambda=450 / 480 \mathrm{~nm})$, yellow $(\lambda=515 / 534 \mathrm{~nm})$, and blue $(\lambda=365 / 415 \mathrm{~nm})$. Immediately before MS dilution, the vial was vigorously vortexed for 15 seconds, sonicated for 4 minutes and vortexed again for additional 15 seconds. MS were manually injected over $\sim 60$ seconds directly into the LAA. A 16-ml arterial blood reference sample was withdrawn from the femoral artery starting 1 minute before MS injection at a constant rate of $5 \mathrm{ml} / \mathrm{min}$. Additionally, a 2-ml blood sample was taken from the coccygeal artery for hematocrit determination. An average hematocrit value of $0.29 \pm 0.02$ was obtained.

\subsubsection{PET image acquisition}

$\mathrm{PET} / \mathrm{CT}$ images were acquired using a Gemini TF-64 scanner (Philips Healthcare, Best, The Netherlands). Each imaging study consisted of a low dose CT scan $(120 \mathrm{kV}, 80 \mathrm{~mA})$ followed by a dynamic 11-min list mode PET acquisition in a single bed position. ${ }^{68} \mathrm{Ga}-\mathrm{DOTA}(115 \pm 27 \mathrm{MBq})$ was prepared in $6 \mathrm{ml}$ and infused at a rate of $1.0 \mathrm{ml} / \mathrm{s}$ through a marginal ear vein, followed by a $6 \mathrm{ml}$ saline flush at the same rate. PET scans started $1 \mathrm{~min}$ prior to the radiotracer injection. At the end of each imaging session, a contrast CT $(1.2 \mathrm{ml} / \mathrm{kg}$, Iomeron 400, Bracco, Milan, Italy) was performed to obtain better anatomical delineation and to confirm that the micro-guide catheter did not leave the LAA (see Fig. 3.1B). PET images were reconstructed with a voxel size of $4 \times$ $4 \times 4 \mathrm{~mm}^{3}$ using a 3D-RAMLA reconstruction algorithm in 42 consecutive frames $(1 \times 60 \mathrm{~s}, 15$ $\times 2 \mathrm{~s}, 8 \times 5 \mathrm{~s}, 8 \times 10 \mathrm{~s}, 1 \times 20 \mathrm{~s}, 3 \times 30 \mathrm{~s}, 1 \times 40 \mathrm{~s}$ and $5 \times 60 \mathrm{~s})$. All corrections for decay, dead time, scatter and random coincidences were applied as implemented on the scanner.

\subsubsection{PET data analysis}

Metal chelates have been widely used in MRI as contrast agents as they distribute in the blood and the extracellular extravascular space [1]. Therefore, we assumed that ${ }^{68}$ Ga-DOTA diffuses bidirectionally between the intravascular and the interstitial space and used a single-tissue compartment model (1TCM). The resulting tissue activity concentration derived from this 1TCM model can be written as:

$$
C_{t}(t)=\frac{F}{1-H} \cdot K_{1} \cdot \operatorname{AIF}(t) \otimes \mathrm{e}^{\frac{-K_{1} \cdot t}{\mathrm{ECV}}},
$$

where $C_{t}(t)$ is the time activity curve (TAC) for the myocardial tissue, $K_{1}$ is the unidirectional transfer rate from blood to tissue (which can be further defined as the product of the extraction fraction and the plasma flow [202], as explained in section 2.4, page 20), $E C V$ is the volume fraction of the extravascular extracellular space, $H$ is the hematocrit, and $F$ is the fraction of free

\footnotetext{
$\ddagger$ Also known as polysorbate 80 ; a nonionic surfactant used to maintain the microspheres in suspension
} 
tracer in plasma. Lastly, $\operatorname{AIF}(t)$ is the arterial input function, which is obtained from the image, particularly from the descending aorta, in order to minimize the effects of statistical noise [213].

Eq. 3.1 describes the bidirectional diffusion of ${ }^{68} \mathrm{Ga}$-DOTA in myocardial tissue in an ideal situation in which the two compartments (the plasma input and the tissue) are perfectly isolated and separated from the rest of the anatomical structures of the heart. However, PET imaging relies on a voxelized analysis of the ROI, and due to the poor spatial resolution of PET, these voxels are large regions (in our case $4 \times 4 \times 4 \mathrm{~mm}^{3}$ ) in which all these anatomical structures (tissue, blood pool and arterioles and venules from the capillary bed) coexist [13]. Hence, activity concentration measured inside any voxel or TAC of our ROI could come from the tissue but also from blood. To take into account this spilled-over activity, Eq. 3.1 can be modified as follows:

$$
C_{t}(t)=\frac{F}{1-H} \cdot K_{1} \cdot \operatorname{AIF}(t) \otimes \mathrm{e}^{\frac{-K_{1} \cdot t}{\mathrm{ECV}}}+V_{\mathrm{LV}} \cdot C_{\mathrm{LV}}(t)+V_{\mathrm{RV}} \cdot C_{\mathrm{RV}}(t),
$$

where $C_{\mathrm{LV}}(t)$ and $C_{\mathrm{RV}}(t)$ are the TACs for the left and right ventricles respectively, and $\mathrm{V}_{\mathrm{LV}}$ and $\mathrm{V}_{\mathrm{RV}}$ are the parameters that represent the spill-over fraction for the LV and RV [159].

These $C_{\mathrm{LV}}(t)$ and $C_{\mathrm{RV}}(t)$ terms were added to the Eq. 3.1 under the assumption that the activity concentration inside each ventricle is well mixed and spatially homogeneous. However, in our experimental studies conducted in pigs, we found differences in activity concentration during certain timeframes within different LV regions, as can be seen in Fig. 3.3. Nevertheless, as shown in the Fig. 3.4, the different behavior of the TACs measured in those ROIs cannot be explained as a simple time delay between curves, since the delay is only observed in the rising time. This is the reason why including an additional parameter related to time delay might not be optimal. To overcome this issue, the contribution of both apical and central LV were included in the model:

$$
C_{t}(t)=\frac{F}{1-H} \cdot K_{1} \cdot \operatorname{AIF}(t) \otimes \mathrm{e}^{\frac{-K_{1} \cdot t}{\mathrm{ECV}}}+V_{\mathrm{AP}} \cdot C_{\mathrm{AP}}(t)+V_{\mathrm{LV}} \cdot C_{\mathrm{LV}}(t)+V_{\mathrm{RV}} \cdot C_{\mathrm{RV}}(t),
$$

where $C_{\mathrm{AP}}(t)$ denotes the TAC inside an apical region of the left ventricle, and now $C_{\mathrm{LV}}(t)$ does only account for the TAC inside its central region. This way, $\mathrm{V}_{\mathrm{LV}}, \mathrm{V}_{\mathrm{AP}}$ and $\mathrm{V}_{\mathrm{RV}}$ are the definitive parameters that represent the spill-over fraction for the central LV, apical LV and RV respectively.

AIF was obtained from an $8 \mathrm{~mm}$ diameter cylindrical volume of interest (VOI) drawn in the descending thoracic aorta over 5 consecutive slices [213]. $C_{\mathrm{LV}}(t)$ and $C_{\mathrm{AP}}(t)$ were obtained from spherical VOIs drawn at the central (15 mm diameter) and apical (12 $\mathrm{mm}$ diameter) regions of the $\mathrm{LV}$ respectively, while VOI for determination of $C_{\mathrm{RV}}(t)$ was manually drawn inside RV over 3-5 slices leaving a margin $(>5 \mathrm{~mm}$ ) from the myocardium. Spill-out from the AIF was corrected normalizing to the average $C_{\mathrm{LV}}(t)$ of the latest frames.

Time activity curves (Fig. 3.5) were fitted voxel-wise including the 5 model parameters $\left(K_{1}, E C V, \mathrm{~V}_{\mathrm{LV}}, \mathrm{V}_{\mathrm{RV}}\right.$ and $\left.\mathrm{V}_{\mathrm{AP}}\right)$ and obtaining parametric maps of $K_{1}$ and $E C V$. Polar maps were generated using available software [158]. The standard American Heart Association (AHA) 17-segment model [34] (detailed in section 2.5, page 23, was applied to determine regional val- 


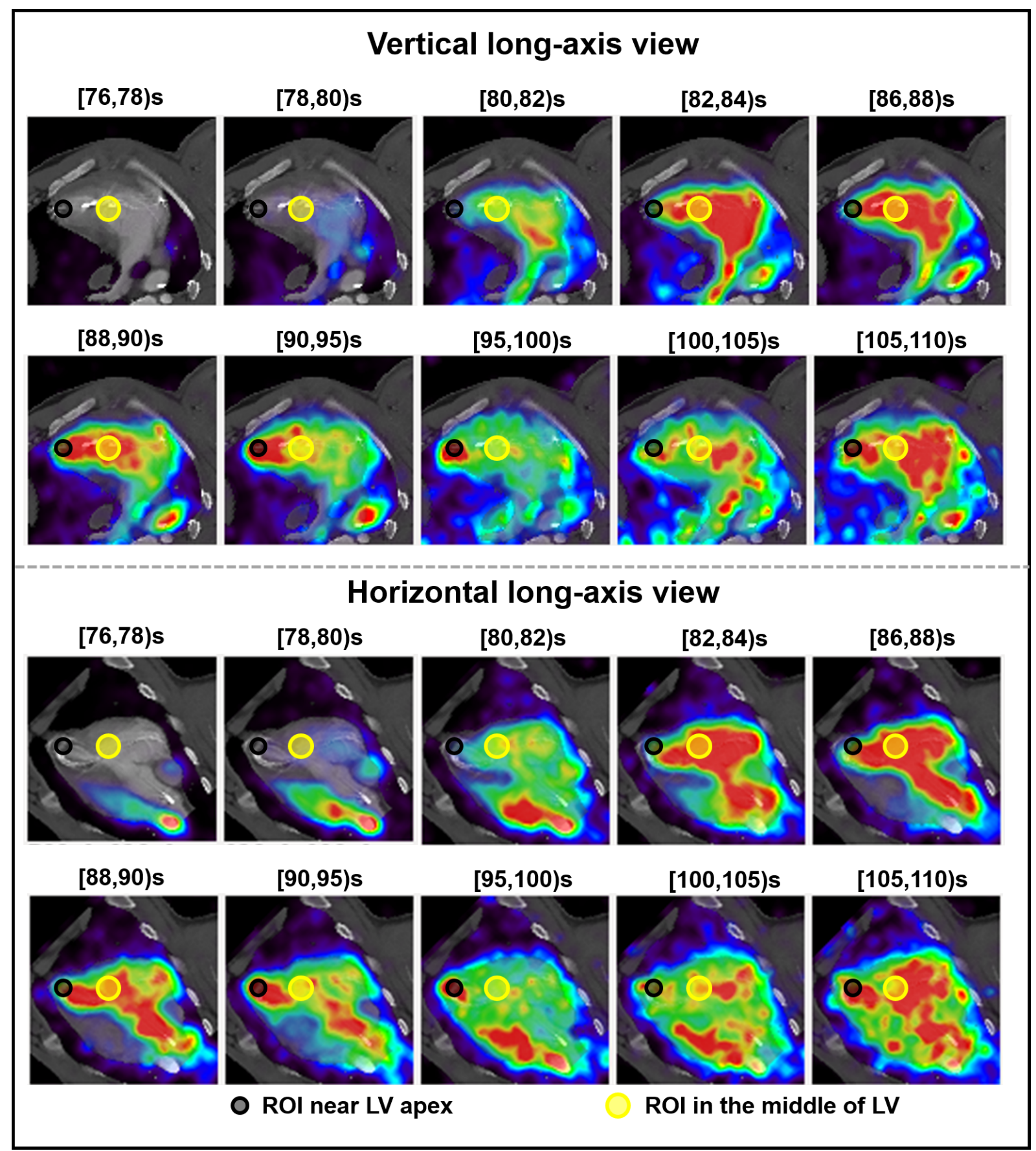

Figure 3.3: Vertical long-axis (two-chamber) and horizontal long-axis (four-chamber) views of the first frames of an illustrative dynamic PET in which the tracer, ${ }^{68} \mathrm{Ga}$-DOTA has been injected into a pig. The two circles denote two spherical volumes of interest (VOIs) in which PET intensity was quantified. These VOIs correspond to the middle of the $L V$ (yellow) and an apical region of the LV (black). The PET images are fused with their corresponding view of the contrast CT scan.

ues of $K_{1}$ and $E C V$. Furthermore, average values were obtained for the three major coronary artery territories: left anterior descending (LAD), left circumflex (LCX), and right coronary artery (RCA). Average values were also computed for the whole myocardium. In order to obtain $M B F_{\mathrm{PET}}$ values, $K_{1}$ should be corrected according to the extraction fraction of ${ }^{68} \mathrm{Ga}$-DOTA. For that purpose $M B F_{\mathrm{MS}}$ and $K_{1}$ values obtained in healthy pigs averaged on the whole myocardium 


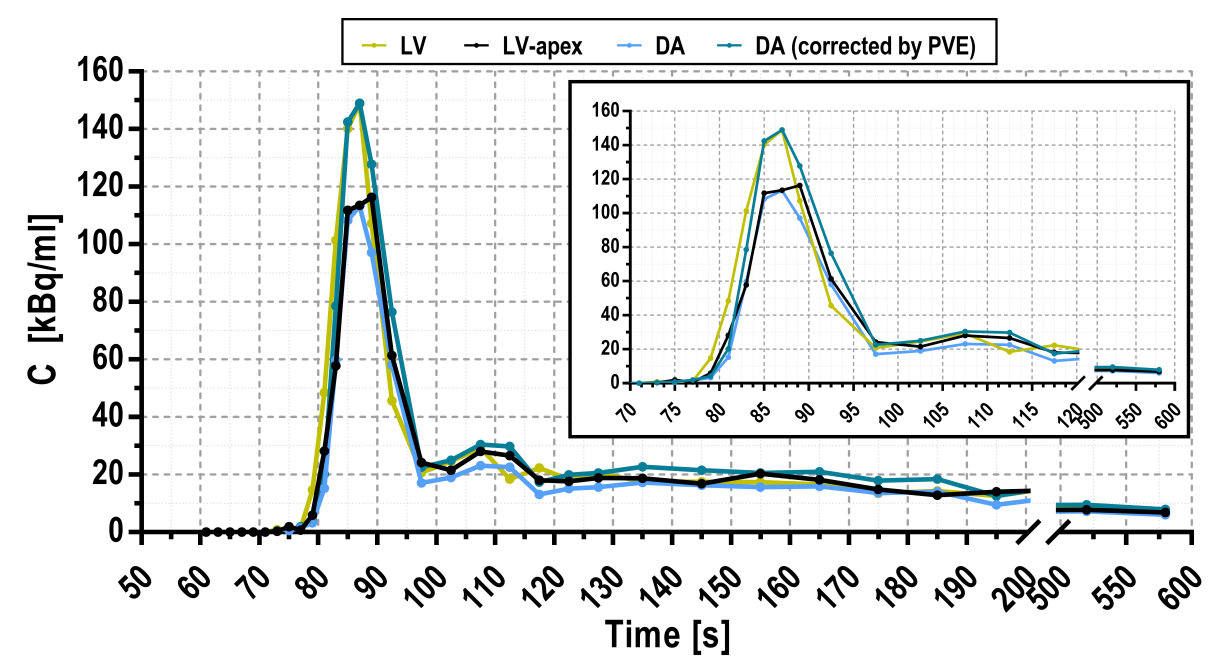

Figure 3.4: Activity concentration measured inside VOIs drawn in Fig. 3.3 presented as a function of time. It can be noticed that these two curves follow different patterns. At early timeframes, activity concentration is higher inside the central region of the LV. However, activity concentration decreases at the same time inside both areas.

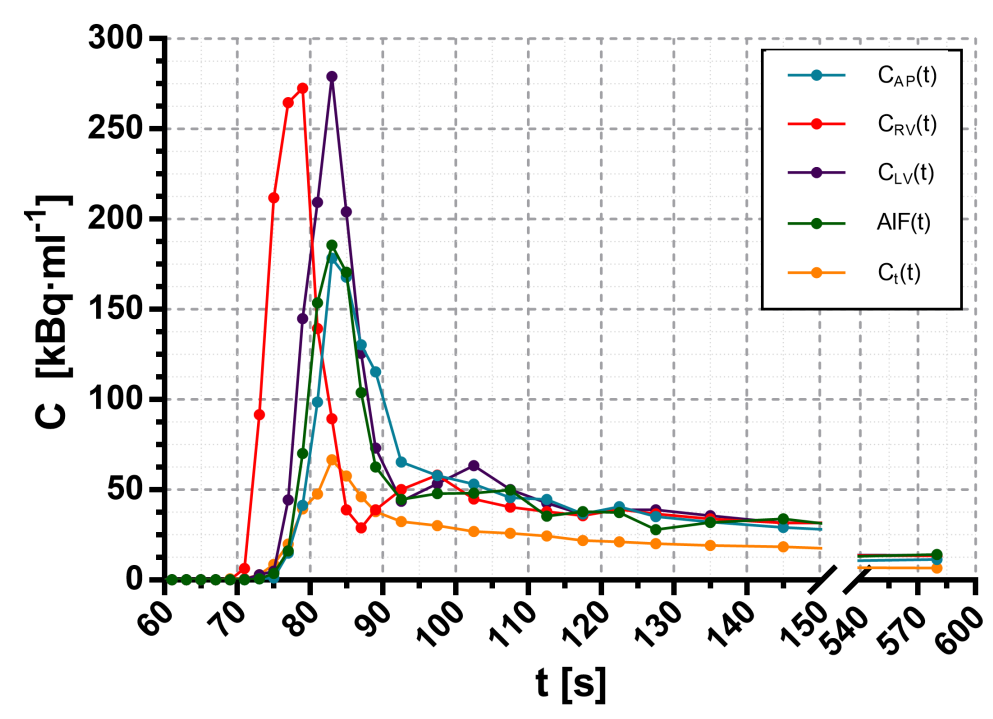

Figure 3.5: Time activity curves (TACs) obtained for an exemplary ${ }^{68}$ Ga-DOTA PET/CT study, including tissue $\left(C_{t}(t)\right)$, left ventricle $\left(C_{\mathrm{LV}}(t)\right)$, apical left ventricle $\left(C_{\mathrm{AP}}(t)\right)$, right ventricle $\left(C_{\mathrm{RV}}(t)\right)$ and $P V C$-corrected arterial input function $(\mathrm{AIF}(t))$ obtained from the descending thoracic aorta.

were fitted to the generalized Renkin-Crone model [39, 176]:

$$
K_{1}=\mathrm{MBF} \cdot\left(1-a \cdot \mathrm{e}^{-\frac{b}{\mathrm{MBF}}}\right),
$$

where $a$ accounts for the dependence of $\mathrm{MBF}$ with the permeability-surface product $(P S)$, and $b$ reflects the basal value of $P S$. 


\subsubsection{Microspheres analysis}

MS recovery and analysis were based on existing protocols [194]. Briefly, the day after imaging session, the animal was euthanized by an intravenous overdose of pentobarbital. The heart was excised and kept at $-20^{\circ} \mathrm{C}$ for 3 hours. Left ventricular myocardial wall was then isolated and sliced following AHA guidelines (see Fig. 3.6). A total of 17 pieces per heart were obtained,
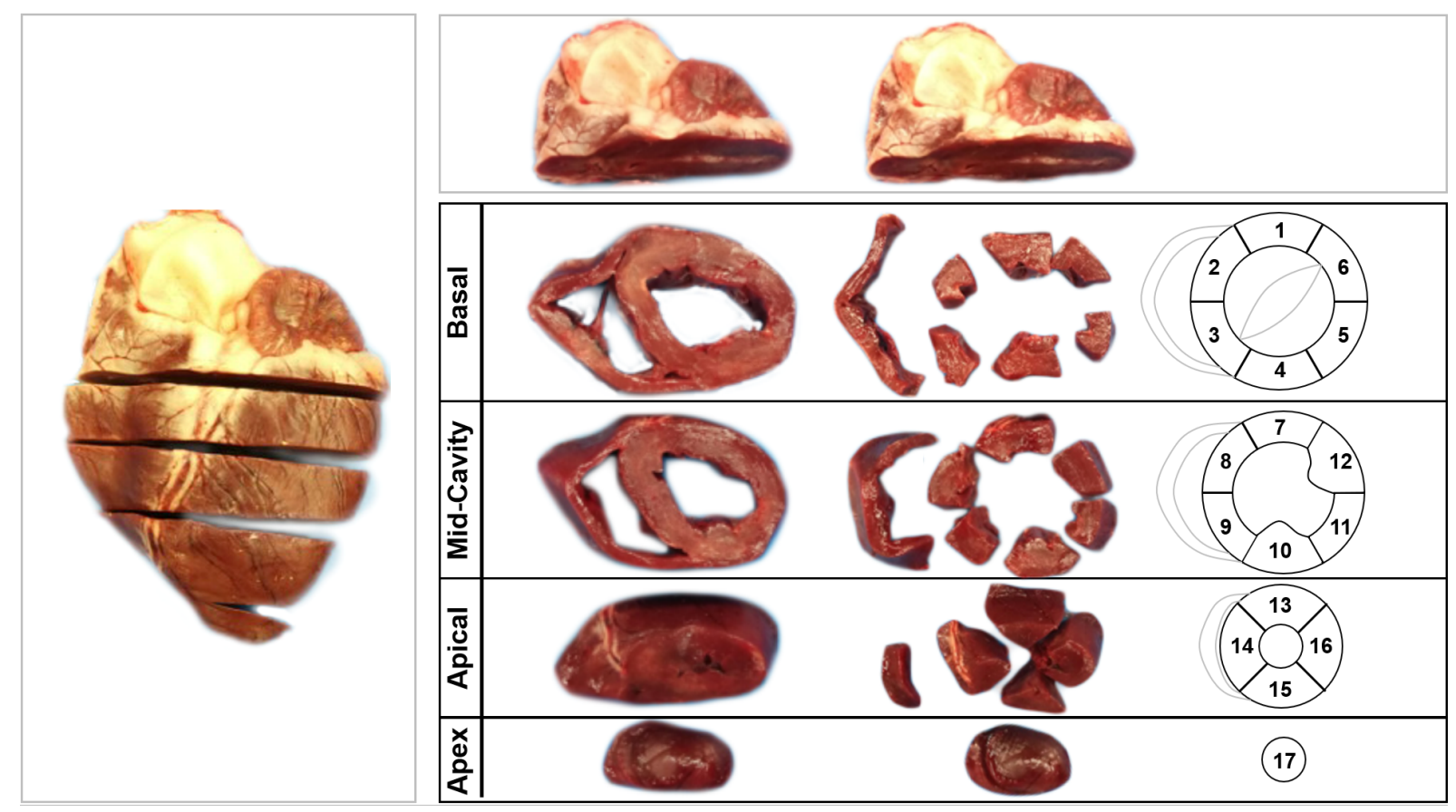

Figure 3.6: Photographs taken during the heart processing done to obtain the 17 segments of the left ventricular myocardium. The division into these segments was intended to be as accurate as possible, following the guidelines provided by [34], and are shown as a schematic drawing in this figure.

weighted with a digital precision scale and individually digested into a $\mathrm{KOH} 4 \mathrm{~N}$ solution $(5 \mathrm{ml}$ $\mathrm{KOH}$ per gram of tissue). At the same time, each reference blood sample withdrawn during the experiment was taken to $40 \mathrm{ml}$ with $2 \%$ Tween 80, followed by addition of $14 \mathrm{ml}$ of $\mathrm{KOH} 16 \mathrm{~N}$. All samples were incubated at $37^{\circ} \mathrm{C}$ with vigorous shaking for $48-72 \mathrm{~h}$. After complete tissue digestion, samples were individually filtered with negative pressure filtration. A different filter (Nylon Net Filter $10 \mu \mathrm{m}$, Millipore, Burlington, MA, USA) was used for each sample. Each digested sample was poured onto the filter, and the containing tube was rinsed with $\sim 20 \mathrm{ml}$ of $2 \%$ Tween 80 to ensure the collection of all the MS. Next, the filter was rinsed with $\sim 10$ $\mathrm{ml}$ of buffer rinse solution $\left(\mathrm{KH}_{2} \mathrm{PO}_{4} / \mathrm{K}_{2} \mathrm{HPO}_{4}\right.$ at $\left.\mathrm{pH}=7.2\right)$ to neutralize the $\mathrm{pH}$ of the nylon filter. Each filter was immersed in $5 \mathrm{ml}$ of 2-ethoxyethyl acetate $98 \%$ (Sigma-Aldrich, Sant Louis, MO, USA) and stored in the dark for $2-3 \mathrm{~h}$, until the complete dissolution of the MS polystyrene cover. The fluorescence of the resultant solution was measured with a Fluorescence Spectrometer (PerkinElmer LS-55) at the emission/excitation wavelengths of 450/480 nm, 515/534 nm and $365 / 415 \mathrm{~nm}$ for the green, yellow and blue MS respectively. Both emission and excitation slits were set at $10 \mathrm{~nm}$. Finally, the fluorescence intensities of each sample were used to compute the MBF $\left(M B F_{\mathrm{MS}}\right)$ following the standard MS reference technique [58]. 


\subsubsection{Statistical analysis}

For the validation of $M B F_{\mathrm{PET}}$, ordinary least-squares regression analysis was used to assess correlation between $M B F_{\mathrm{PET}}$ and $M B F_{\mathrm{MS}}$. This correlation was performed on the three main coronary artery territories by averaging the segmental values obtained according to AHA guidelines. Null hypotheses of slope $=1.0$ and $y$-intercept $=0.0$ were assessed. To test agreement between our proposed method against the gold standard, Bland-Altman plots [26] and intraclass correlation coefficients $(I C C(\mathrm{~A}, 1))$ for a two-way mixed effect model [138] were calculated. Limits of agreement for both markers were set at $95 \%$ confidence level (mean $\pm 1.96 \mathrm{SD}$ ).

\subsection{Results}

\subsubsection{Validation of $M B F_{\mathrm{PET}}$ versus gold standard $M B F_{\mathrm{MS}}$}

Average hemodynamic parameters measured during MS validation studies under each rest/stress condition are shown in Table 3.1. During resting condition, HR was stable and within a normal range, as well as systolic and diastolic blood pressure. Adenosine infusion caused tachycardia and dysrhythmia for few minutes, after which HR stabilized to same rate as before infusion. Adenosine also lowered blood pressure significantly during the same period. The selective A2A receptor agonist CGS-21680 induced tachycardia but in contrast to adenosine, this was maintained (peak HR increment of $70 \%$ at peak HR an $65 \% 10$ min after CGS-21680 infusion). Illustrative records of the HR of two animals that underwent pharmacological stress are shown in Fig. 3.7.
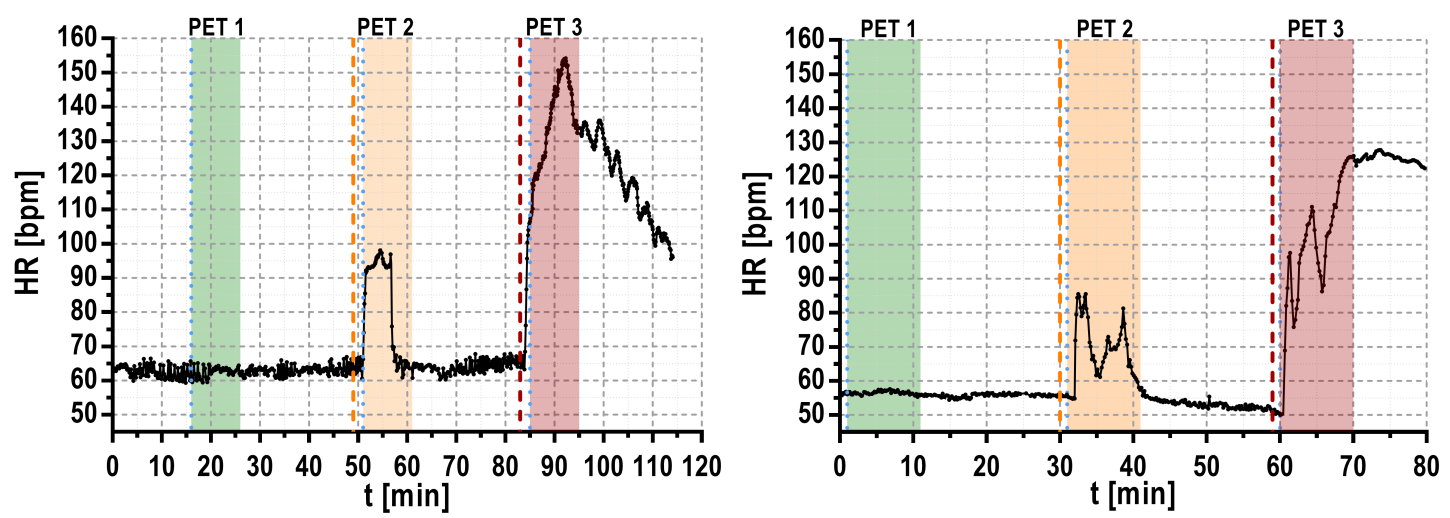

Figure 3.7: HR recorded during the whole imaging session of two different animals. The time at which either adenosine (orange) of CGS (red) was delivered into the animals are marked by a colored dashed vertical line. Green, orange and red boxes denote represent the time windows of the 10-min PET scans performed at rest and under ADO- and CGS-induced stess.

A total of 24 PET scans were performed ( $n=8$ pigs, 3 studies each). Two studies were discarded due to an incomplete extraction of arterial blood reference sample required for $M B F_{\mathrm{MS}}$ quantification. From the 22 remaining studies, regional $M B F_{\mathrm{MS}}$ and $K_{1}$ measurements were obtained following AHA recommendations (the 17th segment, corresponding to the apical region, was discarded in all analyses since $K_{1}$ for this region was overestimated, maybe caused by spillover from the liver [82]). Resultant values were averaged into the three main coronary artery 
Table 3.1: Systemic hemodynamic parameters at baseline and different moments during hyperemia.

\begin{tabular}{lccc}
\hline & HR $\mathbf{( b p m )}$ & Systolic BP $\mathbf{( m m H g )}$ & Diastolic BP $(\mathbf{m m H g})$ \\
\hline Baseline & $79 \pm 21$ & $122 \pm 15$ & $82 \pm 7$ \\
3 min after ADO infusion & $111 \pm 31(43.7)$ & $80 \pm 16$ & $49 \pm 12$ \\
10 min after ADO infusion & $79 \pm 19(1.0)$ & $118 \pm 17$ & $77 \pm 9$ \\
3 min after CGS-21680 & $130 \pm 22(71.4)$ & $75 \pm 15$ & $47 \pm 12$ \\
10 min after CGS-21680 & $120 \pm 17(65.6)$ & $-^{\mathrm{a}}$ & - $^{\mathrm{a}}$ \\
\hline
\end{tabular}

Values shown as Mean \pm SD. Values in parentheses show HR increment (in \%) vs HR right before stress induction.

a No BP measurements were taken for 10 min after CGS-21680 injection.

territories, resulting in a total of 66 paired $M B F_{\mathrm{MS}}$ and $K_{1}$ values. Subsequently, paired measurements were grouped to obtain an average value of the whole myocardium at each physiological condition.

The fit of $M B F_{\mathrm{MS}}$ and $K_{1}$ values averaged on the whole myocardium to the generalized Renkin-Crone model $\left(a=0.82 \pm 0.08, b=2.14 \pm 0.28 \mathrm{ml} \cdot \mathrm{min}^{-1} \cdot \mathrm{g}^{-1}\right.$, Fig. 3.8), resulted into a first-pass tissue extraction fraction for ${ }^{68} \mathrm{Ga}$-DOTA of $\sim 70 \%$ when MBF takes values between 1.8 and $2.4 \mathrm{ml} \cdot \mathrm{min}^{-1} \cdot \mathrm{g}^{-1}$.

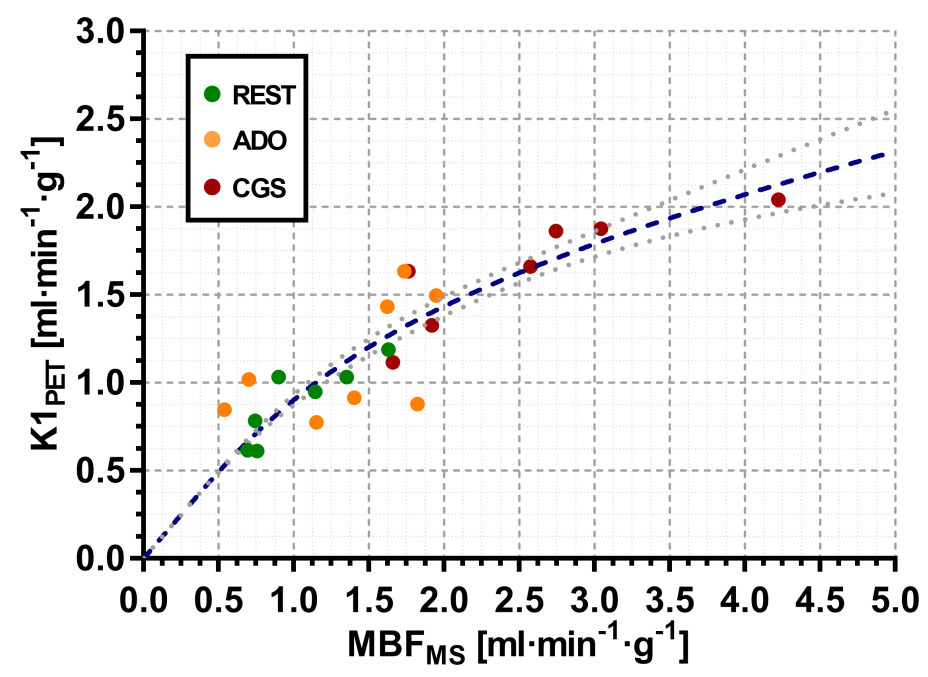

Figure 3.8: Scatter plot of $K_{1}$ obtained by ${ }^{68}$ Ga-DOTA-PET against MBF obtained by fluorescent MS. Each point represents the whole LV myocardium value obtained at different physiological conditions including rest (green), ADO-induced stress (orange) and CGS-induced stress (red). The fit to the Renkin-Crone $\left(K_{1}=\mathrm{MBF} \cdot[1-a \cdot \exp (-b / \mathrm{MBF})]\right)$ model is shown (dashed blue line) including the $95 \%$ confidence interval of the regression line (dotted gray lines).

$M B F_{\mathrm{PET}}$ values (mean $\pm \mathrm{SD}$ ) obtained with ${ }^{68} \mathrm{Ga}$-DOTA were $1.06 \pm 0.33 \mathrm{ml} \cdot \mathrm{min}^{-1} \cdot \mathrm{g}^{-1}$ at rest, $1.45 \pm 0.67 \mathrm{ml} \cdot \mathrm{min}^{-1} \cdot \mathrm{g}^{-1}$ under adenosine-induced stress, and $2.55 \pm 0.89 \mathrm{ml} \cdot \mathrm{min}^{-1} \cdot \mathrm{g}^{-1}$ under CGS-induced stress. Fig. 3.9A shows a good linear correlation $(r=0.77)$ between $M B F_{\text {PET }}$ and $M B F_{\mathrm{MS}}($ slope $=0.91 \pm 0.08$, significantly non-different from $1.0(p=0.25), y$-intercept $=0.21$ $\pm 0.15 \mathrm{ml} \cdot \mathrm{min}^{-1} \cdot \mathrm{g}^{-1}$, significantly non-different from $\left.0.0(p=0.16)\right)$ at the three main coronary artery territories. Fig. $3.9 \mathrm{C}$ shows a strong correlation $(r=0.91)$ when $M B F_{\mathrm{PET}}$ and $M B F_{\mathrm{MS}}$ are averaged over the whole myocardium: $($ slope $=0.96 \pm 0.10$, significantly non-different from 
$1.0(p=0.30), y$-intercept $=0.11 \pm 0.19 \mathrm{ml} \cdot \mathrm{min}^{-1} \cdot \mathrm{g}^{-1}$, significantly non-different from $0.0(p=$ $0.07))$.
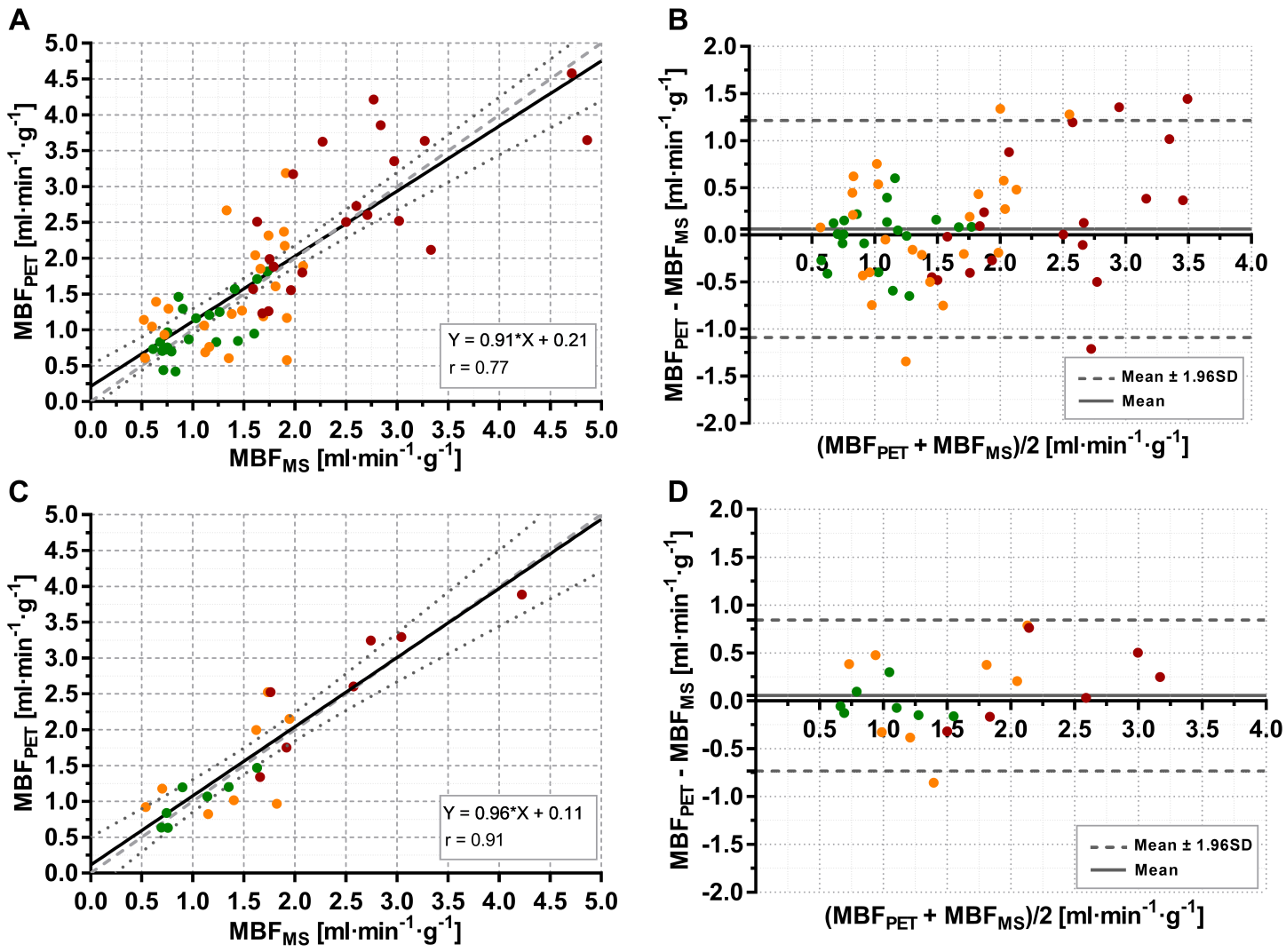

\section{$\odot$ REST $\odot$ ADO CGS}

Figure 3.9: Scatter plots $(\boldsymbol{A}, \boldsymbol{C})$ and Bland-Altman plots $(\boldsymbol{B}, \boldsymbol{D})$ showing correlation between MBF estimated by ${ }^{68} \mathrm{Ga}$-DOTA-PET and by fluorescent MS. Each point represents MBF in one of the three major coronary artery territories $(\boldsymbol{A}$ and $\boldsymbol{B})$, and in the whole $L V$ myocardium $(\boldsymbol{C}$ and $\boldsymbol{D})$. Scatter plots also contain the identity line (dashed gray line) and the linear fit (solid line) including 95\% CL (dotted lines). Datasets corresponding to different physiological conditions are represented in different colors including rest (green), ADO-induced stress (orange) and CGS-induced stress (red). Bland-Altman plots include the mean difference (solid gray line) and the mean $\pm 1.96 S D$ (dashed gray lines).

\subsection{Discussion}

In this chapter, we proposed ${ }^{68} \mathrm{Ga-DOTA}$ as an alternative radiotracer for in vivo imaging and non-invasive assessment of MBF based on PET.

The in vivo validation of MBF values by ${ }^{68} \mathrm{Ga}-\mathrm{DOTA}-\mathrm{PET}$ was performed on sequential scans at rest and during different pharmacologically-induced stress conditions with a $30 \mathrm{~min}$ delay between consecutive scans. The reader might question whether this delay is sufficiently high to ignore the residual activity that may exist inside the animal after the first radiotracer injection. The employed solution to kinetic equations assumes zero activity concentration in tissue at initial time, which is not the case for second and third scans performed on the same animal. However, the radiotracer was injected 1 min after PET scan started and only data 
after tracer injection was included to minimize the residual difference between the model and the measured data. In this way, the time required by the model to equilibrate the tissue to its initial value was excluded from the minimization process. The equations could be solved in more general terms, but for simplicity we decided to use the standard solution since the employed methodology provides the same results.

Our results demonstrate the feasibility of the proposed technique to reliably evaluate MBF under different physiological conditions. Importantly, validation studies (Fig. 3.9) of the MBF values obtained with ${ }^{68} \mathrm{Ga}$-DOTA-PET against the gold-standard - MS - showed a reasonably good agreement when comparing an averaged MBF values over the three main coronary artery territories (mean difference $=0.06 \pm 0.59 \mathrm{ml} \cdot \mathrm{min}^{-1} \cdot \mathrm{g}^{-1}$, Fig. 3.9B) and over the whole myocardium (mean difference $=0.06 \pm 0.40 \mathrm{ml} \cdot \mathrm{min}^{-1} \cdot \mathrm{g}^{-1}$, Fig. 3.9D) .

The extraction fraction for ${ }^{68} \mathrm{Ga}$-DOTA was estimated by fitting $K_{1}$ and $M B F_{\mathrm{MS}}$ values to the Renkin-Crone model (Fig. 3.8). From this fit, a first-pass tissue extraction fraction of $70 \%$ was estimated for ${ }^{68} \mathrm{Ga}$-DOTA for MBF values between 1.8 and $2.4 \mathrm{ml} \cdot \mathrm{min}^{-1} \cdot \mathrm{g}^{-1}$, which is in line with those reported for other perfusion tracers like ${ }^{13} \mathrm{NH}_{3}$ and ${ }^{82} \mathrm{Rb}$ (80\% and $65 \%$ respectively [129]). However, the extraction fraction that we obtained for ${ }^{68}$ Ga-DOTA cannot be directly compared with values reported for other tracers as obtained $K_{1}$ is related to plasma flow instead of blood flow as mentioned in the methods section and because partial volume correction was not applied in the myocardial tissue. Therefore, the estimated tracer extraction function is based on biased estimates of $K_{1}$, and not likely applicable to other imaging conditions.

High accuracy of PET imaging has shown to be superior among all other MBF imaging techniques, achieving the highest diagnostic performance [101, 186]. However, limited availability of PET tracers for MBF, either due to the need for a nearby cyclotron $\left({ }^{13} \mathrm{NH}_{3}, \mathrm{H}_{2}{ }^{15} \mathrm{O}\right)$ or because of the high cost of the ${ }^{82} \mathrm{Rb}$ generators, precluded its further extension in the clinical field. Alternatively, generators accessibility has made ${ }^{68} \mathrm{Ga}$ widely available and ${ }^{68} \mathrm{Ga}$-based tracers are increasingly used in nuclear medicine, e.g., to study neuroendocrine tumors and other somatostatin receptor-associated lesions. Thus, the use of ${ }^{68} \mathrm{Ga}$-DOTA for MBF determination could be an accessible alternative for accurate detection of CAD. However, further studies are needed to identify the clinical potential of this tracer.

\subsubsection{Study Limitations}

The studies described in this work have been performed on a porcine model as it provides a similar and comparable model of the human anatomy and pathophysiology. Results obtained may not be directly extrapolated to clinical setting. Thus, clinical studies are needed to support and underpin the results presented in this study.

Similar to $\mathrm{H}_{2}{ }^{15} \mathrm{O},{ }^{68} \mathrm{Ga}$-DOTA does not provide high myocardial-to-blood ratio and it might yield a suboptimal image quality and lower MBF defect contrast. However, validation results performed at each coronary territory show reasonably good agreement with reference MS values (see Fig. 3.9) supporting the potential clinical use of ${ }^{68} \mathrm{Ga}$-DOTA-PET for non-invasive quantitative determination of regional MBF. 


\subsection{Conclusion}

The proposed ${ }^{68} \mathrm{Ga}$-DOTA-PET imaging technique has shown potential for non-invasive assessment of MBF. The absolute MBF values obtained at rest and during different pharmacologicallyinduced stress conditions covering a broad range of MBF values in healthy pigs were validated using the gold standard (MS). This tracer could provide wide clinical use of high accuracy PET imaging for MBF measurements regardless of the availability of expensive in-house cyclotrons or ${ }^{82} \mathrm{Rb}$ generators. Our results show potential for the clinical implementation of this technique and suggest the necessity to perform clinical studies that explore its possible application in the clinical field. 


\subsection{Introduction}

In the previous chapter, we proposed and validated ${ }^{68} \mathrm{Ga-DOTA}$ as a new MPI tracer for in vivo PET assessment of MBF. As we previously stated, MPI gives insight of how well the heart muscle is perfused. However, perfusion assessment is only a part of the information needed in risk stratification of patients with known or suspected CAD. The missing piece of information is the myocardial viability. It has been demonstrated that there is an association between myocardial viability and improved survival after revascularization in patients with chronic CAD and LV dysfunction [3, 47, 78], and only patients with dysfunctional but viable myocardium may potentially benefit from revascularization [135]. Therefore, the quantification and assessment of myocardial viability becomes of utmost importance to optimize selection of patients with heart failure.

PET is one of the most sensitive techniques to assess cardiac viability. Particularly, FDGPET has been shown to be highly specific in distinguishing viable from non-viable or scarred myocardium [139] by characterizing dysfunctional cardiomyocytes. The myocardial cells tend to obtain energy from free fatty acids in a normal heart during fasting. However, in periods of ischemia or after a meal, the main source of energy switches to glucose (glycolysis). Hence, FDG-PET is able to distinguish between scarred (low glucose uptake) and viable (normal glucose uptake) myocardium [2].

Apart from glucose metabolism, myocardial viability can be determined by quantification of the extracellular volume fraction (ECV) using late gadolinium-enhancement (LGE)-MRI [212], 
which identifies increased extracellular space in areas of infarction and scar. Recently, it has been shown the capability of ${ }^{64} \mathrm{Cu}$-DOTA for the assessment of myocardial viability using PET imaging [109] in analogy to LGE-MRI. In addition, other PET tracers typically used only for MBF assessment have been proposed to evaluate myocardial viability [147].

In the previous chapter we introduced the pharmacokinetic model that rules biodistribution of ${ }^{68} \mathrm{Ga}$-DOTA in the myocardial tissue. From that model, MBF values could be easily obtained from fits to dynamic PET data. Importantly, ECV values could also be computed from the same fit. This fact would make ${ }^{68}$ Ga-DOTA a bimodal MBF (perfusion) + ECV (viability) radiotracer with a high translational possibility.

\subsection{Aim of the chapter}

In this chapter, we propose the use of ${ }^{68} \mathrm{Ga}-\mathrm{DOTA}$ for in vivo PET imaging of ECV and MBF simultaneously. In order to evaluate its feasibility, a myocardial infarction (MI) pig model was employed. ECV and MBF derived within the infarcted areas of the hearts were compared with those obtained from the remote ones, and the ability of ${ }^{68} \mathrm{Ga}$-DOTA to assess myocardial viability was studied.

\subsection{Methods}

\subsubsection{Study design and animal preparation}

This study was conducted according to the guidelines of the current European Directive and Spanish legislation and approved by the regional ethical committee for animal experimentation. The study population consisted of a group of five young Large White pigs (3 females and 2 males, mean weight $=47.9 \pm 1.2 \mathrm{~kg}$ ).

MI was induced by closed-chest ischemia/reperfusion. To do so, an angioplasty balloon was placed into the left anterior descending (LAD) coronary artery, immediately distal to the origin of the first diagonal branch, and occluded it for 40 minutes. Afterwards, the balloon was deflated, and blood flow was re-established. A more detailed explanation of the MI protocol can be found elsewhere $[59,67]$.

Anesthesia was induced by intramuscular injection of ketamine $(20 \mathrm{mg} / \mathrm{kg})$, xylazine $(2$ $\mathrm{mg} / \mathrm{kg})$, and midazolam $(0.5 \mathrm{mg} / \mathrm{kg})$, and maintained by continuous intravenous infusion of ketamine $\left(2 \mathrm{mg} \cdot \mathrm{kg}^{-1} \cdot \mathrm{h}^{-1}\right)$, xylazine $\left(0.2 \mathrm{mg} \cdot \mathrm{kg}^{-1} \cdot \mathrm{h}^{-1}\right)$ and midazolam $\left(0.2 \mathrm{mg} \cdot \mathrm{kg}^{-1} \cdot \mathrm{h}^{-1}\right)$. Animals were intubated and mechanically ventilated with oxygen (fraction of inspired $\mathrm{O}_{2}: 28 \%$ ). The infarctions were confirmed and evaluated 7 days post-infarction by CMR immediately before the ${ }^{68} \mathrm{Ga}$-DOTA-PET/CT studies. PET scans were performed at rest condition. A schematic drawing of the experimental protocol is shown in Fig. 4.1. 


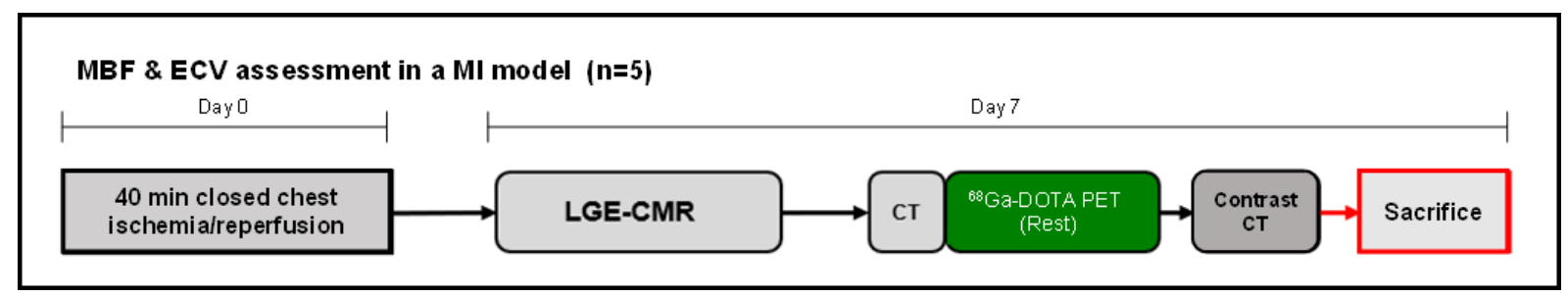

Figure 4.1: Workflow of the study approach.

\subsubsection{CMR protocol and analysis}

CMR scans were performed in the infarcted pigs prior to the PET/CT studies with a 3-T Achieva Tx whole body scanner (Philips Healthcare, Best, The Netherlands) equipped with a 32-element phased-array cardiac coil. The imaging protocol included a standard segmented cine steady-state free-precession (SSFP) sequence to provide high quality anatomical references, and assessment of LV mass, wall thickness and left ventricular ejection fraction (LVEF). The imaging parameters for the SSFP sequence were field of view (FOV), $280 \times 280 \mathrm{~mm}^{2}$; slice thickness, $6 \mathrm{~mm}$ with no gap; repetition time (TR), $2.8 \mathrm{~ms}$; echo time (TE), $1.4 \mathrm{~ms}$; flip angle, $45^{\circ}$; cardiac phases, 30; voxel size, $1.8 \times 1.8 \mathrm{~mm}^{2}$; and number of excitations (NEX), 3 .

To assess infarct size, pigs received intravenous gadopentetate dimeglumine contrast agent (0.40 mmol per $\mathrm{kg}$ body weight), and contrast-enhanced imaging (late gadolinium enhancement (LGE)) was performed after 10 to 15 min using an inversion-recovery spoiled turbo field echo (IR-T1TFE) sequence with the following parameters: FOV, $280 \times 280 \mathrm{~mm}^{2}$; voxel size, $1.6 \times 1.6$ $\mathrm{mm}^{2}$; end-diastolic acquisition; thickness, $6 \mathrm{~mm}$ with no gap; TR, $5.6 \mathrm{~ms}$; TE, $2.8 \mathrm{~ms}$; inversion delay time optimized to null normal myocardium and 2 NEX. CMR images were analyzed using dedicated software (QMassMR 7.6, Medis, Leiden, The Netherlands) by an experienced observer in CMR analysis [60]. Wall thickening measurements were performed using a clinical standard method in the Balance-TFE $1.8 \mathrm{~mm}$ sequence, which consisted on tracing endo and epicardial contours both in systolic and diastolic phases in all the segmented LV.

CMR-derived infarct size was derived using endo and epicardial contours delineated in the LGE sequence. Then, two regions of interest (ROIs) were placed in both the remote and the hyperintense (infarcted) areas (see Fig. 4.2). Finally, infarct size was determined as the fractional area occupied by the hyperintense ROI with respect to the total.

\subsubsection{PET image acquisition}

PET/CT images were acquired using a Gemini TF-64 scanner (Philips Healthcare, Best, The Netherlands). Each imaging study consisted of a low dose CT scan (120 kV, $80 \mathrm{~mA})$ followed by a dynamic 11-min list mode PET acquisition in a single bed position. ${ }^{68}$ Ga-DOTA (139 \pm $37 \mathrm{MBq}$ ) was prepared in $6 \mathrm{ml}$ with normal saline and infused at a rate of $1.0 \mathrm{ml} / \mathrm{s}$ through a marginal ear vein, followed by a $6 \mathrm{ml}$ saline flush at the same rate. PET scans started $1 \mathrm{~min}$ prior to the radiotracer injection. At the end of each imaging session, a contrast CT $(1.2 \mathrm{ml} / \mathrm{kg}$, Iomeron 400, Bracco, Milan, Italy) was performed to obtain better anatomical delineation. PET images were reconstructed with a voxel size of $4 \times 4 \times 4 \mathrm{~mm}^{3}$ using a 3D-RAMLA reconstruction 


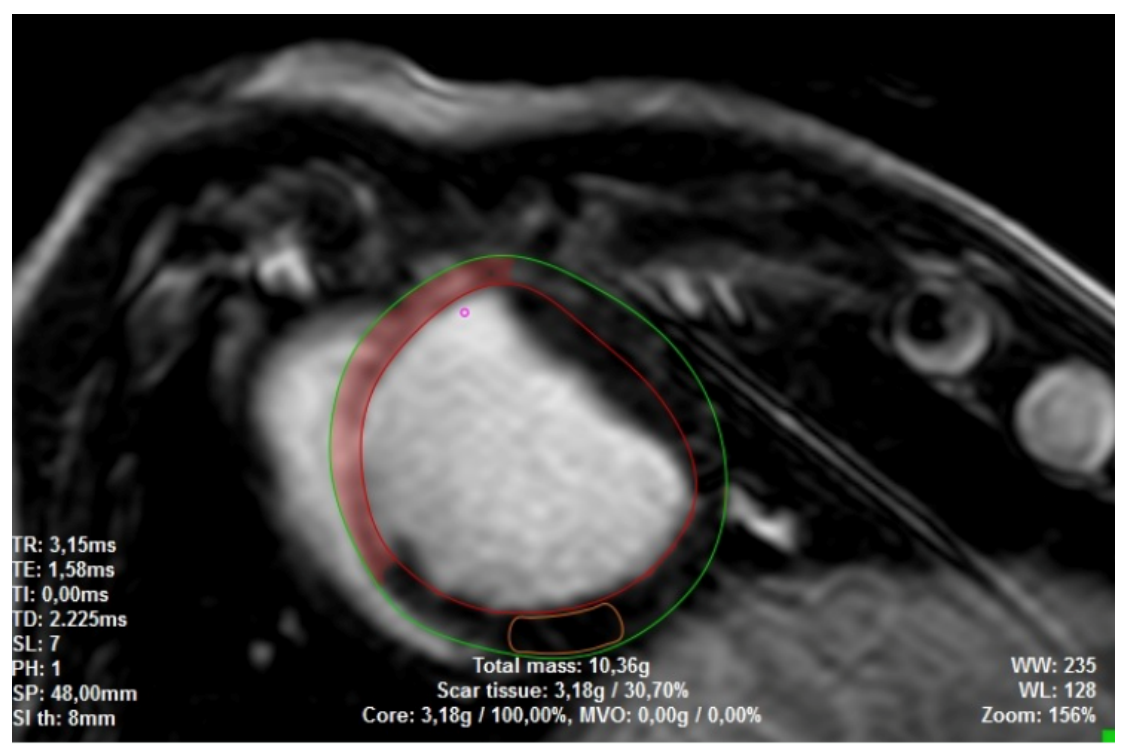

Figure 4.2: Heart short-axis view of one of the animals in our MI model obtained with the LGE-CMR protocol. The image is a screenshot of the software utilized to quantify infarct size. Endocardial (red) and epicardial (green) contours are manually delineated. The software automatically marks as enhanced myocardium the signals with > $6 S D$ above mean of remote ROI intensity (measured inside orange ROI).

algorithm in 42 consecutive frames $(1 \times 60 \mathrm{~s}, 15 \times 2 \mathrm{~s}, 8 \times 5 \mathrm{~s}, 8 \times 10 \mathrm{~s}, 1 \times 20 \mathrm{~s}, 3 \times 30 \mathrm{~s}, 1 \times$ $40 \mathrm{~s}$ and $5 \times 60 \mathrm{~s}$ ). All corrections for decay, dead time, scatter and random coincidences were applied as implemented on the scanner.

\subsubsection{PET data analysis}

PET scans were analyzed following the pharmacokinetic model presented in the previous chapter (section 3.3.4, page 29), as the employed tracer and the tissue of interest are both the same. As before, AIFs were obtained from the images, from $8 \mathrm{~mm}$ diameter cylinders manually drawn inside 5 consecutive slices of the descending aorta. The rest of VOIs needed for the analysis (RV and LV from central and apical areas) were also drawn as explained in the previous chapter (page 30).

The TACs measured over the left ventricular myocardial wall were fitted voxel-wise to Eq. 3.3 (page 30), leading to parametric maps of $E C V$ and $K_{1}$. These maps were converted into the standard 17-segment model polar maps using dedicated software [158]. Regional values of $E C V$ and $K_{1}$ were determined in a segmental (17 AHA segments) and territorial (LAD, LCX, RCA) basis. $K_{1}$ values were converted to $M B F_{\text {PET }}$ by using Renkin-Crone model (Eq. 3.4, page 30) with the parameters obtained in our validation studies.

PET-derived infarct size was computed using $E C V$ polar-plots obtained from ${ }^{68} \mathrm{Ga}$-DOTA PET scans as the percentage of the total myocardial LV with abnormally elevated ECV, considered to be greater than mean + two standard deviations over ECV calculated in healthy animals. This threshold (mean $+2 \mathrm{SD}$ ) was calculated from $E C V$ maps obtained from the healthy animals used in the previous study. Afterwards the $E C V$ polar-plots obtained from these infarcted animals were masked, and total infarcted area was computed with the voxels which presented $E C V$ below the preset threshold. 


\subsubsection{Statistical analysis}

Unless otherwise stated, data are expressed as median and interquartile ranges in the following manner: median(25th percentile; 75 th percentile). As for MI model, $M B F_{\text {PET }}$ and $E C V$ were compared on the three main coronary artery territories averaging the segmental values obtained according to AHA guidelines. These three regions were compared two-by-two by unpaired Mann-Whitney t-test after studying normality of populations with D'Agostino \& Pearson normality test. Independence between the three populations was assessed by Pearson correlation. $\mathrm{F}$ test was used to compare variances and Welch's correction was applied when the variances inside a population were significantly different. In all analyses, p-values $<0.05$ were considered statistically significant.

\subsection{Results}

\subsubsection{Infarct assessment by CMR and PET}

Table 4.1 shows functional values obtained by CMR for the five animals of the study. (Mean \pm SD) LV mass values assessed by LGE-CMR were $69.1 \pm 5.5 \mathrm{~g}$, with a mean infarct mass of 22.2 $\pm 6.0 \mathrm{~g}$, which represents the $(32.0 \pm 7.4) \%$ of the total LV mass. Mean LVEF obtained with cine sequence was $(40.2 \pm 6.4) \%$. PET-derived infarct size assessed as percentage of myocardial LV volume with ECV $>0.45$ ( $2 \mathrm{SD}$ above the mean ECV values obtained in healthy animals) was $(34.3 \pm 14.1) \%$, which is not significantly different from mean infarct size assessed by LGE-MRI $((32.0 \pm 7.4) \%, p<0.0001)$.

Table 4.1: Functional values obtained by CMR.

\begin{tabular}{|c|c|c|c|c|}
\hline Animal \# & $\operatorname{LVEF}(\%)^{\mathrm{a}}$ & LV mass $(\mathrm{g})$ & IS $(g)^{b}$ & IS (\%) \\
\hline 1 & 33.75 & 76.01 & 27.58 & 36.28 \\
\hline 2 & 31.62 & 73.86 & 30.17 & 40.84 \\
\hline 3 & 46.35 & 67.66 & 13.74 & 20.31 \\
\hline 4 & 47.43 & 67.47 & 18.17 & 26.92 \\
\hline 5 & 41.59 & 60.44 & 21.44 & 35.48 \\
\hline
\end{tabular}

a $L V E F$ : Left ventricular ejection fraction.

b $I S$ : Infarct size.

Wall thickening (expressed as diferrence between LV wall thickness in systole and diastole) was $(20 \pm 17) \%,(37 \pm 19) \%$ and $(41 \pm 25) \%$ for LAD, RCA and LCX respectively. Fig. 4.3 provides an example of the analysis of wall thickening. 

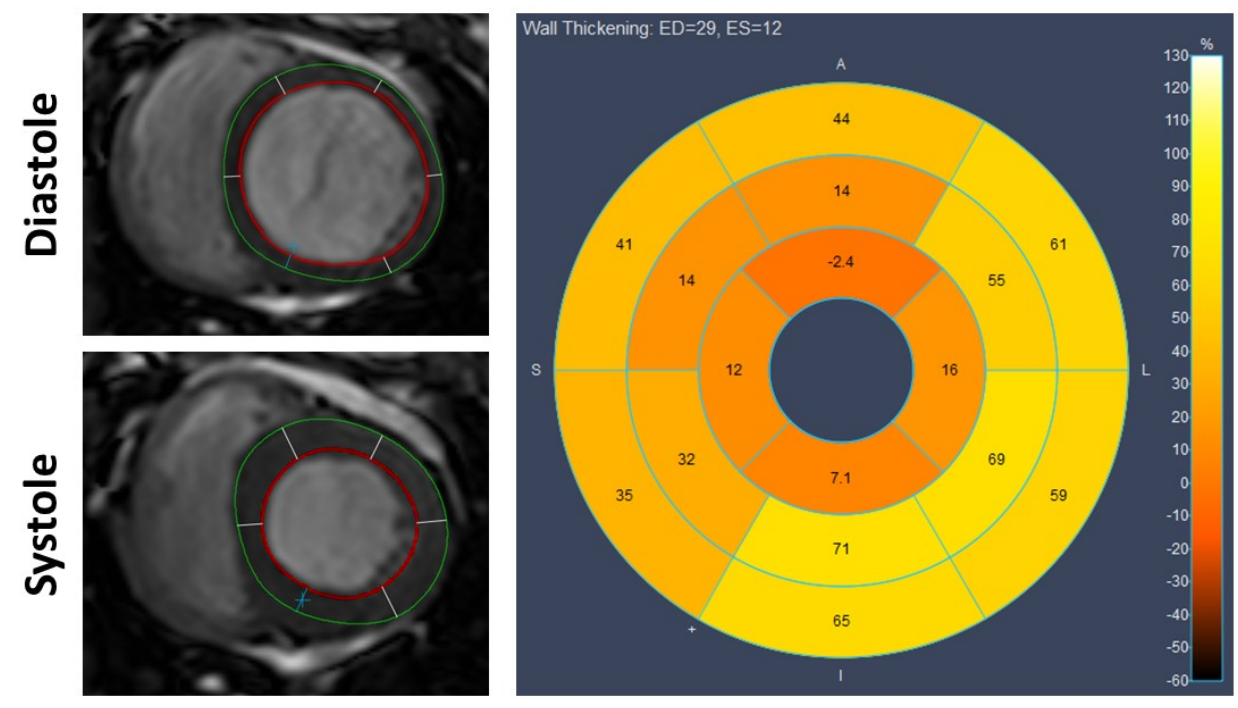

Figure 4.3: Representative example of the wall thickening analysis. Endocardial contours were delineated in red, epicardial contours in green. A bullseye graph was generated after the analysis with the percentual difference for each of the 16 segments.

\subsubsection{Regional ECV and $M B F_{\mathrm{PET}}$ in $\mathrm{MI}$}

Fig. 4.4 shows the TACs measured in infarcted (LAD) and remote (RCA) regions of one of the animals. The fits to the pharmacokinetic models corresponding to the activity concentration in myocardial tissue are also shown. These TACs, along with their fits, show clear different behavior, which is translated into different $K_{1}$ values. The major difference is observed in the shape of the curve when the tracer is entering the tissue (at the earliest time frames), with a more pronounced peak at higher $K_{1}$ values (see dashed lines in Fig. 4.4).
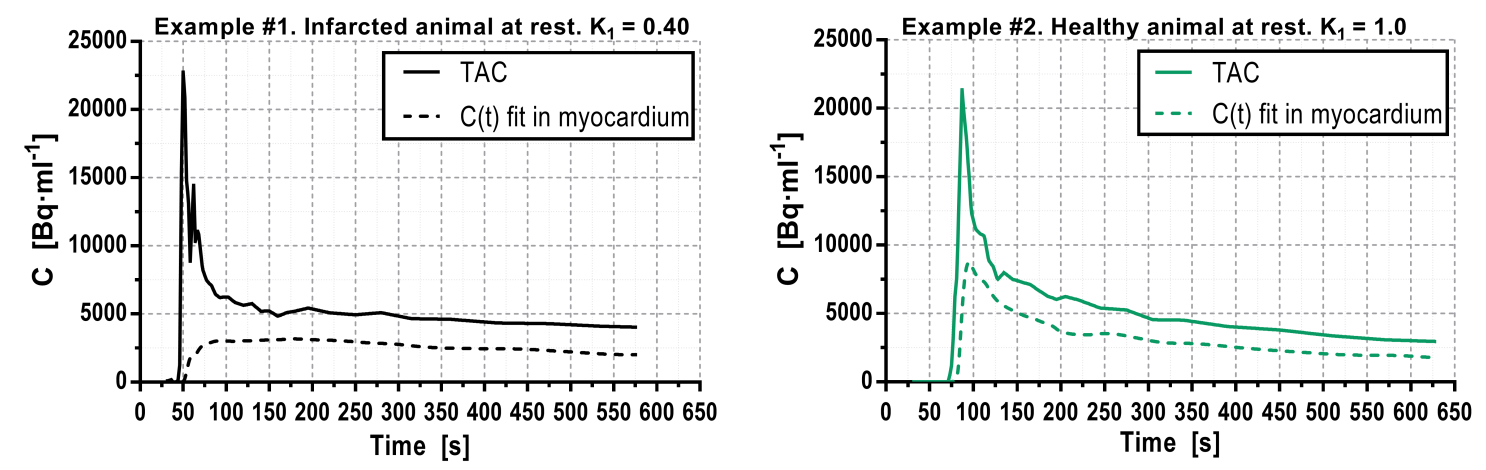

Figure 4.4: TACs (straight lines) measured inside ROIS segmented within LAD (black) and RCA (green) regions. Dashed lines represent the activity concentration fitted in the myocardial tissue ROIs.

Fig. 4.5 shows short-axis LGE-CMR and PET parametric ECV and $K_{1}$ images demonstrating the capability of this technique to distinguish regions with altered ECV and MBF in pigs after MI. Parametric maps are fused with their corresponding contrast-CT images for visualization purposes. In addition, polar plots obtained on infarcted pigs are shown in Fig. 4.6. A decrease in the $K_{1}$ is observed in the infarcted area (LAD) while $E C V$ was increased. 


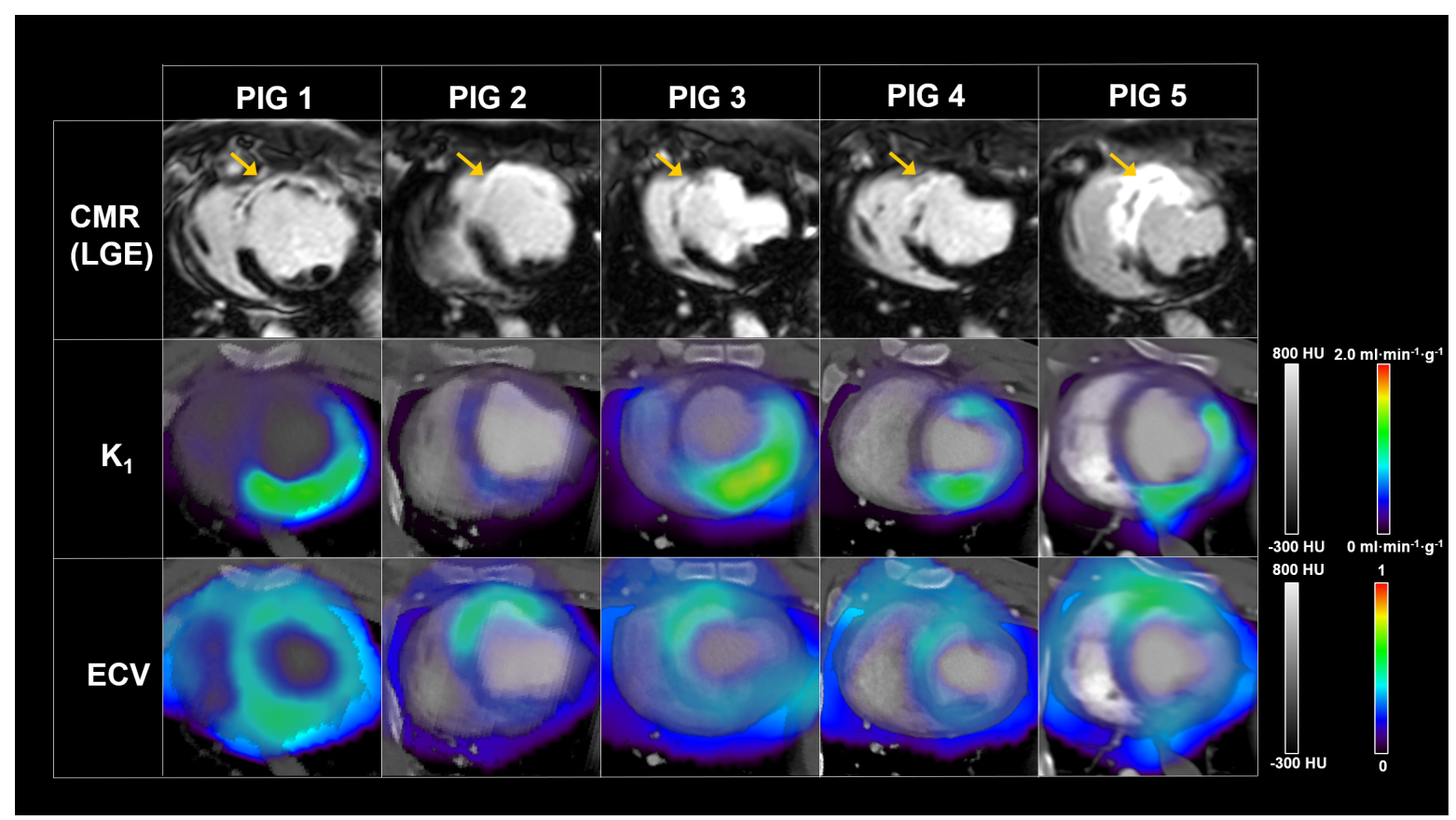

Figure 4.5: Representative short-axis LGE-CMR (top) and PET parametric $K_{1}$ (middle) and ECV (bottom) images obtained for the 5 MI model pigs. Parametric maps (smoothed with a median-3D filter, kernel size of 4) are superimposed with the corresponding contract-CT image (except for pig \#1, where contrast-CT image was not available). Yellow arrows show enhanced areas observed by LGE-CMR.

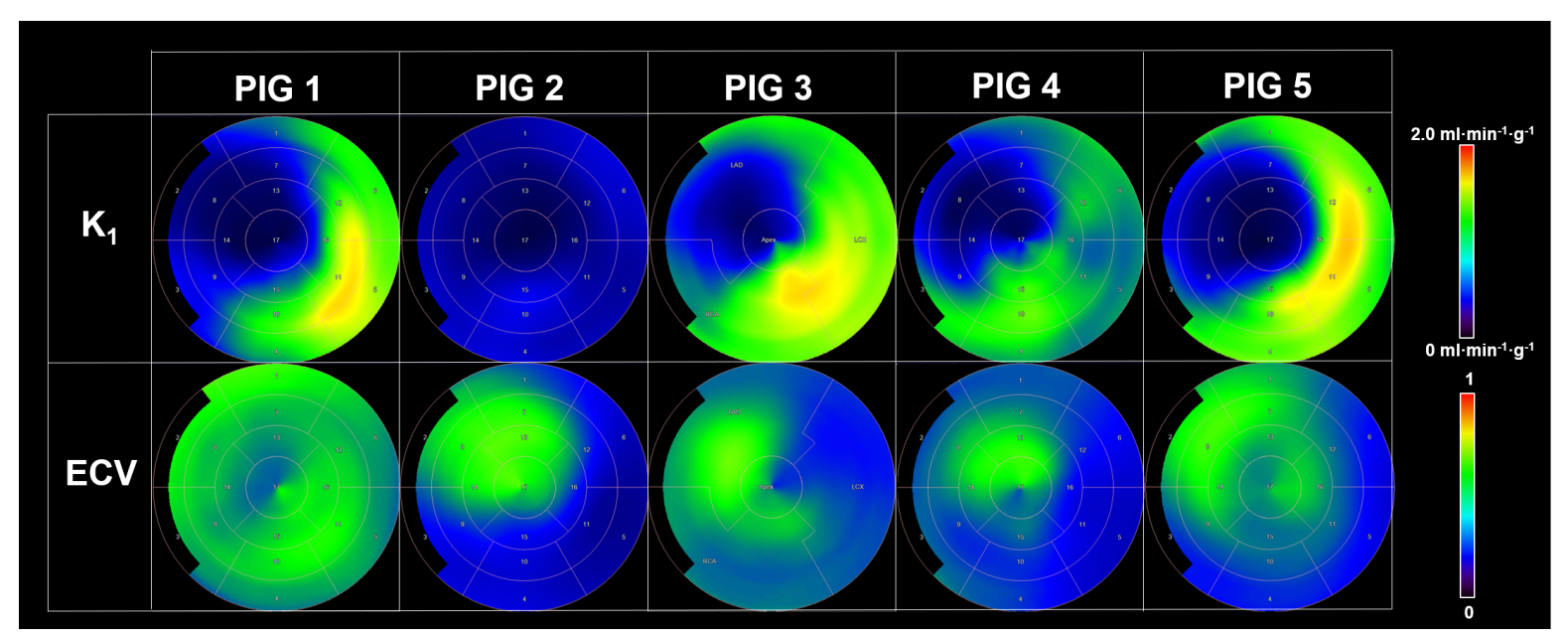

Figure 4.6: Polar plots of $K_{1}$ (top) and ECV (bottom) for the 5 pigs included in the myocardial infarction study. These studies were performed at rest condition. A smoothing filter of $11 \times 11$ kernel size was applied.

Fig. 4.7 shows the quantitative $E C V$ and $M B F_{\mathrm{PET}}$ comparison between the infarcted and remote regions. $M B F_{\mathrm{PET}}$ values obtained with ${ }^{68} \mathrm{Ga}$-DOTA in the infarcted area were significantly reduced in comparison to remote ones: infarcted (LAD): $0.36(0.26 ; 0.57) \mathrm{ml} \cdot \mathrm{min}^{-1} \cdot \mathrm{g}^{-1} \mathrm{vs}$. LCX: $1.35(0.93 ; 1.48) \mathrm{ml} \cdot \mathrm{min}^{-1} \cdot \mathrm{g}^{-1},(p<0.0001)$; and vs. RCA: $1.00(0.54 ; 1.35) \mathrm{ml} \cdot \mathrm{min}^{-1} \cdot \mathrm{g}^{-1}$, $(p<0.0001) . E C V$ increased in the infarcted area (LAD: $0.49(0.41 ; 0.51)$ vs. LCX: $0.30(0.27$ ;0.39), $(p<0.0001)$; and vs. RCA: 0.38 (0.31;0.42), $(p<0.0001))$. 

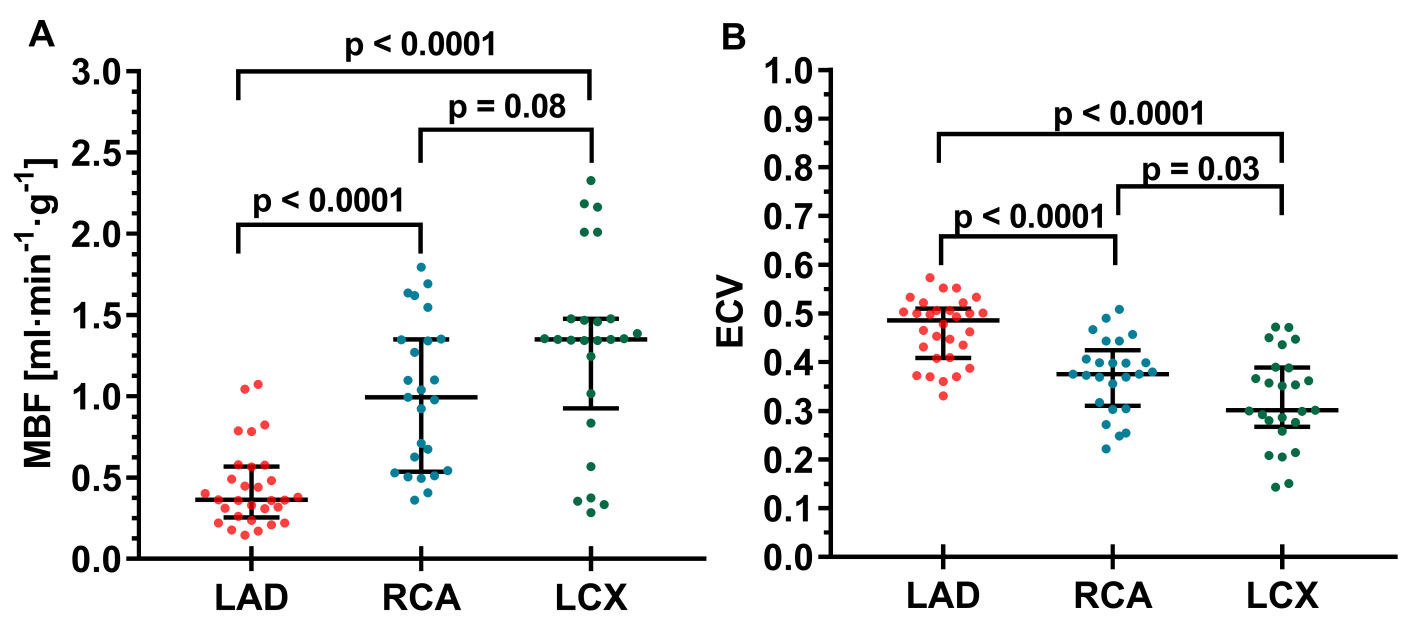

Figure 4.7: Scatter plots of $\operatorname{MBF}_{\mathrm{PET}}(\boldsymbol{A})$ and $E C V(\boldsymbol{B})$ values observed in the three main coronary artery territories for the 5 pigs included in the myocardial infarction study. Each dot corresponds to the averaged value for every AHA segment excluding apex. These studies were performed at rest condition.

\subsection{Discussion}

In this study, we proposed an in vivo imaging technique for non-invasive assessment of MBF and ECV based on ${ }^{68} \mathrm{Ga}$-DOTA-PET. We evaluated this technique in an experimental pig model of myocardial infarction. The presence of an infarction in the LAD coronary artery of the animals was visually confirmed from the very first moment with the LGE-CMR scan. The infarct size depends on the time elapsed between the occlusion of the coronary artery and the reperfusion [83, 173], and a 40-min ischemia/reperfusion model is expected to provide large infarct sizes in the animal. The five pigs had a large infarct size $((32.0 \pm 7.4) \%$ and $(34.3 \pm 14.1) \%$ assessed by CMR and ${ }^{68} \mathrm{Ga}$-DOTA PET). Additionally, wall thickening showed to be diminished in this territory $((20 \pm 17) \%)$ while remained in normal values in RCA and LCX $((37 \pm 19) \%$ and $(41 \pm 25) \%$ respectively) and confirmed the presence of an infarction in the LAD. Wall thickening can be defined as the difference of myocardial segment thickness during systole and diastole. It can be presented in $\mathrm{mm}$ or as a percentage and is directly related to myocardial function abnormalities and correlates to the extent of the infarct size [76, 123, 187]. Large wall thickening is expected in a healthy myocardium, since myocardial wall is thickened during systole (when ventricles contract) and thinned during diastole (when ventricles relax). However, infarcted myocardium loses its contractile ability and wall thickening decreases significantly in the ischemic territory $[55,91,92,197]$.

Absolute quantification of MBF can be used as a surrogate marker for coronary vascular health and to monitor therapeutic interventions in patients with CAD [51]. In addition to MBF, measurement of the ECV in the myocardium can be used to assess myocardial viability and might be valuable to determine the development of fibrosis or edema related to CAD [212, 220]. Our results demonstrate the feasibility of the proposed technique to identify ischemic areas of the myocardium by combined MBF and ECV measurements. Thus, infarcted areas on MI pigs were 
clearly identified (Figs. 4.5 and 4.6) supporting the potential clinical use of ${ }^{68}$ Ga-DOTA-PET for non-invasive quantitative determination of regional MBF and ECV. As expected, $M B F$ values obtained with ${ }^{68} \mathrm{Ga}$-DOTA-PET in the infarcted areas were significantly reduced in comparison to remote non-infarcted regions (see Fig. 4.7A). On the other hand, as it has been demonstrated for this animal model, $E C V$ was significantly increased in the infarcted areas in pigs 7-days post-infarction [59].

Regarding Fig. 4.7, we found a notable difference for $K_{1}$ pattern in animal \#2 seems different to the others. This could be associated to individual variability response to the experimental procedure. Nonetheless, the relative pattern seems to be consistent with the other pigs, although lower values are obtained. Thus, although perfusion values are found in the remote region, even lower values are found in the infarcted region. Either lower initial perfusion at resting condition or physiological differences among animals would explain this abnormality.

Furthermore, a different $E C V$ pattern appeared in animal \#1 of Fig. 4.7. We observed that for this pig a larger spill-over from blood compartment was obtained, which might be the consequence of some imprecision in the model or due to not appropriate delay or dispersion from the AIF obtained from the descending aorta. However, as it was the only case in this study where we observed this behavior, we could not made further conclusions.

Fig. 4.8 provides a deeper analysis for animal \#1 where the AIF was delayed by different amounts of time (0 to 10 seconds). This figure shows how the LAD values remain constant while remote areas clearly differ. However, larger residuals were obtained for increased delays.
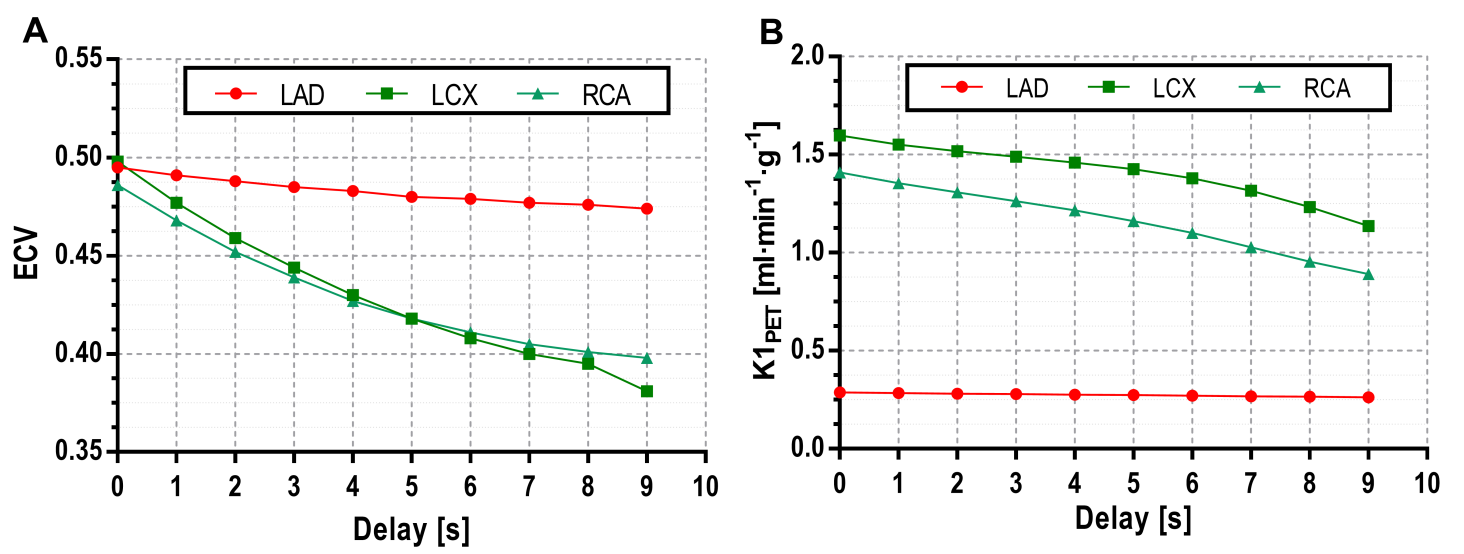

Figure 4.8: $E C V(\boldsymbol{A})$ and $K_{1}(\boldsymbol{B})$ results for TACs corresponding to the three main coronary artery territories as a function of a delay implemented in the pharmacokinetic model. AIF is time-shifted according to the proposed delay in order to account for the time difference between the moment when AIF is measured inside the DA and the moment when the tracer arrives to the myocardial tissue.

This unexpected $E C V$ pattern observed in animal \#1 may also be indeed an accurate measurement of the generalized increase of ECV that could actually be happening in this animal. In fact, it has been reported that diffuse myocardial fibrosis is upregulated by many factors, including remote post-infarct remodeling [185]. And the presence of this diffuse myocardial fibrosis involves increased collagen content, and should increase $E C V$ values [70, 212]. Hence, 
an increased $E C V$ map in remote regions observed in animal \#1 may be due to the presence of diffuse fibrosis as a consequence of post-infarct remodeling. This subtle abnormality cannot be observed with LGE-CMR as this technique only represents local regions of increased fibrosis, but not diffuse fibrosis [148].

\subsubsection{Study Limitations}

Analyses of MBF and ECV on MI were performed including the entire coronary territories to reduce observer-dependent variations. This approach could introduce some bias because the entire myocardial LAD territory may have not been affected by ischemia. However, significant differences of $M B F$ and $E C V$ between infarcted and remote areas were found, suggesting that a more detailed segmentation of the infarcted area could result in even more significant differences.

Histological validation of $E C V$ quantification was not performed in this work. However, a recent study used histology and autoradiography to validate the ability of the chelating agent used here (DOTA) labelled with a different isotope $\left({ }^{64} \mathrm{Cu}\right.$-DOTA) to calculate the extracellular volume fractions of fibrotic cardiac tissues, showing very good correlation with the PET results [109].

The long ischemia/reperfusion protocol utilized in our model was conceived to generate a large myocardial infarction that could provide large differences between ischemic and the remote areas. Nevertheless, we hypothesized that ${ }^{68}$ Ga-DOTA PET could identify less focal scarring due to the high sensitivity of the technique, but we have not yet performed studies on animals with smaller or less focalized defects.

Further experiments should be performed in order to validate the application of this technique for ECV determination in different disease conditions including myocardial infarction and diffuse myocardial fibrosis.

\subsection{Conclusions}

${ }^{68} \mathrm{Ga}$-DOTA PET imaging of animals with a MI model has been demonstrated as an effective tool to assess significant differences in MBF and ECV between different territories of an ischemic heart. Therefore, ${ }^{68} \mathrm{Ga}$-DOTA raises as an alternative to other existing PET tracers for the assessment of MBF in a MI model. Moreover, ${ }^{68} \mathrm{Ga-DOTA-PET} \mathrm{permits} \mathrm{the} \mathrm{simultaneous} \mathrm{as-}$ sessment of myocardial viability in the same scan by measuring $E C V$. Thus, a rest-stress and viability acquisition protocol could be performed within 30 minutes, considerably reducing the scanning times required at present time. 


\subsection{Introduction}

Thus far, we have presented ${ }^{68} \mathrm{Ga}-\mathrm{DOTA}$ as a new PET radiotracer that allows to perform MBF and viability imaging studies. These imaging techniques play a crucial role in CAD management and hence, ${ }^{68} \mathrm{Ga}$-DOTA appears as a promising MPI radiotracer.

However, there are many other diseases that could benefit from the high availability of a perfusion tracer such as ${ }^{68} \mathrm{Ga}$-DOTA even when cardiac perfusion is not the target. Pulmonary perfusion (pulmonary blood flow, PBF) plays also an important role in the evaluation of many lung diseases like chronic obstructive pulmonary disease (COPD), pulmonary hypertension ( $\mathrm{PH})$ or pulmonary embolism. These diseases are frequently described as lung diseases, but it is known that there is a close relationship between heart and lung diseases [44, 81, 84]. In line with this, for example, it is known that adults with congenital heart disease may develop PH [71], and prolonged exposure to small particulate matter is closely related to atherosclerotis development and heart disease [10, 184, 205].

In vivo determination of regional pulmonary blood flow $(\mathrm{PBF})$ is a valuable tool for the evaluation of the aforementioned lung diseases. Different imaging modalities have been suggested to accomplish this task, including MRI [61, 98], scintigraphy [18], SPECT [17], CT [42] and PET $[192,193]$.

Determination of PBF with PET using $\mathrm{H}_{2}{ }^{15} \mathrm{O}$ is considered the clinical standard [144, 155, 177, 193], but the same argument used in the previous chapters could be given in this case; 
the short half-life of ${ }^{15} \mathrm{O}$ and the fact that it requires an on-site cyclotron for its production reduces enormously the availability of this technique. On the contrary, in vivo PET imaging using ${ }^{68} \mathrm{Ga}$-DOTA as a radiotracer for PBF-PET imaging may open a new door in the field, due to its promisingly low cost-effectiveness, ease of production and suitable half-life for clinical studies.

An evaluation of the feasibility of ${ }^{68} \mathrm{Ga}-\mathrm{DOTA}$ as a PBF-PET radiotracer will be presented next. To validate the results, we will simultaneously measure PBF with fluorescent microspheres as well. Blood flow measurements with microspheres (MS) is considered to be the gold standard [168] for the ex vivo validation of cardiac perfusion [156, 195], as we saw in Chapter 3, but also for renal [119] , brain [29, 160] and soft-tissue tumor [107] perfusion imaging. In our case, the MS technique will provide accurate quantitative regional PBF after removing the lung and processing individual tissue samples.

\subsection{Aim of the chapter}

The purpose of this chapter is in line with that in Chapter 3, but this time we evaluated the feasibility of using ${ }^{68} \mathrm{Ga}$-DOTA for in vivo PET imaging of regional PBF in pigs. We validated the results using fluorescent MS as in the previous work.

\subsection{Methods}

\subsubsection{Study design and animal preparation}

As in every in vivo study presented in this thesis, the care and use-of-animals protocol was followed according to the guidelines of the current European Directive and Spanish legislation, and approved by the regional ethical committee for animal experimentation. This study was performed on young Large White pigs of either sex $(\mathrm{n}=4$, mean weight $=41.9 \pm 5.9 \mathrm{~kg})$. Anesthesia protocol followed was the same than the one followed in the previous chapters; animals were sedated with a combination of ketamine $(20 \mathrm{mg} / \mathrm{kg})$, xylazine $(2 \mathrm{mg} / \mathrm{kg})$ and midazolam

$(0.5 \mathrm{mg} / \mathrm{kg})$ and kept anesthetized by intravenous infusion of ketamine $\left(2 \mathrm{mg} \cdot \mathrm{kg}^{-1} \cdot \mathrm{h}^{-1}\right)$, xylazine $\left(2 \mathrm{mg} \cdot \mathrm{kg}^{-1} \cdot \mathrm{h}^{-1}\right)$ and midazolam $\left(0.2 \mathrm{mg} \cdot \mathrm{kg}^{-1} \cdot \mathrm{h}^{-1}\right)$ in saline. The animals were intubated and mechanically ventilated in pressure support ventilation mode with mean fractional concentration of oxygen in inspired gas of 35-40\%, tidal volume of $8 \mathrm{ml} / \mathrm{kg}$, and positive end-expiratory pressure ranged from 7 to $9 \mathrm{~cm} \mathrm{H}_{2} \mathrm{O}$. Respiratory rate was $\approx 18$ beats per minute.

A 7 French pulmonary artery catheter (Swan-Ganz; Edwards Lifesciences World Trade Co. Ltd, Irvine, CA, USA) was inserted through the right external jugular vein using an 8 French introducer sheath (Medtronic, Minneapolis, MN, USA) for continuous pulmonary artery pressure monitoring, MS injection and blood samples extraction. The Swan-Ganz catheter tip was located in the main pulmonary artery. Additionally, ECG and pulse-oximetry were monitored during the entire experiment. 


\subsubsection{PET image acquisition}

PET/CT images were acquired using a Gemini TF-64 scanner (Philips Healthcare, Best, The Netherlands). Animals were placed supine and three ${ }^{68}$ Ga-DOTA-PET scans were obtained under similar physiological conditions for each animal with gaps of 30 minutes between consecutive scans to allow for physical and biological decay. However, some remaining activity was accumulated in subsequent scans as is schematically shown in Fig. 5.1. In order to measure the background activity, a 60 second frame was acquired prior to the radiotracer injection and included in the kinetic modeling. No further background corrections were required. Each scan consisted in a low dose CT scan $(120 \mathrm{kV}, 80 \mathrm{~mA})$ followed by a 10 min list mode PET acquisition in a single bed position covering $18 \mathrm{~cm}$ of axial extension. The radiotracer prepared in $7 \mathrm{ml}$ volume was infused with a pump at a rate of $0.2 \mathrm{ml} / \mathrm{s}$ ( 35 seconds injection) through the marginal ear vein $(66 \pm 33 \mathrm{MBq})$. PET scans were started 1 min prior to the radiotracer injection. Each PET acquisition was reconstructed in 41 consecutive frames $(1 \times 60 \mathrm{~s}, 24 \times 5 \mathrm{~s}, 6 \times 10 \mathrm{~s}, 3 \times$ $20 \mathrm{~s}, 4 \times 30 \mathrm{~s}$ and $3 \times 60 \mathrm{~s}$ ) and 3D-RAMLA reconstruction algorithm was used in all cases producing images with a voxel size of $4 \times 4 \times 4 \mathrm{~mm}^{3}$.

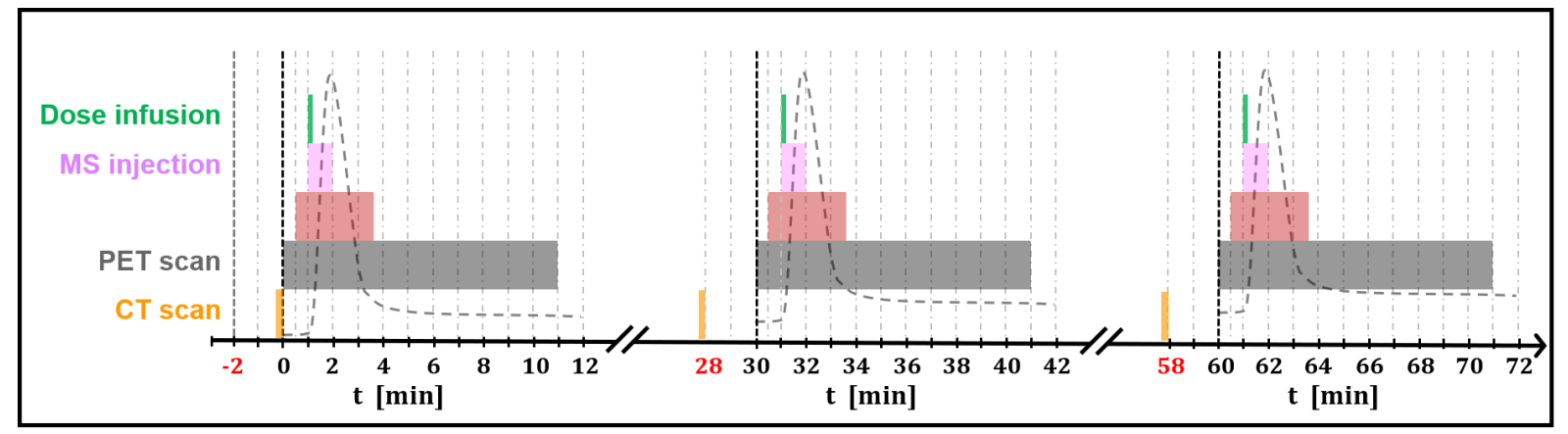

Figure 5.1: Timeline of the protocol followed for each animal. Colored boxes indicate the duration and the time at which every action was being performed. The timeline is superimposed on a schematic AIF (dashed line), and radiotracer accumulation can be noticed at the beginning of the second $(t=30 \mathrm{~min})$ and third $(t=60 \mathrm{~min})$ scans.

Each radiotracer injection was performed simultaneously to the injection of $15-\mu \mathrm{m}$ fluorescent MS (FluoroSpheres $\AA$, Molecular probes, Eugene, OR, USA). Each MS injection consisted of 5 $\times 10^{5}$ beads diluted into $10 \mathrm{ml}$ of saline containing $0.01 \%$ Tween 80 . The MS were manually injected over $\sim 60 \mathrm{~s}$ directly into the right atrium via the Swan-Ganz catheter. Different MS colors were used on each of the three injections provided to the same animal including green $(\lambda$ $=450 / 480 \mathrm{~nm})$, yellow $(\lambda=515 / 534 \mathrm{~nm})$, and red-orange $(\lambda=565 / 580 \mathrm{~nm})$. Immediately before MS dilution, the vial was vigorously vortexed for $15 \mathrm{~s}$, sonicated for 4 min and vortexed again for additional $15 \mathrm{~s}$. Reference blood samples were drawn from the pulmonary artery through the Swan-Ganz into a heparinized syringe at a rate of $5 \mathrm{ml} / \mathrm{min}$ (for $3 \mathrm{~min}$ ) with an automated syringe pump (Harvard PHD 22/2000 Advance Syringe Pump, Harvard Apparatus), starting 1 min before MS injection. Additionally, another blood sample was taken from the pulmonary artery for hematocrit measurement. 


\subsubsection{PET data analysis}

PBF derived from MRI typically uses a single compartment model as the acquisition is obtained during one breath-hold and extravasation can be neglected. However, our PET data is acquired in free-breathing during several minutes and extravasation becomes a relevant factor. Therefore, the use of two-tissue compartments was considered to account for the capillary bed and the interstitial volume. In this way, parametric $\mathrm{PBF}$ images $\left(P B F_{\mathrm{PET}}\right)$ were generated voxel-wise applying a two-compartment exchange model (2CXM) [201] over the dynamic PET images. This model considers the plasma volume of the lung capillary bed as the central compartment which occupies a fractional volume $v_{p}$, with a tracer concentration $C_{p}(t)$, and the interstitial volume as the peripheral compartment which occupies a fractional volume $v_{e}$ with a tracer concentration $C_{e}(t)$. The exchange rate between the two compartments is described by the permeability-surface product $(P S)$. Thus, tracer concentrations over time in both compartments are explained by their mass balance equations (see Eqs. 5.1 and 5.2).

$$
\begin{aligned}
v_{p} \frac{d C_{p}(t)}{d t} & =F_{p} C_{a}(t)-F_{p} C_{p}(t)+P S C_{e}(t)-P S C_{p}(t) \\
v_{e} \frac{d C_{e}(t)}{d t} & =P S C_{p}(t)-P S C_{e}(t)
\end{aligned}
$$

where $C_{a}(t)$ is the radiotracer concentration in the arterial plasma (i.e., the AIF) and $F_{p}$ is the pulmonary plasma flow. Tissue tracer concentration is the sum of concentrations in plasma and interstitial space weighted by each particular fractional volume (see Eq. 5.3).

$$
C_{t}(t)=v_{p} C_{p}(t)+v_{e} C_{e}(t)
$$

This set of differential equations can be solved as the convolution of $C_{a}(t)$ with the impulse response function (IRF):

$$
\begin{aligned}
C_{t}(t) & =C_{a}(t-\delta) \otimes I R F(t) \\
\operatorname{IRF}(t) & =\frac{v_{e}+v_{p}}{v_{e} v_{p}} P S \cdot F_{p}\left(\frac{\mathrm{e}^{-t E_{-}}-\mathrm{e}^{-t E_{+}}}{E_{+}-E_{-}}\right)+F_{p}\left(\frac{E_{+} \mathrm{e}^{-t E_{+}}-E_{-} \mathrm{e}^{-t E_{-}}}{E_{+}+E_{-}}\right),
\end{aligned}
$$

where $E_{+}$and $E_{-}$are positive, non-zero quantities defined as

$$
E_{ \pm}=\frac{1}{2}\left(\frac{v_{e} F_{p}+v_{e} P S+v_{p} P S}{v_{e} v_{p}} \pm \sqrt{\left(\frac{v_{e} F_{p}+v_{e} P S+v_{p} P S}{v_{e} v_{p}}\right)^{2}-\frac{4 P S F_{p}}{v_{e} v_{p}}}\right) .
$$

Therefore, the implemented 2CXM model contains four fit parameters including $v_{p}, v_{e}, F_{p}$ and $P S$. The most relevant parameter for our purpose is the pulmonary plasma flow $\left(F_{p}\right)$, which can be converted into the pulmonary blood flow $(\mathrm{PBF})$ via the hematocrit value of the lung tissue:

$$
P B F=\frac{F_{p}}{1-H_{T}},
$$

where $H_{T}$ represents the hematocrit value. In Eq. 5.7, $P B F$ is obtained in units of volume of 
blood per time and volume of tissue $\left(\mathrm{ml} \cdot \mathrm{min}^{-1} \cdot \mathrm{ml}^{-1}\right)$ but, in order to compare with the (MS) results, $P B F$ must be expressed as volume of blood per time and mass of tissue $\left(\mathrm{ml} \cdot \mathrm{min}^{-1} \cdot \mathrm{g}^{-1}\right)$. To account for this, $P B F$ value was corrected by density and blood fraction. The CT values were used to obtain lung density values (tissue + blood) [90] assuming a linear behavior between $\mathrm{CT}$ value and tissue density in the range from air $\left(-1024 \mathrm{HU}, \rho \approx 0 \mathrm{~g} \cdot \mathrm{cm}^{-3}\right)$ to water $(0 \mathrm{HU}$, $\left.\rho=1 \mathrm{~g} \cdot \mathrm{cm}^{-3}\right)[36,188]$. The blood contribution was subtracted using the plasma fractional volume $\left(v_{p}\right)$ obtained in the minimization process (see Eqs. 5.8 and 5.9).

$$
P B F\left[\mathrm{ml} \cdot \min ^{-1} \cdot \mathrm{g}^{-1}\right]=\frac{P B F\left[\mathrm{ml} \cdot \mathrm{min}^{-1} \cdot \mathrm{ml}^{-1}\right]}{\rho_{\text {lung }}-\frac{v_{p}}{1-H_{T}} \rho_{\text {blood }}},
$$

where a blood density $\left(\rho_{\text {blood }}\right)$ of $1 \mathrm{~g} \cdot \mathrm{cm}^{-3}$ was used and lung density $\left(\rho_{\text {lung }}\right)$ was computed in a pixel by pixel basis as

$$
\rho_{\text {lung }}=\frac{1024+C T_{i}}{1024}
$$

where $C T_{i}$ is the $\mathrm{CT}$ value (HU) measured at voxel $i$.

It can be noticed that the AIF employed for the analysis is delayed $\delta$ seconds with respect to the voxel TACs, as it was derived from the right ventricle and there is some delay until it reaches the lung capillaries. A delay of 2 seconds was used since a transit time of 4 seconds was observed from the right to the left ventricle. The same value was used in other studies with ${ }^{15}$ O-labeled water [177]. The delayed AIFs were interpolated to match PET measurement times.

The radiotracer flows from the pulmonary arteries to the veins through the capillary bed and extravasates to the interstitial space. Therefore, the radiotracer concentration can be expressed in terms of the plasma concentration in the arterial input, the plasma flow, the plasma volume, the permeability-surface area product, and the interstitial volume.

Importantly, this time the AIF was not obtained from the LV but from the RV. This is because the blood that perfuses the lungs is supplied by the pulmonary artery, which carries the blood from the RV to the lungs. Consequently, the arterial input function (AIF) (see Fig. 5.2A) was obtained from the mean voxel value at each time point within a small volume of interest (VOI) drawn inside the right ventricle and was corrected by the pulmonary artery hematocrit to obtain the radiotracer concentration in arterial plasma.

The non-linear fit of the TAC of each voxel was performed by a minimization of the sum of squares using a modified Levenberg-Marquardt method for bound constraints with a Pythoncoded customized software including scipy and numpy libraries. Fig. 5.2B shows an illustrative fit to the average TAC of a large region within the lung.

On each animal, right and left lungs were segmented separately, and each lung was divided into three transversal regions (apical, medial and basal) with the same axial extension to facilitate regional comparison with the MS measurements (see Fig. 5.3). The $P B F$ for each region was computed as the average PBF of those voxels with CT values between -925 and $0 \mathrm{HU}$ in order to reject large vessels and airways. A morphological erosion image filtering with $4 \mathrm{~mm}$ size was performed over the VOI of the lung to avoid spillover contribution from heart or liver. 

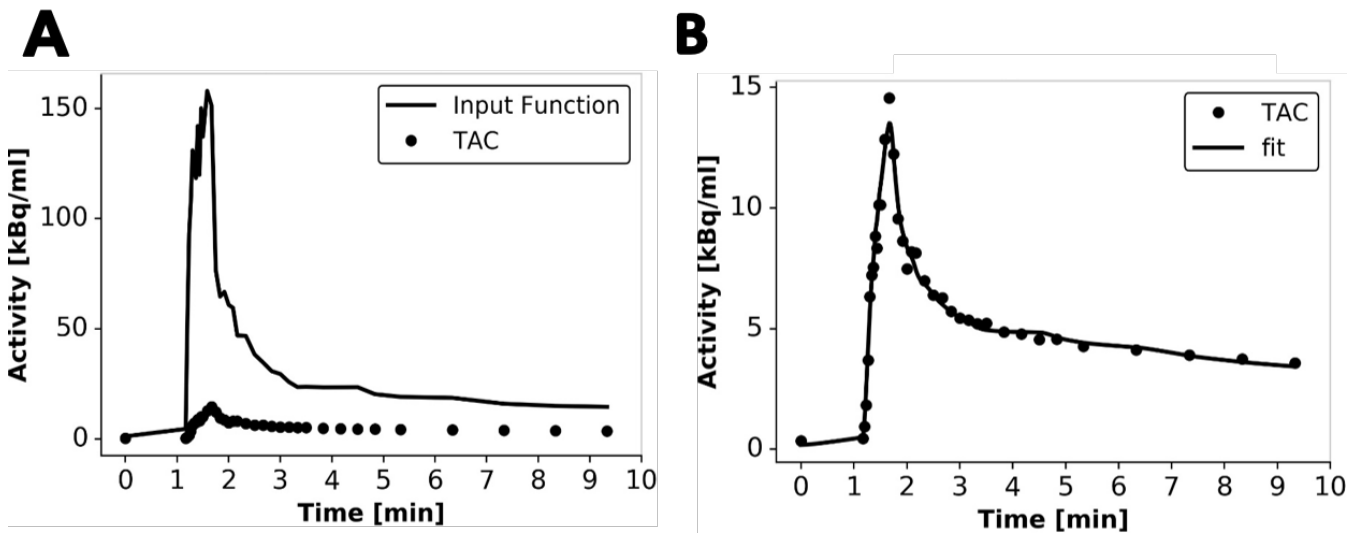

Figure 5.2: A: An example of TACs obtained for a large region of the lung (dots) and right ventricle (solid line). B: $T A C$ from the lung (dots) and fit to a two-compartment exchange model (solid line).

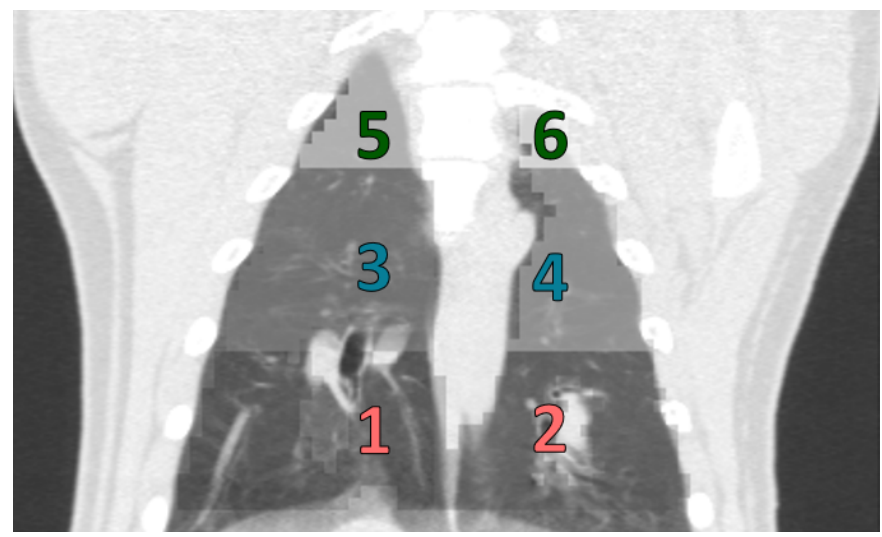

Figure 5.3: Coronal view of an in vivo CT image indicating the segmentation of the lungs performed for the regional validation against MS. Regions 1-2 (red), 3-4 (blue) and 5-6 (green) correspond to the basal, medial and apical zones of the right-left lungs respectively.

\subsubsection{Microspheres analysis}

The MS analysis was based on the same protocol followed in Chapter 3 [194] with minor modifications. In brief, the pigs were sacrificed the day after PET scans were performed and the lungs were extracted. The lungs were expanded to recover anatomic references and make easier the comparison between zones in PET and excised lungs. To this purpose, the pig was sedated as previously described and euthanized by an intravenous overdose of pentobarbital in supine position while intubated. The animal was mechanically ventilated with similar conditions than those for the in vivo experiments. The trachea was clamped at the end of inspiration and the lungs were extracted. An ex vivo CT scan of them was performed to guide the registration between in vivo images and post-mortem validation MS analysis. Afterwards, the lungs were wrapped in plastic film and frozen at $-20^{\circ} \mathrm{C}$. Finally, right and left lungs were separated and individually divided into transversal slices (1-2 cm thickness) (see Fig. 5.4).

For tissue processing, each lung piece was weighted and immersed in a $\mathrm{KOH} 4 \mathrm{~N}$ solution (5 $\mathrm{ml}$ per gram of tissue). At the same time, each reference blood sample withdrawn during the experiment was taken to $60 \mathrm{ml}$ with $2 \%$ Tween 80, followed by addition of $14 \mathrm{ml}$ of $\mathrm{KOH} 16 \mathrm{~N}$. All samples were incubated at $37^{\circ} \mathrm{C}$ under vigorous shaking for $24-48$ hours. This incubation 


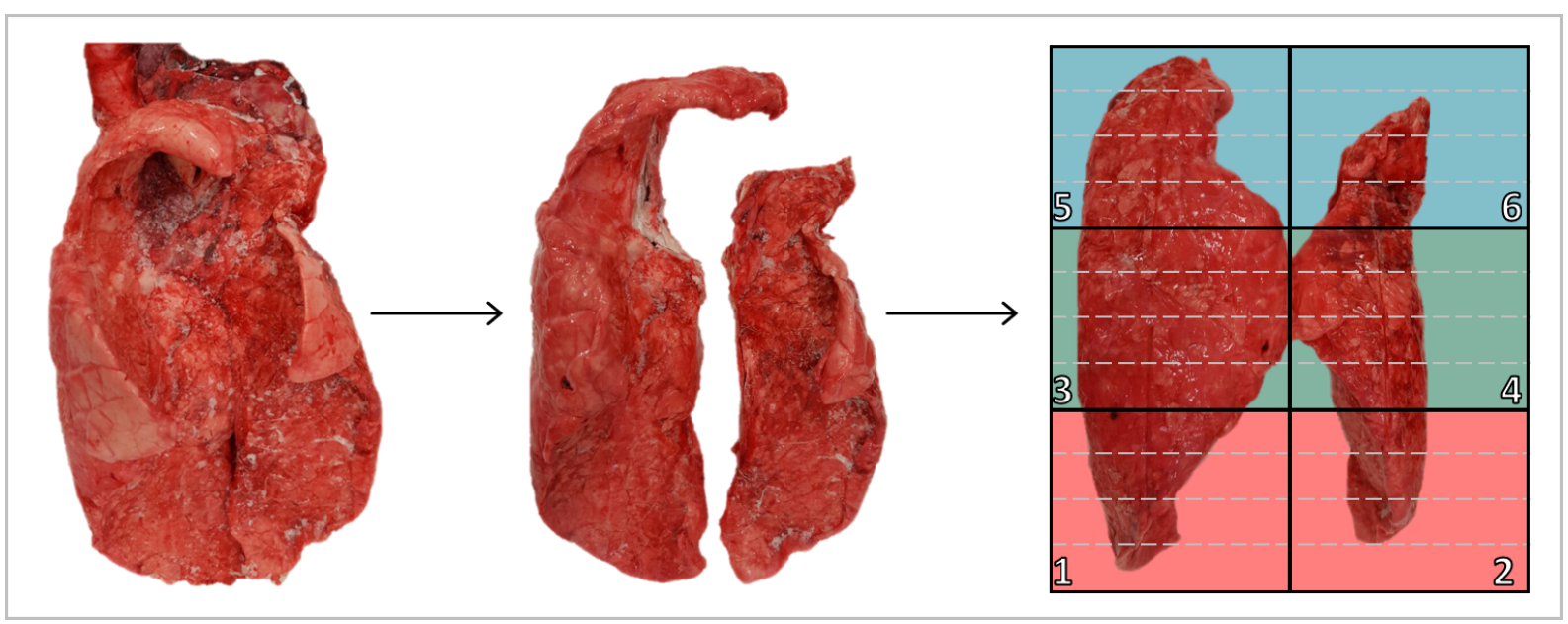

Figure 5.4: Process followed parting from frozen lungs to obtain pieces that were further digested. Both left and right lungs were sliced in three regions: 1-2 (basal), 3-4 (medial) and 5-6 (apical) that would spatially correlate to ROIs in PET analysis, as those drawn in Fig. 5.3.

time (24-48 hours) is shorter than that needed to digest cardiac tissue samples (48-72 hours) as lung tissue is softer.

After complete tissue digestion, samples were individually filtered with negative pressure filtration. A different filter (Nylon Net Filter $10 \mu \mathrm{m}$, Merck Millipore, Burlington, MA, USA) was used for each sample. Each digested sample was poured onto the filter, and the containing tube was rinsed with $\sim 20 \mathrm{ml}$ of $2 \%$ Tween 80 to ensure the collection of all the MS. Next, the filter was rinsed with $\sim 10 \mathrm{ml}$ of buffer rinse solution $\left(\mathrm{KH}_{2} \mathrm{PO}_{4} / \mathrm{K}_{2} \mathrm{HPO}_{4}\right.$ at $\left.\mathrm{pH}=7.2\right)$ to neutralize the $\mathrm{pH}$ of the nylon filter.

Each filter was immersed in $10 \mathrm{ml}$ of cellosolve acetate (2-ethoxyethyl acetate 98\%, Sigma, Saint Louis, MO, USA) and stored in the dark for $2-3 \mathrm{~h}$, until the complete dissolution of the MS polystyrene cover. The fluorescence of the resultant solution was measured with a fluorescence spectrometer (PerkinElmer LS 55, Waltham, MA, USA) at the emission/excitation wavelengths of 450/480 nm, 515/534 nm and 565/580 nm for the green, yellow and red-orange MS respectively. Both emission and excitation slits were set at $5.0 \mathrm{~nm}$ for every reading. Finally, the fluorescence intensities of each sample were used to compute the PBF ( $P B F_{\mathrm{MS}}$ ) following the standard MS reference technique [58]. Each sample was assigned to one of the lung six regions segmented in the parametric $P B F_{\mathrm{PET}}$ images (see Fig. 5.3). The PBF of each region was calculated adding the fluorescent and weight values of the samples assigned to it. 


\subsubsection{Statistical analysis}

$P B F_{\mathrm{PET}}$ and $P B F_{\mathrm{MS}}$ values were directly compared by regression analysis. $\mathrm{F}$ test was used to study the null hypothesis of the $y$-intercept of the linear fits being zero. Also, Pearson correlation coefficient was estimated, and Bland-Altman plot was used to assess agreement between $P B F_{\mathrm{PET}}$ and $P B F_{\mathrm{MS}}$ results. All the measurements were statistically considered as independent events as the MS results showed high variability for measurements repeated on the same animal and a wide range of $\mathrm{PBF}$ values was covered with all the animals. As usual, $\mathrm{p}<0.05$ was considered statistically significant.

\subsection{Results}

Physiological variables were stable during the scan. Heart rate was $100 \pm 16$ beats per minute (bpm), mean pulmonary artery pressure was always under $25 \mathrm{mmHg}$, and oxygen saturation was over $98 \%$. A hematocrit value of 0.3 , similar to the value used in other perfusion studies with varied techniques, was used for all analyses.

\subsubsection{Parametric PBF maps}

Fig. 5.5 shows examples of $P B F_{\mathrm{PET}}$ images at different axial slices, demonstrating the capability of this technique to produce $3 \mathrm{D}$ regional $\mathrm{PBF}$. The images are fused with their corresponding CT slices for visualization purposes only. PBF values are displayed only for those voxels with $\mathrm{CT}$ values in the range from -925 to $0 \mathrm{HU}$. As expected, the dorsal regions show higher PBF values compared to ventral regions as a consequence of the supine position of the animal during the imaging sessions [178].

\subsubsection{Comparison $\boldsymbol{P} \boldsymbol{B} \boldsymbol{F}_{\mathrm{PET}}$ versus $\boldsymbol{P} \boldsymbol{B} \boldsymbol{F}_{\mathrm{MS}}$}

Bland-Altman plot (Fig. 5.6) shows the evaluation of the agreement between $P B F_{\mathrm{PET}}$ and $P B F_{\mathrm{MS}}$ including 57 samples. Measured bias was $-1.86 \mathrm{ml} \cdot \mathrm{min}^{-1} \cdot \mathrm{g}^{-1}$ and limits of agreement (LOA) ranged from -11.79 to $8.08 \mathrm{ml} \cdot \mathrm{min}^{-1} \cdot \mathrm{g}^{-1}$. The slightly negative trend $($ slope $=-0.14)$ found in linear fit of these data $\left(P B F_{\mathrm{PET}^{-}} P B F_{\mathrm{MS}}\right.$ differences against $P B F_{\mathrm{PET}}-P B F_{\mathrm{MS}}$ average) was not significant $(p=0.16)$, so no correction was applied to the data, and agreement between PBF measurement with PET and gold standard MS could be concluded.

The MS measurement corresponding to the blood sample of the third scan in pig \#4 showed atypical and extremely low fluorescence values compared to background level. As this can increase the probability of measurement errors, the 6 points corresponding to this scan were excluded from the analysis. Results of the agreement without the data exclusion lead to a bias and LOA of $-3.51 \mathrm{ml} \cdot \mathrm{min}^{-1} \cdot \mathrm{g}^{-1}$ and from $-16.30 \mathrm{ml} \cdot \mathrm{min}^{-1} \cdot \mathrm{g}^{-1}$ to $9.27 \mathrm{ml} \cdot \mathrm{min}^{-1} \cdot \mathrm{g}^{-1}$ respectively.

Evaluation of the correlation between $P B F_{\mathrm{PET}}$ and $P B F_{\mathrm{MS}}$ including 57 samples is shown in Fig. 5.7. The null hypothesis of a $y$-intercept $=0$ was rejected by the $F$ test, and the $P B F_{\mathrm{PET}^{-}}$ $P B F_{\mathrm{MS}}$ pair of values were fitted to a line with non-zero $y$-intercept. The methods showed a good and significant correlation $(r=0.77, p<0.0001)$ when perfusion across all the measured 


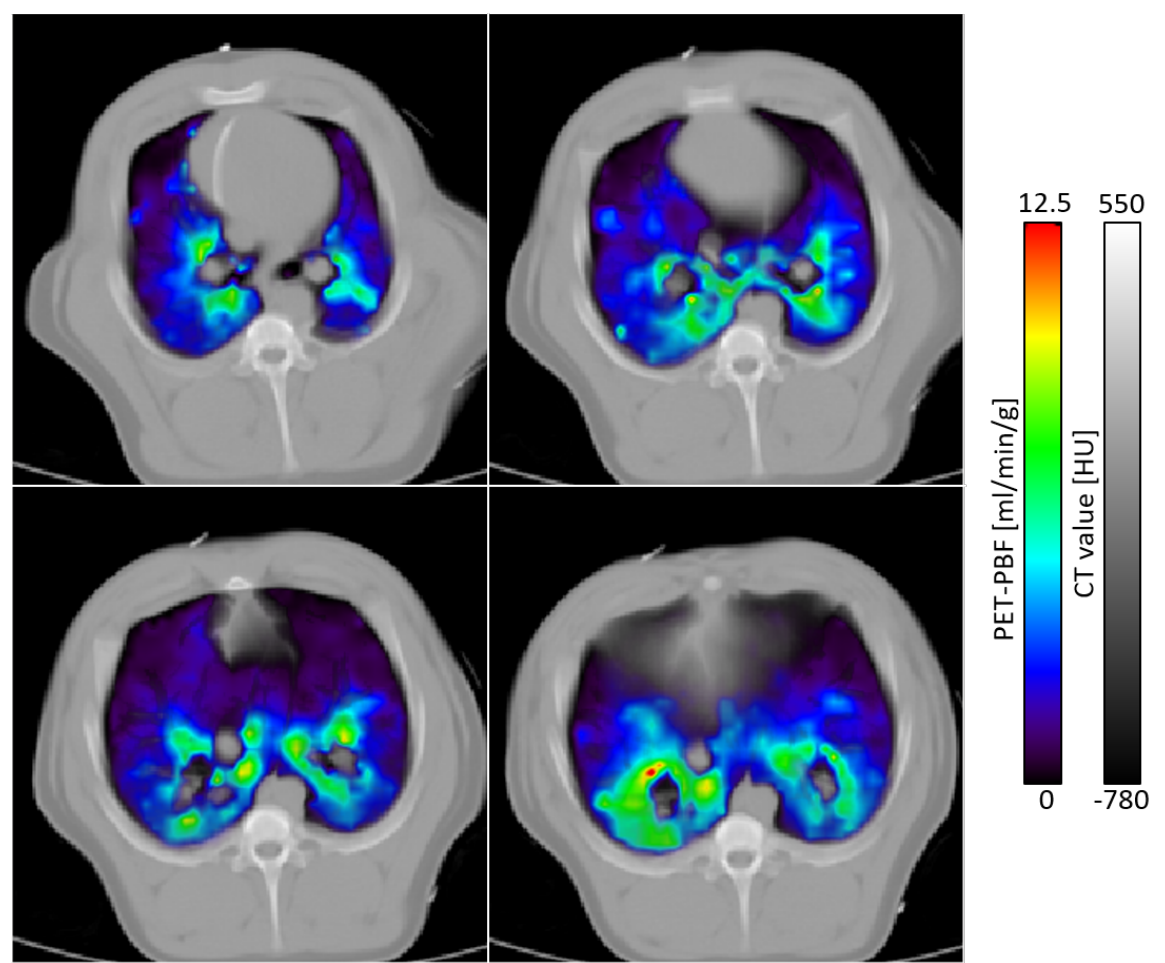

Figure 5.5: Fused transverse parametric $P B F_{\mathrm{PET}}$ and $C T$ images at four different axial locations of the same animal.

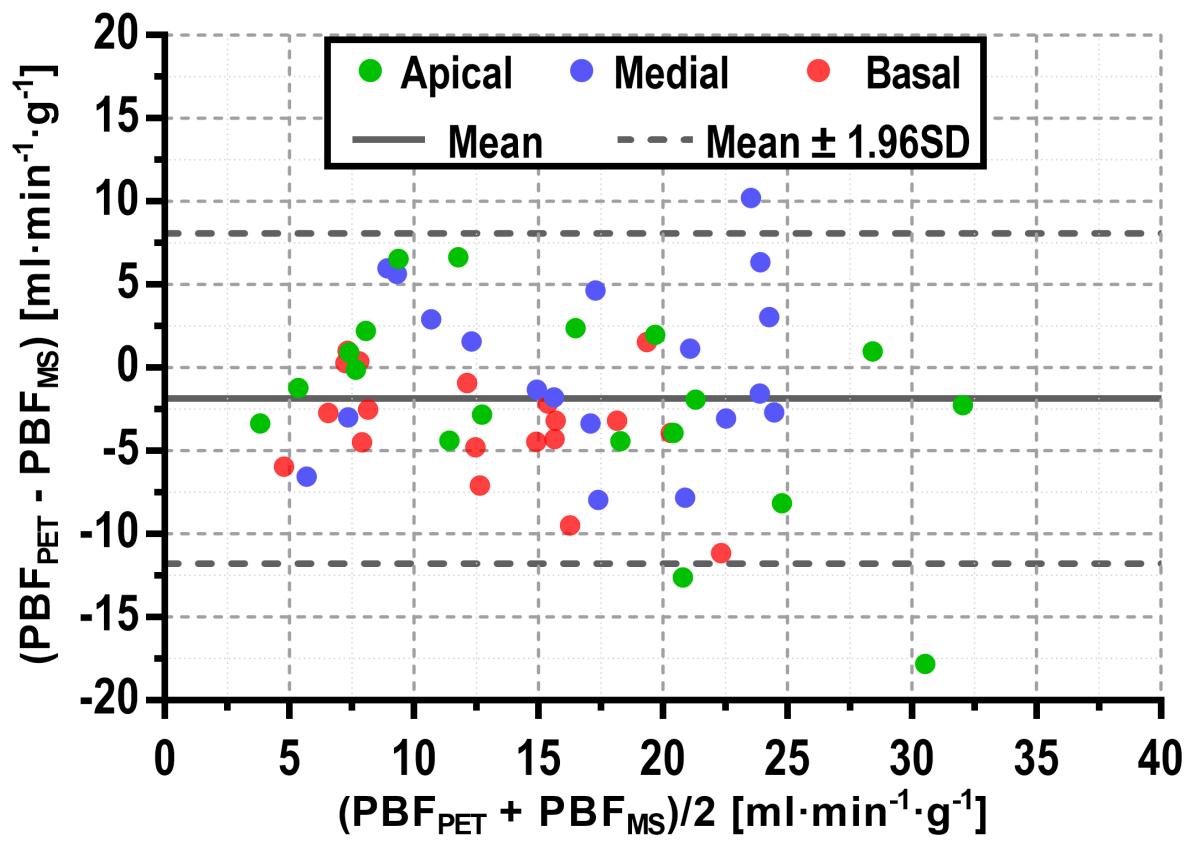

Figure 5.6: Assessment of agreement between $P B F_{\mathrm{PET}}$ and $P B F_{\mathrm{MS}}$. Apical (green), medial (blue) and basal (red) regions are shown. The solid lines represent the mean bias $\left(-1.86 \mathrm{ml} \cdot \mathrm{min}^{-1} \cdot \mathrm{g}^{-1}\right)$ and the dashed lines represent the $95 \%$ confidence interval (mean $\pm 1.96 \mathrm{SD}$ ).

regions of the lung were evaluated, and was maintained when the evaluation was done by lung zones: $r=0.83(p<0.0001), r=0.72(p<0.0001)$ and $r=0.82(p<0.0001)$ for apical, medial 
and basal zones respectively. The goodness of fit worsens $(r=0.66, p<0.0001$ for the entire lung; $r=0.76, p<0.0001$ for the apical; $r=0.63, p<0.0001$ for the medial; and $r=0.74$, $p<0.0001$ for the basal zone) when the correlation is performed without the exclusion of the 6 points mentioned before, which is in line with the possibility of measurement errors.

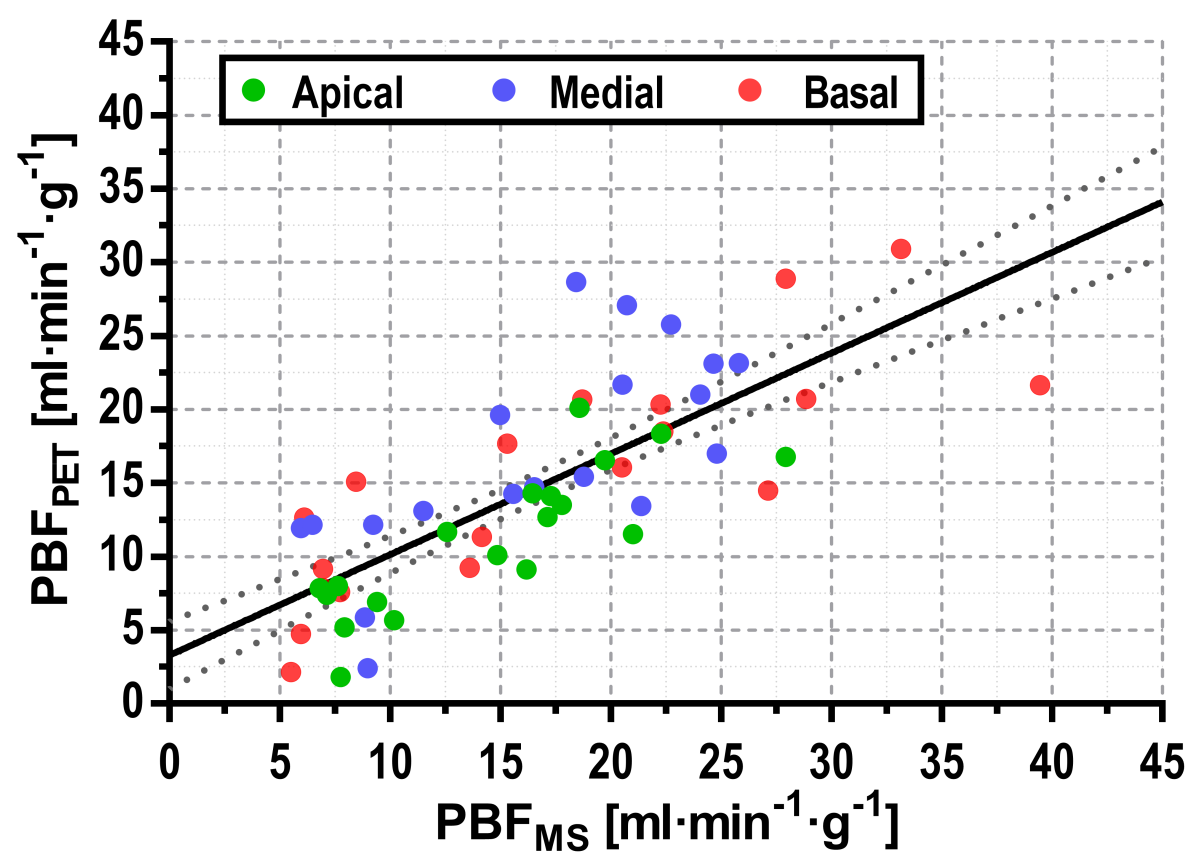

Figure 5.7: Correlation between $P B F_{\mathrm{PET}}$ and $P B F_{\mathrm{MS}}$. Apical (green), medial (blue) and basal (red) regions are shown. The dashed line represents regression line to all the points $(r=0.77, p<0.0001)$.

\subsection{Discussion}

In this chapter, the use of ${ }^{68} \mathrm{Ga}-\mathrm{DOTA}-\mathrm{PET}$ for the in vivo quantitative determination of regional $\mathrm{PBF}$ is proposed. The methodology required to perform these studies was implemented and tested in healthy pigs. Finally, the in vivo measurements of regional PBF were validated using fluorescent MS. This is a reliable and easily implementable alternative to dynamic contrast enhanced MRI, where quantification is very challenging due to the non-lineal dependence of signal intensity with the Gadolinium-based contrast agent concentration [155]. This is even more important due to the fact that these agents, either linear or macrocyclic, are under investigation for multiple results demonstrating their potential accumulation in various tissues regardless of renal function [137]. Our alternative has a simpler implementation and provides quantitative measures of the regional blood flow compared to recent approaches using dual energy CT imaging $[64,100]$. Compared to other PET based alternatives such as $\mathrm{H}_{2}{ }^{15} \mathrm{O}$ [192] or dissolved ${ }^{13} \mathrm{~N}_{2}$ [152] that need an on-site cyclotron, our solution could be potentially more widely available due to the introduction of gallium generators in the field and the approval of different gallium-chelated agents for human use. Our local estimation cost is 100 euros per study including proportional use of the generator, reactive agents and lab technicians. Compared to other nuclear medicine tech- 
niques such as ${ }^{99 m}$ Tc macroaggregated albumin [17], which also reflects true perfusion, SPECT shows lower spatial resolution and longer acquisition times.

We have demonstrated the capability of the proposed technique to obtain in vivo 3D regional PBF. Comparative $P B F_{\mathrm{PET}}$ and $P B F_{\mathrm{MS}}$ values in dorsal and ventral regions were not obtained due to the difficulty to achieve a good in vivo and ex vivo registration.

The results of this study show potential for ${ }^{68} \mathrm{Ga}$-DOTA radiotracer in clinical practice for measuring PBF. Pulmonary perfusion is an important variable for understanding lung function, especially when it can be described regionally. Such relevance has allowed the advances in imaging techniques for lung perfusion and perfusion distribution to become an attractive tool for diagnosis and outcomes prediction and evaluation. For example, differences in perfusion patterns measured by dual CT $[79,141]$ are being proposed for diagnosis of $\mathrm{PH}$ and even to differentiate pulmonary arterial hypertension (PAH) from chronic thromboembolic pulmonary hypertension (CTEPH) [74]. Recently Lau et al. [116] showed using SPECT/CT that pulmonary pre-capillary hypertension showed a redistribution of flow changing the gravidity influence, which appears as a potential tool for disease severity evaluation. Not only PH but also other lung diseases such as COPD have shown alterations in perfusion, which in this disease is related to impaired pulmonary function indexes, appearing also promising for severity evaluation.

The good correlation existing between $P B F_{\mathrm{PET}}$ and $P B F_{\mathrm{MS}}$ (see Fig. 5.7) shows high potential for the determination of quantitative regional $\mathrm{PBF}$ in vivo and non-invasively using ${ }^{68} \mathrm{Ga}$-DOTA-PET. Noteworthy, the $r$-value and slope obtained in this study are comparable to those calculated by Schuster et al. [193] $(r=0.77$, slope $=0.92)$ and Richard et al. [177] $(r=0.79$, slope $=0.79)$ using PET and ${ }^{15}$ O-labeled water. Unfortunately, there is no PBF obtained by CT to compare with our results $[64,100]$.

The obtained $P B F_{\mathrm{PET}}$ values display a small underestimation compared to $P B F_{\mathrm{MS}}$ representing only $10 \%$ of the maximum PBF obtained. The underestimation could be explained by the difference between the hematocrit of the blood contained in an arteriole or venule of the capillary bed (tube hematocrit $H_{T}$ ) relative to the hematocrit of blood entering or leaving it (discharge hematocrit $H_{D}$ ). This difference can be explained by the Fåhræus effect [57] and results in a decreasing hematocrit as blood traverses the microvasculature. In our work we assumed that $H_{T}$ equals to $H_{D}$, but a proper correction would result in an increment of PBF values as shown in Eq. 5.10. Pries et al. [167] reported a $H_{T} / H_{D}$ ratio of 0.65 for $H_{D}=0.3$ at $10 \mu \mathrm{m}$ diameter capillaries. This correction would increase PBF by $15 \%$.

$$
P B F^{\prime}=P B F \frac{1-H_{T}}{1-H_{D}}
$$

It also has to be noticed that Pearson correlation values between $P B F_{\mathrm{MS}}$ and $P B F_{\mathrm{PET}}$ is limited by the registration inaccuracy between the regions of the in vivo PET scan and the $e x$ vivo MS measurements. A possible improvement for this comparison would be the use of ${ }^{68} \mathrm{Ga}$ labeled MS that could be quantified by a PET scan keeping the animal in the same position as in the ${ }^{68} \mathrm{Ga-DOTA}$ scan. 
Another source of error can be the delay between the AIF derived from the right ventricle and the arrival of the radiotracer to every tissue voxel [87]. Imprecise delays can produce deviations up to $40 \%$ [177]. In this study, we assumed a constant delay of 2 seconds, but further improvements can be performed in order to include this delay time as a free parameter in the non-linear fit. Finally, the AIF was not corrected by partial volume effect that can have quantitative effects on the results [96].

Although the animals were studied under basal conditions, a wide variability of heart rate and PBF values was obtained. This was probably due to the fact that the animals were mechanically ventilated in pressure support ventilation mode, which required adjusting the anesthesia between consecutive scans in order to maintain the animal stable under mechanical ventilation. However, this effect was transient, and all animals remained stable across each acquisition. In the other hand, such variations allowed us to explore a wider range of perfusion values.

\subsubsection{Study limitations}

Despite the promising results, this study was performed just in normal animals. However, the main possible applications of this new method are related with the study of diseased states. As pulmonary flow is related with important physiologic processes such as gas exchange and also right ventricle afterload, the ability to track it in a quantitative and reliable way in usual clinical practice could potentially improve disease understanding and patient care. Although non-disease states were studied, PBF was evaluated in a wide range of values. Also, to the best of our knowledge both the tracer behavior itself and the implemented analysis should remain valid in pathologic conditions. Based on this, we believe our $P B F_{\mathrm{PET}}$ using ${ }^{68}$ Ga-DOTA appears as a potential quantitative diagnostic imaging biomarker of endothelial dysfunction in important lung diseases. This, however, still needs to be proven.

Another limitation of our study is the small number of animals $(n=4)$. However, 57 independent measures were used for the agreement and correlation studies corresponding to the three scans performed to each animal and the three transversal regions of each lung. With this, we were able to find acceptable agreement and good and significant correlation between $P B F_{\mathrm{PET}}$ and the gold standard measurements. Using a larger number of animals could have improved our results through a decrease in measured variability but it is probably unjustified by the current needs of reducing the number of experimental animals.

Finally, as most of the current implemented methods, ${ }^{68}$ Ga-DOTA $P B F_{\text {PET }}$ can offer a regional perfusion estimation, which represents a mean value across the entire respiratory cycle. However, mainly due to the volume and pressure changes within the lungs during the respiration it is reasonable to expect that the local perfusion be different according to the respiratory phase. In this way dynamic evaluation of lung perfusion in normal and diseased status could appear as a promissory research field. This aspect could be studied with the proposed technique by applying respiratory synchronization to measured PET data or performing data acquisition during apnea or at the end-of-expiration. However, this was out of the scope of this study. 


\subsection{Conclusions}

In this study, the determination of regional PBF using ${ }^{68}$ Ga-DOTA-PET imaging was proposed, implemented and validated. Assessment of PBF with this technique allows combining the high quantitative accuracy of PET imaging with the much easier access to ${ }^{68} \mathrm{Ge} /{ }^{68} \mathrm{Ga}$ generators compared to existing techniques using $\mathrm{H}_{2}{ }^{15} \mathrm{O}$ that require an on-site cyclotron. In this way ${ }^{68}$ Ga-DOTA-PET appears as a potential method for measuring PBF in clinical settings with an extended use, and widens the range of applications of ${ }^{68}$ Ga-DOTA-PET imaging. 


\subsection{Introduction}

The work shown in the previous chapters has proposed the use of ${ }^{68}$ Ga-DOTA as a new PET radiotracer, which would allow to expand the use of PET for the clinical evaluation of MBF, viability and PBF [11, 12, 109, 214, 215]. Thanks to its ease of production and low cost, ${ }^{68} \mathrm{Ga}$ DOTA may join the club of the most used radiotracers in clinical cardiac studies $\left({ }^{18} \mathrm{FDG}, \mathrm{H}_{2}{ }^{15} \mathrm{O}\right.$, ${ }^{13} \mathrm{NH}_{3}$ and $\left.{ }^{82} \mathrm{Rb}\right)$. Noteworthy, ${ }^{68} \mathrm{Ga}$-DOTA possesses a special feature that the aforementioned do not, and it has not been exploited yet; ${ }^{68} \mathrm{Ga}$ emits an additional high-energy gamma ray apart from the $\beta^{+}$decays, and this fact may be useful as we will see next.

It has been stated that PET is a diagnostic molecular imaging technique that allows in vivo monitoring of metabolic processes within the body based on the biodistribution of a radiotracer that is administered to the patient. There is a wide variety of available radiotracers that provide access to different biological aspects such as glucose metabolism, cell proliferation, hypoxia or blood flow, and among the different radiotracers available, each one shows strengths and limitations for a particular clinical application [225]. Based on this knowledge, the nuclear medicine physician selects the tracer that will provide the most specific and reliable information for the patient under study. However, in many clinical cases, diagnostic accuracy can be increased considerably if complementary information is obtained from different tracers. In fact, an example of diagnosis using multiple tracers is found in $\mathrm{CAD}$, which includes evaluation of myocardial blood flow (MBF) using tracers as ${ }^{13} \mathrm{NH}_{3}, \mathrm{H}_{2}{ }^{15} \mathrm{O}$ or ${ }^{82} \mathrm{Rb}$, and assessment of myocardial metabolism 
and viability using ${ }^{18} \mathrm{FDG}$. In this way, a better understanding of the pathophysiology of CAD is obtained [73].

Conventional PET imaging has usually been limited to a single tracer per scan. Therefore, in order to perform PET examinations with multiple tracers on the same patient, different scans should be performed sequentially if the half-life of one tracer is short enough (i.e., tracers based on ${ }^{13} \mathrm{~N},{ }^{15} \mathrm{O}$ or ${ }^{82} \mathrm{Rb}$ ) to allow fast clearance of the tracer before the next tracer is administered. Otherwise, scans can be performed in different days. These procedures lead to extended scan time and to increased cost and complexity of patient management. Those limitations can be diminished by performing PET imaging on patients that have been administered with multiple radiotracers. However, multi-tracer PET imaging is still a challenging approach as annihilation photon pairs emitted from either tracer are indistinguishable. Therefore, some extra information is needed to disentangle the signal coming from each tracer.

Two main strategies have been proposed so far in order to enable the possibility of performing PET scans with multiple tracers simultaneously. The first approach uses dynamic imaging with staggered injections. In this case, a multiple-tracer compartment model is used applying constraints on the kinetic behavior in order to separate each tracer contribution from the multitracer PET signal $[97,105,217]$. In a second approach, at least one of the injected tracers must be labeled with a radioisotope that emits a prompt gamma in addition to the positron, which can be detected in coincidence with the annihilation photons [5, 37]. With this additional information, the signal coming from both tracers can be isolated by energy discrimination within the PET scanner. However, a high branching ratio of the prompt gamma is required in these cases, reducing the list of tracer candidates to ${ }^{124} \mathrm{I}$ or those with similar prompt gamma branching ratio.

\subsection{Aim of the chapter}

In this chapter, we propose a new technique for multi-tracer PET imaging that uses dynamic imaging and multi-tracer compartment modelling, including an explicitly derived arterial input function (AIF) for each tracer. In order to end up with a separate AIF for each radiotracer, blood samples were collected during the PET/CT acquisitions and further analyzed by gamma spectroscopy. Once separate AIFs were obtained, multi-tracer compartment modelling was applied to determine the kinetic parameters associated to each tracer. This methodology was implemented and validated in pigs by combination of ${ }^{68} \mathrm{Ga}$-DOTA and ${ }^{18} \mathrm{FDG}$. 


\subsection{Methods}

\subsubsection{Study design and experiment overview}

In the first place, in vitro studies were performed as a proof of concept of our proposed methodology. Samples containing unknown mixtures of two isotopes $\left({ }^{18} \mathrm{~F}\right.$ and $\left.{ }^{68} \mathrm{Ga}\right)$ were analyzed by means of gamma spectroscopy. Several calibration procedures were accomplished in order to obtain the individual contribution of each tracer. For in vivo studies, ${ }^{18} \mathrm{FDG}$ and ${ }^{68} \mathrm{Ga}$-DOTA tracers were administered to healthy pigs and dynamic PET scans were performed. Manual blood samples were collected throughout the PET scan and analyzed by gamma spectroscopy to obtain a separate AIF for each tracer. A multi-tracer compartment model was applied on the dynamic PET imaging using those explicitly separated AIFs. Finally, the model was used to determine the uptake of each tracer at the end of the PET scan on each segment of the myocardium and the results were compared with those obtained ex vivo directly from myocardial tissue. For that purpose, animals were sacrificed, and the heart was excised in segments that were further analyzed to determine the individual uptake of each tracer ex vivo. A schematic drawing of the experimental protocol is shown in Fig. 6.1.

\subsubsection{In vitro tracer separation by gamma spectroscopy}

We analyzed different combinations of two tracers, one based on a pure positron emitter $\left({ }^{18} \mathrm{~F}\right)$ and the other one based on a non-pure positron emitter $\left({ }^{68} \mathrm{Ga}\right)$. While ${ }^{18} \mathrm{~F}$ only emits annihilation photons of $511 \mathrm{keV},{ }^{68} \mathrm{Ga}$ emits additional photons, but only those emitted at $1.077 \mathrm{MeV}$ have a significant contribution (3.22\%). Therefore, a sample containing an unknown combination of both isotopes could be analyzed by means of gamma spectroscopy. To determine the concentration of each tracer in a sample, a methodology was developed using a well counter (Wallac 1470 Perkin Elmer, Waltham, MA, USA) configured to record events during 1 minute at different energy windows simultaneously, one of them covering the entire energy spectrum (200-2000 $\mathrm{keV}$, hereafter named as $\left.W_{200-2000}\right)$ and the other one covering only high energy emissions (900$2000 \mathrm{keV}$, hereafter named as $\left.W_{900-2000}\right)$. Dead time correction and background subtraction were implemented but not decay correction due to the unknown isotope combination. The amount of ${ }^{68} \mathrm{Ga}$ and ${ }^{18} \mathrm{~F}$ contained in the sample was derived using the quotient $\left(Q_{S}\right)$ between events recorded at $W_{200-2000}$ and $W_{900-2000}$ energy windows as explained below. The relationship between $Q_{S}$ and the relative activity of ${ }^{68} \mathrm{Ga}\left(R_{G a}\right)$ and ${ }^{18} \mathrm{~F}\left(R_{F}\right)$ in a sample (i.e., the individual fractional contribution of ${ }^{68} \mathrm{Ga}$ and ${ }^{18} \mathrm{~F}$ to the total activity of the sample) was calibrated using a set of ${ }^{68} \mathrm{Ga} /{ }^{18} \mathrm{~F}$ mixtures. Seven $1 \mathrm{ml}$ samples were prepared containing ${ }^{68} \mathrm{Ga}:{ }^{18} \mathrm{~F}$ activity ratios of 1:0, 9:1, 4:1, 3:2, 2:3, 1:4 and 0:1. These samples were analyzed in the well counter and the $Q_{S}$ values were represented against the known relative activities obtaining a linear relationship (see Fig. 6.2).

Decay correction was applied to recorded values. Since in the subsequent animal studies blood samples may be collected with different sample volumes $\left(V_{S}\right)$, a calibration had to be performed to account for variations in detection efficiency of gamma rays with different energy and different geometrical distribution. For that purpose, $\mathrm{Q}$ values were recorded using pure ${ }^{18} \mathrm{~F}$ 


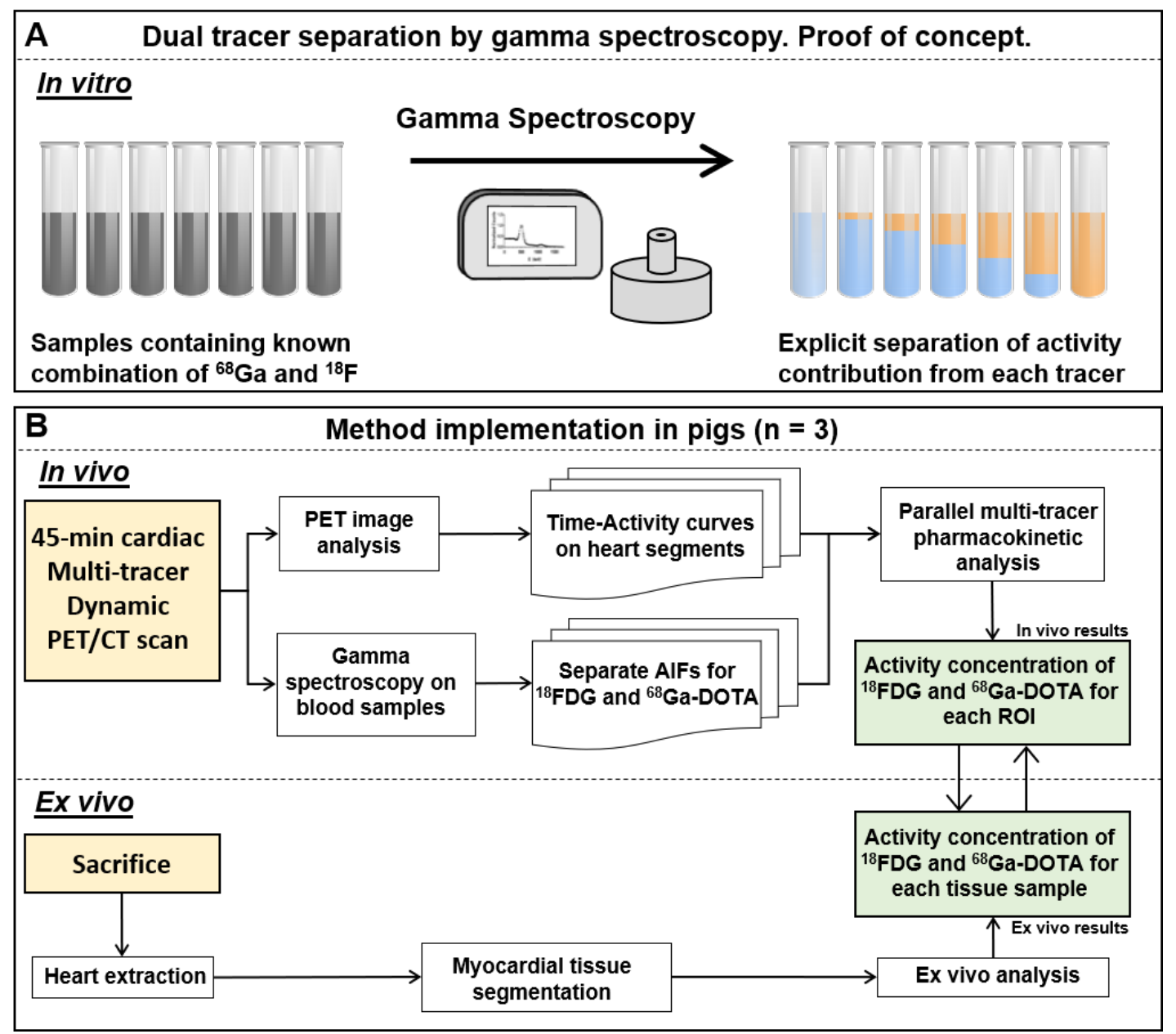

Figure 6.1: Schematic drawing of the study design. A: Firstly, our proposed tracer separation methodology based on gamma spectroscopy was evaluated in vitro as a proof of concept. Samples containing a known combination of two radioisotopes $\left({ }^{18} \mathrm{~F}\right.$ and $\left.{ }^{68} \mathrm{Ga}\right)$ were analyzed and the activity concentrations of each separate radioisotope were obtained. B: Afterwards, this methodology was implemented in vivo. To do so, three pigs underwent 45min cardiac dynamic PET/CT scans in which ${ }^{68}$ Ga-DOTA and ${ }^{18}$ FDG were injected with a 5-min time gap. After PET/CT examination, the animals were sacrificed and their hearts were excised, divided into segments and analyzed to obtain the activity concentration of ${ }^{18}$ FDG and ${ }^{68}$ Ga-DOTA inside each segment. These results were compared against those obtained in vivo by parallel multi-tracer pharmacokinetic analysis on the same regions of interest (ROIs) of their hearts. Explicitly separated AIFs needed for the pharmacokinetic analysis were obtained from the pigs with our proposed method by gamma spectroscopy of a set of blood samples withdrawn during the scan.

$\left(Q_{F}(V)\right)$ and ${ }^{68} \mathrm{Ga}\left(Q_{G a}(V)\right)$ samples $(\sim 20 \mathrm{kBq}$ each) with volumes ranging from 50 to $2000 \mu \mathrm{l}$ (see Fig. 6.3). For known $Q_{F}(V)$ and $Q_{G a}(V)$ within a sufficiently wide volume range, $R_{G a}$ and $R_{F}$ can be obtained for a sample with known volume $\left(V_{S}\right)$ by solving the following equations:

$$
\begin{gathered}
Q_{S}\left(V_{S}\right)=R_{G a} \cdot Q_{G a}\left(V_{S}\right)+R_{F} \cdot Q_{F}\left(V_{S}\right) \\
R_{G a}+R_{F}=1 .
\end{gathered}
$$

Afterwards, the absolute activity concentrations of each tracer (i.e., $A_{F}$ and $A_{G a}$ ) can be obtained 


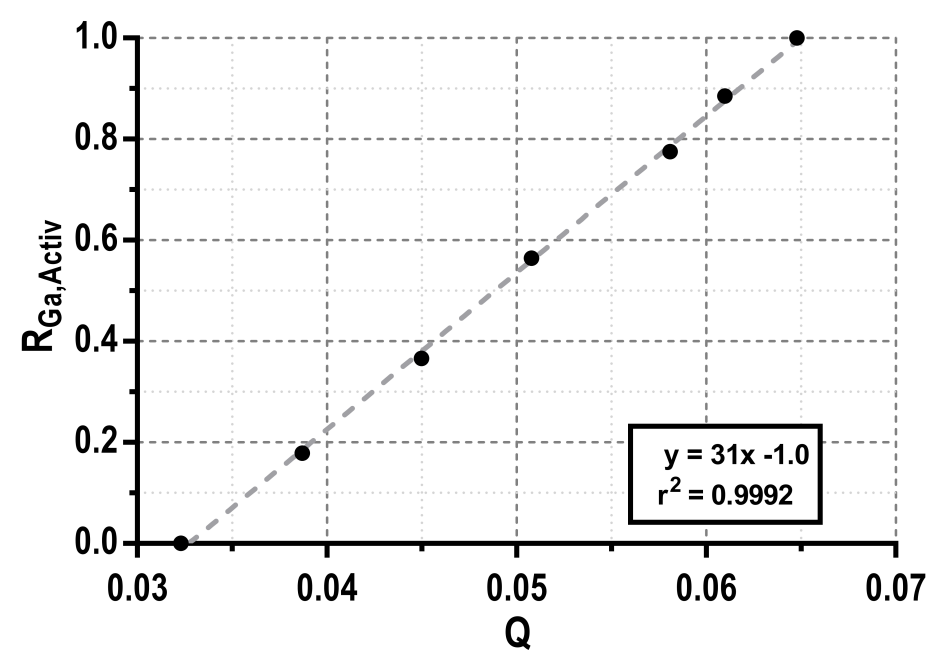

Figure 6.2: Calibration of $Q_{S}$ values from a set of $1 \mathrm{ml}$ samples with mixed ${ }^{68} \mathrm{Ga}$ and ${ }^{18} \mathrm{~F}$ at different activity ratios. The linear fit (dashed line) shows an excellent linear correlation $\left(r^{2}=0.9992\right)$ between both datasets.

for a sample of known volume $V_{S}$ as follows:

$$
A_{G a}\left[\mathrm{kBq} \cdot \mathrm{ml}^{-1}\right]=\frac{A_{t o t} \cdot R_{G a}}{V_{S}},
$$

where $A_{\text {tot }}$ is the total activity of the sample and can be derived from the next equation:

$$
W_{200-2000}=W_{F}+W_{G a}=A_{t o t}\left(\varepsilon_{F} R_{F}+\varepsilon_{G a} R_{G a}\right)
$$

where $W_{F}$ and $W_{G a}$ are the events recorded for each isotope, and $\varepsilon_{F}$ and $\varepsilon_{G a}$ are volumedependent calibration factors obtained from pure ${ }^{18} \mathrm{~F}$ and ${ }^{68} \mathrm{Ga}$ samples respectively (see Fig. 6.4). Finally, before the kinetic model could be individually applied for each tracer, $A_{F}$ and $A_{G a}$ were converted to $\beta^{+}$decays $\cdot \mathrm{s}^{-1} \cdot \mathrm{ml}^{-1}$ multiplying by their respective branching ratios in order to match the units obtained from the PET images.

Following this procedure, explicitly separated AIFs can be obtained from a multi-tracer PET scan by analyzing a set of blood samples withdrawn from the subject throughout the study and obtaining $A_{F}$ and $A_{G a}$ for each timepoint. The feasibility of this methodology was investigated in animal studies as described below.

\subsubsection{Animal protocol}

This in vivo study was also conducted according to the guidelines of the current European Directive and Spanish legislation and approved by the regional ethical committee for animal experimentation. Three healthy female Large White pigs (mean weight $=45 \pm 4 \mathrm{~kg}$ ) were anesthetized by intramuscular injection of ketamine $(20 \mathrm{mg} / \mathrm{kg})$, xylazine $(2 \mathrm{mg} / \mathrm{kg})$, and midazolam $(0.5 \mathrm{mg} / \mathrm{kg})$, and maintained by continuous intravenous infusion of ketamine $\left(2 \mathrm{mg} \cdot \mathrm{kg}^{-1} \cdot \mathrm{h}^{-1}\right)$, xylazine $\left(0.2 \mathrm{mg} \cdot \mathrm{kg}^{-1} \cdot \mathrm{h}^{-1}\right)$, and midazolam $\left(0.2 \mathrm{mg} \cdot \mathrm{kg}^{-1} \cdot \mathrm{h}^{-1}\right)$. Oxygen saturation levels via pulse oximetry, and ECG signal were monitored throughout the study. Coccygeal artery of the animal 


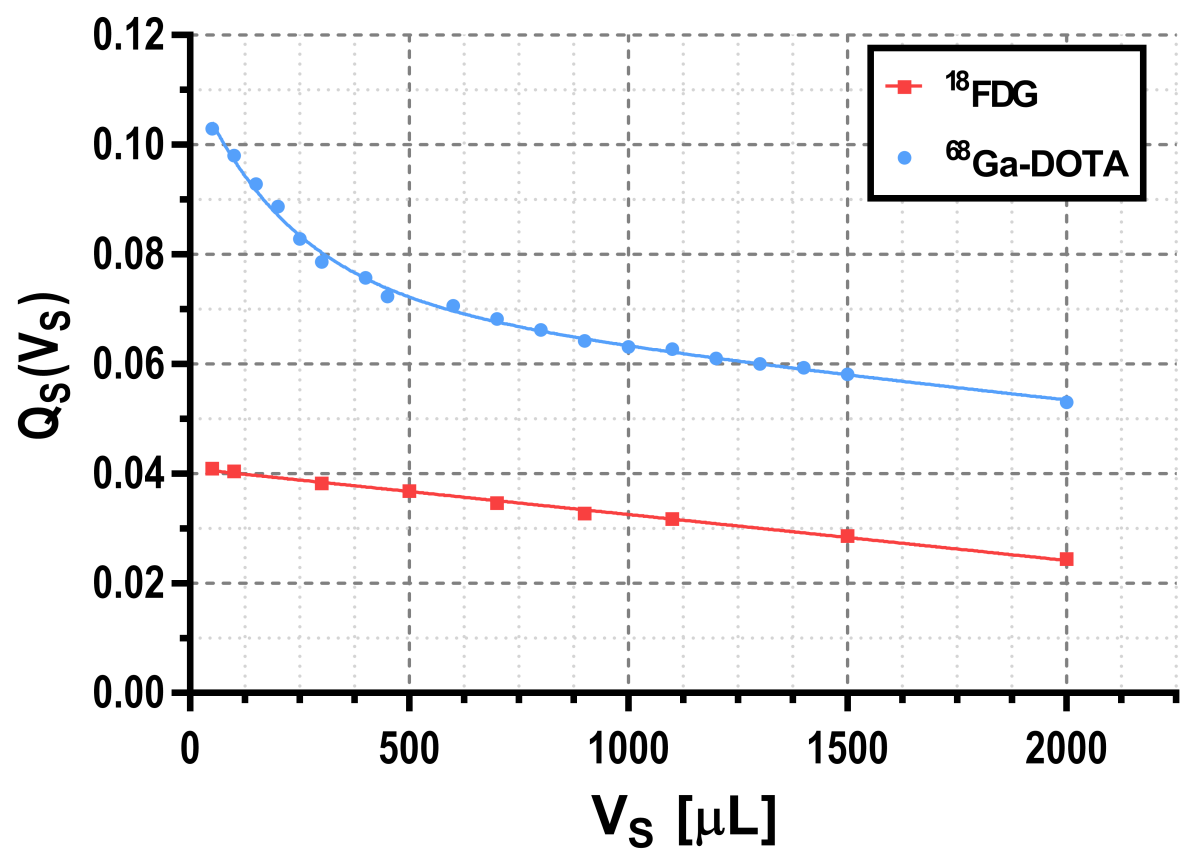

Figure 6.3: Variation of $Q_{S}$ values measured with the well counter for pure ${ }^{18} \mathrm{~F}$ (red squares) and ${ }^{68}$ Ga (blue circles) with different sample volumes $\left(V_{S}\right)$. Results were fitted to a straight line and a sum of two exponential functions respectively in order to obtain the $Q_{S}$ values for different volumes.

was cannulated and connected to a peristaltic pump placed as close as possible to minimize blood dispersion inside the tubing.

\subsubsection{PET/CT image acquisition}

PET/CT images were acquired using a Gemini TF-64 scanner (Philips Healthcare, Best, The Netherlands). Each imaging study consisted of a low dose CT scan $(120 \mathrm{kV}, 80 \mathrm{~mA})$ followed by a dynamic 45-min list mode PET acquisition in a single bed position covering the entire heart. ${ }^{18} \mathrm{FDG}(155 \pm 12 \mathrm{MBq})$ and ${ }^{68} \mathrm{Ga}-\mathrm{DOTA}(142 \pm 33 \mathrm{MBq})$ were injected 1 and 6 minutes after PET scan was started respectively. Both radiotracers were prepared in $6 \mathrm{ml}$ and infused at a rate of $1.0 \mathrm{ml} / \mathrm{s}$ through a marginal ear vein, followed by a $6 \mathrm{ml}$ saline flush at the same rate. Arterial blood was withdrawn during the PET scan through a 1.6-mm internal diameter peristaltic pump tubing (TYGON-XL6, Saint-Gobain, Courbevoie, France) at $5 \mathrm{ml} / \mathrm{min}$ for the first 7 minutes, and then at $2 \mathrm{ml} / \mathrm{min}$ for the rest of the scan. Blood collection from the coccygeal artery started immediately after the first radiotracer injection and continued during the whole study. During the first 12 minutes, blood was collected into sample tubes according to the following scheme: 20 $\times 5 \mathrm{~s}, 8 \times 10 \mathrm{~s}, 6 \times 20 \mathrm{~s}, 24 \times 5 \mathrm{~s}, 6 \times 10 \mathrm{~s}, 6 \times 20 \mathrm{~s}, 4 \times 30 \mathrm{~s}$. After that, 11 more samples were collected for 1 minute with 2 min gaps among samples. PET images were reconstructed with a voxel size of $4 \times 4 \times 4 \mathrm{~mm}^{3}$ using a 3D-RAMLA reconstruction algorithm in 85 consecutive frames $(1 \times 60 \mathrm{~s}, 25 \times 5 \mathrm{~s}, 8 \times 10 \mathrm{~s}, 4 \times 20 \mathrm{~s}, 24 \times 5 \mathrm{~s}, 3 \times 10 \mathrm{~s}, 5 \times 20 \mathrm{~s}, 5 \times 60 \mathrm{~s}, 4 \times 120$ $\mathrm{s}, 4 \times 180 \mathrm{~s}$ and $1 \times 300 \mathrm{~s}$ ). Corrections for dead time, scatter and random coincidences were applied as implemented on the scanner. Decay and branching ratio corrections were not applied 
A

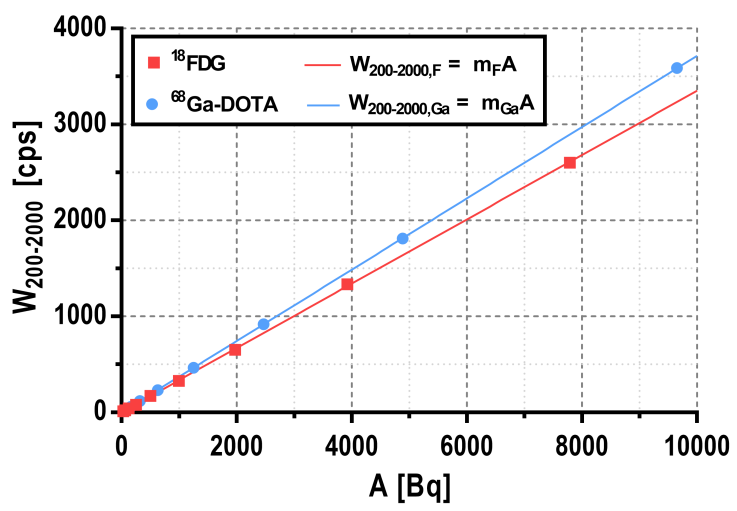

B

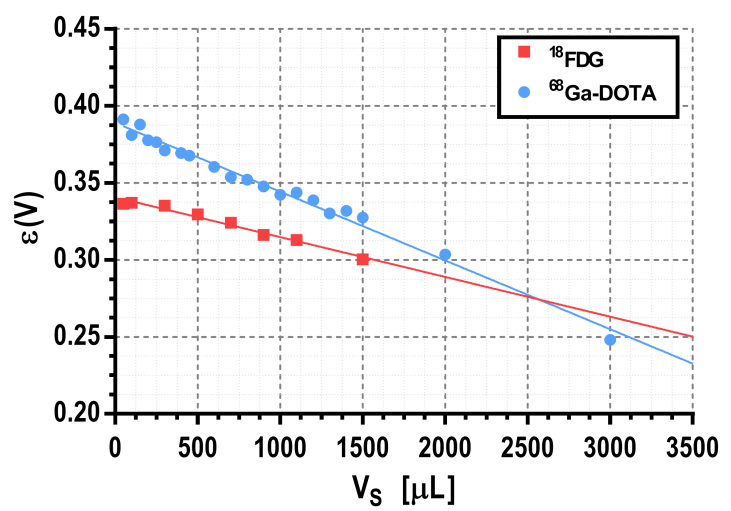

Figure 6.4: A: Calibration profiles obtained in the well counter for $300-\mu l$ pure ${ }^{18} \mathrm{~F}$ (red squares) and ${ }^{68}$ Ga (blue circles) samples with different activity values using the full energy window ( $\left.W_{200-2000}\right)$. Each dataset was fitted to a straight line with $y$-intercept forced to be 0 obtaining the calibration factors $\varepsilon_{F}=0.335 \mathrm{cps} / B q$ and $\varepsilon_{G a}=0.371$ cps/Bq at this volume. B: Variation of calibration factors with the sample volume for ${ }^{18} F\left(\varepsilon_{F}\right)$ and ${ }^{68} G a\left(\varepsilon_{G a}\right)$.

as the amount of ${ }^{68} \mathrm{Ga}$ and ${ }^{18} \mathrm{~F}$ on each voxel was unknown and their values differ $\left(t_{1 / 2}\left({ }^{68} \mathrm{Ga}\right)=\right.$ $67.77 \mathrm{~min}$ and $t_{1 / 2}\left({ }^{18} \mathrm{~F}\right)=109.77 \mathrm{~min}, B r_{G a}=0.891$ and $\left.\mathrm{Br}_{F}=0.967\right)$. Therefore, reconstructed images were expressed as $\beta^{+}$decays $\cdot \mathrm{s}^{-1} \cdot \mathrm{ml}^{-1}$.

\subsubsection{Separate AIF derivation from blood sample gamma spectroscopy}

After each PET/CT examination, the vials containing the collected blood samples were centrifuged briefly to provide a reproducible geometrical distribution of the blood before performing the measurements in the well counter. The volume for each blood sample was determined as the weight difference between empty and filled vial and considering a blood density of $1.03 \mathrm{~g} / \mathrm{ml}$ [180]. Then, the individual activity concentration of ${ }^{18} \mathrm{FDG}$ and ${ }^{68} \mathrm{Ga-DOTA}\left(A_{F}\right.$ and $\left.A_{G a}\right)$ for each blood sample was calculated using Eqs. (6.1)-(6.4). Consequently, the AIFs obtained from blood samples for each tracer $\left(A I F_{B S, F}\right.$ and $\left.A I F_{B S, G a}\right)$ were derived as time series of this values.

Delay and dispersion corrections were applied to $A I F_{B S, F}$ and $A I F_{B S, G a}$ using the imagederived $\operatorname{AIF}\left(A I F_{I D}\right)$ as this one lacks from delay and dispersion. $A I F_{I D}$ was obtained from an 8-mm diameter cylindrical volume of interest (VOI) drawn in the descending thoracic aorta over 5 consecutive slices of the dynamic PET images. Spill-out from the AIF was corrected normalizing to the activity measured inside a $10 \mathrm{~mm}$-diameter spherical VOI placed inside the left ventricle averaged over the latest frames. Delay was corrected by maximizing the cross-correlation between $A I F_{B S}$ (sum of $A I F_{B S, F}$ and $A I F_{B S, G a}$ ) and $A I F_{I D}$. In order to obtain dispersion-free AIFs, we assumed that at the moment of second tracer injection (at time $t_{2}$ ), the blood concentration of the first tracer was changing slowly and therefore did not suffer from dispersion. Thus, dispersion before $t_{2}$ was corrected by using the $A I F_{I D}$ as there was only contribution from the first tracer. After $t_{2}$, we assumed that $A I F_{I D, F}$ and $A I F_{B S, F}$ were equal and dispersion-free AIF for the second tracer could be obtained by direct subtraction of $A I F_{I D}$ and $A I F_{B S, F}$. Thus, dispersion-free $A I F_{F}$ and $A I F_{G a}$ used for pharmacokinetic analysis was derived as follows: 


$$
A I F_{G a}=\left\{\begin{array}{ll}
0 & , t<t_{2} \\
A I F_{I D}-A I F_{B S, F} & , t \geq t_{2}
\end{array} \quad A I F_{F}=\left\{\begin{array}{ll}
A I F_{I D} & , t<t_{2} \\
A I F_{B S, F} & , t \geq t_{2}
\end{array},\right.\right.
$$

\subsubsection{Kinetic modelling and image analysis}

Parallel multi-tracer compartment modelling [97, 105, 108, 114], was applied to the recorded PET data where each tracer's kinetic behavior was introduced according to its pharmacokinetic model and to its individual AIF. ${ }^{68} \mathrm{Ga}$-DOTA diffuses bidirectionally between the intravascular and the interstitial space suggesting the use of a single-tissue compartment model $(1 \mathrm{TCM})[11,215]$ (see Fig. 6.5A). On the other hand, ${ }^{18} \mathrm{FDG}$ is explained with an irreversible two-tissue compartment kinetic model (2TCM). (Fig. 6.5B). Therefore, the total tracer concentration measured in the tissue $\left(C_{t i s}(t)\right)$ could be expressed as the sum contribution from both tracers:

$$
C_{t i s}(t)=\sum_{i=G a, F} C_{t i s, i}(t)+\operatorname{PVE}(t)=\sum_{i=G a, F} \operatorname{IRF}_{i}\left(\left\{k_{j, i}\right\}, t\right) \otimes C_{p, i}(t)+\operatorname{PVE}(t),
$$

where $I R F_{i}\left(\left\{k_{j, i}\right\}, t\right)$ is the impulse response function for tracer $i,\left\{k_{j, i}\right\}$ are the kinetic parameters, $C_{p, i}(\mathrm{t})$ is the activity concentration in plasma for tracer $i$ and $P V E(t)$ denotes the spill-over of radioactivity coming from LV and RV into myocardium. These IRFs can be described by the pharmacokinetic model that follows each tracer:

$$
\begin{aligned}
\operatorname{IRF}_{G a}\left(K_{1, G a}, k_{2, G a}, t\right) & =K_{1, G a} \cdot \mathrm{e}^{-k_{2, G a} t} \\
\operatorname{IRF}_{F}\left(K_{1, F}, k_{2, F}, k_{3, F}, t\right) & =K_{1, F}\left(\frac{k_{2, F}}{k_{2, F}+k_{3, F}} \mathrm{e}^{-\left(k_{2, F}+k_{3, F}\right) t}+\frac{k_{3, F}}{k_{2, F}+k_{3, F}}\right) .
\end{aligned}
$$

In order to obtain the free ${ }^{68} \mathrm{Ga}$-DOTA concentration in plasma $C_{p, G a}(t)$, hematocrit $(H)$ and free metabolite fraction (F) must be used. These values have been previously determined [215]. On the other hand, ${ }^{18} \mathrm{FDG}$ concentration in plasma for myocardial tissue has already been described [162]. Therefore, the relation between $A I F(t)$ and $C_{p}(t)$ for both tracers can be then described as:

$$
\begin{gathered}
C_{p, G a}(t)=\frac{F}{1-H} \cdot A I F_{G a}(t) \\
C_{p, F}(t)=(0.8+0.0012 t) \cdot A I F_{F}(t)
\end{gathered}
$$

PVE contribution was not split for each tracer as it can be considered a function of the total blood activity concentration. It can be further decomposed in different components as:

$$
\operatorname{PVE}(t)=V_{A P} \cdot C_{A P}(t)+V_{L V} \cdot C_{L V}(t)+V_{R V} \cdot C_{R V}(t)
$$

where $V_{L V}, V_{R V}$ and $V_{A P}$ represent the spill-over fraction for the central LV, RV, and apical LV respectively [159] and $C_{L V}(t), C_{R V}(t)$ and $C_{A P}(t)$ represent the corresponding time activity curves in those regions. The apical term was added to account for temporal differences observed between the central LV and the apical LV in swine hearts. The obtained kinetic parameters were 
not affected by the fact that decay correction was not applied to AIFs and $C_{t i s}(t)$ functions since both are affected in the same way.

The model was applied on TACs obtained from PET images. For that purpose, myocardium was segmented using available software [158] following the standard AHA 17-segment model [34], obtaining one TAC $\left(C_{t i s}(t)\right.$ in Eq. (6.6)) per segment. $C_{L V}(t)$ and $C_{A P}(t)$ were obtained from spherical VOIs drawn at the central (15 mm diameter) and apical (12 $\mathrm{mm}$ diameter) regions of the LV respectively, while VOI for determination of $C_{R V}(t)$ was manually drawn inside RV over 3-5 slices leaving a margin $(>5 \mathrm{~mm}$ ) from the myocardium. The 5 -parameter model described on Eqs. (6.6)-(6.11) was used to fit the data from each myocardial segment with a constrained Levenberg-Marquardt algorithm.

A Pharmacokinetic model for ${ }^{68} \mathrm{Ga}$-DOTA

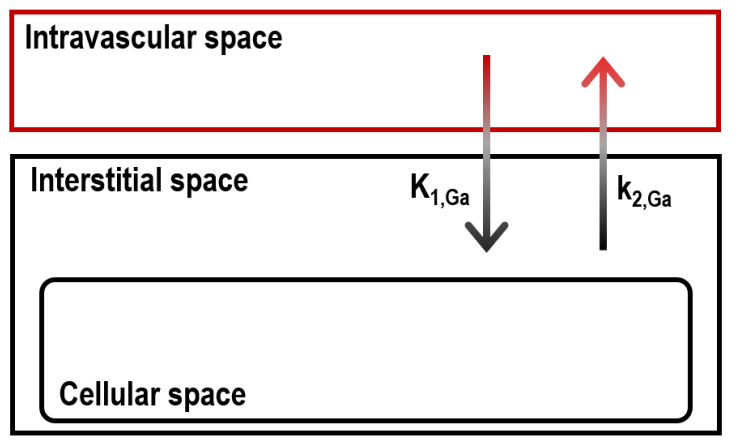

B Pharmacokinetic model for ${ }^{18} \mathrm{FDG}$

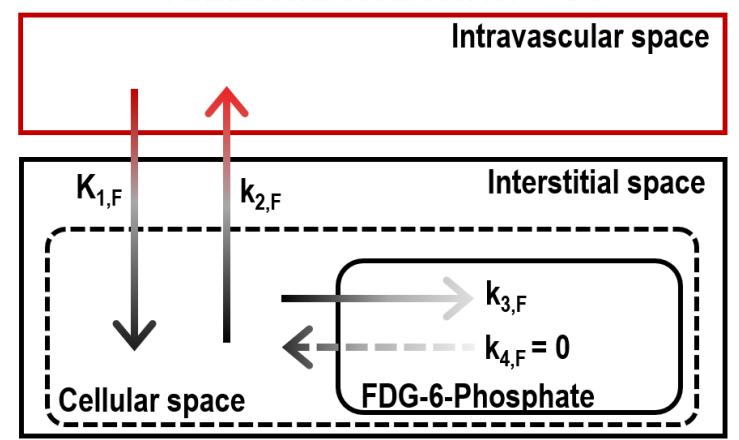

Figure 6.5: Kinetic compartment models followed by ${ }^{68} \mathrm{Ga-DOTA}(\boldsymbol{A})$ and ${ }^{18} \mathrm{FDG}(\boldsymbol{B})$ in myocardial tissue. The model for ${ }^{68} \mathrm{Ga}$-DOTA is a single tissue compartment model as the radiotracer diffuses bidirectionally between intravascular space and extravascular extracellular space (interstitial space). The model for ${ }^{18}$ FDG is an irreversible two-tissue compartment model as the radiotracer diffuses bidirectionally between intravascular and cellular space and, once it enters the myocyte, it is phosphorylated to ${ }^{18}$ FDG-6-Phosphate and remains trapped since it cannot be further metabolized.

\subsubsection{In vivo versus ex vivo myocardial tissue analysis}

The concentration of both tracers at the end of the PET scan $\left(C_{t i s, F}\left(t_{\text {end }}\right)\right.$ and $\left.C_{t i s, G a}\left(t_{\text {end }}\right)\right)$ were computed for each myocardial segment using Eq. (6.6). In addition, the corresponding relative activities $\left(R_{F, P E T}\right.$ and $\left.R_{G a, P E T}\right)$ as well as standardized uptake values $\left(S U V_{F, P E T}\right.$ and $\left.S U V_{G a, P E T}\right)$ were also derived in the same regions at the last timeframe of the scans. In order to validate these results, analogous measurements were obtained from myocardial tissue samples at the same regions of the same animals that had undergone the PET examinations.

For that purpose, each animal was sacrificed at the end of the PET scans and the heart was excised and divided into 17 segments also following AHA guidelines [34]. Each segment was further divided into three smaller portions to obtain triplicate measurements. These 51 samples were weighted and measured in the well counter. In order to increase the accuracy of myocardial samples analysis, the measurements in the well counter were performed several times for each sample for 15 hours using the full energy window $\left(W_{200-2000}\right)$. Measurements were corrected for dead time and background. The counts recorded as a function of time were fitted to a sum of 
two exponential functions in order to recover the contribution from each tracer:

$$
W_{200-2000}(t)=W_{F}(t)+W_{G a}(t)=W_{F}\left(t_{0}\right) \mathrm{e}^{-\lambda_{F} t}+W_{G a}\left(t_{0}\right) \mathrm{e}^{-\lambda_{G a} t},
$$

where $\lambda_{F}$ and $\lambda_{G a}$ are the radioactive decay constants for ${ }^{18} \mathrm{~F}$ and ${ }^{68} \mathrm{Ga}$ respectively and $W_{F}$ and $W_{G a}$ are the counts measured in the well counter from each isotope. $W_{F}\left(t_{0}\right)$ and $W_{G a}\left(t_{0}\right)$ were fitted using Eq. (6.12) and converted to activity using the corresponding calibration factors (see Fig. 6.4). Activity values were decay corrected at sacrifice time and the ex vivo relative activities for ${ }^{18} \mathrm{FDG}\left(R_{F, \text { ex vivo }}\right)$ and ${ }^{68} \mathrm{Ga-DOTA}\left(R_{\text {Ga,ex vivo }}\right)$ were obtained. Results obtained on each myocardial segment were averaged over triplicate samples. SUV values were also derived and extrapolated to the final timeframe of the scan for each tracer $\left(S U V_{F, \text { ex vivo }}\right.$ and $\left.S U V_{\text {Ga,ex vivo }}\right)$.

The ${ }^{18} \mathrm{FDG}$ relative activities derived from tissue samples $\left(R_{F, \text { ex vivo }}\right)$ and from multi-tracer PET imaging $\left(R_{F, P E T}\right)$ were compared using Pearson's correlation and the root mean square error (RMSE), which is defined as follows:

$$
\operatorname{RMSE}(\%)=\sqrt{\frac{1}{N} \sum_{s=1}^{N}\left(R_{F, \text { ex vivo }}^{s}-R_{F, P E T}^{s}\right)^{2}},
$$

where $s$ is the myocardial segment and $N$ is the number of myocardial segments analyzed $(N=$ 17). In addition, SUV values derived from multi-tracer PET imaging were compared to values obtained from excised myocardial segments. For any statistical analysis, data are expressed as mean \pm SD unless otherwise stated.

\subsection{Results}

\subsubsection{Tracer separation by gamma spectroscopy}

The results on the calibration procedure performed to separate the contribution of ${ }^{18} \mathrm{~F}$ - and

${ }^{68}$ Ga-based tracers from blood samples containing a mixture of both tracers is presented here. Fig. 6.2 shows a linear behavior $\left(r^{2}>0.999\right)$ between the relative activity for ${ }^{68} \mathrm{Ga}\left(R_{G a}\right)$ of different ${ }^{68} \mathrm{Ga}^{18}{ }^{18} \mathrm{~F}$ mixture samples and the $Q$ value measured in the well counter. Fig. 6.3 shows these $Q_{S}$ values for pure ${ }^{18} \mathrm{~F}$ and ${ }^{68} \mathrm{Ga}$ samples with volumes ranging from 50 to $2000 \mu \mathrm{l}$. Of note, the well counter detection efficiency for the high energy gamma photon emitted by ${ }^{68} \mathrm{Ga}$ is relatively higher at low sample volumes probably due to geometrical considerations. When the sample volume is small, high energy events represent about $4 \%$ of the total counts for ${ }^{18} \mathrm{~F}$ samples while it raises up to $10 \%$ for ${ }^{68} \mathrm{Ga}$ samples. These $Q_{S}\left(V_{S}\right)$ profiles were fitted to a straight line and a sum of two exponential functions respectively in order to interpolate to any given sample volume. Fig. 6.4A shows the calibrations performed to translate the measurements obtained in the well counter using the full energy window to activity (data shown for ${ }^{18} \mathrm{~F}$ and $68 \mathrm{Ga}$ ). Data presented in Fig. 6.4A were obtained from $300 \mu \mathrm{l}$ samples. However, the calibration factors are also volume dependent. Therefore, the calibration was repeated for different sample volumes to account for this effect (see Fig. 6.4B). 


\subsubsection{In vivo validation of multi-tracer PET against tissue analysis}

Fig. 6.6A shows an illustrative $A I F_{B S, F}$ and $A I F_{B S, G a}$ obtained from collected blood samples that were analyzed using the gamma spectroscopy methodology previously described. The corresponding $A I F_{I D}$ is shown in Fig. $6.6 \mathrm{~B}$ as well as the dispersion-free AIFs for each tracer $\left(A I F_{F}\right.$ and $A I F_{G a}$ ) that were obtained using the methodology explained in its corresponding methods section.
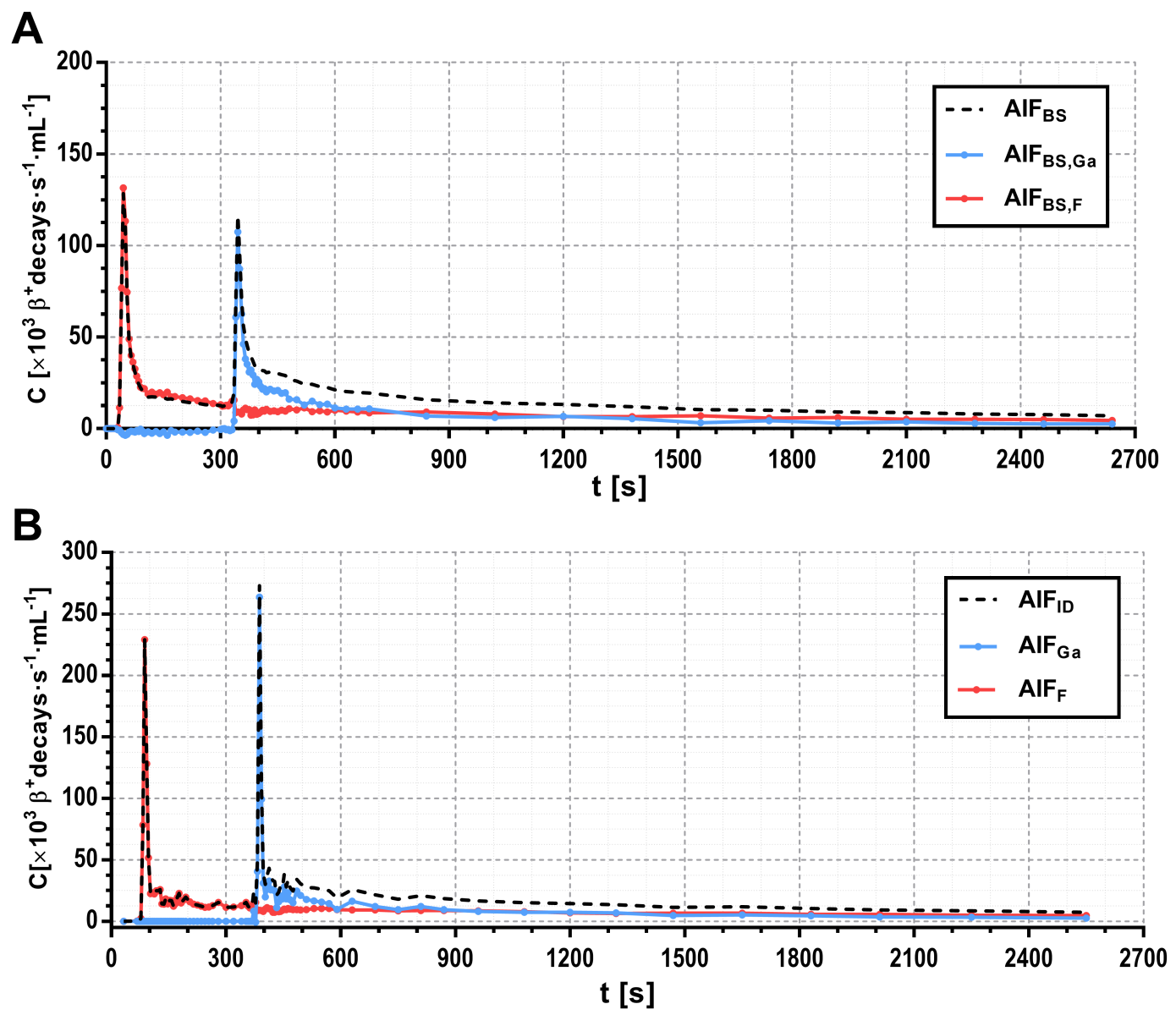

Figure 6.6: $A: A I F_{B S, F}$ (red) and $A I F_{B S, G a}$ (blue) obtained from manual blood sampling during PET scan applying the gamma spectroscopic method. Black dashed line shows the sum of both tracers. B: AIF ID (black dashed line) obtained from the dynamic PET images using an ROI drawn in the descending thoracic aorta and delay corrected and dispersion-free contributions from ${ }^{18} \mathrm{FDG}$ (red) and ${ }^{68}$ Ga-DOTA (blue) obtained as detailed in Eq. (6.5).

Fig. 6.7 illustrates myocardial tissue TACs $\left(C_{t i s}(t)\right)$ obtained from dynamic PET data for each of the animals included in this study. These TACs were fitted using the multi-tracer compartment model shown in Eq. (6.6). The separate contribution obtained for ${ }^{18} \mathrm{FDG}$ and ${ }^{68} \mathrm{Ga}$-DOTA are presented in Fig. 6.6 along with the total tissue signal including the spill-over.

Fig. 6.8A shows the comparison of the relative activity for ${ }^{18} \mathrm{FDG}$ obtained from multitracer compartment modelling at the end of the PET scans $\left(R_{F, P E T}\right)$ and from excised tissue $\left(R_{F, \text { ex vivo }}\right)$ for each animal and myocardial segment. A very good correlation was obtained 


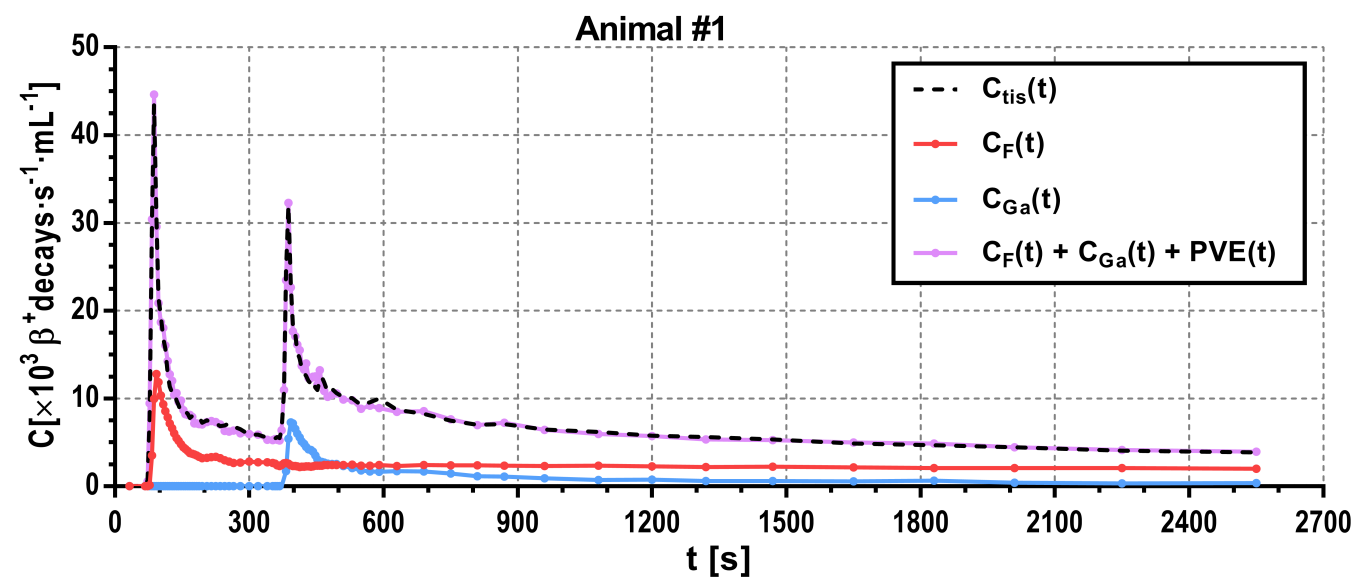

Animal \#2

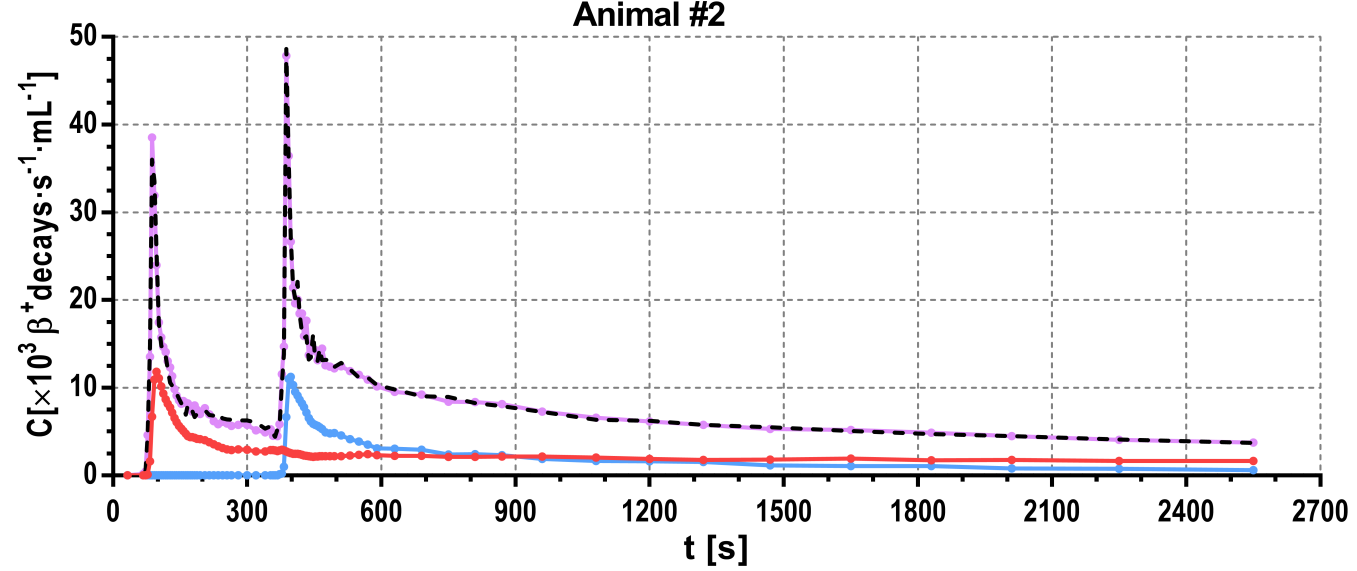

Animal \#3

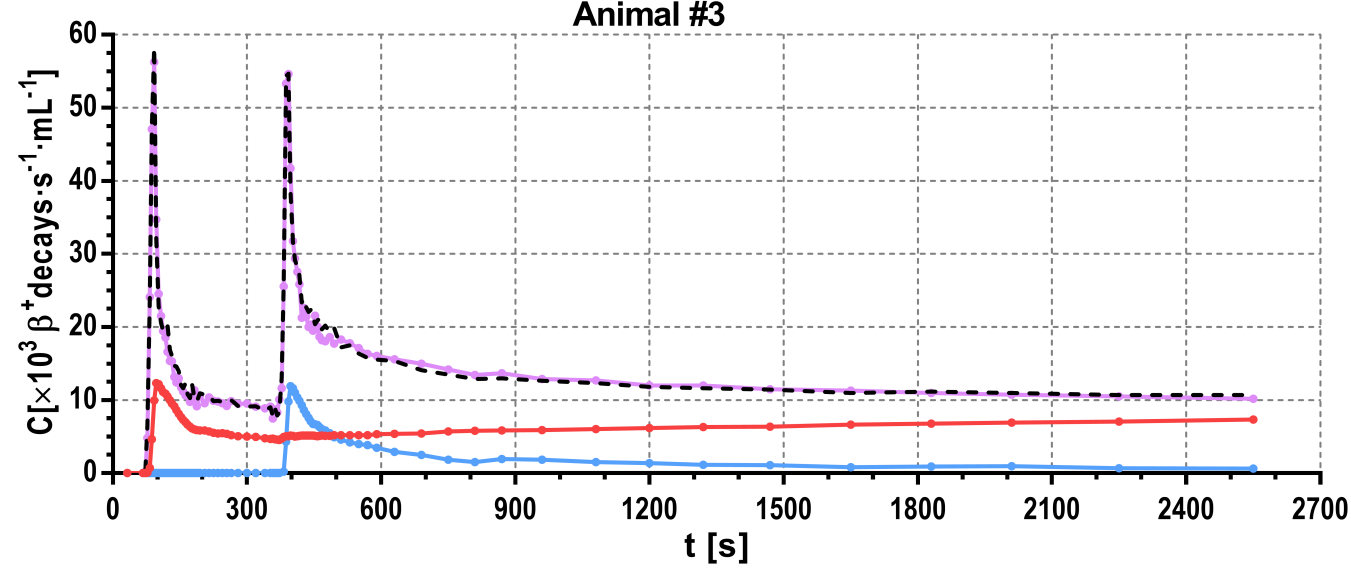

Figure 6.7: Myocardial tissue TACs obtained from dynamic PET images for each animal included in this study (black dashed lines). Data was fitted to the multi-tracer compartment model shown in Eq. (6.6) (purple line) and separated into tissue TACs for ${ }^{18}$ FDG (red) and ${ }^{68}$ Ga-DOTA (blue).

(Pearson's $r=0.95, p<0.0001)$. Mean \pm SD $R_{F, P E T}\left(R_{F, \text { ex vivo }}\right)$ obtained were $0.84 \pm 0.03$ $(0.83 \pm 0.02), 0.70 \pm 0.03(0.64 \pm 0.02)$ and $0.91 \pm 0.02(0.91 \pm 0.01)$ for animals $\# 1, \# 2$ and $\# 3$ respectively. These averaged results, as well as RMSE and individualized SUVs for ${ }^{18} \mathrm{FDG}$ and ${ }^{68} \mathrm{Ga}$-DOTA contributions are presented in Table 6.1. SUV values obtained for ${ }^{68} \mathrm{Ga}$-DOTA were similar in all animals. $S U V_{G a}$ is low $(\sim 0.3)$ because this tracer reaches equilibrium between 
the plasma and the interstitial space and therefore, the tracer does not accumulate in tissue. On the other hand, low $S U V_{F, P E T}$ were obtained for animals \#1 (0.97) and \#2 (0.62) while higher values were obtained in the third animal (2.54). These SUV values are highly correlated (Pearson's $r=0.98, p<0.0001)$ with those obtained from excised tissue $\left(S U V_{F, \text { ex vivo }}\right.$ and $\left.S U V_{G \text { a,ex vivo }}\right)$. The higher $S U V_{F}$ of the third animal agrees with lower RMSE values obtained for this animal since higher uptake lead to lower statistical noise in the pharmacokinetic analysis, as well as in the measurements performed on excised tissue. In all cases obtained RMSE values were below $7 \%$.

A

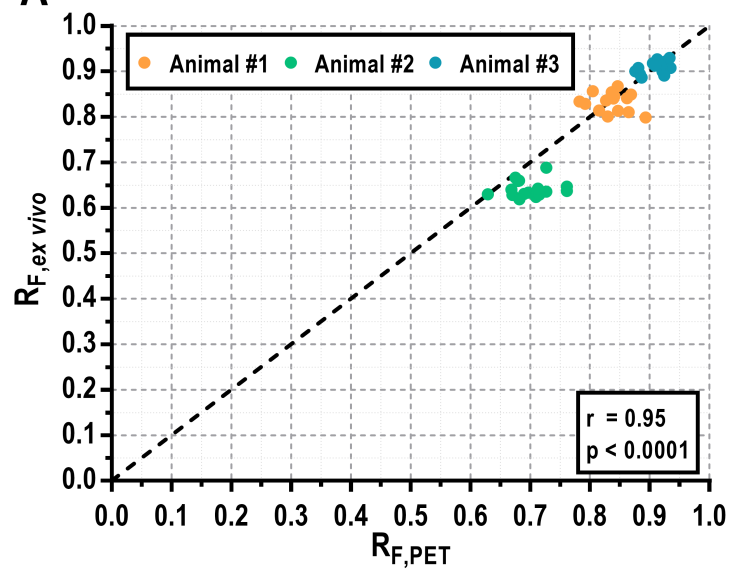

B

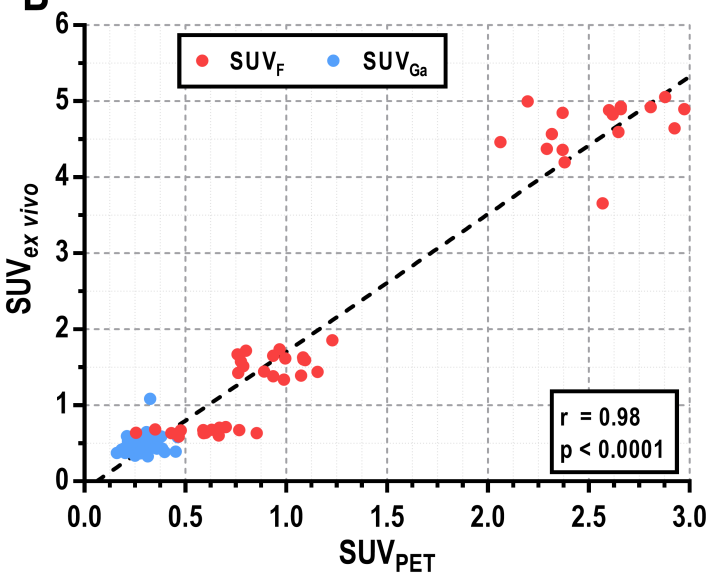

Figure 6.8: Linear correlation between relative activities for ${ }^{18} F D G(\boldsymbol{A})$ and between $S U V s$ for both ${ }^{18} F D G$ and ${ }^{68} \mathrm{Ga}$-DOTA (B) obtained from multi-tracer compartment modelling at the last frame of the PET scan $\left(R_{F, P E T}\right.$, $\left.S U V_{P E T}\right)$ and from excised tissue $\left(R_{F, \text { ex vivo }}, S U V_{\text {ex vivo }}\right)$. Each dot represents one of the 17 myocardial segments for each animal. The results are highly correlated $(r=0.95, p<0.0001$ for relative activities and $r=0.98$, $p<0.0001$ for SUVs).

Table 6.1: Relative activities and SUVs obtanied with PET and ex vivo tissue analysis.

\begin{tabular}{cccccccc}
\hline Animal & $R_{F, P E T}{ }^{\mathrm{a}}$ & $R_{F, \text { exvivo }}$ & RMSE(\%) & SUV $_{\text {Ga,PET }}{ }^{\mathrm{c}}$ & SUV $_{\text {Ga,ex vivo }}$ & $S U V_{F, P E T}$ & SUV $_{F, \text { ex vivo }}$ \\
\hline$\# 1$ & $0.84 \pm 0.03$ & $0.83 \pm 0.02$ & 3.6 & $0.30 \pm 0.07$ & $0.51 \pm 0.09$ & $0.96 \pm 0.15$ & $1.56 \pm 0.14$ \\
$\# 2$ & $0.70 \pm 0.03$ & $0.64 \pm 0.02$ & 6.8 & $0.27 \pm 0.08$ & $0.39 \pm 0.03$ & $0.60 \pm 0.16$ & $0.65 \pm 0.03$ \\
$\# 3$ & $0.91 \pm 0.02$ & $0.91 \pm 0.01$ & 1.7 & $0.28 \pm 0.05$ & $0.54 \pm 0.06$ & $2.55 \pm 0.26$ & $4.65 \pm 0.36$ \\
\hline
\end{tabular}

$R_{F, P E T}$ and $R_{F, \text { exvivo }}$ values are represented as the mean $\pm \mathrm{SD}$ of all the myocardial segments analyzed for each animal along with their comparison obtained using the RMSE value. Mean \pm SD SUV for each tracer obtained from multi-tracer PET analysis and excised tissue are also shown.

${ }^{\text {a }} R_{F}:{ }^{18} \mathrm{FDG}$ relative activity.

${ }^{\mathrm{b}} \mathrm{RMSE}(\%)$ : Root-mean square error expressed as a percentage.

c $S U V$ : Standardized uptake value. 


\subsection{Discussion}

The methodology described above allows explicit measurement of a separate AIF for each tracer while other existing methods rely on AIFs based on representative patients [106] or using extrapolation techniques [183]. Our technique requires using at least one tracer based on a non-pure positron emitter. The analysis is based on the different energy spectra of the emission of the two radiotracers involved. A spectroscopic analysis of blood samples containing both tracers can be performed in order to obtain the concentration of each individual tracer. This technique is able to resolve the individual contribution of the two radiotracers when the energy of the additional gamma rays emitted by the non-pure positron emitter differs from the energy of annihilation photons. This fact, however, rules out the possibility of combining tracers based on the same isotope, or both tracers based on pure positron emitters such as ${ }^{18} \mathrm{~F}$ or ${ }^{15} \mathrm{O}$. On the other hand, ${ }^{68} \mathrm{Ga}$, with its high-energy emission at $1.077 \mathrm{MeV}$, can become a suitable wildcard isotope for this technique. ${ }^{68} \mathrm{Ga}$ has emerged as a very promising isotope for PET imaging with many relevant applications in clinical diagnosis [196]. Therefore, further combinations of tracers based on ${ }^{18} \mathrm{~F}$ and ${ }^{68} \mathrm{Ga}$, different from that shown in this study, might benefit from this work, and this is the reason why the combination ${ }^{18} \mathrm{FDG}^{68} \mathrm{Ga-DOTA}$ was chosen for this work.

In this chapter, we developed a calibration procedure that allows the determination of individual tracer concentration of samples containing an unknown mixture of the isotopes used in this study $\left({ }^{18} \mathrm{~F}\right.$ and $\left.{ }^{68} \mathrm{Ga}\right)$. For that purpose, samples were analyzed in a well counter recording events at two energy windows. The ratio between the counts recorded in both energy windows was later employed to determine the relative activity of each isotope. Corrections were made to account for different sample volumes (see Fig. 6.3). A 45 min dynamic PET scan was performed on each animal and blood samples were collected during the entire acquisition and further analyzed with the well counter to determine the AIF for each tracer. A multi-tracer compartment model was later applied to recover the individual tissue TAC for each tracer on individual myocardial segments (see Fig. 6.7). Radiotracer concentrations at the last timeframe of their PET scan were validated against both ${ }^{18} \mathrm{FDG}$ and ${ }^{68} \mathrm{Ga}$-DOTA concentration measured with the well counter on excised myocardial tissue. Results show that the proposed multi-tracer PET imaging technique offers very similar results to those obtained as a reference from ex vivo analysis (see Fig. 6.8), with RMSE below $7 \%$ in all cases. Moreover, $S U V$ for ${ }^{68} \mathrm{Ga}$-DOTA and ${ }^{18} \mathrm{FDG}$ were obtained showing normal ${ }^{68} \mathrm{Ga}$-DOTA uptake for healthy pigs [215] and variable ${ }^{18} \mathrm{FDG}$ uptake as expected, since no prior glucose load was used [127]. An overestimation of $S U V_{\text {ex vivo }}$ values compared to $S U V_{P E T}$ values can be observed, which might be explained by partial volume effect in PET data.

There are other techniques that use non-pure positron emitters with prompt gamma emissions and utilize the PET scanner to record coincidence events containing annihilation and prompt-gamma photons. These prompt-gamma photons are later used in the reconstruction process to separate the contribution from each tracer [5]. However, a very large branching ratio of the prompt gamma photons is required to obtain enough sensitivity of this type of events and therefore, those techniques are limited to less common isotopes like ${ }^{124} \mathrm{I}$. It should be noted that 
in the proposed method, the additional photons emitted by the non-pure positron emitter are not required to be emitted promptly. They can be delayed with respect to the positron decay as they do not have to be detected in coincidence for the spectroscopic analysis.

Finally, it must be noted that in this study, the spectroscopic analysis of the blood samples was performed using a well counter. However, an online blood sampling detector [31, 179] could be also used, which would further simplify the implementation of this technique. In that case, blood would be extracted from the patient through a catheter that passes through a gamma photon detector and a similar methodology to the one applied with the gamma counter would be used. In that way, AIF separation could be obtained immediately while minimizing the radiation exposure of the personnel and avoiding technical issues such as volume dependence of blood samples.

\subsection{Conclusions}

In this chapter we proposed a novel technique to PET scans with two tracers during the same acquisition using multi-tracer compartment modelling. It is based on the explicit separation of individual AIF based on a spectroscopic analysis of the emission spectra of each tracer. The proposed technique was implemented in vivo by performing cardiac PET/CT studies on 3 healthy pigs, which were injected with ${ }^{18} \mathrm{FDG}$ and ${ }^{68} \mathrm{Ga-DOTA}$ during the same acquisition and successfully validated against their analogous ex vivo measurements. 


\subsection{Introduction}

In the previous chapter, we proposed and evaluated a new technique for multi-tracer PET imaging based on blood spectroscopic analysis. With this method, the radioactivity emitted from each radioisotope could be detected, providing independent AIFs for each radiotracer.

The spectroscopic analysis tested in vivo was carried out by measuring the energy spectra of a set of time-ordered blood samples manually withdrawn from the animals. However, AIF obtained from a set of blood samples may lack a good time resolution and is limited by the rate at which the technologist can obtain those samples. Additionally, manual blood sampling implies an increase of radiation exposure of the operating personnel and is more prone to error as it requires rapid manual handling.

To address these issues, several automatic blood sampling devices with a radioactivity detector integrated have been developed over the years. They are based on either positron [38, 118] or annihilation photon detection. Most of these gamma detection devices use scintillation crystals (such as BGO [27], GSO [224], NaI [157] or LYSO [179]) coupled to a photomultiplier tube (PMT). However, alternatives to PMT have also been proposed, such a CZT-based device [56] and a LSO crystal coupled to an avalanche photodiode (APD) [31], which is more compact and can operate under magnetic fields, although APD gain is highly temperature dependent.

In this chapter, we propose an online blood-sampling detector made with two detectors based on silicon photomultipliers ( $\mathrm{SiPMs})$ and $\mathrm{CsI}(\mathrm{Tl})$ scintillation crystals working in coincidence. 
SiPMs are compact, MR-compatibles, inexpensive, can be operated at low voltage, and have a very high gain. $\mathrm{CsI}(\mathrm{Tl})$ has been selected for its high detection efficiency, high light yield and absence of intrinsic radioactivity, which allows performing measurements in single and coincidence modes making it suitable for PET and SPECT radiotracers.

Moreover, our prototype not only provides the live photon count rate emitted from the blood, but also stores and analyzes the gamma energy spectrum of each event recorded during the acquisition (either single or coincidence). This feature makes possible to determine the AIF even when there is more than one radiotracer circulating in blood and makes possible to distinguish the individual contributions of each radiotracer to the total AIF by using the blood spectroscopic analysis described in the previous chapter.

\subsection{Aim of the chapter}

The aim of this chapter is to design, develop and characterize the blood sampling detector described above. We evaluated in vivo its performance and tested its capability for separation of dual AIFs using the spectroscopic analysis described in the previous chapter.

\subsection{Methods}

\subsubsection{Blood sampling detector design}

The blood sampling detector consists of two detection units, each one made with a $50 \times 50 \times$ $25 \mathrm{~mm}^{3} \mathrm{CsI}(\mathrm{Tl})$ scintillation crystal with diffuse surfaces (Scionix Holland, Bunnik, The Netherlands) wrapped with a white diffuse plastic reflector. On the center of one of the $50 \times 25 \mathrm{~mm}^{2}$ faces, an area of $4 \times 4 \mathrm{~mm}^{2}$ is left unwrapped for optical readout. Each crystal is coupled with optical grease to a SiPM (ASD-RGB4S-P, AdvanSiD, Trento, Italy) with an active area of 4 $\times 4 \mathrm{~mm}^{2}$ operated at $31 \mathrm{~V}$. SiPMs are connected to amplification boards based on inverting transimpedance amplifiers. Crystals are placed side by side along one of the $50 \times 50 \mathrm{~mm}^{2}$ faces with an $11.5 \mathrm{~mm}$ gap between them (see Fig. 7.1). The crystals, SiPMs and readout electronics are placed within a 3D-printed enclosure. The blood sampling catheter is placed in the center of the gap between crystals in a 3D-printed U-grooved holding cassette. This piece can be fixed to the detector enclosure (see Fig. 7.1), allowing for measurements in single and coincidence modes and ensuring a good reproducibility. The detector shielding is made of a double layer of $3 \mathrm{~cm}$ thick lead bricks in order to minimize the detection of external radiation. 


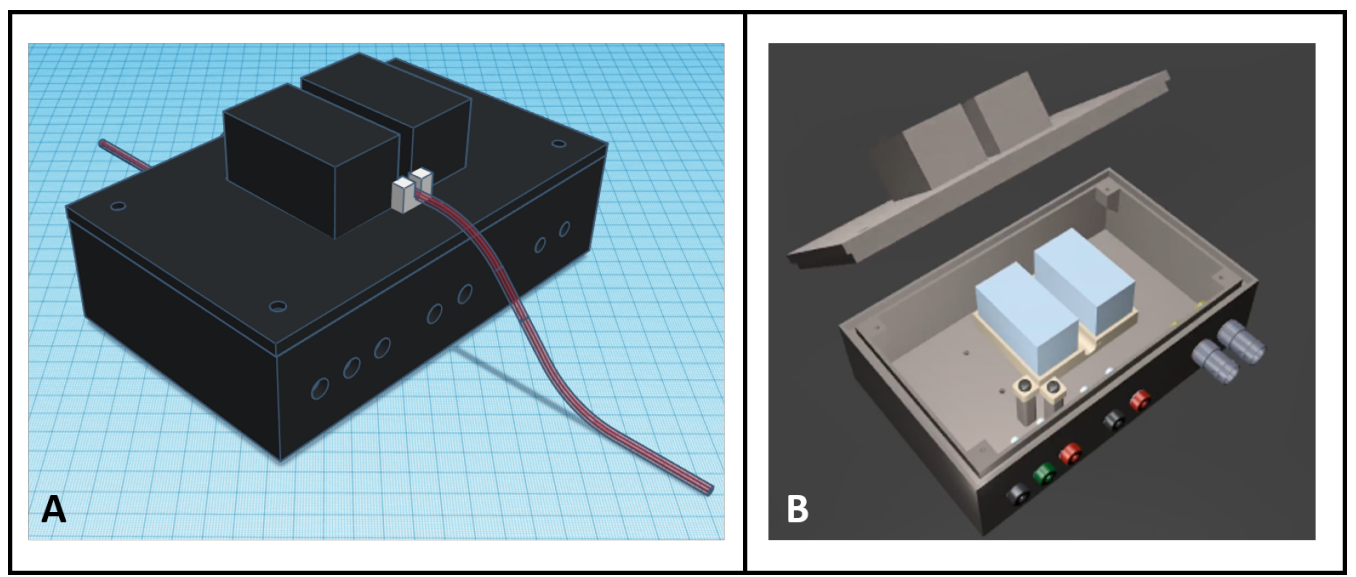

Figure 7.1: External $(\boldsymbol{A})$ and internal $(\boldsymbol{B})$ views of the blood sampling detector developed in this study. The device consists of two $50 \times 50 \times 25 \mathrm{~mm}^{3} \mathrm{CsI}(\mathrm{Tl})$ scintillation crystals (blue boxes) coupled on one of the $50 \times$ $25 \mathrm{~mm}^{2}$ faces to a $4 \times 4 \mathrm{~mm}^{2}$ SiPM (hidden in this illustration). Crystals are placed at $11.5 \mathrm{~mm}$ distance. The catheter (red tube) is placed in the gap between crystals with a holding cassette (white piece).

\subsubsection{Data acquisition and signal processing}

The signals from both detection units are digitized (15 MS/s) with an oscilloscope (Picoscope Series 2206A, Pico Technology Ltd, Cambridgeshire, UK) and sent to a PC for further processing using a custom-made application based on the oscilloscope's C ++ API. All pulses triggered by a falling edge discriminator are integrated for $2 \mu$ s to obtain the energy deposited by the gamma photons and stored as single events for each detector. The signal is also recorded for $1 \mu$ s pretrigger, and this part is used for baseline correction. Time stamps are generated by the leadingedge discrimination in both detectors. Single events with a time difference below $300 \mathrm{~ns}$ are also stored as coincidence events. Random coincidences are estimated and subtracted through the singles rates using standard procedure. Environmental background events are subtracted from single and coincidence events. For that purpose, a 2 hour measurement with no activity in the catheter is used.

\subsubsection{Device characterization}

\section{Sensitivity, energy resolution, coincidence resolving time and count rate losses}

In order to characterize the detector, a $0.8 \mathrm{~mm}$ internal diameter (ID) catheter (Tygon S3 E-3603, Saint-Gobain Performance Plastics Co., Akron, OH, USA) was filled with ${ }^{18}$ FDG at an initial activity concentration of $900 \mathrm{kBq} / \mathrm{mL}$ and placed in the blood sampling detector with the active length centered with the detection units. A 15 hour acquisition was performed consisting in 150 frames of 1 minute duration with 5-minute gap intervals. The energy spectra were obtained and calibrated using the $511 \mathrm{keV}$ peak for every acquisition in order to compensate for temperaturedependent gain variations. The energy resolution at the $511 \mathrm{keV}$ photopeak was obtained by fitting to a gaussian.

Sensitivity was computed as the slope of the linear fit of the events rate (singles or coincidences) measured within an energy window of 350-700 keV against their corresponding activity concentration. This fit was performed for the low count rate measurements. Count rate losses were estimated for single events assuming that no events are lost at low count rate. Coincidence 
resolving time (CRT) was derived from a gaussian fit of the detection time difference histogram for coincidence events within the same energy window of 350-700 keV.

\section{Minimum detectable activity}

Minimum detectable activity (MDA) determines the smallest activity concentration that can be detected with a certain confidence level [40]. MDA depends on sensitivity of the detector $(s)$, the duration of the measurement $(T)$, and background events $\left(N_{B}\right)$ detected during $T$. In terms of $\mathrm{kBq} / \mathrm{mL}$, and at a $95 \%$ confidence level, MDA can be described as:

$$
\mathrm{MDA}=\frac{4.65 \sqrt{N_{B}+2.71}}{B r_{\beta^{+}} T s},
$$

where $B r_{\beta^{+}}$is the branching ratio for $\beta^{+}$decays $\left(0.967\right.$ for $\left.{ }^{18} \mathrm{~F}\right) . N_{B}$ was measured with and without the presence of an external source of activity. In the first case, only the environmental radiation contributes to background radiation, whereas in the second case, the radiation emitted from the patient itself can penetrate the shielding and contribute to background signal. Consequently, MDA was determined in both scenarios for both single and coincidence events using an energy window of 350-700 keV. Details about the setup employed for the background measurements with an external activity source are given in the following section. In each case, background measurements of 2-3 minutes were performed in three independent acquisitions. The results are presented as mean $\pm \mathrm{SD}$.

\subsubsection{In vivo evaluation}

The performance of the blood sampling detector was evaluated in vivo in animals injected with ${ }^{18}$ FDG. The study was conducted according to the guidelines of the current European Directive and Spanish legislation and approved by the regional ethical committee for animal experimentation. In this case, three healthy female LArge White pigs (mean weight $=45 \pm 4 \mathrm{~kg}$ ) were anesthetized by intramuscular injection of ketamine $(20 \mathrm{mg} / \mathrm{kg})$, xylazine $(2 \mathrm{mg} / \mathrm{kg})$, and midazolam $(0.5 \mathrm{mg} / \mathrm{kg})$, and maintained by continuous intravenous infusion of ketamine $\left(2 \mathrm{mg} \cdot \mathrm{kg}^{-1} \cdot \mathrm{h}^{-1}\right)$, xylazine $\left(0.2 \mathrm{mg} \cdot \mathrm{kg}^{-1} \cdot \mathrm{h}^{-1}\right)$, and midazolam $\left(0.2 \mathrm{mg} \cdot \mathrm{kg}^{-1} \cdot \mathrm{h}^{-1}\right)$. Oxygen saturation levels and ECG were monitored throughout the study. The coccygeal artery of the animal was cannulated, and arterial blood was withdrawn through a $0.8 \mathrm{~mm}$ ID catheter at $5 \mathrm{ml} / \mathrm{min}$ using a peristaltic pump. The animals received a bolus injection of heparin and the catheter was washed with heparinized saline to prevent clotting. The animal was placed in a PET/CT Gemini TF-64 scanner (Philips Healthcare, Best, The Netherlands) and the scanner table was moved to the position were cardiac PET acquisitions are routinely performed. The detector was placed at about 40 $\mathrm{cm}$ from the animal's tail in order to minimize blood dispersion inside tubing. ${ }^{18} \mathrm{FDG}(155 \pm$ $12 \mathrm{MBq}$ ) was prepared in $6 \mathrm{ml}$ and infused at a rate of $1.0 \mathrm{ml} / \mathrm{s}$ through a marginal ear vein, followed by a $6 \mathrm{ml}$ saline flush at the same rate. The acquisition with the detector started with the dose injection and lasted for 5 minutes. The AIF was obtained with the detector $\left(A I F_{D}\right)$ in consecutive 5 second frames using the single events recorded in the $350-700 \mathrm{keV}$ energy window and converted to activity concentration using the sensitivity obtained from the previous 
characterization of the detector. Afterwards, measurements for MDA determination with an external source of activity were performed by placing an empty catheter in the device and leaving everything else in the same position. Also, decay correction was applied.

In order to validate $A I F_{D}$ results, blood samples were collected after passing through the blood sampling detector (at the end of the catheter). Withdrawn blood was collected into sample tubes according to the following temporal scheme: $20 \times 5 \mathrm{~s}, 8 \times 10 \mathrm{~s}, 6 \times 20 \mathrm{~s}$. Then, the tubes were briefly centrifuged to provide a reproducible geometrical distribution of the blood and later analyzed with a well counter (Wallac 1470 Perkin Elmer, Waltham, MA, USA) applying dead time and decay corrections. The well counter had been previously calibrated to convert measurements to activity values as detailed in Chapter 6. The volume for each blood sample was determined as the weight difference between empty and filled tubes and considering a blood density of $1.03 \mathrm{~g} / \mathrm{ml}$ [180]. Finally, the activity concentration of ${ }^{18} \mathrm{FDG}$ was calculated for each blood sample obtaining the AIF derived from the well counter $\left(A I F_{W C}\right)$. The time delay existing between $A I F_{D}$ and $A I F_{W C}$ was corrected by maximizing the cross-correlation between both curves, which had been previously interpolated every 5 seconds.

\subsubsection{Multi-tracer AIF detection by spectroscopic analysis}

Pure $\beta^{+}$-emitter isotopes such as ${ }^{18} \mathrm{~F}$ only emit $511-\mathrm{keV}$ annihilation photons, while non-pure $\beta^{+}$isotope like ${ }^{68} \mathrm{Ga}$ emit additional photons, although only those emitted at $1.077 \mathrm{MeV}$ have a significant contribution (3.22\%). Thus, the ratio of events recorded at high-energy (> $750 \mathrm{keV})$ and low-energy windows (350-700 keV) (see Fig. 7.2) can be used to determine the amount of ${ }^{18} \mathrm{~F}$ and ${ }^{68} \mathrm{Ga}$ in a sample containing any combination of both isotopes.

A

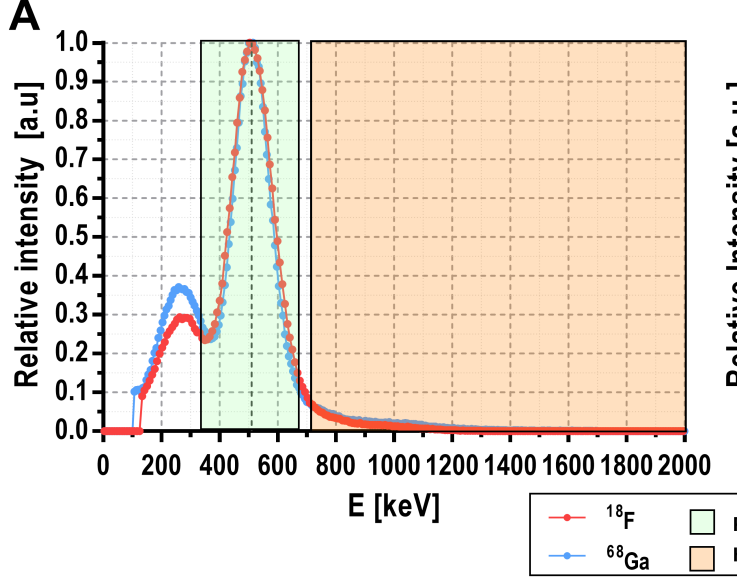

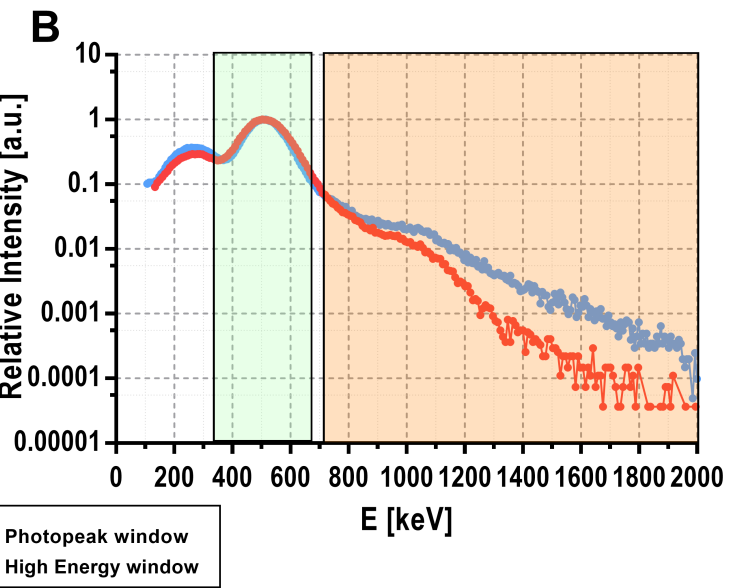

Figure 7.2: Normalized energy spectra of single events recorded from ${ }^{18} \mathrm{~F}$ (pure $\beta^{+}$-emitter, red) and the ${ }^{68} \mathrm{Ga}$ (non-pure $\boldsymbol{\beta}^{+}$-emitter, blue) shown in linear $(\boldsymbol{A})$ and logarithmic $(\boldsymbol{B})$ scales. The green and orange boxes represent the energy windows set at [350, 700] and [750, 2000] keV to distinguish between photopeak (low energy) and highenergy events. The events recorded within the high energy window are relatively higher for ${ }^{68} \mathrm{Ga}$ than for ${ }^{18} \mathrm{~F}$ compared to the events recorded in the photopeak.

Two acquisitions were performed so as to obtain the calibration data required to implement the proposed method. A $0.8 \mathrm{~mm}$ ID catheter was filled with ${ }^{68} \mathrm{Ga}$ or ${ }^{18} \mathrm{~F}$ respectively with an initial activity concentration of $1200 \mathrm{kBq} / \mathrm{mL}$ (measured with an activimeter). Afterwards, the 
catheter was placed in the blood sampling detector and data was recorded for several hours acquiring frames of 1 minute with 5-minute gap intervals. Each frame was processed to obtain the total SR at high energy window $\left(750-2000 \mathrm{keV}, S_{H E}\right)$ and the coincidences rate at low energy window (350-700 keV, $C_{L E}$ ). The ratio between $S_{H E}$ and $C_{L E}$ could be used, in theory, to calibrate the measurements for each isotope. However, we observed that, at higher count rates, the increase of $S_{H E}$ is not proportional to $C_{L E}$ due to pile-up events. Therefore, in order to include this effect in the calibration, $S_{H E}$ must be calibrated as a function of $C_{L E}$. For that purpose, the variation of $S_{H E}$ against $C_{L E}$ was represented and fitted to a third-degree polynomial for each isotope $\left(S_{H E, F}\left(C_{L E}\right)\right.$ and $\left(S_{H E, G}\left(C_{L E}\right)\right.$ for pure ${ }^{18} \mathrm{~F}$ and ${ }^{68} \mathrm{Ga}$ respectively). When measuring $S_{H E}$ and $C_{L E}$ for a sample containing an unknown mixture of ${ }^{18} \mathrm{~F}$ and ${ }^{68} \mathrm{Ga}$ $\left(S_{H E, M i x}\right)$, the relative activity of each isotope $\left(a_{G a, D}\right.$ and $a_{F, D}$, being $\left.a_{F, D}+a_{G a, D}=1\right)$ can be obtained using the following expression:

$$
S_{H E, M i x}\left(C_{L E}\right)=a_{G a, D} \cdot S_{H E, G}\left(C_{L E}\right)+\left(1-a_{G a, D}\right) \cdot S_{H E, F}\left(C_{L E}\right),
$$

assuming that the contribution of pile-up events is equally distributed between both isotopes.

The ability of the developed detector to obtain separated AIFs of tracers labelled with different isotopes $\left({ }^{68} \mathrm{Ga}\right.$ and $\left.{ }^{18} \mathrm{~F}\right)$ was tested in vitro. For that, a catheter filled with a mixture of $73 \%{ }^{68} \mathrm{Ga}$ and $27 \%{ }^{18} \mathrm{~F}$ with an initial total activity concentration of $1200 \mathrm{kBq} / \mathrm{mL}$ was placed in the detector. The activity was measured separately for each isotope with an activimeter and the mixture was prepared afterwards. Data were recorded for several hours acquiring frames of 1 minute duration with 5-minute gap intervals. The relative activity of both isotopes was constantly changing over time due to their different half-lives ( $\sim 110 \mathrm{~min}$ for ${ }^{18} \mathrm{~F}$ and $\sim 68 \mathrm{~min}$ for $\left.{ }^{68} \mathrm{Ga}\right)$.

The initial activity concentration $\left(C\left(t_{i}\right)=1200 \mathrm{kBq} / \mathrm{ml}\right)$ was much higher than the typical values that can be measured in an AIF of an in vivo experiment on large animals. In those studies, the activity concentration usually ranges between 10 and $200 \mathrm{kBq} / \mathrm{mL}$, and the duration of the timeframes of the dynamic PET acquisition are frequently set from 5 seconds (in those frames where the activity concentration is high and changes rapidly) up to 60-180 seconds (for those frames where there activity concentration is low and the changes over the time is less significative). Hence, in order to evaluate our experiment in more realistic conditions, our 1 minute acquisitions were trimmed (and only the first $t^{\prime}$ seconds of acquisition were used) depending on the activity concentration of each acquisition as follows:

$$
t^{\prime}=\left\{\begin{array}{lll}
60 s & , \text { when } \quad \max (C(t))<10 \mathrm{kBq} / \mathrm{ml} \\
10 s & , \text { when } \quad 10 \mathrm{kBq} / \mathrm{ml} \leq \max (C(t))<50 \mathrm{kBq} / \mathrm{ml} . \\
5 s \quad \text {, when } \quad 50 \mathrm{kBq} / \mathrm{ml} \leq \max (C(t))
\end{array}\right.
$$

$S_{H E, M i x}$ and $C_{L E}$ were obtained for each frame and $a_{G a, D}$ was calculated using Eq. (7.2). These results were compared against known values $\left(a_{G a, A}\right)$ obtained from their initial activity and their half-lives. The mean relative difference between $a_{G a, D}$ and $a_{G a, A}$ was obtained and reported as 
a percentage.

\subsection{Results}

\subsubsection{Detector performance and in vivo evaluation}

The energy resolution and the CRT of the blood sampling detector was determined using one of the acquisitions performed at low count rate obtaining 35\% FWHM at $511 \mathrm{keV}$ (see Fig. 7.2) and 174 ns FHWM (see Fig. 7.3) respectively. The count rate losses for single events are shown in Fig. 7.4. Fig. 7.4A displays the recorded $\mathrm{SR}$ as a function of the activity concentration within the catheter and Fig. 7.4B illustrates the deviation of measured SR from the expected value as a function of the activity concentration. In can be seen that, for an activity concentration within the range of standard in vivo experiments $(10-400 \mathrm{kBq} / \mathrm{mL})$, the count-rate losses are below $2 \%$. Random coincidences were also computed and can be considered negligible $(<0.3 \%)$. The sensitivities obtained for single and coincidence events were $22.6 \mathrm{cps} \cdot \mathrm{kBq}^{-1} \cdot \mathrm{ml}^{-1}$ and 1.7 cps $\cdot \mathrm{kBq}^{-1} \cdot \mathrm{ml}^{-1}$ respectively.

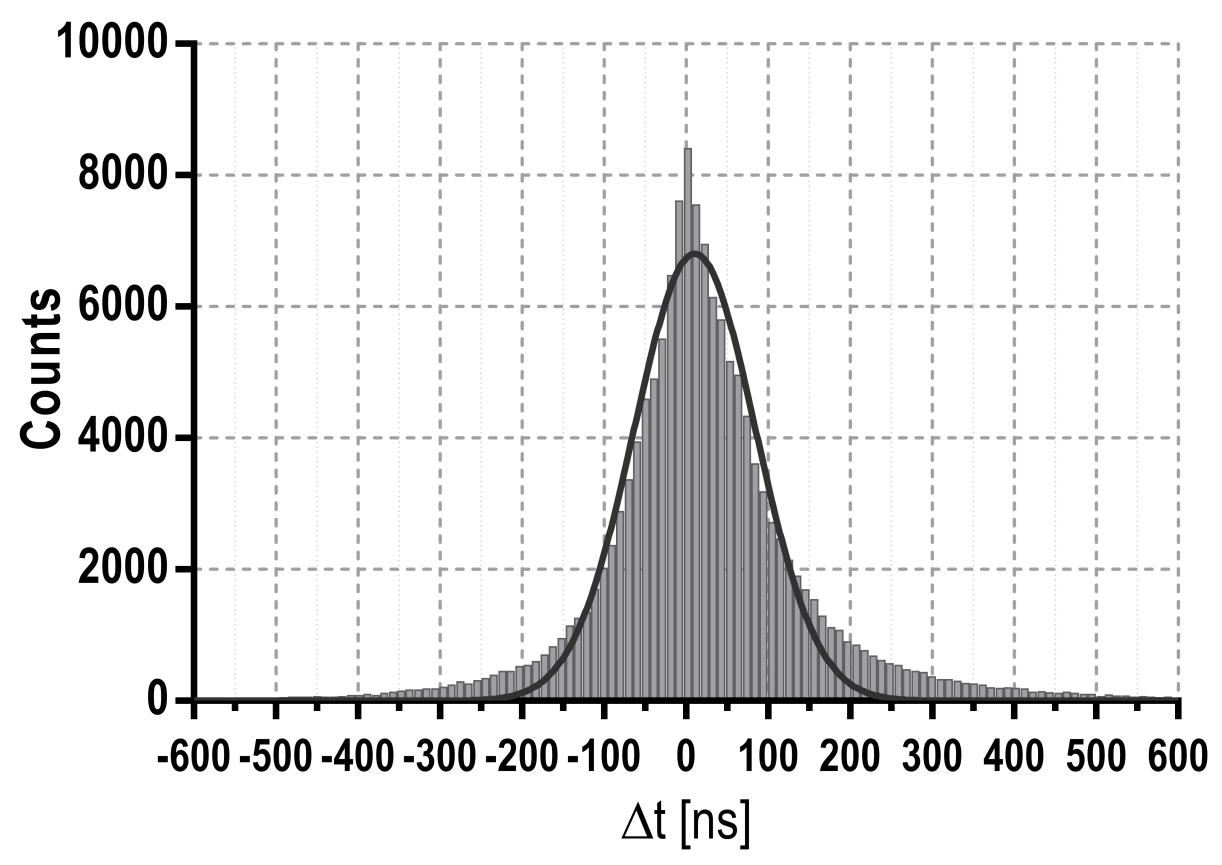

Figure 7.3: Time difference histogram obtained with the blood detector using ${ }^{18} \mathrm{~F}$ for a 1 minute acquisition with an energy window of 350-700 keV. The line represents the gaussian fit of the histogram, leading to a FWHM of $175 \mathrm{~ns}$.

The MDA was computed for single and coincidence events with and without an external activity source. In the absence of an external source, the MDA was $0.05 \pm 0.02 \mathrm{kBq} / \mathrm{mL}$ (singles) and $0.10 \pm 0.03 \mathrm{kBq} / \mathrm{mL}$ (coincidences) while the results with an external source were $0.30 \pm$ $0.08 \mathrm{kBq} / \mathrm{mL}$ (singles) and $0.25 \pm 0.05 \mathrm{kBq} / \mathrm{mL}$ (coincidences).

Fig. 7.5 shows the AIFs obtained with our detector $\left(A I F_{D}\right)$ from three in vivo studies in 
A

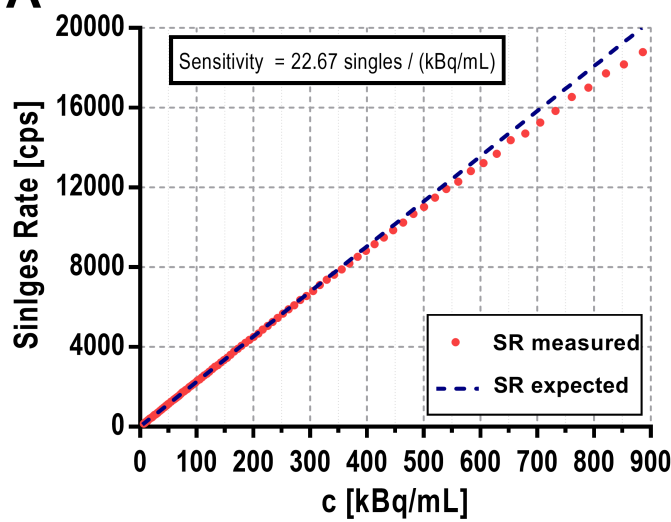

B

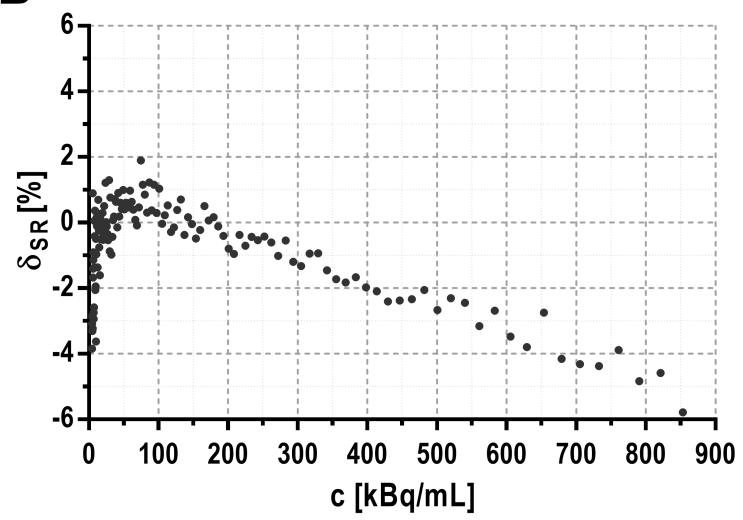

Figure 7.4: $\boldsymbol{A}$ : Singles rate detected by the device as a function of activity concentration (c, red dots) inside the catheter. A linear fit of the measured $S R$ at low $c$ when count rate losses are negligible is also shown (blue dashed line). B: Count rate losses $\left(\delta_{S R}\right)$ as a function of activity concentration.

which blood was withdrawn at a rate of $5 \mathrm{ml} / \mathrm{min}$ from a $0.8 \mathrm{~mm}$ ID catheter. An excellent correlation between $A I F_{D}$ and the blood samples analyzed with the well counter $\left(A I F_{W C}\right)$ was found $(r=0.996, p<0.0001)$.
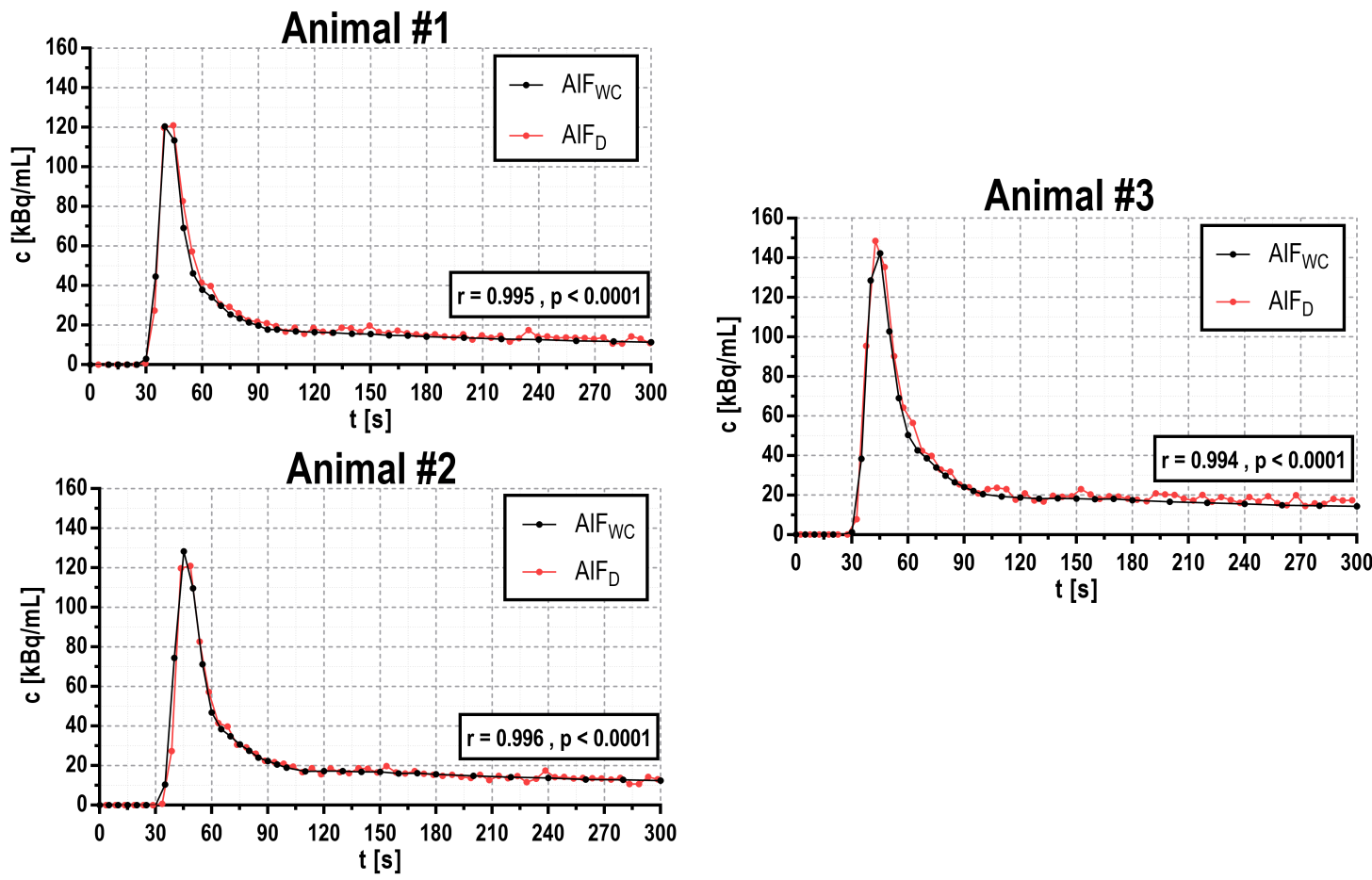

Figure 7.5: AIFs obtained with the blood sampling detector ( $A I F_{D}$, red curves) compared to the AIFs obtained from collected blood samples analyzed in a well counter (AIF $F_{W C}$, black curves) on three pigs that were injected with ${ }^{18}$ FDG. The Pearson's correlation obtained in all cases is excellent (mean $r=0.996, p<0.0001$ ). 


\subsubsection{Multi-tracer AIF separation by spectroscopic analysis}

Fig. 7.6 shows the calibration curves performed for the in vitro measurements of pure ${ }^{18} \mathrm{~F}$ and pure ${ }^{68} \mathrm{Ga}\left(S_{H E, F}\right.$ and $S_{H E, G}$ respectively) as well as the high energy SR corresponding to an unknown mixture of these radioisotopes $\left(S_{H E, M i x}\right)$. It can be observed that the $S_{H E, M i x}$ dataset gets closer to the pure ${ }^{18} \mathrm{~F}$ measurements for lower $C_{L E}$ as ${ }^{18} \mathrm{~F}$ activity decreases slower than for ${ }^{68} \mathrm{Ga}$ and consequently the relative activity of ${ }^{18} \mathrm{~F}$ increases over time. All datasets tend to $S_{H E}=0$ at low activity concentrations, which confirms that the background subtraction to every acquisition has been performed correctly.

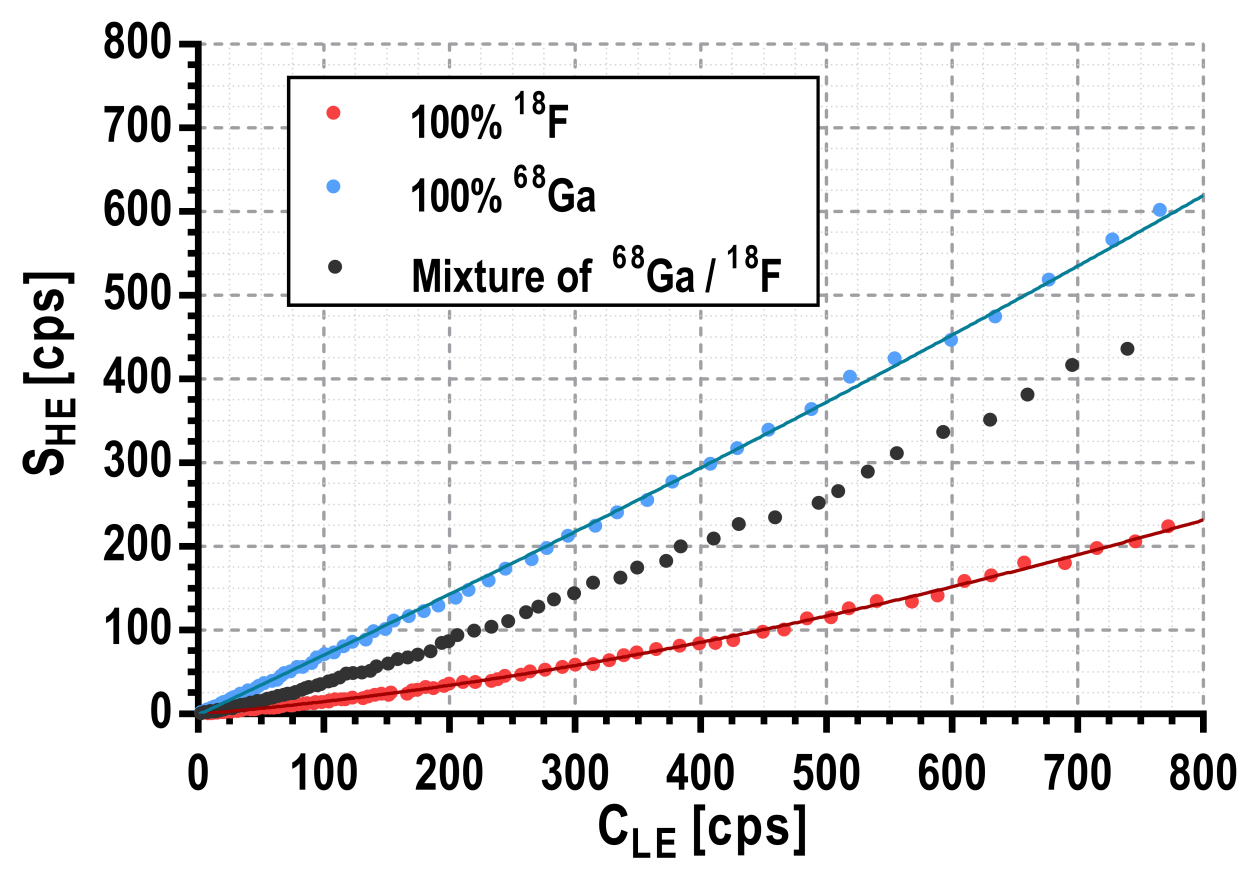

Figure 7.6: Singles rates measured within the high energy window $\left(S_{H E}\right)$ as a function of the coincidence rate measured inside the low energy window $\left(C_{L E}\right)$ for measurements performed with pure ${ }^{18} \mathrm{~F}$ (red dots), pure ${ }^{68} \mathrm{Ga}$ (blue dots), and a mixture of both radioisotopes (black dots). The results for the pure samples were fitted to a thirddegree polynomial (blue and red lines for pure ${ }^{68} \mathrm{Ga}$ and ${ }^{18} \mathrm{~F}$ respectively). These fits are used as the calibration curves named as $S_{H E, F}$ and $S_{H E, G a}$ in Eq. (7.2)).

The relative activity of ${ }^{68} \mathrm{Ga}$ in the mixture was calculated using Eq. (7.2) and the comparison against the known values shows a very strong correlation $(r=0.97, p<0.0001$, Fig. 7.7). The mean relative difference between $a_{G a, D}$ and $a_{G a, A}$ was $\delta=(3 \pm 10) \%$. When the acquisition was trimmed as described in Eq. (7.3) to analyze more realistic activity concentrations and timeframe duration, the correlation was still very good $(r=0.91, p<0.0001)$, with only a slight increase in the variation of the mean deviation from the true values $(\delta=(2 \pm 13) \%)$. 


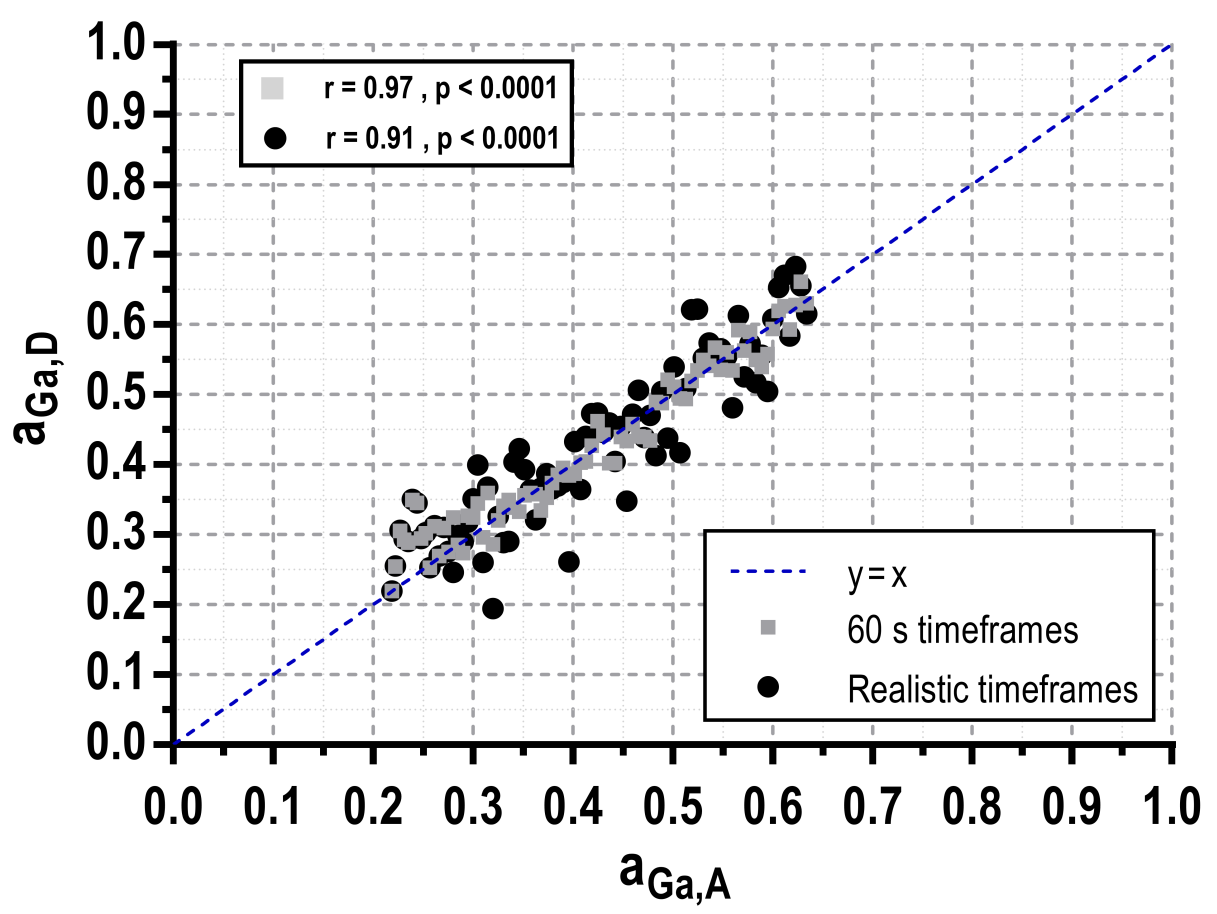

Figure 7.7: Comparison between the relative activity of ${ }^{68} \mathrm{Ga}$ obtained with the blood sampling detector using the gamma spectroscopy analysis of a mixture of ${ }^{68} \mathrm{Ga}$ and ${ }^{18} \mathrm{~F}\left(a_{G a, D}\right)$ and the known relative activity $\left(a_{G a, A}\right)$. The data collected from the 1 min acquisitions were analyzed entirely (gray squares) and partially (following scheme given in Eq. (7.3), black dots). Pearson's $r$ correlation of the datasets with the true values $\left(a_{G a, A}\right)$ are $r=0.97$ and $r=0.91$ respectively. Dashed blue line represents the identity line.

\subsection{Discussion}

The results show that the detector presented in this study has a high sensitivity, and it can obtain accurate and stable measurements of AIFs under realistic conditions. The device can work within a wide range of activity concentrations (up to $400 \mathrm{kBq} / \mathrm{mL}$ with dead-time losses below $2 \%$, Fig. $7.4)$ and presents a very low MDA for both single and coincidence events $(0.25$ and $0.30 \mathrm{kBq} / \mathrm{mL}$ respectively) in presence of an external activity source. The device is potentially MR-compatible thanks to the SiPM-based detection system, although few minor changes (connectors, electronic components, ... ) would be required to enable this option. The in vivo performance of the device has been studied with three pigs leading to an excellent correlation (mean correlation $r=0.996$, all with $p<0.0001$ ) between the AIFs obtained with the device and those obtained from the analysis of collected blood samples in a well counter.

The configuration parameters used in these studies, such as activity concentrations, tubing size and timeframe scheme are similar to those used in human studies. Therefore, this device would be suitable for utilization in the clinical routine. In case of studies with rats, the inner diameter of the tubing usually ranges from 0.18 to $0.64 \mathrm{~mm}$, which translates into a reduction of 60 to $95 \%$ of the active volume. However, the injected dose per gram for rats is about 30 times higher than for humans. Therefore, our device could also be used in rat studies as similar 
count rate to that obtained in pig studies is expected. Moreover, the blood withdrawal rate could be reduced proportionally to the catheter volume reduction [31] while keeping a similar blood renewal rate in the active length of the device. For example, for a $0.18 \mathrm{~mm}$ ID tubing, blood could be withdrawn at a rate of $0.25 \mathrm{ml} / \mathrm{min}$ with similar accuracy to the results presented in this work.

When measuring AIF with a blood sampling detector, blood activity dispersion inside the tubing reveals as a critical factor that may introduce large errors in the final quantification. Many approaches have been proposed to correct dispersion issues [95, 143, 151] analytically, but it is still advisable to minimize the main sources or dispersion in the experimental setup, such as tubing length or blood withdrawal rate. In this aspect, the compact design of the device as a consequence of the use of SiPM detectors makes possible to place it in close proximity to the subject, which turns into a reduced blood dispersion effect. Furthermore, the capability of the detector to record coincidence events reduce the background events detected from external sources.

Finally, a blood sampling spectroscopic analysis similar to the one proposed in the previous chapter was tested using the blood sampling detector with mixtures of a pure $\beta^{+}$-emitter $\left({ }^{18} \mathrm{~F}\right)$ and a non-pure $\beta^{+}$-emitter $\left({ }^{68} \mathrm{Ga}\right)$. The detection of additional gamma photons emitted by ${ }^{68} \mathrm{Ga}$ (see Fig. 7.2) permitted to disentangle the activity of each radioisotope. The poor energy resolution (35\% FWHM at $511 \mathrm{keV}$ ) and CRT (174 ns FWHM) obtained is due to the large difference between the size of the SiPMs $\left(4 \times 4 \mathrm{~mm}^{2}\right)$ and the size of the scintillation crystal $(50 \times 50 \times$ $25 \mathrm{~mm}^{3}$ ). Although the energy resolution is not a critical factor for standard blood sampling analysis, it may limit the accuracy for blood sampling spectroscopy. However, validation results shown on Fig. 7.7 demonstrate the capability of the developed device to separate (with a very good correlation, $r=0.91, p<0.0001)$ the contribution of ${ }^{18} \mathrm{~F}$ and ${ }^{68} \mathrm{Ga}$ for a sample containing a mixture of both isotopes. Nevertheless, the CRT did not affect to the device performance as the obtained fraction of random events was very low in all cases.

\subsection{Conclusions}

We have developed a blood sampling detector based on SiPM technology capable of recording simultaneously single and coincidence events with different energy windows. The performance parameters of this detector have been obtained leading to excellent results compared with other devices presented in the literature. The detector has been tested in vivo with several pigs injected with a single radiotracer and the results were validated showing excellent results. To our knowledge, available blood sampling detectors can only measure single-tracer AIFs. In contrast, a gamma spectroscopic analysis technique has been successfully implemented and validated in our detector for its application in multi-tracer PET studies when one of the radiotracers is based on a non-pure $\beta^{+}$-emitter. Therefore, the device presented in this study allows performing fully automatic single- and multiple-tracer PET studies. Moreover, this is the first blood sampling detector based on SiPM technology which offers many advantages in terms of cost, compactness, performance and MR-compatibility. 


\section{8}

The original aim of the work carried out throughout this dissertation was not to give an answer to certain scientific questions, but rather to offer new possibilities in the PET field so as to widen its worldwide availability. Consequently, during this conclusion section, a list of answers to particular hyphoteses will not be provided; instead an enumeration of the tools proposed and developed, along with the benefits they may provide to the scientific community, will be enumerated.

i. The novel PET radiotracer ${ }^{68} \mathrm{Ga}$-DOTA has been successfully proposed as a myocardial blood flow tracer. Its feasibility has been demonstrated and validated in pigs under different rest-stress conditions against a perfusion gold standard.

ii. The same tracer, ${ }^{68} \mathrm{Ga}$-DOTA, has also been proposed to be used as an estimator of myocardial viability. The ability to distinguish healthy and ischemic regions of infarcted hearts has been tested in pigs that had undergone a myocardial infarction.

iii. ${ }^{68} \mathrm{Ga}$-DOTA has also been proposed as a pulmonary blood flow PET radiotracer. It has been validated against a perfusion gold standard in healthy pigs under rest condition.

iv. A new method for multiple-tracer PET imaging has been proposed, implemented and validated. It is based on the gamma spectroscopic analysis of blood samples that may contain more than one radiotracer. The feasibility of separating the signal coming from both tracers is linked to the utilization of a non-pure beta emitter radionuclide as the labeling agent of at least one of the radiotracers. 
v. A new blood sampling detector has been developed to carry out the proposed multi-tracer PET spectroscopic analysis. The detector has been characterized and tested under realistic clinical PET experimental conditions. The capability of the detector to explicitly separate the signal emitted from both radiotracers has also been evaluated and validated.

Here we present the impact that these conclusions may have in the expansion of cardiac PET worldwide:

I. The short half-life together with the high cost of production of the radiotracers used for MBF assessment has hindered a broader application of PET in clinical cardiology, despite its superlative diagnostic value. A radiotracer like the one proposed in this thesis $\left({ }^{68} \mathrm{Ga}\right.$ DOTA) could overcome those limitations, since it can be produced from a long duration benchtop generator. Moreover, its half-life of 68 min facilitates its regional distribution, thus eliminating the need of having a ${ }^{68} \mathrm{Ge} /{ }^{68} \mathrm{Ga}$ generator in every hospital. These economical advantages, together with its demonstrated feasibility as a radiotracer for MBF and viability assessment, could translate into a worldwide spread of cardiac PET imaging.

II. The confirmed capability of ${ }^{68} \mathrm{Ga}$-DOTA to quantify PBF enlarges its versatility as a perfusion tracer. Moreover, following the examples provided in this thesis, new perfusion applications may be found for this radiotacer. A wider range of ${ }^{68} \mathrm{Ga}$ clinical applications could motivate the hospitals to undertake the investment in a ${ }^{68} \mathrm{Ge} /{ }^{68} \mathrm{Ga}$ generator.

III. Multi-tracer PET is capable of reducing the scanning time (from hours or days to minutes) of cardiac studies in which MBF assessment and viability are required, via rest-stress tests and FDG scans, respectively. In addition, multi-tracer PET eliminates misalignment problems that may appear when repeating single-tracer scans in different sessions. These advantageous properties could translate into an increase in the patient throughput, thus leading to improved cost-effectiveness of PET.

IV. The spectroscopic analysis in which our proposed multi-tracer PET technique is based does not need human intervention. A blood detector, such as the one presented in this work, may be used in order to minimize radiation exposure of the technical personnel. This could encourage the implantation of multi-tracer PET in the clinical setting.

Taking into account the statements enumerated above, we firmly believe that the work presented throughout this thesis will contribute to some extent to the expansion of positron emission tomography in the clinical practice. 
1. Aime, S. \& CARAvan, P. Biodistribution of gadolinium-based contrast agents, including gadolinium deposition. in Journal of Magnetic Resonance Imaging 30 (2009), 1259-1267.

2. Al Moudi, M. \& Sun, Z.-H. "Diagnostic value of (18)F-FDG PET in the assessment of myocardial viability in coronary artery disease: A comparative study with (99m)Tc SPECT and echocardiography." Journal of geriatric cardiology : JGC 11, 229-236 (2014).

3. Allman, K. C., Shaw, L. J., Hachamovitch, R. \& Udelson, J. E. "Myocardial viability testing and impact of revascularization on prognosis in patients with coronary artery disease and left ventricular dysfunction: a meta-analysis." Journal of the American College of Cardiology 39, 1151-1158 (2002).

4. Anderson, D. H. Compartmental modelling and tracer kinetics. English (Springer-Verlag, Berlin; New York, 1983).

5. Andreyev, A. \& Celler, A. "Dual-isotope PET using positron-gamma emitters." Physics in Medicine and Biology 56, 4539-4556 (2011).

6. Araujo, L. I. et al. "Noninvasive quantification of regional myocardial blood flow in coronary artery disease with oxygen-15-labeled carbon dioxide inhalation and positron emission tomography." Circulation 83, 875-885 (1991).

7. Arnett, D. K. et al. "2019 ACC/AHA Guideline on the Primary Prevention of Cardiovascular Disease." Circulation 0 (June 2019).

8. Asaria, P., Chisholm, D., Mathers, C., Ezzati, M. \& Beaglehole, R. "Chronic disease prevention: health effects and financial costs of strategies to reduce salt intake and control tobacco use." The Lancet 370, 2044-2053 (2007).

9. Atтix, F. H. Introduction to radiological physics and radiation dosimetry (John Wiley \& Sons, 2008).

10. Auerbach, O., Hammond, E. C. \& Garfinkel, L. "Smoking in Relation to Atherosclerosis of the Coronary Arteries." New England Journal of Medicine 273, 775-779 (Oct. 1965). 
11. Autio, A. et al. "Assessment of blood flow with (68)Ga-DOTA PET in experimental inflammation: a validation study using (15)O-water." eng. American journal of nuclear medicine and molecular imaging 4, 571-9 (2014).

12. Autio, A. et al. "68Ga-DOTA chelate, a novel imaging agent for assessment of myocardial perfusion and infarction detection in a rodent model." Journal of Nuclear Cardiology (2019).

13. BACHARACH, S. L. et al. Myocardial blood flow by PET: correction for spillover and partial volume. in [1990] Proceedings Computers in Cardiology (1990), 53-56.

14. Bacharach, S. L. \& Buvat, I. "Attenuation correction in cardiac positron emission tomography and single-photon emission computed tomography." Journal of Nuclear Cardiology 2, 246-255 (1995).

15. BAER, F. M. et al. "Assessment of viable myocardium by dobutamine transesophageal echocardiography and comparison with fluorine-18 fluorodeoxyglucose positron emission tomography." Journal of the American College of Cardiology 24, 343-353 (1994).

16. Bailey, D. L., Maisey, M. N., Townsend, D. W. \& Valk, P. E. Positron emission tomography (Springer, 2005).

17. Baje, M. \& Jonson, B. "Ventilation/Perfusion SPECT for Diagnosis of Pulmonary Embolism and Other Diseases." International Journal of Molecular Imaging 2011 (2011).

18. BAJC, M. et al. "EANM guidelines for ventilation/perfusion scintigraphy." European Journal of Nuclear Medicine and Molecular Imaging 36, 1356-1370 (2009).

19. Beaglehole, R., Ebrahim, S., Reddy, S., Voûte, J. \& Leeder, S. "Prevention of chronic diseases: a call to action." The Lancet 370, 2152-2157 (2007).

20. Bengel, F. M., Higuchi, T., Javadi, M. S. \& Lautamäki, R. "Cardiac Positron Emission Tomography." Journal of the American College of Cardiology 54, 1-15 (2009).

21. Benjamin, E. J. et al. Heart Disease and Stroke Statistics'2017 Update: A Report from the American Heart Association. 10, e146-e603 (2017).

22. Bergmann, S. R., Herrero, P., Markham, J., Weinheimer, C. J. \& Walsh, M. N. "Noninvasive quantitation of myocardial blood flow in human subjects with oxygen-15labeled water and positron emission tomography." Journal of the American College of Cardiology 14, 639-652 (1989).

23. Berman, D. S. et al. "Underestimation of extent of ischemia by gated SPECT myocardial perfusion imaging in patients with left main coronary artery disease." Journal of Nuclear Cardiology 14, 521-528 (2007).

24. Berman, D. S. et al. "Phase II safety and clinical comparison with single-photon emission computed tomography myocardial perfusion imaging for detection of coronary artery disease: flurpiridaz F 18 positron emission tomography." Journal of the American College of Cardiology 61, 469-477 (2013).

25. Betts, J. G. et al. Anatomy \& Physiology (OpenStax College, Rice University, 2013). 
26. Bland, J. M. \& Altman, D. "Statistical methods for assessing agreement between two methods of clinical measurement." The Lancet 327, 307-310 (1986).

27. Boellatrd, R., Van Lingen, A., Van Balen, S. C. M., Hoving, B. G. \& Lammertsma, A. A. "Characteristics of a new fully programmable blood sampling device for monitoring blood radioactivity during PET." European Journal of Nuclear Medicine 28, 81-89 (2001).

28. Bonow, R. O., Dilsizian, V., Cuocolo, A. \& Bacharach, S. L. "Identification of viable myocardium in patients with chronic coronary artery disease and left ventricular dysfunction. Comparison of thallium scintigraphy with reinjection and PET imaging with 18F-fluorodeoxyglucose." Circulation 83, 26-37 (1991).

29. Boś, A. et al. "Cerebral blood flow quantification in the rat: a direct comparison of arterial spin labeling MRI with radioactive microsphere PET." EJNMMI research 2, 47 (Sept. 2012).

30. Breeman, W. a. P. \& Verbruggen, A. M. "The 68Ge/68Ga generator has high potential, but when can we use 68Ga-labelled tracers in clinical routine?" European Journal of Nuclear Medicine and Molecular Imaging 34, 978-981 (2007).

31. Breuer, J., Grazioso, R., Zhang, N., Schmand, M. \& Wienhard, K. "Evaluation of an MR-compatible blood sampler for PET." Physics in Medicine $\mathscr{E}$ Biology 55, 5883 (2010).

32. Browne, J. \& De Pierro, A. B. "A row-action alternative to the EM algorithm for maximizing likelihood in emission tomography." IEEE transactions on medical imaging 15, 687-699 (1996).

33. Bulwer, B. E., Rivero, J. M. \& Solomon, F. S. D. Echocardiography Pocket Guide: The Transthoracic Examination (Jones \& Bartlett Learning, 2010).

34. Cerqueira, M. D. et al. "Standardized Myocardial Segmentation and Nomenclature for Tomographic Imaging of the Heart." Circulation 105, 539-542 (Jan. 2002).

35. Cherry, S. R., Sorenson, J. A. \& Phelps, M. E. Physics in Nuclear Medicine (Saunders, 2003).

36. Constantinou, C., Harrington, J. C. \& DeWerd, L. A. "An electron density calibration phantom for CT-based treatment planning computers." Medical Physics 19 (1992).

37. Conti, M. \& ERIksson, L. "Physics of pure and non-pure positron emitters for PET : a review and a discussion." EJNMMI Physics (2016).

38. Convert, L. et al. "Real-Time Microfluidic Blood-Counting System for PET and SPECT Preclinical Pharmacokinetic Studies." Journal of Nuclear Medicine 57, 1460-1466 (2016).

39. Crone, C. "The Permeability of Capillaries in Various Organs as Determined by Use of the "Indicator Diffusion" Method." Acta Physiologica Scandinavica 58, 292-305 (Aug. 1963). 
40. Currie, L. A. "Limits for qualitative detection and quantitative determination. Application to radiochemistry." Analytical Chemistry 40, 586-593 (1968).

41. DAAR, A. S. et al. "Grand challenges in chronic non-communicable diseases." Nature 450, 494 (Nov. 2007).

42. Dakin, J. H., Evans, T. W., Hansell, D. M. \& Hoffman, E. A. "Regional Pulmonary Blood Flow in Humans and Dogs by 4D Computed Tomography(1)." Academic radiology 15, 844-852 (2008).

43. Danad, I. et al. "Quantitative Assessment of Myocardial Perfusion in the Detection of Significant Coronary Artery Disease: Cutoff Values and Diagnostic Accuracy of Quantitative [15O]H2O PET Imaging." Journal of the American College of Cardiology 64, 1464-1475 (2014).

44. Delgado, J. F. "The Pulmonary Circulation in Heart Failure." Revista Española de Cardiología (English Edition) 63, 334-345 (2010).

45. Dempster, A. P., Laird, N. M. \& Rubin, D. B. "Maximum likelihood from incomplete data via the EM algorithm." Journal of the Royal Statistical Society: Series B (Methodological) 39, 1-22 (1977).

46. Di Carli, M. F. \& Murthy, V. L. "Cardiac PET/CT for the Evaluation of Known or Suspected Coronary Artery Disease." RadioGraphics 31, 1239-1254 (Sept. 2011).

47. Di CARLi, M. F. et al. "Value of metabolic imaging with positron emission tomography for evaluating prognosis in patients with coronary artery disease and left ventricular dysfunction." The American Journal of Cardiology 73, 527-533 (1994).

48. Dilsizian, V., Chandrashekhar, Y. \& Narula, J. "Quantitative PET Myocardial Blood Flow: "Trust, But Verify"." JACC: Cardiovascular Imaging 10, 609-610 (2017).

49. Dilsizian, V. \& Pohost, G. M. Cardiac CT, PET and MR (Wiley-Blackwell, 2019).

50. Dilsizian, V. et al. "Myocardial viability in patients with chronic coronary artery disease. Comparison of $99 \mathrm{mTc}$-sestamibi with thallium reinjection and $[18 \mathrm{~F}]$ fluorodeoxyglucose." Circulation 89, 578-587 (1994).

51. Dilsizian, V. et al. "PET myocardial perfusion and metabolism clinical imaging." Journal of Nuclear Cardiology 16, 651-651 (2009).

52. Dobaczewski, M., Gonzalez-Quesada, C. \& Frangogiannis, N. G. "The extracellular matrix as a modulator of the inflammatory and reparative response following myocardial infarction." eng. Journal of molecular and cellular cardiology 48, 504-511 (Mar. 2010).

53. DÜPPEnBECKeR, P. M. et al. "Development of an MRI-compatible digital SiPM detector stack for simultaneous PET/MRI." eng. Biomedical physics \& engineering express 2, 15010 (Feb. 2016). 
54. Elefteriades, J. A., Tolis, G., Levi, E., Mills, L. K. \& Zaret, B. L. "Coronary artery bypass grafting in severe left ventricular dysfunction: excellent survival with improved ejection fraction and functional state." Journal of the American College of Cardiology 22, 1411-1417 (1993).

55. Epstein, F. H. et al. "MR tagging early after myocardial infarction in mice demonstrates contractile dysfunction in adjacent and remote regions." Magnetic Resonance in Medicine 48, 399-403 (Aug. 2002).

56. EsPaGnet, R. et al. "A CZT-based blood counter for quantitative molecular imaging." EJNMMI Physics 4 (2017).

57. FAnraeus, R. "The suspension stability of the blood." Physiological Reviews 9, 241-274 (Apr. 1929).

58. Fan, F. C., Schuessler, G. B., Chen, R. Y. \& Chien, S. "Determinations of blood flow and shunting of 9- and 15-micrometer spheres in regional beds." American Journal of Physiology - Heart and Circulatory Physiology 237, H25-H33 (1979).

59. Fernández-Jiménez, R. et al. "Pathophysiology underlying the bimodal edema phenomenon after myocardial ischemia/reperfusion." Journal of the American College of Cardiology 66, 816-828 (2015).

60. Fernández-Jiménez, R. et al. "Effect of Ischemia Duration and Protective Interventions on the Temporal Dynamics of Tissue Composition after Myocardial Infarction." Circulation Research 121, 439-450 (2017).

61. Fink, C., Bock, M., Puderbach, M., Schmähl, A. \& Delorme, S. "Partially Parallel Three-Dimensional Magnetic Resonance Imaging for the Assessment of Lung Perfusion -Initial Results." Investigative Radiology 38 (2003).

62. Foley, J. R. J., Plein, S. \& Greenwood, J. P. "Assessment of stable coronary artery disease by cardiovascular magnetic resonance imaging: Current and emerging techniques." eng. World journal of cardiology 9, 92-108 (Feb. 2017).

63. ForD, E. S. et al. "Explaining the Decrease in U.S. Deaths from Coronary Disease, 1980-2000." New England Journal of Medicine 356, 2388-2398 (June 2007).

64. Fuld, M. K. et al. "Pulmonary Perfused Blood Volume with Dual-Energy CT as Surrogate for Pulmonary Perfusion Assessed with Dynamic Multidetector CT." Radiology 267, 747756 (June 2013).

65. Fuster, V., Kelly, B. B. \& Vedanthan, R. "Promoting global cardiovascular health: Moving forward." Circulation 123, 1671-1678 (2011).

66. García-Maceira, P. \& Mateo, J. "Silibinin inhibits hypoxia-inducible factor- $1 \alpha$ and $\mathrm{mTOR} / \mathrm{p} 70 \mathrm{~S} 6 \mathrm{~K} / 4 \mathrm{E}-\mathrm{BP} 1$ signalling pathway in human cervical and hepatoma cancer cells: implications for anticancer therapy." Oncogene 28, 313-324 (2009). 
67. García-Prieto, J. et al. " $\beta 3$ adrenergic receptor selective stimulation during ischemia/reperfusion improves cardiac function in translational models through inhibition of mPTP opening in cardiomyocytes." Basic Research in Cardiology 109 (2014).

68. Gaziano, T. A. "Economic burden and the cost-effectiveness of treatment of cardiovascular diseases in Africa." Heart 94, 140 LP -144 (Feb. 2008).

69. Gaziano, T. A., Opie, L. H. \& Weinstein, M. C. "Cardiovascular disease prevention with a multidrug regimen in the developing world: a cost-effectiveness analysis." The Lancet 368, 679-686 (2006).

70. Gazoti Debessa, C. R., Mesiano Maifrino, L. B. \& Rodrigues de Souza, R. "Age related changes of the collagen network of the human heart." Mechanisms of Ageing and Development 122, 1049-1058 (2001).

71. Gerhard-Paul, D. \& A., G. M. "Pulmonary Vascular Disease in Adults With Congenital Heart Disease." Circulation 115, 1039-1050 (Feb. 2007).

72. Geworski, L., Knoop, B. O., de Cabrejas, M. L., Knapp, W. H. \& Munz, D. L. "Recovery correction for quantitation in emission tomography: a feasibility study." European journal of nuclear medicine 27, 161-169 (2000).

73. Ghosh, N., Rimoldi, O. E., Beanlands, R. S. B. \& Camici, P. G. "Assessment of myocardial ischaemia and viability: role of positron emission tomography." European Heart Journal 31, 2984-2995 (2010).

74. Giordano, J. et al. "Lung perfusion characteristics in pulmonary arterial hypertension $(\mathrm{PAH})$ and peripheral forms of chronic thromboembolic pulmonary hypertension (pCTEPH): Dual-energy CT experience in 31 patients." European Radiology 27 (Aug. 2016).

75. Glenny, R. W., Bernard, S. \& Brinkley, M. "Validation of fluorescent-labeled microspheres for measurement of regional organ perfusion." Journal of Applied Physiology 74, 2585-2597 (1993).

76. Götte, M. J. W. et al. "Quantification of regional contractile function after infarction: strain analysis superior to wall thickening analysis in discriminating infarct from remote myocardium." Journal of the American College of Cardiology 37, 808-817 (2001).

77. Gunn, R. N., Gunn, S. R. \& Cunningham, V. J. "Positron Emission Tomography Compartmental Models." Journal of Cerebral Blood Flow E Metabolism 21, 635-652 (2001).

78. HAAs, F. et al. "Preoperative Positron Emission Tomographic Viability Assessment and Perioperative and Postoperative Risk in Patients With Advanced Ischemic Heart Disease." Journal of the American College of Cardiology 30, 1693 LP -1700 (Dec. 1997).

79. Hachulla, A.-L., Lador, F., M Soccal, P., Montet, X. \& Beghetti, M. "Dualenergy computed tomographic imaging of pulmonary hypertension." Swiss medical weekly 146 (Sept. 2016). 
80. Hall, J. E. \& Guyton, A. C. Guyton and Hall Textbook of Medical Physiology (Saunders/Elsevier, 2011).

81. Han, M. K., Mclaughlin, V. V., Criner, G. J. \& Martinez, F. J. "Pulmonary Diseases and the Heart." Circulation 116, 2992-3005 (Dec. 2007).

82. Harms, H. J. et al. "Comparison of clinical non-commercial tools for automated quantification of myocardial blood flow using oxygen-15-labelled water PET/CT." European Heart Journal Cardiovascular Imaging 15, 431-441 (2014).

83. Hausenloy, D. J. \& Yellon, D. M. "Myocardial ischemia-reperfusion injury: a neglected therapeutic target." The Journal of Clinical Investigation 123, 92-100 (Jan. 2013).

84. Hecht, H. H. "Heart Failure and Lung Disease." Circulation 14, 265-290 (Aug. 1956).

85. Hein, T. W., Belardinelli, L. \& Kuo, L. "Adenosine A(2A) receptors mediate coronary microvascular dilation to adenosine: role of nitric oxide and ATP-sensitive potassium channels." Journal of Pharmacology and Experimental Therapeutics 291, 655-664 (1999).

86. Heller, G. V., Calnon, D. \& Dorbala, S. "Recent advances in cardiac PET and PET/CT myocardial perfusion imaging." Journal of Nuclear Cardiology 16, 962-969 (2009).

87. Herrero, P., Hartman, J. J., Senneff, M. J. \& Bergmann, S. R. "Effects of Time Discrepancies Between Input and Myocardial Time-Activity Curves on Estimates of Regional Myocardial Perfusion with PET." Journal of Nuclear Medicine 35, 558-566 (1994).

88. Herrero, P., Markham, J., Shelton, M. E., Weinheimer, C. J. \& Bergmann, S. R. "Noninvasive quantification of regional myocardial perfusion with rubidium- 82 and positron emission tomography. Exploration of a mathematical model." Circulation 82, 1377-1386 (1990).

89. Hickeson, M. et al. "Use of a corrected standardized uptake value based on the lesion size on CT permits accurate characterization of lung nodules on FDG-PET." European journal of nuclear medicine and molecular imaging 29, 1639-1647 (2002).

90. Holman, B. F. et al. "Improved correction for the tissue fraction effect in lung PET/CT imaging." Physics in Medicine and Biology 60, 7387-7402 (2015).

91. Holman, E. R. et al. "Quantitative analysis of regional left ventricular function after myocardial infarction in the pig assessed with cine magnetic resonance imaging." Magnetic Resonance in Medicine 34, 161-169 (Aug. 1995).

92. Holman, E. R. et al. "Detection and Quantification of Dysfunctional Myocardium by Magnetic Resonance Imaging: A New Three-dimensional Method for Quantitative WallThickening Analysis." Circulation 95, 924-931 (Mar. 1997).

93. Hunt, S. A. "ACC/AHA 2005 guideline update for the diagnosis and management of chronic heart failure in the adult: a report of the American College of Cardiology/American Heart Association Task Force on Practice Guidelines (Writing Committee to Update the 2001 Guideli." Journal of the American College of Cardiology 46, e1-e82 (2005). 
94. Hutchins, G. D. et al. "Noninvasive quantification of regional blood flow in the human heart using N-13 ammonia and dynamic positron emission tomographic imaging." Journal of the American College of Cardiology 15, 1032-1042 (1990).

95. Iida, H., Kanno, I., Miura, S., Murakami, M. \& Takahashi, K. "Error Analysis of a Quantitative Cerebral Blood Flow Measurement Using H215Q Autoradiography and Positron Emission Tomography, With Respect to the Dispersion of the Input Function." Journal of Cerebral Blood Flow \& Metabolism, 536-545 (1986).

96. IIDA, H. et al. "Use of the Left Ventricular Time-Activity Curve as a Noninvasive Input Function in Dynamic Oxygen-15-Water Positron Emission Tomography." Journal of Nuclear Medicine 33, 1669-1677 (1992).

97. Ikoma, Y., Toyama, H. \& Suhara, T. "Simultaneous quantification of two brain functions with dual tracer injection in PET dynamic study." International Congress Series 1265, 74-78 (Aug. 2004).

98. Ingrisch, M. et al. "Assessment of Pulmonary Perfusion With Breath-Hold and FreeBreathing Dynamic Contrast-Enhanced Magnetic Resonance Imaging: Quantification and Reproducibility." Investigative Radiology 49 (2014).

99. IskAnder, S. \& IskANDRIAn, A. E. "Prognostic utility of myocardial viability assessment." American Journal of Cardiology 83, 696-702 (Mar. 1999).

100. Iyer, K. S. et al. "Quantitative Dual-Energy Computed Tomography Supports a Vascular Etiology of Smoking-induced Inflammatory Lung Disease." American Journal of Respiratory and Critical Care Medicine 193, 652-661 (Nov. 2015).

101. JAARsma, C. et al. "Diagnostic performance of noninvasive myocardial perfusion imaging using single-photon emission computed tomography, cardiac magnetic resonance, and positron emission tomography imaging for the detection of obstructive coronary artery disease: A meta-anal." Journal of the American College of Cardiology 59, 1719-1728 (2012).

102. JACQUEZ, J. A. Compartmental analysis in biology and medicine (BioMedware, 1996).

103. James, S. L. et al. "Global, regional, and national incidence, prevalence, and years lived with disability for 354 diseases and injuries for 195 countries and territories, 1990-2017: a systematic analysis for the Global Burden of Disease Study 2017." The Lancet 392, 1789-1858 (Nov. 2018).

104. Jiménez Borreguero, L. J. \& Ruiz-Salmerón, R. "Assessment of Myocardial Viability in Patients Before Revascularization." Revista Española de Cardiología (English Edition) 56, 721-733 (2003).

105. Kadrmas, D. J. \& Rust, T. C. Feasibility of rapid multi-tracer PET tumor imaging. in IEEE Symposium Conference Record Nuclear Science 2004. 4 (Oct. 2004), 2664-2668 Vol. 4.

106. Kadrmas, D. J., Rust, T. C. \& Hoffman, J. M. "Single-scan dual-tracer FLT+FDG PET tumor characterization." Physics in medicine and biology 58, 429-449 (Feb. 2013). 
107. Kairento, A.-L., Brownell, G. L., Schluederberg, J. \& Elmaleh, D. R. "Regional Blood-Flow Measurement in Rabbit Soft-Tissue Tumor with Positron Imaging Using the C15O2 Steady-State and Labeled Microspheres." Journal of Nuclear Medicine 24, 11351142 (Dec. 1983).

108. Kardmas, D., Di Bella, E., Black, N. \& Rust, T. Rapid multi-tracer PET imaging systems and methods. US patent US7848557B2. 2010.

109. KIm, H. et al. "64Cu-DOTA as a surrogate positron analog of Gd-DOTA for cardiac fibrosis detection with PET: Pharmacokinetic study in a rat model of chronic MI." Nuclear Medicine Communications 37, 188-196 (2016).

110. Kim, R. J. et al. "The use of contrast-enhanced magnetic resonance imaging to identify reversible myocardial dysfunction." New England Journal of Medicine 343, 1445-1453 (2000).

111. Knoll, G. F. Radiation detection and measurement (John Wiley \& Sons, 2010).

112. Knuesel, P. R. et al. "Characterization of dysfunctional myocardium by positron emission tomography and magnetic resonance: relation to functional outcome after revascularization." Circulation 108, 1095-1100 (2003).

113. Ko, G. B. et al. "Simultaneous Multiparametric PET/MRI with Silicon Photomultiplier PET and Ultra-High-Field MRI for Small-Animal Imaging." Journal of Nuclear Medicine 57, 1309-1315 (2016).

114. Koeppe, R. A. et al. "Dual-[11C]Tracer Single-Acquisition Positron Emission Tomography Studies." Journal of Cerebral Blood Flow 65 Metabolism 21, 1480-1492 (2001).

115. Lang, R. M. et al. "Recommendations for Cardiac Chamber Quantification by Echocardiography in Adults: An Update from the American Society of Echocardiography and the European Association of Cardiovascular Imaging." Journal of the American Society of Echocardiography 28, 1-39.e14 (Jan. 2015).

116. LAU, E. M. T. et al. "Pulmonary hypertension leads to a loss of gravity dependent redistribution of regional lung perfusion: a SPECT/CT study." Heart 100, 47 LP -53 (Jan. 2014).

117. LeComte, R. "Novel detector technology for clinical PET." European Journal of Nuclear Medicine and Molecular Imaging 36, 69-85 (Mar. 2009).

118. Lee, K., Fox, P. T., Lancaster, J. L. \& Jerabek, P. A. "A positron-probe system for arterial input function quantification for positron emission tomography in humans." Review of Scientific Instruments 79, 64301 (June 2008).

119. Lemoine, S. et al. "Renal Perfusion: Noninvasive Measurement with Multidetector CT versus Fluorescent Microspheres in a Pig Model." Radiology 260, 414-420 (Aug. 2011).

120. Lercher, M. J. \& Wienhard, K. "Scatter correction in 3-D PET." IEEE Transactions on Medical Imaging 13, 649-657 (Dec. 1994). 
121. Lewis, J. F. \& Bairey Merz, C. N. in (eds Goldman, M. B., Troisi, R., Rexrode, K. M. B. T. .--. W. \& Edition), H. () 975-989 (Academic Press, 2013).

122. Ley, S. \& Ley-Zaporozhan, J. "Pulmonary perfusion imaging using MRI: Clinical application." eng. Insights into Imaging 3, 61-71 (Feb. 2012).

123. Lieberman, A. N. et al. "Two-dimensional echocardiography and infarct size: relationship of regional wall motion and thickening to the extent of myocardial infarction in the dog." Circulation 63, 739-746 (Apr. 1981).

124. LIM, S. S. et al. "Prevention of cardiovascular disease in high-risk individuals in low-income and middle-income countries: health effects and costs." The Lancet 370, 2054-2062 (2007).

125. Lloyd-Jones, D. et al. "Executive Summary: Heart Disease and Stroke Statistics - 2010 Update." Circulation 121, 948-954 (Feb. 2010).

126. Lopez, A. D., Mathers, C. D., Ezzati, M., Jamison, D. T. \& Murray, C. J. L. "Global and regional burden of disease and risk factors, 2001: systematic analysis of population health data." The Lancet 367, 1747-1757 (May 2006).

127. Machac, J. et al. "Positron emission tomography myocardial perfusion and glucose metabolism imaging." Journal of Nuclear Cardiology 13, e121-e151 (Nov. 2006).

128. MADDAhI, J. et al. "Phase I, first-in-human study of BMS747158, a novel 18F-labeled tracer for myocardial perfusion PET: dosimetry, biodistribution, safety, and imaging characteristics after a single injection at rest." Journal of Nuclear Medicine 52, 1490-1498 (2011).

129. Maddahi, J. \& Packard, R. R. S. "Cardiac PET perfusion tracers: Current status and future directions." Seminars in Nuclear Medicine 44, 333-343 (2014).

130. Maddahi, J. et al. "Dosimetry, biodistribution, and safety of flurpiridaz F 18 in healthy subjects undergoing rest and exercise or pharmacological stress PET myocardial perfusion imaging." Journal of Nuclear Cardiology (Nov. 2018).

131. Mart\’’Inez MöLleR, Challenges in Multimodality Imaging using Positron Emission Tomography. PhD thesis (Technische Universität München, 2009).

132. Martin, C. C., Christian, B. T., Satter, M. R., Nickerson, L. D. H. \& Nickles, R. J. "Quantitative PET with positron emitters that emit prompt gamma rays." IEEE Transactions on Medical Imaging 14, 681-687 (Dec. 1995).

133. Martin, E. \& Hine, R. S. A Dictionary of Biology (OUP Oxford, 2008).

134. Mathers, C. D. \& Loncar, D. "Projections of global mortality and burden of disease from 2002 to 2030." PLoS medicine 3, e442 (2006).

135. Matsuo, S., Nakajima, K. \& Kinuya, S. "Clinical use of nuclear cardiology in the assessment of heart failure." eng. World journal of cardiology 2, 344-356 (Oct. 2010).

136. McCrary, J. R., Wann, L. S. \& Thompson, R. C. "PET imaging with FDG to guide revascularization in patients with systolic heart failure." The Egyptian Heart Journal 65, 123-129 (2013). 
137. McDonald, R. J. et al. "Intracranial Gadolinium Deposition after Contrast-enhanced MR Imaging." Radiology 275, 772-782 (2015).

138. McGraw, K. O. \& Wong, S. P. "Forming inferences about some intraclass correlation coefficients." Psychological Methods 1, 30-46 (1996).

139. Medical Advisory Secretatiat. Positron Emission Tomography for the Assessment of Myocardial Viability: An Evidence-Based Analysis. Tech. rep. 16 (Health Quality Ontario, 2005), 1-167.

140. Medical Advisory Secretatiat. Single photon emission computed tomography for the diagnosis of coronary artery disease: an evidence-based analysis. Tech. rep. 8 (June 2010), $1-64$.

141. Meinel, F. G. et al. "Assessing Pulmonary Perfusion in Emphysema: Automated Quantification of Perfused Blood Volume in Dual-Energy CTPA." Investigative Radiology 48 (2013).

142. Mensah, G. A. et al. "Decline in Cardiovascular Mortality: Possible Causes and Implications." eng. Circulation research 120, 366-380 (Jan. 2017).

143. Meyer, E., Brain, M., Centre, I. \& Imaging, M. B. "Simultaneous Correction for Tracer Arrival Delay and Dispersion in CBF Measurements by the H2150 Autoradiographic Method and Dynamic PET." Journal of Nuclear Medicine 30, 1069-78 (1989).

144. Mintun, M. A., Ter-Pogossian, M. M., Green, M. A., Lich, L. L. \& Schuster, D. P. "Quantitative measurement of regional pulmonary blood flow with positron emission tomography." Journal of Applied Physiology 60, 317-326 (1986).

145. Moccetti, F. \& Lindner, J. R. in (eds Solomon, S. D., Wu, J. C. \& Gillam, L. D. B. T. .-.- E. E.) 130-139.e3 (Elsevier, 2019).

146. Al-Mohammad, A. et al. "Prevalence of hibernating myocardium in patients with severely impaired ischaemic left ventricles." Heart (British Cardiac Society) 80, 559-564 (Dec. 1998).

147. Moody, J. B. et al. "The utility of 82Rb PET for myocardial viability assessment: Comparison with perfusion-metabolism 82Rb-18F-FDG PET." Journal of Nuclear Cardiology 26, 374-386 (2019).

148. Moon, J. C. "What Is Late Gadolinium Enhancement in Hypertrophic Cardiomyopathy?" Revista Española de Cardiología (English Edition) 60, 1-4 (2007).

149. Moran, A. E. et al. "Temporal trends in ischemic heart disease mortality in 21 world regions, 1980 to 2010: the Global Burden of Disease 2010 study." eng. Circulation 129, 1483-1492 (Apr. 2014).

150. Morris, E. D., Endres, C. J., Schmidt, K. C., Christian, B. T. \& Fisher, R. E. "Kinetic modeling in positron emission tomography." 
151. Munk, O. L., Keiding, S. \& Bass, L. "A method to estimate dispersion in sampling catheters and to calculate dispersion-free blood time-activity curves." Medical Physics 35, 3471-3481 (2008).

152. Musch, G. \& Venegas, J. G. "Positron Emission Tomography Imaging of Regional Pulmonary Perfusion and Ventilation." eng. Proceedings of the American Thoracic Society 2, 522-527 (Dec. 2005).

153. Muzic JR, R. F. \& DiFilippo, F. P. "Positron emission tomography-magnetic resonance imaging: technical review." eng. Seminars in roentgenology 49, 242-254 (July 2014).

154. NAmdar, M. et al. "Integrated PET/CT for the Assessment of Coronary Artery Disease: A Feasibility Study." Journal of Nuclear Medicine 46, 930-935 (June 2005).

155. NeEB, D. et al. "Quantification of pulmonary blood flow (PBF): Validation of perfusion MRI and nonlinear contrast agent (CA) dose correction with $\mathrm{H} 215 \mathrm{O}$ positron emission tomography (PET)." Magnetic Resonance in Medicine 62, 476-487 (2009).

156. Nekolla, S. G. et al. "Evaluation of the novel myocardial perfusion positron-emission tomography tracer 18F-BMS-747158-02: Comparison to $13 \mathrm{~N}$-ammonia and validation with microspheres in a pig model." Circulation 119, 2333-2342 (May 2009).

157. Nelson, A. D. et al. "Continuous arterial positron monitor for quantitation in PET imaging." eng. American journal of physiologic imaging 5, 84-88 (1990).

158. Nesterov, S. V. et al. "Myocardial perfusion quantitation with15O-labelled water PET: High reproducibility of the new cardiac analysis software (Carimas ${ }^{\mathrm{TM}}$ )." European Journal of Nuclear Medicine and Molecular Imaging 36, 1594-1602 (2009).

159. Nordström, J. et al. "Calculation of left ventricular volumes and ejection fraction from dynamic cardiac-gated (15)O-water PET/CT: 5D-PET." eng. EJNMMI physics 4, 26 (Nov. 2017).

160. Oohara, K., Usui, A., Murase, M., Tanaka, M. \& Abe, T. "Regional cerebral tissue blood flow measured by the colored microsphere method during retrograde cerebral perfusion." The Journal of Thoracic and Cardiovascular Surgery 109, 772-779 (1995).

161. Pennell, D. J. et al. "Society for Cardiovascular Magnetic Resonance; Working Group on Cardiovascular Magnetic Resonance of the European Society of Cardiology. Clinical indications for cardiovascular magnetic resonance (CMR): consensus panel report." Eur Heart J 25, 1940-1965 (2004).

162. Phelps, M. E. et al. "Tomographic measurement of local cerebral glucose metabolic rate in humans with (F-18)2-fluoro-2-deoxy-D-glucose: Validation of method." Annals of Neurology 6, 371-388 (1979).

163. Phelps, M. E., Hoffman, E. J., Mullani, N. A. \& Ter-Pogossian, M. M. "Application of Annihilation Coincidence Detection to Transaxial Reconstruction Tomography." Journal of Nuclear Medicine 16, 210-224 (1975). 
164. Phelps, M. E. et al. "Investigation of [18F]2-Fluoro-2-Deoxyglucose for the Measure of Myocardial Glucose Metabolism." Journal of Nuclear Medicine 19, 1311-1319 (1978).

165. Piepoli, M. F. et al. "2016 European Guidelines on cardiovascular disease prevention in clinical practice: The Sixth Joint Task Force of the European Society of Cardiology and Other Societies on Cardiovascular Disease Prevention in Clinical Practice." European Heart Journal 37, 2315-2381 (May 2016).

166. Powsner, R. A., Powsner, E. R. \& Powsner, R. A. "Essential nuclear medicine physics" (2006).

167. Pries, A. R., Secomb, T. W., Gaentgens, P. \& Gross, J. F. "Blood flow in microvascular networks. Experiments and simulation." Circulation Research 67, 826-834 (1990).

168. Prinzen, F. W. \& Bassingthwaighte, J. B. Blood flow distributions by microsphere deposition methods. Jan. 2000.

169. Rahimtoola, S. H. "The hibernating myocardium." American Heart Journal 117, 211221 (1989).

170. Rahimtoola, S. H. "Hibernating myocardium has reduced blood flow at rest that increases with low-dose dobutamine." Circulation 94, 3055-3061 (1996).

171. Rahimtoola, S. H. "Hibernating myocardium. How and in whom?." Journal of the American College of Cardiology 30, 1701-1706 (1997).

172. RATiB, O. et al. "Positron tomography with deoxyglucose for estimating local myocardial glucose metabolism." Journal of nuclear medicine: official publication, Society of Nuclear Medicine 23, 577-586 (1982).

173. Redel, A. et al. "Impact of Ischemia and Reperfusion Times on Myocardial Infarct Size in Mice In Vivo." Experimental Biology and Medicine 233, 84-93 (Jan. 2008).

174. Renker, D. "Geiger-mode avalanche photodiodes, history, properties and problems." Nuclear Instruments and Methods in Physics Research Section A: Accelerators, Spectrometers, Detectors and Associated Equipment 567, 48-56 (2006).

175. Renker, D. "New trends on photodetectors." Nuclear Instruments and Methods in Physics Research Section A: Accelerators, Spectrometers, Detectors and Associated Equipment 571, 1-6 (2007).

176. Renkin, E. M. "Transport of potassium-42 from blood to tissue in isolated mammalian skeletal muscles." eng. The American journal of physiology 197, 1205-1210 (Dec. 1959).

177. Richard, J.-C. et al. "Comparison of PET with Radioactive Microspheres to Assess Pulmonary Blood Flow." Journal of Nuclear Medicine 43, 1063-1071 (2002).

178. Richter, T. et al. Effect of Prone Position on Regional Shunt, Aeration, and Perfusion in Experimental Acute Lung Injury. eng. Aug. 2005.

179. Roehrbacher, F. et al. "Development and performance test of an online blood sampling system for determination of the arterial input function in rats." EJNMMI Physics 2, 1-19 (2015). 
180. Rosentrater, K. \& Flores, R. Physical and rheological properties of slaughterhouse swine: blood and blood components, 683-689 (Jan. 1997).

181. Rотн, G. A. et al. "Global, regional, and national age-sex-specific mortality for 282 causes of death in 195 countries and territories, 1980-2017: a systematic analysis for the Global Burden of Disease Study 2017." The Lancet 392, 1736-1788 (Nov. 2018).

182. Rousset, O. G., Ma, Y. \& Evans, A. C. "Correction for Partial Volume Effects in PET: Principle and Validation." Journal of Nuclear Medicine 39, 904-911 (1998).

183. Rust, T. C. et al. "Rapid dual-injection single-scan 13N-ammonia PET for quantification of rest and stress myocardial blood flows." Physics in medicine and biology 51, 5347-5362 (Oct. 2006).

184. Sackett, D. L., Gibson, R. W., Bross, I. D. J. \& Pickren, J. W. "Relation between Aortic Atherosclerosis and the Use of Cigarettes and Alcohol." New England Journal of Medicine 279, 1413-1420 (Dec. 1968).

185. Sado, D. M., Flett, A. S. \& Moon, J. C. "Novel imaging techniques for diffuse myocardial fibrosis." Future Cardiology 7, 643-650 (Sept. 2011).

186. Sampson, U. K., Dorbala, S., Limaye, A., Kwong, R. \& Di Carli, M. F. "Diagnostic Accuracy of Rubidium-82 Myocardial Perfusion Imaging With Hybrid Positron Emission Tomography/Computed Tomography in the Detection of Coronary Artery Disease." Journal of the American College of Cardiology 49, 1052-1058 (2007).

187. Sasayama, S., Franklin, D., Ross Jr., J., Kemper, W. S. \& McKown, D. "Dynamic changes in left ventricular wall thickness and their use in analyzing cardiac function in the conscious dog: A study based on a modified ultrasonic technique." American Journal of Cardiology 38, 870-879 (Dec. 1976).

188. SAw, C. B. et al. "Determination of CT-to-density conversion relationship for image-based treatment planning systems." Medical Dosimetry 30, 145-148 (2005).

189. Schelbert, H. R. et al. "Regional myocardial perfusion assessed with N-13 labeled ammonia and positron emission computerized axial tomography." The American journal of cardiology 43, 209-218 (1979).

190. Schindler, T. H., Schelbert, H. R., Quercioli, A. \& Dilsizian, V. "Cardiac Pet Imaging for the Detection and Monitoring of Coronary Artery Disease and Microvascular Health." JACC: Cardiovascular Imaging 3, 623-640 (2010).

191. Schindler, T. H. et al. "Role of PET in the evaluation and understanding of coronary physiology." Journal of Nuclear Cardiology 14, 589-603 (2007).

192. Schuster, D. P., Anderson, C., Kozlowski, J. \& Lange, N. "Regional Pulmonary Perfusion in Patients with Acute Pulmonary Edema." Journal of Nuclear Medicine 43, 863-870 (2002). 
193. Schuster, D. P., Kaplan, J. D., Gauvain, K., Welch, M. J. \& Markham, J. "Measurement of Regional Pulmonary Blood Flow with PET." Journal of Nuclear Medicine 36, 371-377 (1995).

194. Serrat, M. A. "Measuring bone blood supply in mice using fluorescent microspheres." Nat. Protocols 4, 1749-1758 (Nov. 2009).

195. SHerif, H. M. et al. "Simplified Quantification of Myocardial Flow Reserve with flurpiridaz F 18: Validation with Microspheres in a Pig Model." Journal of Nuclear Medicine 52, 617624 (2011).

196. Shetty, D., Lee, Y. S. \& JeOng, J. M. "68Ga-labeled radiopharmaceuticals for positron emission tomography." Nuclear Medicine and Molecular Imaging 44, 233-240 (2010).

197. Shimkunas, R. et al. "Left ventricular myocardial contractility is depressed in the borderzone after posterolateral myocardial infarction." eng. The Annals of thoracic surgery 95, 1619-1625 (May 2013).

198. Skorton, D. J., Schelbert, H. R., Wolf, G. L. \& Brundage, B. H. Cardiac imaging: a companion to Braunwald's heart disease. 1996.

199. Smith, S. C. et al. "AHA/ACCF Secondary Prevention and Risk Reduction Therapy for Patients With Coronary and Other Atherosclerotic Vascular Disease: 2011 Update." Circulation 124, 2458-2473 (Nov. 2011).

200. Soret, M., Bacharach, S. L. \& Buvat, I. "Partial-Volume Effect in PET Tumor Imaging." Journal of Nuclear Medicine 48, 932-945 (2007).

201. Sourbron, S. P. \& Buckley, D. L. "Tracer kinetic modelling in MRI: estimating perfusion and capillary permeability." Physics in Medicine and Biology 57, R1 (2012).

202. Sourbron, S. P. \& Buckley, D. L. "On the scope and interpretation of the Tofts models for DCE-MRI." Magnetic Resonance in Medicine 66, 735-745 (2011).

203. SRINIVAS, S. M. et al. "A recovery coefficient method for partial volume correction of PET images." Annals of Nuclear Medicine 23, 341-348 (June 2009).

204. Standring, S. Gray's Anatomy: The Anatomical Basis of Clinical Practice (Churchill Livingstone/Elsevier, 2008).

205. SuWA, T. et al. "Particulate air pollution induces progression of atherosclerosis." Journal of the American College of Cardiology 39, 935-942 (2002).

206. Tarantola, G., Zito, F. \& Gerundini, P. "PET Instrumentation and Reconstruction Algorithms in Whole-Body Applications." Journal of Nuclear Medicine 44, 756-769 (2003).

207. TARKIA, M. et al. "Evaluation of 68Ga-labeled tracers for PET imaging of myocardial perfusion in pigs." Nuclear Medicine and Biology 39, 715-723 (2012).

208. Ter-Pogossian, M. M., Phelps, M. E., Hoffman, E. J. \& Mullani, N. A. "A PositronEmission Transaxial Tomograph for Nuclear Imaging (PETT)." Radiology 114, 89-98 (Jan. 1975). 
209. TORIGIAn, D. A. et al. "PET/MR imaging: technical aspects and potential clinical applications." Radiology 267, 26-44 (2013).

210. Townsend, D. W. \& Defrise, M. Image-reconstruction methods in positron tomography CERN-93-02 (CERN, 1993).

211. Tunstall-Pedoe, H. et al. "Estimation of contribution of changes in coronary care to improving survival, event rates, and coronary heart disease mortality across the WHO MONICA Project populations." The Lancet 355, 688-700 (Feb. 2000).

212. UGAnder, M. et al. "Extracellular volume imaging by magnetic resonance imaging provides insights into overt and sub-clinical myocardial pathology." eng. European heart journal 33, 1268-1278 (May 2012).

213. Van der Weerdt, A. P. et al. "Image-derived input functions for determination of MRGlu in cardiac (18)F-FDG PET scans." Journal of nuclear medicine : official publication, Society of Nuclear Medicine 42, 1622-9 (2001).

214. Velasco, C. et al. "Assessment of regional pulmonary blood flow using 68Ga-DOTA PET." EJNMMI Research 7, 7 (2017).

215. Velasco, C. et al. "Quantitative assessment of myocardial blood flow and extracellular volume fraction using 68Ga-DOTA-PET: A feasibility and validation study in large animals." Journal of Nuclear Cardiology (Mar. 2019).

216. Verani, M. S. "Thallium-201 single-photon emission computed tomography (SPECT) in the assessment of coronary artery disease." The American Journal of Cardiology 70, E3E9 (1992).

217. Verhaeghe, J. \& Reader, A. J. "Simultaneous water activation and glucose metabolic rate imaging with PET." Physics in Medicine and Biology 58, 393-411 (2013).

218. Vogel, R. et al. "The quantification of absolute myocardial perfusion in humans by contrast echocardiography: algorithm and validation." Journal of the American College of Cardiology 45, 754-762 (2005).

219. Webb, P. P., McIntyre, R. J. \& Conradi, J. "Properties of avalanche photodiodes." R.C.A. Review 35, 234-278 (1974).

220. White, S. K., Sado, D. M., Flett, A. S. \& Moon, J. C. "Characterising the myocardial interstitial space: The clinical relevance of non-invasive imaging." Heart 98, 773-779 (2012).

221. Wikiversity. WikiJournal of Medicine/Medical gallery of Blausen Medical 2014. 2019.

222. World Health Organization. International statistical classification of diseases and related health problems (World Health Organization, 2004).

223. World Health Organization. Prevention of cardiovascular disease (CVDs). Tech. rep. (World Health Organization, 2016). 
224. Yamamoto, S. et al. "A compact and high sensitivity positron detector using dual-layer thin GSO scintillators for a small animal PET blood sampling system." Physics in Medicine and Biology 55, 3813-3826 (2010).

225. YAng, Y., He, M. Z., LI, T. \& YAnG, X. "MRI combined with PET-CT of different tracers to improve the accuracy of glioma diagnosis: a systematic review and meta-analysis." Neurosurgical Review (Sept. 2017).

226. YU, M. et al. "BMS-747 158-02: A novel PET myocardial perfusion imaging agent." Journal of Nuclear Cardiology 14, 789-798 (2007).

227. Zaidi, H. \& Montandon, M.-L. "Scatter compensation techniques in PET." PET clinics 2, 219-234 (2007).

228. ZIADI, M. C. "Myocardial flow reserve (MFR) with positron emission tomography (PET)/computed tomography $(\mathrm{CT})$ : clinical impact in diagnosis and prognosis." eng. Cardiovascular diagnosis and therapy 7, 206-218 (Apr. 2017). 


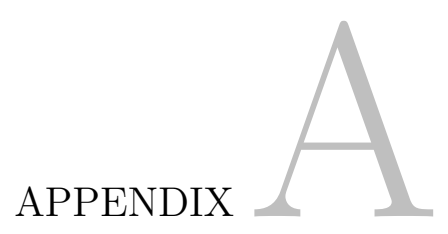

PUBLICATIONS DERIVED FROM THIS THESIS

\section{Publications in peer-reviewed journals}

i. Velasco, C., Mateo, J., Santos, A., Mota-Cobián, A., Herranz, F., Pellico, J., Mota, R. A., España, S., \& Ruiz-Cabello, J. Assessment of regional pulmonary blood flow using 68Ga-DOTA PET. EJNMMI Research 7, 7 (2017).

ii. Velasco, C., Mota-Cobián, A., Mota, R. A., Pellico, J., Herranz, F., GalánArriola, C., Ibáñez, B., Ruiz-Cabello, J., Mateo, J. \& España, S. Quantitative assessment of myocardial blood flow and extracellular volume fraction using 68Ga-DOTAPET: A feasibility and validation study in large animals. Journal of Nuclear Cardiology (2019).

\section{Articles submitted to peer-reviewed journals}

i. Velasco, C., Mota-Cobián, A., Mateo, J. \& España, S. Explicit measurement of multi-tracer arterial input function for PET imaging using blood sampling spectroscopy. Submitted to IEEE Transactions on Medical Imaging (2019).

ii. Velasco, C., Mota-Cobián, A., Mateo, J. \& España, S. Development of a blood sampling detector for multi-tracer PET using gamma spectroscopy. Under preparation (2019). 


\section{Communications in international congresses}

i. Velasco, C., Mateo, J., Mota-Cobián, A. \& España, S. Dual tracer input function for PET imaging using blood sampling spectroscopy. Oral presentation at 2018 IEEE Nuclear Science Symposium and Medical Imaging Conference. Sydney (Australia). 2018.

ii. Velasco, C., Mateo, J., Santos, A., Mota-Cobián, A., Herranz, F., Pellico, J., Mota, R. A., España, S., \& Ruiz-Cabello, J. Quantitative pulmonary blood flow with PET using a diffusible tracer based on 68Ga. Oral presentation at European Molecular Imaging Meeting. EMIM 2018. San Sebastián (Spain). 2018.

iii. Mateo, J., Velasco, C., Mota-Cobián, A., Mota, R. A. \& España, S. Comparison of $18 \mathrm{~F}-\mathrm{FDG}$ and $18 \mathrm{~F}-\mathrm{NaF}$ for non-invasive assessment of plaque progression with $\mathrm{PET} / \mathrm{CT}$ in a rabit model of atherosclerosis. Poster presentation at European Molecular Imaging Meeting. EMIM 2018. San Sebastián (Spain). 2018.

iv. Santos, A., Velasco, C., Mateo, J., Mota-Cobián, A., España, S. \& RuizCABello, J. Assessment of regional pulmonary blood flow using 68Ga-DOTA PET. Poster presentation at 2017 International Workshop on Pulmonary Imaging. Filadelfia (USA). 2017.

v. España, S., Arias, T., Velasco, C., Pellico, J., Herranz, F., Ruiz-Cabello, J. \& MAteo, J. Feasibility of Gallium-68 chelates as diffusible PET tracers for cardiac imaging. Poster presentation at Annual Congress of the European Association of Nuclear Medicine. EANM 2016. Barcelona (Spain). 2016.

vi. Velasco, C., Mateo, J., Ruiz-Cabello, J. \& España, S. New analysis tool for automatic and unsupervised analysis of dynamic cardiac PET studies. Poster presentation at Annual Congress of the European Association of Nuclear Medicine. EANM 2016. Barcelona (Spain). 2016.

vii. Mateo, J., Velasco, C., Arias, T., Pellico, J., Herranz, F., Ruiz-Cabello, J. \& EspañA, S. Evaluation of myocardial perfusion and extracellular volume fraction in pigs using 68Ga-DOTA PET. Poster presentation at World Molecular Imaging Congress. WMIC 2016. New York (USA). 2016.

viii. Velasco, C., Mateo, J., Arias, T., Ruiz-Cabello, J. \& España, S. Fully automatic analysis tool for dynamic cardiac PET studies. Poster presentation at European Molecular Imaging Meeting. EMIM 2016. Utrecht (The Netherlands). 2016.

ix. España, S., Arias, T., Velasco, C., Pellico, J., Herranz, F., Ruiz-Cabello, J. \& MAteo, J. Assessment of myocardial perfusion and extracellular volume fraction using 68Ga-DOTA-PET. Poster presentation at European Molecular Imaging Meeting. EMIM 2016. Utrecht (The Netherlands). 2016.

x. Velasco, C., Mateo, J., Santos, A., Ruiz-Cabello, J. \& España, S. Dual cardiacrespiratory gating PET imaging: implementation and validation. Oral presentation at Molecular Imaging Workshop 2015 CIC biomaGUNE. San Sebastián (Spain). 2015. 
1TCM One Tissue Compartment Model

2CXM Two Compartment Exchange Model

2TCM Two Tissue Compartment Model

3D-RAMLA 3D Dedicated Row Action Maximum Likelihood Algorithm

ADO Adenosine

AHA American Heart Association

AIF Arterial Input Function

APD Avalanche Photodiode

BP Blood Pressure

CAD Coronary Artery Disease

CFR Coronary Flow Reserve

CGS CGS-21680

CMR Cardiac Magnetic Resonance

COPD Chronic Obstructive Pulmonary Disease

CRT Coincidence Resolving Time

CT Computed Tomography

CVD Cardiovascular Disease

DOTA 1,4,7,10-tetraazacyclododecane-N, $\mathrm{N}^{\prime}, \mathrm{N}^{\prime \prime}, \mathrm{N}^{\prime \prime \prime}$-tetraacetic acid

ECG Electrocardiogram

ECV Extracellular Volume Fraction

FBP Filtered Backprojection

FDA Food and Drug Administration

FDG 2-Deoxy-2- $\left[{ }^{18} \mathrm{~F}\right]$ fluoroglucose

FOV Field of View 
FWHM Full Width at Half Maximum

HR Heart Rate

HU Hounsfield Units

ICC Interclass Correlation Coefficient

ID Internal Diameter

IHD Ischemic Heart Disease

IRF Impulse Response Function

IS Infarct Size

LAA Left Atrial Appendage

LAD Left Anterior Descending coronary artery

LCX Left Circumflex coronary artery

LGE Late Gadolinium Enhancement

LOA Limits of Agreement

LOR Line of Response

LV Left Ventricle

LVEF Left Ventricular Ejection Fraction

MBF Myocardial Blood Flow

MDA Minimum Detectable Activity

MI Myocardial Infarction

MIP Maximum Intensity Projection

ML-EM Maximum Likelihood Expectation Maximization

MPI Myocardial Perfusion Imaging

MRI Magnetic Resonance Imaging

MS Microspheres

OSEM Ordered Subsets Expectation Maximization

PAH Pulmonary Arterial Hypertension

PBF Pulmonary Blood Flow

PET Positron Emission Tomography

PH Pulmonary Hypertension

PMT Photomultiplier Tube

PS Permeability-Surface product

PVC Partial Volume Correction

PVE Partial Volume Effect

RCA Right Coronary Artery

RMSE Root Mean Square Error

ROI Region of Interest

RV Right Ventricle

SD Standard Deviation

SiPM Silicon Photomultiplier 
SPECT Single Photon Emission Computed Tomography

SR Singles Rate

SUV

Standardized Uptake Value

TAC

Time Activity Curve

VOI

Volume of Interest 
APPENDIX

ADVANCED IMAGING TECHNIQUES FOR CARDIOVASCULAR RESEARCH

ABSTRACT

\section{Introduction}

According to the World Health Organization, cardiovascular diseases (CVDs) are the first cause of death globally. CVDs are a cluster of disorders that involve heart and blood vessels. Among them, coronary artery disease $(\mathrm{CAD})$ is the most important disease in terms of mortality, causing more than $50 \%$ of the annual deaths. Over the last decades, many recognized international organisms, such as the World Health Organization and the American College of Cardiology have done great efforts to reduce the mortality and morbidity of CAD. In this line, accurate diagnosis and cost-effective management of CAD have revealed to be of utmost importance.

Several imaging techniques are currently used in the clinical practice to provide a diagnosis and clinical assessment of the disease. Among them, Positron Emission Tomography (PET) is considered to be the "gold standard" for noninvasive assessment of myocardial perfusion and viability, the two most relevant physiological parameters used to diagnose and manage patients with known or suspected CAD.

However, despite its unquestioned diagnostic value, PET still faces several difficulties towards its expansion as a clinical tool utilized worldwide. This is due to factors such as the high cost of the scanners and the extremely low availability of the radiopharmaceuticals required to perform the tests (mainly due to their cyclotron-based production pathway and their short half-lives). 


\section{Objectives}

In this thesis we addressed some of those difficulties by exploring new applications of a ${ }^{68} \mathrm{Ga}$ labeled radiotracer $\left({ }^{68} \mathrm{Ga}\right.$-DOTA $) .{ }^{68} \mathrm{Ga}$ can be obtained from a ${ }^{68} \mathrm{Ge} /{ }^{68} \mathrm{Ga}$ generator and has a half-life of 68 minutes, which makes it a convenient candidate for its widespread clinical use.

We proposed and validated the use of ${ }^{68} \mathrm{Ga}$-DOTA as a radiotracer for assessment of myocardial blood flow (MBF), myocardial viability and pulmonary blood flow (PBF). Additionally, we introduced a new methodology to perform a PET scan in which this tracer could be coinjected simultaneously with some other radiotracers such as ${ }^{18} \mathrm{FDG}$ (multi-tracer PET). Lastly, we developed an automatic detector able to perform blood spectroscopy analysis, which offered the possibility to perform multi-tracer PET with minimal human intervention.

\section{Methods}

To test the capability of ${ }^{68} \mathrm{Ga}-\mathrm{DOTA}$ to measure $\mathrm{MBF}$, viability and $\mathrm{PBF}$, different groups of Large White pigs underwent PET/CT scans using ${ }^{68} \mathrm{Ga}-\mathrm{DOTA}$ as the injected radiotracer. For PBF studies, a group of healthy pigs $(n=4)$ were scanned under rest conditions. For MBF studies, a group of 8 pigs were scanned under rest and pharmacologically-induced stress in order to perform rest/stress tests, as it is done for humans in clinical routine. Additionally, a group of 5 pigs were scanned 7 days after the induction of a myocardial infarction (MI) to assess viability and MBF in a MI model.

$\mathrm{MBF}$, extracellular volume fraction (ECV, for viability assessment) and PBF maps were obtained after fitting the dynamic PET images to the corresponding pharmacokinetic model followed by ${ }^{68} \mathrm{Ga}$-DOTA in each tissue under study. Global and regional perfusion maps for the myocardial tissue (MBF) and lungs (PBF) were obtained. For validation purposes, the "goldstandard" technique used in tissue perfusion quantification (fluorescent-labeled microspheres (MS)) was simultaneosly performed along with the PET/CT scans.

The blood sampling spectroscopic methodology was evaluated and calibrated in vitro using different ${ }^{68} \mathrm{Ga} /{ }^{18} \mathrm{~F}$ mixtures. Then, it was tested in pigs $(n=3)$ injected with ${ }^{68} \mathrm{Ga}$-DOTA and ${ }^{18} \mathrm{FDG}$ in the same acquisition. The activity concentration of each radiotracer in myocardial tissue was subsequently measured ex vivo.

The automatic blood sampling detector was built from scratch and characterized using a catheter filled with different ${ }^{68} \mathrm{Ga} /{ }^{18} \mathrm{~F}$ mixtures. Finally, it was additionally evaluated in vivo in $n=3$ pigs under conditions resembling to those encountered in clinical routine. 


\section{Results}

Regarding MBF quantification and validation with ${ }^{68}$ Ga-DOTA-PET, a strong correlation $(r=$ 0.91 ) between MBF measured with PET and MS was obtained (slope $=0.96 \pm 0.10$, y-intercept $\left.=0.11 \pm 0.19 \mathrm{ml} \cdot \mathrm{min}^{-1} \cdot \mathrm{g}^{-1}\right)$. For the myocardial infarction model, MBF values obtained with ${ }^{68} \mathrm{Ga}-\mathrm{DOTA}-\mathrm{PET}$ in the infarcted area (LAD, left anterior descendant) were significantly reduced in comparison to remote ones LCX (left circumflex artery, $p<0.0001$ ) and RCA (right coronary artery, $p<0.0001)$. In addition, ${ }^{68} \mathrm{Ga}$-DOTA-PET detected a significant ECV increase in the infarcted area $(p<0.0001)$.

The correlation evaluation between ${ }^{68} \mathrm{Ga}$-DOTA-PET and MS as a PBF radiotracer also showed a good and significant correlation $(r=0.74, p<0.0001)$.

The gamma spectroscopic analysis on blood samples proposed for multi-tracer PET imaging was also succesfully validated, showing a correlation of $r=0.95(p<0.0001)$ for ${ }^{18} \mathrm{FDG}$ concentration in myocardium measured with multi-tracer PET and by ex vivo validation.

The blood sampling detector was able to measure the arterial input function in pigs in an experimental setup under realistic conditions.

\section{Discussion and conclusions}

${ }^{68} \mathrm{Ga}$-DOTA-PET allowed accurate non-invasive assessment of MBF and ECV in pigs with myocardial infarction and under rest-stress conditions. This technique could provide wide access to quantitative measurement of both MBF and ECV with PET imaging. ${ }^{68}$ Ga-DOTA-PET was also demonstrated to be a potential inexpensive method for measuring PBF in clinical settings.

As for multi-tracer PET imaging, the proposed methodology allowed explicit measurement of separate arterial input functions, offering very similar results to those obtained as a reference from the ex vivo analysis of the tissue under evaluation.

Finally, a novel blood sampling device was developed and characterized, showing performance parameters similar to other devices in the literature. Noteworthy, this detector has the additional and unique feature of allowing us to perform multi-tracer PET by means of a gamma spectroscopic analysis of the blood flowing between its detection blocks.

All the results summarized in this abstract may contribute to spread the use of PET in clinical routine, either by the clinical use of ${ }^{68} \mathrm{Ga}$-DOTA as an inexpensive but accurate radiotracer for MBF, PBF or viability assessment, or by the implementation of multi-tracer PET, which could lead to cost reduction of PET examinations by shortening the scanning time and eliminating misalignment inaccuracies. This multi-tracer PET methodology could also be safely implemented using our proposed automated device that permits to perform the gamma spectroscopic analysis on blood samples with minimal human intervention. 
APPENDIX

TÉCNICAS DE IMAGEN AVANZADA APLICADAS A LA INVESTIGACIÓN CARDIOVASCULAR

\section{RESUMEN}

\section{Introducción}

Según la Organización Mundial de la Salud (OMS), las enfermedades cardiovasculares son, cada año, la primera causa de muerte en el mundo. De ellas, más de la mitad son causadas por la enfermedad de las arterias coronarias. En las últimas décadas, numerosos organismos internacionales de reconocido prestigio, como la propia OMS o el Colegio Americano de Cardiología, han centrado sus esfuerzos en reducir la mortalidad y la morbilidad de esta enfermedad y han establecido como factores clave el diagnóstico preciso y el tratamiento eficaz y económico de la enfermedad.

En la actualidad, existen diversas técnicas de diagnóstico por imagen que nos permiten evaluar clínicamente esta enfermedad. De entre todas ellas, la tomografía por emisión de positrones (PET por sus siglas en inglés) destaca como la técnica de referencia para la evaluación de la perfusión y viabilidad del miocardio, que son dos de los parámetros fisiológicos más importantes a la hora de diagnosticar y tratar a pacientes de los que se sabe o se sospecha que pueden padecer la enfermedad de las arterias coronarias.

No obstante, y a pesar de su demostrado valor diagnóstico, el PET no ha conseguido establecerse como la técnica más utilizada a nivel global para estudios cardiacos. Los motivos son principalmente dos: el alto coste de las máquinas y la poca disponibilidad de los radiofármacos necesarios para ejecutar dichos estudios (ante todo debido a la corta vida media que poseen los 
radioisótopos usados como marcadores, y a que la mayoría de estos solo pueden ser producidos por ciclotrones).

\section{Objetivos}

En esta tesis abordamos algunas de las dificultades arriba mencionadas. Para ello exploramos nuevas aplicaciones de un radiotrazador marcado con ${ }^{68} \mathrm{Ga}$, el ${ }^{68} \mathrm{Ga}$-DOTA. La ventaja de este radiotrazador radica en que el ${ }^{68} \mathrm{Ga}$ tiene una vida media adecuada (68 minutos) y puede ser obtenido de un generador de ${ }^{68} \mathrm{Ge} /{ }^{68} \mathrm{Ga}$ de manera económica.

En este trabajo planteamos y validamos el uso de ${ }^{68} \mathrm{Ga}$-DOTA como un radiotrazador capaz de medir la perfusión miocárdica (MBF por sus siglas en inglés), la viabilidad del miocardio (mediante la cuantificación de la fracción de volumen extracelular; ECV por sus siglas en inglés) y por último la perfusión pulmonar ( $\mathrm{PBF}$ por sus siglas en inglés). En otro orden de cosas, propusimos una nueva metodología que permitía realizar estudios PET en los que ${ }^{68} \mathrm{Ga}$-DOTA pudiese ser inyectado simultáneamente junto con otro trazador, como el ${ }^{18} \mathrm{FDG}$ (esta técnica recibirá el nombre de PET multitrazador). Por último, tambien desarrollamos un detector automatizado capaz de ejecutar autónomamente el análisis por espectroscopía gamma necesario para llevar a cabo estos estudios multi-trazador, minimizando así la necesidad de intervención humana en la realización de dichos estudios.

\section{Métodos}

Para evaluar la capacidad de ${ }^{68} \mathrm{Ga}-\mathrm{DOTA}$ como radiotrazador para cuantificar MBF, ECV y PBF, se utilizaron distintos grupos de cerdos Large White. A estos se les realizó PET/TACs utilizando ${ }^{68} \mathrm{Ga}$-DOTA como radiotrazador. Concretamente, para los estudios de perfusión pulmonar se utilizaron animales sanos $(n=4)$, que fueron escaneados en reposo. Para los estudios de perfusión de miocardo se utilizaron 8 cerdos sanos, que fueron escaneados en reposo y bajo condiciones de estrés inducido farmacológicamente mediante adenosina y CGS-21680 (con el objetivo de ejecutar pruebas de reposo/estrés, como las que se realizan clínicamente a diario en cualquier hospital). Por último, un grupo de 5 cerdos fue sometido a una intervención quirúrgica en la que se les indujo un infarto de miocardio. 7 días tras la intervención se les realizó un PET/TAC con ${ }^{68} \mathrm{Ga}$-DOTA para valorar la viabilidad y la perfusión miocárdica mediante la cuantificación de MBF y ECV.

Los mapas de MBF, ECV y PBF fueron obtenidos como parámetros de ajuste de las imágenes PET dinámicas tomadas en cada estudio. Dichos ajustes se realizaron utilizando el modelo farmacocinético que ${ }^{68} \mathrm{Ga-DOTA}$ sigue en cada tejido a estudiar. Con ello se obtuvieron mapas de perfusión miocárdica y pulmonar tanto a nivel global como a nivel regional. Estos resultados fueron validados utilizando como referencia los valores de perfusión obtenidos con microesferas fluorescentes inyectadas junto con el ${ }^{68} \mathrm{Ga}-\mathrm{DOTA}$.

La metodología propuesta para PET multitrazador fue evaluada y puesta a punto tanto in vitro (utilizando distintas mezclas ${ }^{68} \mathrm{Ga} /{ }^{18} \mathrm{~F}$ ) como in vivo (utilizando para ello 3 cerdos Large 
White que fueron inyectados con ${ }^{68} \mathrm{Ga}$-DOTA y ${ }^{18} \mathrm{FDG}$ durante la misma adquisición y a los que posteriormente se les midió ex vivo la concentración de actividad de cada radiotrazador en el miocardio).

El detector automático de radioactividad en sangre fue construido desde cero y caracterizado utilizando catéteres llenados con diferentes mezclas de ${ }^{68} \mathrm{Ga}$ y ${ }^{18} \mathrm{~F}$. Por último, el detector se testó en cerdos $(n=3)$ en condiciones experimentales similares a las que podrían darse durante su uso clínico.

\section{Resultados}

Los valores de MBF medidos con PET y con las microesferas mostraron una fuerte correlación $(r=0.91)$ (pendiente $=0.96 \pm 0.10$, ordenada en el origen $\left.=0.11 \pm 0.19 \mathrm{ml} \cdot \mathrm{min}^{-1} \cdot \mathrm{g}^{-1}\right)$. Para el modelo de infarto de miocardio se obtuvo que los valores de MBF medidos mediante ${ }^{68} \mathrm{Ga}-$ DOTA-PET en el área infartada (arteria descendente anterior izquierda) eran significativamente menores que los obtenidos en las regiones remotas (en las arterias circunfleja izquierda y coronaria derecha, ambas con una significancia estadística $p<0.0001)$. El ECV se vio aumentado en la zona infartada $(p<0.0001)$.

Por otro lado, la correlación entre ${ }^{68} \mathrm{Ga-DOTA-PET} \mathrm{y} \mathrm{la} \mathrm{perfusión} \mathrm{obtenida} \mathrm{con} \mathrm{las} \mathrm{microes-}$ feras para la perfusión pulmonar demostró ser también buena $(r=0.74, p<0.0001)$.

El análisis basado en espectroscopía gamma de muestras de sangre propuesto para el PET multitrazador fue validado satisfactioramente, con una correlación excelente de $r=0.95$ ( $p<$ 0.0001) entre la concentracion de ${ }^{18} \mathrm{FDG}$ en miocardio medida con la técnica PET multitrazador y su valor de referencia obtenido de las medidas ex vivo.

Por último, el detector de radioactividad en sangre desarrollado fue capaz de medir satisfactoriamente bajo condiciones próximas a las reales la concentración en sangre arterial de los cerdos en los que fue testado.

\section{Discusión y conclusiones}

El radiotrazador para PET ${ }^{68} \mathrm{Ga}$-DOTA resultó ser capaz de medir de manera no invasiva la perfusión miocárdica y la fracción de volumen extraceular en cerdos que padecían infarto de miocardio y bajo condiciones de reposo y estrés. Este nuevo trazador podría ofrecer mayor accesibilidad al PET para medir de manera cuantitativa MBF y ECV gracias a que el radioisótopo en el que está basado, ${ }^{68} \mathrm{Ga}$, puede obtenerse de manera económica de un generador de ${ }^{68} \mathrm{Ge} /{ }^{68} \mathrm{Ga}$. A todo ello podemos añadir que ${ }^{68} \mathrm{Ga}$-DOTA tambien sirve como radiotrazador PET capaz de evaluar de manera precisa la perfusión pulmonar, ofreciendo así un amplio abanico de posibilidades como radiotrazador para estudios de imagen PET cardiovascular.

En cuanto a la técnica de PET multitrazador, la metodología propuesta nos permitió obtener explícitamente medidas de la concentración en sangre de cada trazador de manera independiente. 
Los resultados, además, fueron validados satisfactoriamente frente a medidas de referencia ex vivo muy similares a las obtenidas con nuestra metodología.

En cuanto al detector de radioactividad en sangre, este fue desarrollado y caracterizado satisfactoriamente, mostrando un desempeño similar a otros aparatos presentes en la literatura. No obstante, nuestro detector posee como característica adicional y única la posibilidad de realizar estudios PET multitrazador mediante el análisis por espectroscopía gamma de la sangre que vaya pasando entre los dos bloques de detección que lo forman.

Todos estos resultados enumerados en este resumen podrían contribuir a potenciar el uso del PET en la práctica clínica, bien sea por la introducción del ${ }^{68} \mathrm{Ga}-\mathrm{DOTA}$ como un radiotrazador rentable pero preciso para la medida de MBF, PBF o viabilidad miocárdica, o por la implementación de estudios PET multitrazador. El uso de estudios PET multitrazador podría reducir los costes de la técnica al acortar los tiempos de escaneado por paciente y reducir los errores derivados de un mal alineamiento de la posición del paciente en las distintas adquisiciones. Además, el sistema automático de detección de radioactividad en sangre podría permitir implantar estos estudios PET multitrazador sin necesidad de intervención humana, lo que evitaría la exposición a la radiación del personal técnico. 

